REVISTA ESPAÑOLA DE DISCAPACIDAD

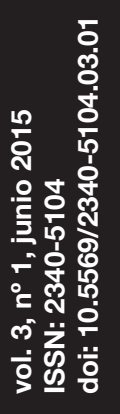

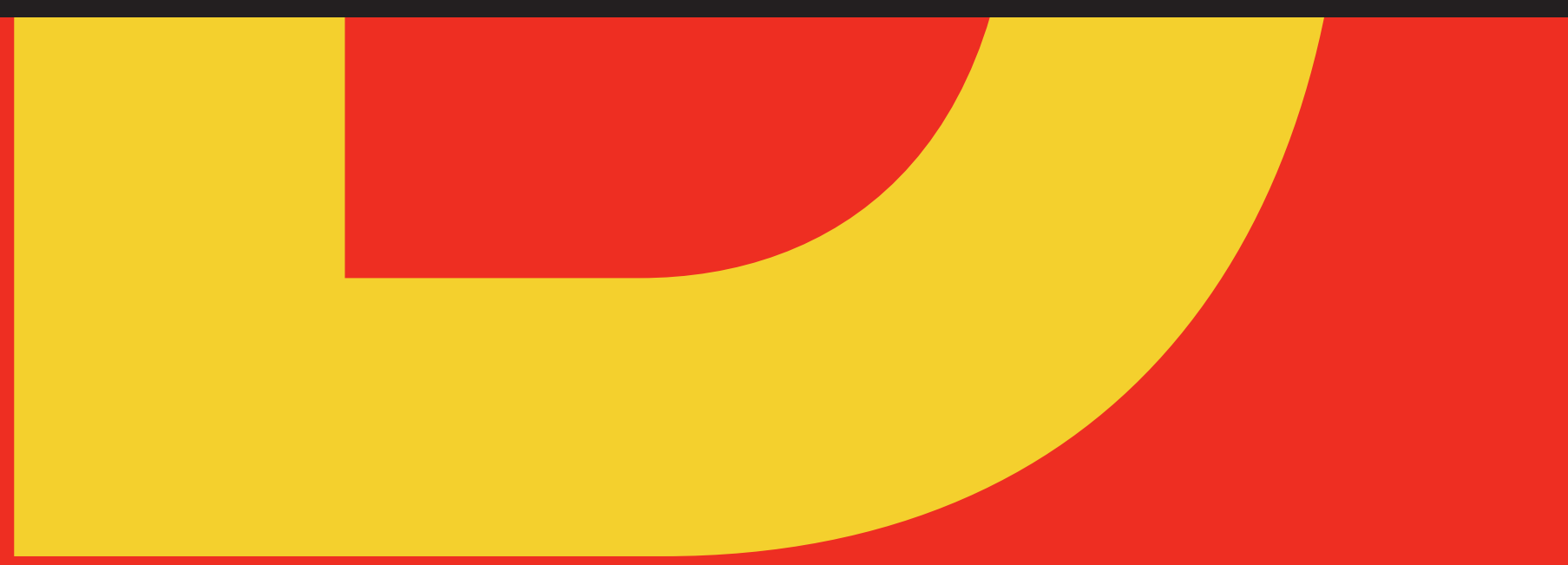


La Revista Española de Discapacidad (REDIS) es una revista electrónica de carácter científico, orientada a la publicación de artículos de investigación y/o de reflexión académica, científica y profesional en el ámbito de la discapacidad, desde una perspectiva multidisciplinar y en consonancia con el modelo social de la discapacidad y la visión de ésta como una cuestión de derechos humanos.

Es una revista de acceso abierto, revisada por pares y dirigida a todas las personas y entidades que trabajan e investigan en el campo de la discapacidad. Su periodicidad es semestral.

\section{Edita}

Centro Español de Documentación sobre Discapacidad (CEDD)

Fundación Eguía Careaga - SIIS Centro de Documentación y Estudios

Real Patronato sobre Discapacidad

C/ Serrano, 140. 28006 Madrid

Tel. 917452449

cedd@cedd.net

\section{Director}

Ignacio Tremiño Gómez (Director del Real Patronato sobre Discapacidad, Director General de Políticas de Apoyo a la Discapacidad, Ministerio de

Sanidad, Servicios Sociales e lgualdad)

\section{Secretario de redacción}

Eduardo Díaz Velázquez (Centro Español de Documentación sobre Discapacidad, CEDD)

\section{Consejo de redacción}

Antonio Jiménez Lara (Consultor social independiente)

Emiliano Díez Villoria (Servicio de Información sobre Discapacidad - SID; Universidad de Salamanca)

Joseba Zalakain Hernández (SIIS-Centro de Documentación y Estudios, Fundación Eguía Careaga)

Juan Antonio Ledesma (Comité Español de Representantes de Personas con Discapacidad, CERM)

$M^{\mathrm{a}}$ Ángeles Aguado Sánchez (Subdirectora General de Gestión, Instituto de Mayores y Servicios Sociales, IMSERSO)

Mercedes Jaraba Sánchez (Subdirectora General de Coordinación y Ordenación, Dirección General de Políticas de Apoyo a la Discapacidad, Ministerio de Sanidad, Servicios Sociales e lgualdad)

Rafael de Muslera Maesso (Consejero Técnico - Coordinador, Real Patronato sobre Discapacidad)

\section{Consejo asesor}

Agustín Huete García (Universidad de Salamanca / Intersocial)

Agustina Palacios Rizzo (Universidad Nacional de Mar del Plata)

Ana Sastre Campo (Comité Español de Representantes de Personas con Discapacidad, CERMI)

Ángel Calle Montero (Instituto de Mayores y Servicios Sociales, IMSERSO)

Belén Ruiz Mezcua (Universidad Carlos III de Madrid - Centro Español del Subtitulado y de la Audiodescripción, CESyA)

Clarisa Ramos Feijóo (Universidad de Alicante)

Claudia Grau Rubio (Universidad de Valencia)

Climent Giné y Giné (Universidad Ramón Llull)

Demetrio Casado Pérez (Seminario de Intervención y Políticas Sociales, SIPOSO)

Fernando Fantova Azcoaga (Consultor social independiente)

Francisco Alcantud Marín (Universidad de Valencia)

Gerardo Echeita Sarrionandia (Universidad Autónoma de Madrid)

Gregorio Rodríguez Cabrero (Universidad de Alcalá de Henares)

Javier Tamarit Cuadrado (FEAPS, Confederación Española de Organizaciones en favor de las Personas con Discapacidad Intelectual o del Desarrollo)

Jesús Hernández Galán (Fundación ONCE)

Juan Luis Quincoces Soler (Centro Nacional de Tecnologías de la Accesibilidad, CENTAC)

Liliana Pantano (Universidad Católica Argentina / Consejo Nacional de Investigaciones Científicas y Técnicas, CONICET, Argentina)

Manuel López Risco (Universidad de Extremadura)

María López González (Universidad de Córdoba)

María Luz Esteban Saiz (Centro de Normalización Lingüística de la Lengua de Signos Española, CNLSE)

Mario Toboso Martín (Consejo Superior de Investigaciones Científicas, CSIC)

Miguel A. V. Ferreira (Universidad Complutense de Madrid)

Miguel Ángel Verdugo Alonso (Universidad de Salamanca)

Natxo Martínez Rueda (Universidad de Deusto)

Paulino Azúa Berra (Instituto para la Calidad de las ONGs, ICONG)

Unai Martín Roncero (Universidad del País Vasco)

Xavier Etxeberria Mauleón (Universidad de Deusto)

Yolanda María De la Fuente Robles (Universidad de Jaén)

\section{Diseño}

Estudio Lanzagorta

\section{Maquetación}

Concetta Probanza

ISSN: $2340-5104$

DOI: <http://dx.doi.org/10.5569/2340-5104.03.01>

NIPO: 689-15-006-1

Indexada en:

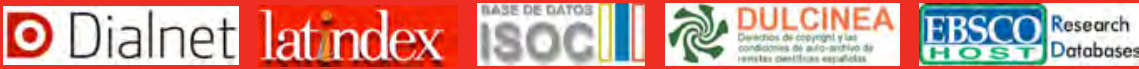

REDIS tiene una licencia Creative Commons: Reconocimiento - NoComercial - SinObraDerivada (BY-NC-ND). No se permite un uso comercial de la obra original ni la generación de obras derivadas. Está permitida la reproducción total o parcial por cualquier medio de los artículos de la revista, siempre que se cite la fuente y el autor o auto-res de los mismos. 


\section{Índice}

\section{ARTículos}

7 La exclusión social en los hogares con algún miembro con discapacidad durante el período de crisis en España

Sagrario Anaut Bravo Javier Arza Porras

29 Las personas con discapacidad en España: inserción laboral y crisis económica

Joydi Hernández Díaz José María Millán Tapia

57 El empleo de las personas con diversidad funcional en la prensa: $A B C$ y EI País (1978-2012)

Borja González Luna Antonio Iáñez Domínguez

77 Relaciones interpersonales en niños y jóvenes con trastornos del espectro del autismo y discapacidad intelectual

Lucía Morán Suárez

Laura E. Gómez Sánchez

$\mathrm{M}^{\mathrm{a}}$ Ángeles Alcedo Rodríguez

93 Evaluación de la calidad de vida en personas con discapacidades significativas: aplicación de la Escala San Martín en la Fundación Obra San Martín

Irene Hierro Zorrilla

Miguel Ángel Verdugo Alonso Laura E. Gómez Sánchez Sonia Fernández Ezquerra Patricia Cisneros Fernández
107 Validez y fiabilidad del Sistema de Detección Precoz de los Trastornos del Desarrollo: 3 a 36 meses

Francisco Alcantud Marín Yurena Alonso Esteban Darío Rico Bañón

123 Las dificultades de clasificación diagnóstica en Atención Temprana. La experiencia en dos unidades de Galicia

Jaime Ponte Mittelbrunn

141 La incidencia de los patronatos nacionales en la política educativa de las enseñanzas de sordos (1910-1978)

Alfredo Alcina Madueño Luisa Navarro Juárez

\section{TRIBUNAS}

163 Recomendaciones CODEPEH 2014

Faustino Núñez Batalla Carmen Jáudenes Casaubón Jose Miguel Sequí Canet Ana Vivanco Allende Jose Zubicaray Ugarteche

187 La lectura fácil: una apuesta de valor para las organizaciones

Jorge M. Pérez García Laura López de la Cruz
Revista Española de Discapacidad, $2(2): 3-4$. 
193 Nuevas medidas de protección legal de personas con discapacidad: la asistencia

Josep Ruf i Aixàs

Josep Tresserras Basela

211 Responsabilidad social empresarial e integración laboral de personas con discapacidad intelectual. Estudio de caso

Antonio Blanco Prieto

\section{RESEÑAS}

221 Carolina Ferrante (2014): Renguear el estigma. Cuerpo, deporte y discapacidad motriz (Buenos Aires, 1950-2010). Argentina: Biblos

Daniela Testa
223 Patricia Brogna (2014): Adultez, trabajo y discapacidad. El trabajo de crecer. México: Trillas

Carolina Ferrante

227 Marcelo Silberkasten (2014): La construcción imaginaria de la discapacidad (Segunda Edición Ampliada). Buenos Aires: Topía Editorial

Carolina Ferrante

\section{BREVES RESEÑAS} BIOGRÁFICAS 


\section{ARTículos}





\section{La exclusión social en los hogares con algún miembro con discapacidad durante el período de crisis en España}

\author{
Social exclusion in households with members \\ with disabilities during the Spanish economic \\ crisis
}

\section{Resumen}

El análisis del impacto que la crisis ha tenido en la discriminación, la pobreza y, especialmente, la exclusión social de las personas y hogares con algún miembro con discapacidad, es el principal objeto de este artículo. Para ello se ha utilizado, como fuente principal, la serie de encuestas realizada por la Fundación FOESSA en los años 2007, 2009 y 20I3. Se observa que el impacto de la crisis no ha sido tan grande en las personas y hogares con discapacidad como en el conjunto de la población de España. Sin embargo, la estabilidad de unos niveles de pobreza y exclusión, que persisten en ser superiores a los registrados en el conjunto de la población, nos informa sobre las limitaciones que las políticas sociales actuales tienen para lograr modificaciones significativas en esta realidad que afecta a los Derechos Humanos de las personas con discapacidad.

\section{Palabras clave}

Discapacidad, exclusión social, España, crisis.

\begin{abstract}
This article analyses the impact that the economic crisis has had on discrimination, poverty and social exclusion among people with disabilities and households with members with disabilities. For this analysis, a series of surveys conducted by the FOESSA Foundation in 2007 , 2009 and 2013 were used. The effect of the economic crisis has not been as great among people with disabilities and households that include members with disabilities as among the overall Spanish population. However, the fact that poverty and exclusion levels among the former group remained higher than those of the overall Spanish population reflects the limitations of current social policies in changing this situation which affects the human rights of people with disabilities.
\end{abstract}

\section{Keywords}

Disability, social exclusion, Spain, economic crisis.

\section{Sagrario Anaut Bravo \\ <sanaut@unavarra.es>}

Universidad Pública de Navarra

\section{Javier Arza Porras}

<javier.arza@unavarra.es>

Universidad Pública de Navarra
Para citar:

Anaut, S. y Arza, J. (20I 5): "La exclusión social en los hogares con algún miembro con discapacidad durante el período de crisis en España”, Revista Española de Discapacidad, 3 (I): 7-28.

Doi: <http://dx.doi.org/IO.5569/23405IO4.03.OI.OI>

Fecha de recepción: I 8-O2-20 I 5 Fecha de aceptación: I3-05-20I 5 


\section{Introducción}

El surgimiento de nuevos modelos de comprensión de la discapacidad ha facilitado el desarrollo de abordajes con un carácter más integral. La consideración de las múltiples dimensiones de un fenómeno de características biopsicosociales, como es el que nos ocupa, ha permitido que el foco deje de estar centrado únicamente en los aspectos biologicistas y asistenciales. Así, conceptos como derechos humanos, ciudadanía, inclusión social o participación social, cada vez están más presentes en el ámbito discursivo de la discapacidad.

En este artículo se ha abordado específicamente la relación entre la discapacidad y la exclusión social, un concepto vinculado a estos nuevos modelos de comprensión holística de la discapacidad. La exclusión social es un fenómeno multidimensional diferenciado del tradicional concepto de pobreza. Si la pobreza se suele asociar únicamente a la falta de recursos económicos, el concepto de exclusión implica la consideración de otras muchas variables: educación, salud, vivienda, vínculos familiares y sociales, empleo, etc. En ese sentido, la exclusión social supone una acumulación de carencias en todas (o casi todas) esas variables, implicando la ruptura del vínculo social, la privación de derechos sociales y, en definitiva, la desigualdad.

Para dimensionar el alcance de la exclusión social en los hogares con algún miembro con discapacidad se han explotado las tres encuestas sobre integración social y necesidades sociales de la Fundación FOESSA (2007, 2009 y 2013). De ellas también se ha obtenido información sobre la pobreza en esos hogares y en las personas con discapacidad. Para completar la visión de lo que supone la exclusión social se ha introducido un apartado dedicado a la experiencia de la discriminación a partir de la Encuesta 3000 del CIS.

Con la mirada puesta en el análisis longitudinal, el artículo se adentra en la tendencia de los impactos de la exclusión social durante la crisis en los hogares sin y con algún miembro con discapacidad. De sus comportamientos se podrá deducir si la brecha entre ambas modalidades de hogares se acrecienta o no.

\section{Inclusión social, derechos humanos y discapacidad}

El estudio de la discapacidad en España ha estado condicionado por la disponibilidad de fuentes de información estadística (Puga y Abellán, 2004:7; Huete y Quezada, 20I2). Hasta la Encuesta sobre discapacidades, deficiencias y minusvalias (I986) y, sobre todo, desde la Encuesta sobre discapacidad, deficiencias y estado de salud (EDDES) de I999, la mayoría de los estudios publicados se centraron en propuestas de intervención sobre algún tipo de discapacidad (Béland y Zunzunegui, I995; Barton, I998), en políticas o estrategias socio-sanitarias (Verdugo et al., I994; IMSERSO, I997) y en colectivos concretos (Bermejo et al., 2002). Esta situación cambiará con la disponibilidad de los datos de la EDDES y la aprobación de la segunda Clasificación del funcionamiento, de la discapacidad y de la salud por la OMS en 200I. Trabajos como los de Abellán (2000), Verdugo (2000), Palacios (2006, 2008), Seelman (2004), Querejeta (2004) o De Lorenzo y Pérez Bueno (2007) apuntan hacia nuevos modelos y enfoques de la discapacidad, una mayor precisión conceptual y cuantitativa de la realidad de la discapacidad, así como hacia los retos de una sociedad posmoderna.

El creciente interés por la inclusión social de las personas con discapacidad ha abierto interrogantes sobre el cómo lograrla, a partir de qué y de quién, hacia dónde, con qué medios propios y colectivos. El desafío para la sociedad se ha traducido en el desarrollo de políticas sociales con capacidad para atender las diferentes dimensiones de la discapacidad. En este sentido el enfoque basado en los derechos humanos se presenta como un cambio en la 
mirada social y personal. El Informe Mundial sobre la Discapacidad de la OMS (20II: 9-II) insiste en que la discapacidad es una cuestión de derechos humanos, por cuanto las personas con discapacidad experimentan situaciones de desigualdad y de violación de la dignidad, en ocasiones, por prejuicios y abusos, y tienen serias dificultades para lograr su autonomía personal.

Con este enfoque de recuperación de derechos se han publicado estudios, como los Informes para España sobre Derechos Humanos y Discapacidad, elaborados por CERMI desde 2008. Otros trabajos, como los de Etxebarría (2008) y Díaz (2010) avanzaban en su reflexión hacia el concepto de ciudadanía de las personas con discapacidad, señalando la necesidad de considerar la participación de estas personas en su vida, no sólo en aspectos asistenciales, sino en los sociales y políticos. Recientemente, Alonso (20II), Martínez Ríos (20I I y 20I3) o Raya et al. (20I2 y 20I3), coinciden en mostrar la necesidad de un cambio de enfoque y paradigma hacia los derechos humanos, sin el cual no se podrá superar la situación recogida en el Informe de la ONU citado.

Sobre la idea de los derechos humanos se apoya el modelo social de tratamiento de la discapacidad (Raya y Caparrós, 20I3: I9I-I98). Este modelo se ha ido introduciendo, desde la década de los sesenta del siglo XX, hasta alcanzar hoy un alto nivel de consenso en la producción científica en cuanto a su definición y a las implicaciones que tiene en materia de políticas socio-sanitarias, de intervención y de desarrollo de un tejido comunitario más inclusivo. En paralelo, han irrumpido discursos renovados como los que consideran la discapacidad una condición humana, de modo que ninguna persona cuenta con todas las capacidades que demanda la sociedad o el entorno (Anaut et al, 20I2). También aquellos otros que promueven una visión holística e integradora (biopsicosocial) de las situaciones de discapacidad (De Lorenzo y Pérez Bueno, 2007).

Así como se ha evolucionado hacia una concepción social del constructo "discapacidad"
(Anaut et al., 20I 2: 27-34), hay autores que avanzan hacia una definición social de la ciudadanía, en concreto, de ciudadanía multicultural, de ciudadanía diversa. Muchas de las entidades del ámbito de la discapacidad sensorial y el Movimiento de Vida Independiente (Palacios y Romañach, 2006: 34-35) han reivindicado este posicionamiento en el que las personas con discapacidad presentan una diversidad más a las del resto de personas (diversidad funcional). El reconocimiento de una mayor diversidad requiere que el contexto/ entorno elabore o re-elabore respuestas que garanticen la igualdad de oportunidades. Las instituciones públicas, en este punto, han de garantizar el completo ejercicio de la ciudadanía. Este enfoque implica una actuación no sólo reactiva que remueva las barreras a la participación, sino una línea de trabajo promocional que impulse las medidas necesarias para ofrecer oportunidades a las personas en función de sus necesidades.

La relación entre el modelo social y los derechos humanos queda plasmada, igualmente, en la legislación de España, especialmente desde la aprobación de la Convención de la ONU sobre los derechos de las personas con discapacidad, como reflejan en sus trabajos el Colectivo Ioé (20I2) y Marbán (20I3). Se ha avanzado en la defensa de los derechos de las personas con discapacidad y su inclusión social, por ejemplo, con la Ley 26/20I I y el Real Decreto Legislativo $\mathrm{I} / 20 \mathrm{I} 3^{\mathrm{I}}$. Asimismo, se ha seguido la recomendación de la Convención de la ONU y de la Estrategia Europea sobre Discapacidad, 2010-2020 (2010), para elaborar y activar la Estrategia Española sobre Discapacidad (20I22020). En ella destacan como obstáculos a la adaptación del entorno a las personas con discapacidad: la insuficiencia y las limitaciones de las políticas y normas, sobre todo, en cuanto a su eficacia; las actitudes sociales negativas; una financiación insuficiente; la falta de

I. Ley 26/20I I, de I de agosto, de adaptación normativa a la Convención Internacional sobre los Derechos de las Personas con Discapacidad; Real Decreto Legislativo I/2013, de 29 de noviembre, por el que se aprueba el Texto Refundido de la Ley General de derechos de las personas con discapacidad y de su inclusión social. 
participación de las personas con discapacidad; los obstáculos a la información; y la limitación en la accesibilidad.

Ciertamente, todos estos pasos dados hasta la fecha suponen un salto cualitativo en el desarrollo de un modelo de derechos humanos en materia de discapacidad. Pero la realidad cotidiana no siempre se ajusta a la construcción conceptual y legal. Trabajos como el de Huete (20I3b: 2I) resaltan una cierta mejoría en materia de sensibilización y concienciación de la sociedad sobre la discapacidad. Sin embargo, los datos de la Encuesta Social Europea (2010)2, que él maneja, muestran la persistencia de la situación de invisibilización de la población con discapacidad y la consiguiente experiencia de la discriminación y la exclusión social. En las siguientes páginas se procederá al análisis de la realidad de la discapacidad a partir de las encuestas sobre integración social y necesidades sociales (EINSFOESSA) para constatar si se han producido esos mismos avances que apuntarían a la reducción de la situación de exclusión y pobreza de las personas y los hogares con algún miembro con discapacidad.

\section{La discapacidad en la encuesta sobre integración social y necesidades sociales de la Fundación FOESSA (EINSFOESSA)}

Trabajos recientes como los de Rodríguez Álvarez (2013: 75-94), Huete (20I2: I66-I67) o Raya Díez (2012: 47-72) identifican y analizan distintas bases de datos que recogen información cuantitativa sobre la discapacidad en la sociedad. Además de las encuestas específicas sobre discapacidad del INE de los años I986, I999 y 2008, es posible acceder a otras más genéricas como la Encuesta de Condiciones de Vida (ECV) y la Encuesta de Población Activa

2. Es un estudio comparado y longitudinal que se lleva a cabo cada dos años, en el que participan alrededor de 30 países europeos. Trata de analizar la evolución en actitudes y comportamientos de la población europea. Cuenta con una muestra de personas con discapacidad.
(EPA). Sus datos facilitan comparar la situación en la que se encuentran las personas con y sin discapacidad. En este segundo grupo de encuestas se encuentran las EINSFOESSA.

Hasta la fecha se han realizado tres EINSFOESSA (2007, 2009 y 2013), cuyo objetivo central ha sido cuantificar las condiciones de vida y la exclusión social en España. A partir de sus datos, se ha procedido a la medición de la exclusión social con la aplicación de un sistema de 35 indicadores que recogen las principales dimensiones de la exclusión: empleo, consumo, participación política, educación, vivienda, salud, conflicto social y aislamiento social. Con la suma ponderada de todos esos indicadores se obtiene el denominado Índice Sintético de Exclusión Social (ISES). A partir de ahí, y de acuerdo con la incidencia de los diferentes indicadores de exclusión en cada uno de los hogares y personas encuestados, han quedado distribuidos en cuatro grupos: integración, exclusión precaria, exclusión moderada y exclusión severa (Trujillo, 20I4: 667-668). Para poder comparar los resultados de las tres encuestas se ha utilizado el sistema de ponderación de los indicadores correspondiente al año 2007.

Por su parte, la medición de la pobreza ha seguido un enfoque metodológico estándar en la Unión Europea: línea de la pobreza relativa. Se ha calculado "sobre la base de la variable monetaria de los ingresos y teniendo en cuenta las unidades de consumo del hogar y las escalas de equivalencia” (Trujillo, 20I4: 669).

En cuanto al procedimiento seguido, ha sido muy similar en las tres encuestas. Como unidad de encuestación se han tomado los hogares. El muestreo ha sido bietápico: selección de secciones censales y selección mediante rutas aleatorias. Ello ha facilitado el acceso a suficientes hogares en situación de exclusión social. El tamaño muestral final en 2013 fue de 8.769 cuestionarios de hogares. 
Tabla 1: Cuantificación del universo, muestra y margen de la EINSFOESSA de 2013

\begin{tabular}{|l|c|}
\hline Universo, muestra, margen & Cuantificación \\
\hline Universo población & 47.129 .783 \\
\hline Universo hogares & 17.440 .800 \\
\hline Muestra población & 24.775 \\
\hline Muestra hogares & 8.776 \\
\hline Margen de error población & $+0,6$ \\
\hline Margen de error hogares & $+1,0$ \\
\hline Número de Municipios & 530 \\
\hline
\end{tabular}

Fuente: Trujillo (2014: 665).

Para facilitar la obtención de la muestra necesaria se elaboraron dos cuestionarios (filtro y completo) que se pasaron en dos fases. En la primera, se contactó con los hogares y se pasó el cuestionario filtro. Con la información recogida se clasificó a cada hogar en: hogar con indicios de exclusión y hogar sin indicios. De la muestra total, 6.073 correspondieron a los primeros hogares y 2.696 a los segundos.

En la segunda fase se pasó el cuestionario extenso, compuesto por 99 preguntas codificadas. Estas preguntas se agrupan en ocho bloques de extensión muy variada. Los dos bloques más extensos (más de veinte preguntas cada uno) tratan la situación económica y la percepción de la situación en la que se encuentran los hogares en España. El resto de bloques recogen datos básicos de los hogares y sus miembros, el nivel de estudios y formación, el estado de salud, autovalimiento y necesidades específicas, el empleo, la vivienda y los servicios sociales.

La discapacidad aparece recogida en el bloque dedicado al estado de salud, autovalimiento y necesidades específicas. En la explotación de las dos primeras encuestas (2007 y 2009) se detectó que la pregunta referida a la detección de casos con discapacidad era imprecisa: "¿Alguna persona del hogar padece alguna minusvalía, enfermedad crónica o problemas graves de salud que le genere limitaciones para realizar las actividades diarias?”. Para solventar esta cuestión se introdujo en el cuestionario de $20 \mathrm{I} 3$ una pregunta previa más concisa: “¿Alguna persona del hogar padece alguna minusvalía/ discapacidad?". Este cambio ha producido una reducción del número de hogares con algún miembro con discapacidad respecto a las dos encuestas anteriores. Una leve distorsión que también pudo detectarse en sentido contrario en la encuesta de 2009 , entonces como efecto de la extensión de los reconocimientos de la situación de dependencia y no siempre la diferenciación entre discapacidad y dependencia por parte de las personas entrevistadas.

\section{Discapacidad y pobreza}

Las personas con discapacidad, y los hogares en los que viven, alcanzan niveles de pobreza más elevados. Ahora bien, la discapacidad no es sinónimo de pobreza, sino un factor más de riesgo. Trabajos como los de Pérez Bueno y Huete (2008) o de Anaut et al. (2010) demostraron que esta realidad se mantenía en el tiempo al margen de la bonanza o crisis económica, si bien detectaron que las políticas dirigidas a un apoyo más intensivo sobre los hogares que tenían algún miembro con discapacidad amortiguaban la intensidad de la pobreza. Es decir, permanece la tradicional interrelación discapacidad-pobreza de carácter bidireccional, pero con matices en función de la intensidad y diversidad de las políticas públicas y del nivel de impacto de las crisis.

Para entender la relación bidireccional del binomio discapacidad-pobreza, Martínez Ríos (2013: I 2-22) realiza una revisión de diferentes propuestas teóricas que han contribuido a que la discapacidad sea tenida en cuenta como un aspecto importante para lograr un avance económico general. Desde ahí, concluye la autora, puede establecerse un patrón común en el que la discapacidad se caracteriza por suponer un mayor coste de vida, dependiendo ese coste de la naturaleza y nivel de severidad de la discapacidad, así como de las barreras 
actitudinales, sociales y físicas (Martínez Ríos, 2OI3: 25).

Otras aproximaciones focalizan su interés en el impacto de la crisis actual sobre el empleo y la pobreza, analizando por tanto los ingresos de los hogares con algún miembro con discapacidad (Anaut et al., 2010: 225-235). Huete (2013b: I4), por ejemplo, ha calculado que los niveles medios de ingresos en los hogares donde vive alguna persona con discapacidad son inferiores a los de aquellos sin miembro con discapacidad, según la Encuesta Social Europea de 20 Io.

Estas diferencias se acrecientan en los niveles de ingresos más bajos: el 35,8 1 \% de la población con discapacidad vive en hogares con ingresos iguales o inferiores a 900 euros, frente al $20,48 \%$ en la población general. Asimismo, el 36, I $4 \%$ de la población con discapacidad reconoce dificultades para llegar a fin de mes, frente al I9,I3 \% de la población general.

Marbán et al. (201 2: 57) introduce ciertas concreciones al tratar la incidencia de la pobreza a partir de los datos de la EDAD 2008. El hecho de que la tasa de pobreza de las personas con discapacidad sea "casi el doble que la del resto de la población” se entiende que es efecto de la estructura demográfica de este colectivo caracterizado por su envejecimiento y feminización. De esta forma, la modalidad de ingreso que predomina en los hogares con personas con discapacidad son las pensiones contributivas $(75 \%$, frente al $39 \%$ de promedio en el resto de hogares). En cuanto a la feminización, Huete (2013 a: 39) estima que el riesgo de pobreza afectaba por igual a mujeres y varones con discapacidad en 2008 , si bien se detectaban diferencias en cuanto a la situación de pobreza extrema ( $17,3 \%$ de las mujeres y i I \% de los varones) y de carencia de prestaciones $(47 \%$ de mujeres y $40 \%$ de varones en 2OII).

Otros autores (Whitehead y Dahlgren, 2006; Benach y Muntaner, 20I0; OMS, 20II) se han centrado más en la influencia de los determinantes sociales en la salud. Sostienen que la vinculación entre pobreza y discapacidad se explica por diferentes factores complementarios: el tener los hogares pobres mayor riesgo de padecer enfermedades y accidentes; mayores dificultades de los hogares pobres para financiar determinados tratamientos de rehabilitación; y el empobrecimiento que puede ocasionar la discapacidad por las dificultades de inserción laboral, las limitaciones de las pensiones y los gastos extra en fármacos, tratamientos y apoyos técnicos.

Con el mismo trasfondo que pone en evidencia la relación entre discapacidad y pobreza, se expresa el Informe de Cruz Roja sobre vulnerabilidad social (Malgesini, 20I3: I3-I 5). En él, se reitera el peso del ámbito económico en esta situación y se destaca la progresiva homogeneización del mapa que identifica los diversos perfiles de vulnerabilidad.

La última EINSFOESSA (2013) ha facilitado disponer de una serie breve de encuestas sobre la situación de pobreza por colectivos. Como se recoge en el siguiente gráfico, la crisis económico-financiera ha seguido agravando los niveles de pobreza de las personas sin discapacidad ( $19,4 \%$ en 2009 y $28,7 \%$ en 20I3), en tanto se han estabilizado los de las personas con discapacidad (en torno al $25 \%$ ) entre 2009 y 2013 . Al mismo tiempo, la situación de las personas con discapacidad, con y sin certificado de discapacidad, ha tendido a igualarse. Ambos procesos adquieren un carácter claramente novedoso que requiere un análisis.

Estas tendencias pueden explicarse, aunque parcialmente, por la representación de las personas en situación de dependencia reconocida entre quienes dicen tener discapacidad (40,6\%) y por el incremento en la muestra de las personas con discapacidad y certificados de reconocimiento de la misma (2007: 60\%; 2009: $53 \%$; y 20I3: $80 \%$ ). Por tanto y coincidiendo con Belzunegui et al. (2OI4: 54), todo apunta a que ciertos mecanismos y prestaciones de protección que se han ido implantando, como las transferencias públicas vinculadas al reconocimiento de la situación de dependencia (Ley 39/2006) y/o las dedicadas a la discapacidad, o como la aplicación de la Estrategia global para el empleo de las personas 

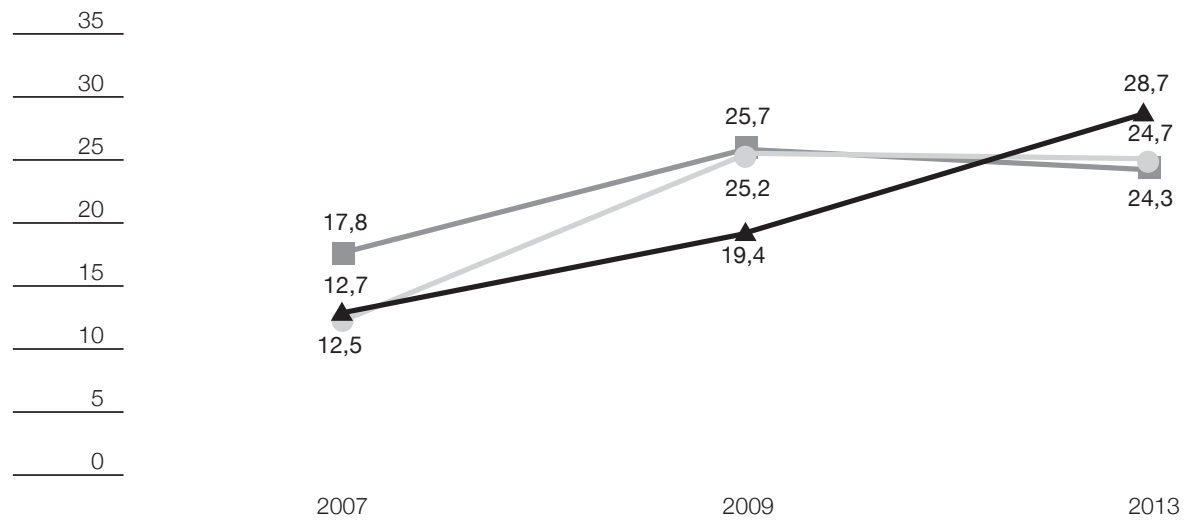

Sin discapacidad

Con discapacidad

Con discapacidad + Certificado

Fuente: EINSFOESSA 2007, 2009 y 2013.

con discapacidad (2008-I2), han estado amortiguando, que no reduciendo, la intensidad del creciente impacto de la situación de crisis actual.

El carácter multidimensional de la pobreza también requiere adentrarse en matices sobre su intensidad. La pobreza severa entre las personas con discapacidad se ha mantenido en niveles idénticos entre 2007 y $2013(4,7 \%)$, mientras que en el conjunto de la población ha aumentado del $3,5 \%$ al $7,3 \%$. La pobreza moderada, en cambio, se ha incrementado en más de seis puntos entre las personas con discapacidad ( $13 \%$ en 2007 y I9,6\% en 2013 ) 3 . Es decir, el empobrecimiento se produce por la entrada en esta situación de quienes no eran pobres. Este hecho pudo constatarse ya en la EINSFOESSA de 2009. En ese momento se produjo un desplazamiento hacia la pobreza moderada, tanto desde las situaciones de no

3. El Informe Olivenza 20I4 establece que la pobreza severa afecta al $14,7 \%$ de las personas con discapacidad y que la pobreza moderada lo hace al $32 \%$ (Observatorio Nacional de la Discapacidad, 2015:46I) pobreza como de pobreza severa, dando como resultado un crecimiento global de la pobreza en las personas con discapacidad (del I 7,8 \% en 2007 al 25,7\% en 2009).

En 2013, la situación experimenta cambios mínimos respecto al año 2009, detectándose una ligera reducción global de la pobreza ( I,4 puntos), aunque aún se mantiene una diferencia de seis puntos y medio respecto al porcentaje de pobreza registrado antes de la crisis. En comparación con el conjunto de la población, la pobreza entre las personas con discapacidad sigue siendo elevada, a pesar del importante crecimiento experimentado en la pobreza del conjunto de la población española desde el inicio de la crisis.

Estos datos vuelven a llamar la atención sobre las limitaciones de las prestaciones sociales, incluso las asociadas a los reconocimientos de dependencia y/o discapacidad, a la hora de paliar las situaciones más graves. No obstante, han ejercido su función paliativa desde el momento en que ha descendido el peso de las 
personas con discapacidad en situación de pobreza severa respecto del total de personas encuestadas: $7,7 \%$ en $2007,8,7 \%$ en 2009 y 4,6\% en 20I3. Asimismo, han evitado mantener una progresión ascendente de los casos de pobreza moderada: $7,9 \%$ en 2007 , I I, $5 \%$ en 2009 y $6,8 \%$ en 2013 .

Coincide este resultado con la afirmación de Ayala (20I4: 43) para el conjunto de la sociedad, según la cual los aumentos de la pobreza durante períodos de crisis solo pueden evitarse con una elevada inversión en recursos sociales. En el caso que nos ocupa ha habido más recursos garantizados de los sistemas de protección social destinados a las personas con discapacidad y con una situación de dependencia que para la población sin discapacidad, y eso a pesar de los recortes. Ahora bien, estos recursos han sido insuficientes para reducir el elevado nivel de pobreza de las personas con discapacidad y para modificar la tendencia más allá de la estabilización.

Por su parte, la pobreza en los hogares con algún miembro con discapacidad ha seguido la misma tendencia descrita a título individual, si bien con una mayor representación de la incidencia de la pobreza respecto al conjunto de hogares. Así, en 2013, los hogares con alguna persona con discapacidad que se encontraban en situación de pobreza moderada eran el I 8,3 \% del conjunto de hogares en esa misma situación, y el I $4, \mathrm{I} \%$ entre los hogares en pobreza severa, en tanto las personas con discapacidad representaban el $6,8 \%$ y $4,6 \%$, respectivamente, del conjunto de personas encuestadas.

Se confirma que la pobreza creció en los hogares con alguna persona con discapacidad y, sobre todo, el impacto fue importante entre $2007 \mathrm{y}$ 2009. Se observa, en cambio, una suave mejoría entre 2009 y $20 \mathrm{I}_{3}$, que se traduce en el paso del $27,7 \%$ de hogares con algún miembro con discapacidad en situación de pobreza en 2009 al 24,I \% en 20I3, básicamente, por la salida de la pobreza moderada (del $24,2 \%$ en 2009 al I9,7\% en 2013).

A su vez, las diferencias entre disponer o no de un certificado de discapacidad apenas son visibles, excepto en 2007. Cabía esperar que disponer de un certificado podía evitar las situaciones de pobreza severa, pero no

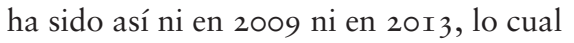
pone en cuestión la efectividad real de este reconocimiento que posibilita el acceso a más prestaciones.

Gráfico 2. Porcentajes de niveles de pobreza de hogares con algún miembro con discapacidad (total) y aquellos que además cuentan con un certificado de discapacidad (2007, 2009 y 2013)
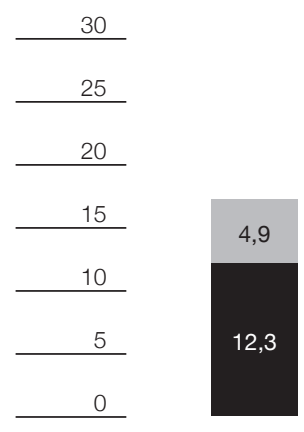

Total

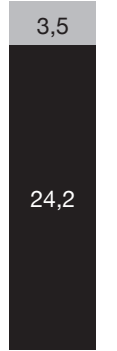

Total

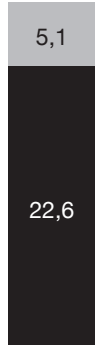

Certificado 2009

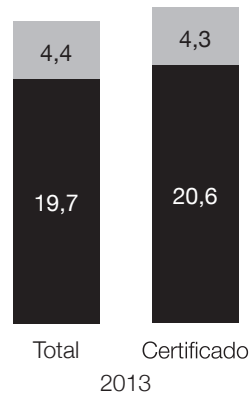

Pobreza moderada

Pobreza severa

Fuente: EINSFOESSA 2007, 2009 y 2013. 
En suma, las personas con discapacidad y los hogares en los que residen siguen manteniendo altos niveles de pobreza, sobre todo moderada. Ciertamente, no ha empeorado tanto su situación en los últimos años de la crisis como la de quienes no tienen discapacidad, pero este hecho no puede ocultar que la incidencia de la pobreza sigue siendo muy alta.

Es decir, la situación de estabilidad de la pobreza individual presentada entre 2009 y $20 \mathrm{I}_{3}$, a pesar de la profundización de la crisis, resulta un tanto engañosa. Quizá solo supone dar un respiro y reconocer la capacidad paliativa de las políticas sociales.

Otras aproximaciones realizadas al tema, como las de Huete (2013b: I3), corroboran esta conclusión, si bien lo hacen tomando como indicador el riesgo de pobreza de la población con discapacidad (el 48,4\% se halla por encima de los límites de riesgo de pobreza). En todo caso, parece cierto que se reproduce, al igual que sucede entre las personas que perciben una pensión contributiva, el hecho de una mejoría de la posición relativa de quienes tienen una discapacidad y de los hogares con algún miembro con discapacidad por la estabilidad en la percepción de ciertas prestaciones.

5. La exclusión social: el espejismo de la estabilidad

A partir de los datos de la Encuesta Social Europea, Huete afirma que las personas con discapacidad sufren un situación de exclusión "en el ámbito educativo y alcanzan inferiores niveles de estudios que el resto de la población; disponen de menos oportunidades para acceder al mercado de trabajo; hacen frente a restricciones extraordinarias para participar activamente en la sociedad, y desarrollar una vida afectiva y social normalizada" (2OI3b: 2I). A conclusiones similares llegan, entre otros, los trabajos de Huete (20I3a), Colectivo Ioé (20I2) y Anaut et al. (2010).
Durante el período analizado a través de las tres EINSFOESSA, no se observan cambios muy significativos en las situaciones de exclusiónintegración que afectan a las personas con discapacidad. Comparando el año 2013, respecto al periodo anterior a la crisis, se observa un incremento de casi ocho puntos en las situaciones de integración precaria. Este incremento se ha producido por el desplazamiento desde la exclusión moderada hacia la integración precaria ( 5 , I puntos), pero también desde la integración plena a la integración precaria (3,7 puntos). Asimismo, se ha detectado que la exclusión severa se ha incrementado en un punto. En suma, aunque se han producido algunos pequeños transvases porcentuales entre los cuatro tipos de integración-exclusión, la crisis no ha incrementado el espacio social de la exclusión de las personas con discapacidad $(33 \%$ en 2007 y $29 \%$ en 2013 ).

Esta imagen puede completarse comparando la situación de las personas con discapacidad respecto a la del conjunto de la población española. Si en el periodo anterior a la crisis la incidencia de la exclusión era prácticamente I7 puntos superior en las personas con discapacidad, en el año 2013 se ha reducido la distancia a cinco puntos. Esta tendencia a la aproximación en los porcentajes de exclusión se ha producido fundamentalmente por el espectacular aumento de la misma en el conjunto de la población, y no tanto porque haya mejorado significativamente la situación entre las personas con discapacidad.

La situación descrita puede hacerse extensible en sus grandes rasgos a la de los hogares. Se observa un incremento de 4,6 puntos en el porcentaje de hogares en integración precaria, así como una subida de un punto en las situaciones de exclusión severa (gráfico 6). Estos datos reiteran que la crisis no ha incrementado el impacto de la exclusión en los hogares donde habita alguna persona con discapacidad (29,6\% en el año 2007 y $28 \%$ en el año 20I3).

La comparación con los hogares de la población general nos indica una tendencia a 
la aproximación en los porcentajes de hogares excluidos. Si en el año 2007 el porcentaje de hogares excluidos en los que habitaba alguna persona con discapacidad era I4 puntos superior en comparación con el conjunto de la población, en el año $20 I_{3}$ la diferencia se reduce a 6,I puntos. También en este caso la aproximación se produce por la agudización de las situaciones de exclusión de la población en su conjunto.

Gráfico 3. Evolución de los niveles de integración social en el conjunto de hogares y en los hogares con alguna persona con discapacidad (2007-2013)

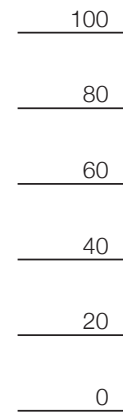

0
2007

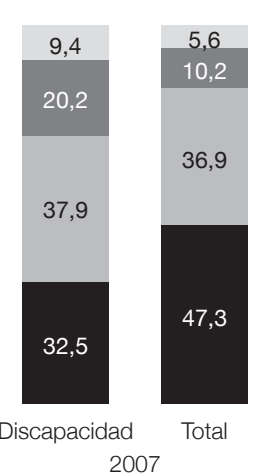

Integrado

Integración precaria

Exclusión moderada

Exclusión severa

Fuente: EINSFOESSA 2007, 2009 y 2013.
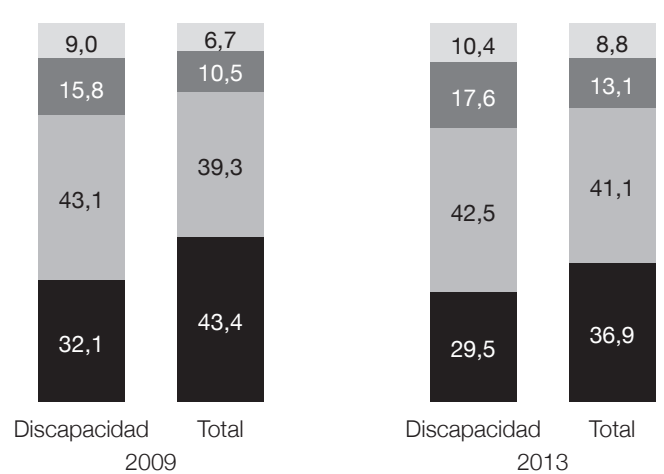

Discapacidad Total 2013

\section{Gráfico 4. Evolución de los niveles de integración-exclusión en los hogares con alguna persona con} discapacidad que cuenta con certificado de discapacidad (2007-2013)

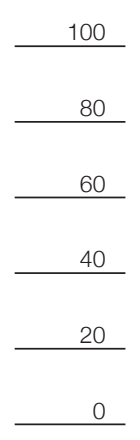

Integrado

Integración precaria

Exclusión moderada

Exclusión severa

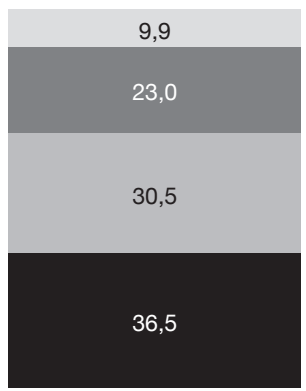

2007

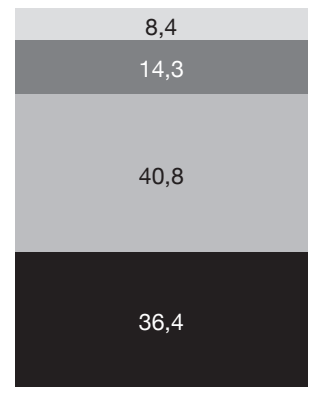

2009

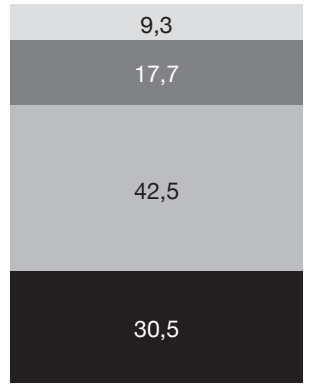

2013

Fuente: EINSFOESSA 2007, 2009 y 2013. 
Disponer de certificado de discapacidad, como se ha apuntado en el apartado dedicado a la situación de pobreza, no impide que un hogar se encuentre en situación de exclusión. En el siguiente gráfico se comprueba la evolución de estos hogares entre el año 2007 y el 20I3. En ese periodo se observó una mejoría al desplazarse algunos hogares ( Io puntos de diferencia) del espacio de la exclusión social al de la integración precaria. Sin embargo, entre el año 2009 y el 2013 vuelve a aumentar en cuatro puntos el espacio de la exclusión (tanto moderada como severa) y se reduce en seis el de la integración. Gráfico 7. Evolución de los niveles de integración-exclusión en los hogares con alguna persona con discapacidad que cuenta con certificado de discapacidad (2007-2013)

En conclusión, el empeoramiento en la situación de las personas con discapacidad y de los hogares con algún miembro con discapacidad no es tan acusado como en el caso de la población general. Siendo más estable su situación, la tendencia descrita durante los años de crisis es hacia la reducción de la integración, al tiempo que se incrementan ligeramente las situaciones de exclusión severa y, sobre todo, de integración precaria.

\section{Las dimensiones de la exclusión social}

La evolución seguida por las diferentes dimensiones de la exclusión en los hogares con algún miembro con discapacidad dibuja trayectorias diversas en los tres momentos en que se han elaborado las EINSFOESSA. Si comparamos la situación del año 20I3, respecto a la recogida en el periodo anterior a la crisis (2007), podemos observar cierta estabilidad en las dimensiones de empleo, educación, vivienda y aislamiento social, mientras que se reduce la exclusión en consumo y salud, y se incrementa en la exclusión política y en conflicto social. Los mayores porcentajes de exclusión, respecto al conjunto de los hogares, se observan en salud, educación y conflicto social. Así, uno de cada tres hogares en situación de exclusión en salud tiene alguna persona con discapacidad, prácticamente lo mismo en el caso de la exclusión en educación y uno de cada cuatro en el caso del conflicto social.

Tabla 2. Porcentaje de hogares con algún miembro con discapacidad respecto del total de hogares según la dimensión de exclusión social (2007-2013)

\begin{tabular}{|l|c|c|c|}
\hline & $\mathbf{2 0 0 7}$ & $\mathbf{2 0 0 9}$ & $\mathbf{2 0 1 3}$ \\
\hline Exclusión del empleo & 12,6 & 19 & 16,2 \\
\hline $\begin{array}{l}\text { Exclusión del } \\
\text { consumo }\end{array}$ & 22,6 & 21,7 & 15,9 \\
\hline Exclusión política & 6,3 & 11,3 & 13,4 \\
\hline $\begin{array}{l}\text { Exclusión de la } \\
\text { educación }\end{array}$ & 28,7 & 31,5 & 29,6 \\
\hline $\begin{array}{l}\text { Exclusión de la } \\
\text { vivienda }\end{array}$ & 19,6 & 21,6 & 19,3 \\
\hline Exclusión de la salud & 41,7 & 54,8 & 34,9 \\
\hline Conflicto social & 17 & 27,9 & 24,9 \\
\hline Aislamiento social & 13,5 & 15,7 & 15 \\
\hline
\end{tabular}

Fuente: Elaboración propia a partir de EINSFOESSA 2007, 2009 y 2013.

Por otro lado, las diferentes dimensiones de la exclusión han afectado de forma diversa a las situaciones de integración precaria, exclusión moderada y exclusión severa en 2013 (gráfico 5). La exclusión en educación, vivienda, salud y empleo, por ese orden, son las dimensiones más presentes en los hogares precarios con algún miembro con discapacidad. En los hogares en exclusión moderada, los mayores déficits se concentran en las dimensiones de política, aislamiento social, conflicto social y salud. Los conflictos sociales, el aislamiento, la vivienda $\mathrm{y}$, especialmente, los problemas de consumo, sobresalen en aquellos hogares afectados por la exclusión severa.

Hay que destacar, por tanto, que los déficits o problemas ligados al propio engranaje de los sistemas de protección social se convierten en factores desencadenantes de la pérdida de 
integración de los hogares con alguna persona con discapacidad. Estos ámbitos pierden protagonismo en las dos situaciones de exclusión (moderada y severa), cuando las dificultades en la dimensión política, los conflictos sociales y el aislamiento social adquieren mayor protagonismo. Es también aquí y, sobre todo, en la exclusión severa, donde se hace visible la problemática del consumo (dificultades para acceder a bienes considerados básicos y la pobreza extrema).

El análisis de las tres EINSFOESSA permite concluir que la dimensión educativa ha experimentado cierta mejoría en algunos aspectos, como el porcentaje de hogares con alguna persona analfabeta mayor de 65 años ( $16,4 \%$ de los hogares con algún miembro con discapacidad en 2007 y 9,4\% en 2013 ), o con alguna persona de I 6 a 64 años sin completar estudios $(6,7 \%$ en 2009 y $4,4 \%$ en 2013$)$. No obstante, sigue siendo preocupante que, entre los hogares con una formación mínima, siga habiendo una alta representación de hogares que tienen alguna persona con discapacidad (uno de cada cuatro hogares en los que hay alguna persona de I 6 a 64 años que no tiene estudios).
La vivienda, así como su entorno, forma parte de los derechos sociales básicos y, en el caso de la discapacidad, determina de manera muy relevante las posibilidades de participación social. Los indicadores referidos a la vivienda de la última EINSFOESSA muestran un empeoramiento de los hogares con algún miembro con discapacidad, aunque se haya reducido el hacinamiento $(6,8 \%$ en 2007 y $3,6 \%$ en $\left.20 \mathrm{I}_{3}\right)$ y la tenencia en precario de la vivienda ( $4 \%$ en 2007 y I, $3 \%$ en 2013 ).

Se ha detectado un incremento en el porcentaje de hogares que declaran un entorno muy degradado (0,6\% en 2007 y 2,I \% en $20 \mathrm{I} 3$ ) y barreras arquitectónicas en el hogar $(4,8 \%$ en 2009 y $6,8 \%$ en 20I3). También es preocupante que un porcentaje significativo de hogares declare tener problemas de insalubridad, humedades, suciedad, olores, etc., en sus viviendas ( I I,7\% en 20I3). Asimismo, se ha incrementado el porcentaje de hogares que tienen que hacer un esfuerzo de gasto excesivo en vivienda $(6, \mathrm{I} \%$ en 2007 y 9, I \% en $20 \mathrm{I} 3)$, lo que puede redundar en su empobrecimiento y en las dificultades para acometer mejoras necesarias en sus viviendas.

Gráfico 5. Hogares con algún miembro con discapacidad, afectados por las dimensiones de la exclusión social en 2013 (\% respecto de la dimensión de exclusión)

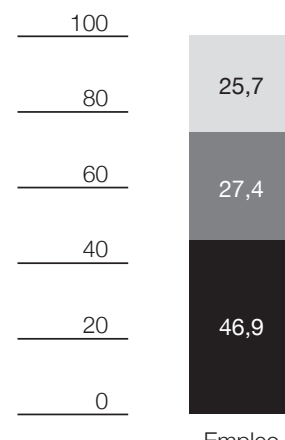

Empleo
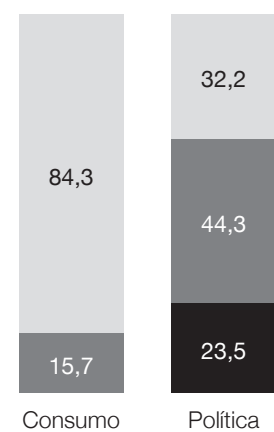

Política

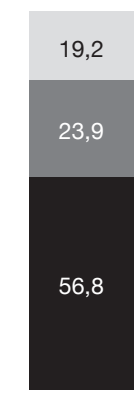

Educación

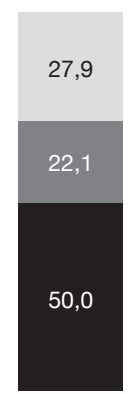

Vivienda

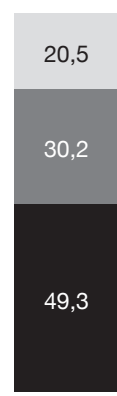

Salud

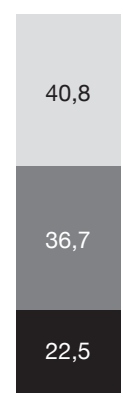

Conflicto

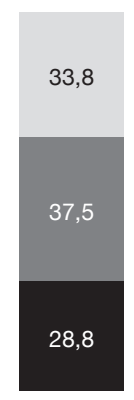

Aislamiento

Integración precaria

Exclusión moderada

Exclusión severa

Fuente: EINSFOESSA 2013. 
Los hogares en los que vive alguna persona con discapacidad están especialmente representados entre los hogares que sufren situaciones de exclusión en salud. Aunque ha disminuido el porcentaje de hogares con todas las personas adultas padeciendo problemas graves de salud y limitación de la actividad diaria (I 6,9\% en 2007 y I $4,7 \%$ en 2013 ) se trata de un conjunto de hogares con necesidades múltiples y complejas. Especialmente preocupantes son los casos que declaran haber pasado hambre en los últimos io años (de 3,2 \% en 2007 a 4,6\% en 2013 ), que no compran medicinas, ni siguen tratamientos/ dietas por problemas económicos (de 9,9\% en 2007 a I $8,6 \%$ en 20I3), o que tienen alguna persona dependiente y no reciben apoyo $(6,6 \%$ en 2007 a $7, \mathrm{I} \%$ en 2013 ).

Se observa, por último, una importante presencia de estos hogares entre aquellos que sufren situaciones de conflicto familiar. Así, según la EINSFOESSA de 20I3, uno de cada tres hogares que declaran tener malas relaciones en la familia tiene alguna persona con discapacidad. La sobrecarga que sufren muchas de estas familias, que en ocasiones no cuentan con los suficientes apoyos sociales, puede estar detrás de una mayor presencia de conflictos familiares.

\subsection{Indicadores económicos de la exclusión social}

Los datos aportados por el INE (2013: I), sobre el empleo de las personas de I 6 a 64 años, permite visualizar la enorme brecha que separa a las personas con y sin discapacidad en este ámbito. $\mathrm{El}$ 36,6\% de las personas con discapacidad reconocida era considerada población activa en $20 \mathrm{I} 2$, frente al $77 \%$ de la población sin discapacidad. Su tasa de empleo era del $24,5 \%$, es decir, más de 30 puntos de diferencia con respecto a las personas sin discapacidad. En cuanto a la tasa de paro de las personas con discapacidad era 8 puntos superior.

Los datos obtenidos a través de las encuestas EINSFOESSA confirman que la tasa de actividad en las personas de I 6 a 64 años

Tabla 3. Tasas de actividad, empleo y paro de las
personas con y sin discapacidad entre 16 y 64
años (2009 y 2012)
\begin{tabular}{|l|c|c|c|c|}
\hline & \multicolumn{2}{|c}{ Con } \\
discapacidad & discapacidad \\
\cline { 2 - 5 } & $\mathbf{2 0 0 9}$ & $\mathbf{2 0 1 2}$ & $\mathbf{2 0 0 9}$ & $\mathbf{2 0 1 2}$ \\
\hline Tasa de actividad & 36,2 & 36,6 & 75,4 & 77 \\
\hline Tasa de empleo & 28,3 & 24,5 & 61,8 & 57,8 \\
\hline Tasa de paro & 21,8 & 33,1 & 18,1 & 25 \\
\hline
\end{tabular}

Fuente: INE (20I3: 5).

con discapacidad se ha situado en torno al 3 I \% durante el periodo analizado. Entre la población activa con discapacidad afirman estar trabajando en torno al $62 \%$ en las dos últimas encuestas. Esto supone un porcentaje del $20 \%$ respecto del total de personas con discapacidad de I 6 a 64 años en el año 2013 .

Disponer de un empleo, como se ha reiterado en los últimos años, no es sinónimo de integración social plena. En el siguiente gráfico se constata esta afirmación ya que, aunque la mayor parte de las personas con empleo se sitúan en el espacio de la integración (plena o precaria), también existe un porcentaje de en torno al $20 \%$ que se encuentran en 2013 en el espacio social de la exclusión (moderada o severa). Además, el análisis de la evolución experimentada desde el año 2007 indica que se ha producido una tendencia hacia el incremento de la integración precaria y, más levemente, de la exclusión moderada.

A pesar de la tendencia al empeoramiento en la situación de las personas con discapacidad que trabajan, son estas personas y quienes perciben alguna pensión o se dedican a labores del hogar las que se encuentran en un mayor nivel de integración en el año 2013. No obstante, el porcentaje de precariedad en la integración es superior al $40 \%$ en los tres casos. Las personas que buscan empleo son las que se encuentran en una situación más difícil. Prácticamente el $58 \%$ se sitúan en el campo de la exclusión (moderada o severa). 
Gráfico 6. Distribución porcentual en los espacios de integración/exclusión de las personas con discapacidad que trabajan $(2007,2009$ y 2013)

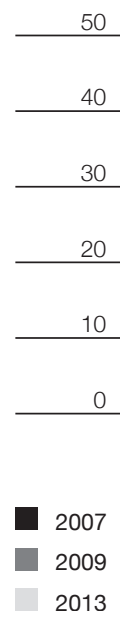

Fuente: EINSFOESSA 2007, 2009 y 2013.

Tabla 4. Distribución porcentual en los espacios de integración/exclusión según la ocupación de las personas con discapacidad mayores de 16 años (2013)

\begin{tabular}{|l|c|c|c|c|}
\hline & Integrado & $\begin{array}{c}\text { Integración } \\
\text { precaria }\end{array}$ & $\begin{array}{c}\text { Exclusión } \\
\text { moderada }\end{array}$ & Exclusión severa \\
\hline Trabajando & 34,7 & 43,7 & 16,6 & 5 \\
\hline Buscando empleo & 3,5 & 38,6 & 28,9 & 28,9 \\
\hline Estudiante & 55 & 35 & 5 & 5 \\
\hline $\begin{array}{l}\text { Percibía alguna pensión/ } \\
\text { ingresos prejubilación }\end{array}$ & 26,7 & 46,3 & 18,9 & 8 \\
\hline Labores del hogar & 31,1 & 42,2 & 18 & 8,7 \\
\hline Otras & 33,9 & 36,1 & 13,1 & 16,9 \\
\hline
\end{tabular}

Fuente: EINSFFOESSA 2013.

En el proceso de búsqueda de empleo, un elemento a tener en cuenta es la inscripción en los servicios públicos de empleo. Resulta reseñable el elevado porcentaje de personas con discapacidad que no se inscriben en este tipo de servicios. Según las EINSFOESSA, entre el año 2007 y el 20I3, únicamente el $20 \%$ de las personas de 16 a 64 años con discapacidad estaban inscritas. Hipotéticamente, podríamos vincular este dato con la pérdida de expectativas de muchas personas con discapacidad respecto a la posibilidad de encontrar un empleo, y especialmente respecto a poder encontrarlo a través de ese tipo de servicios.

Respecto a los hogares en los que alguna persona tiene discapacidad, se registran algunos indicadores de exclusión en la dimensión de empleo e ingresos económicos (tabla 5). Especialmente destacables son los porcentajes 
Tabla 5. Incidencia de los indicadores del eje económico de exclusión social en los hogares con algún miembro con discapacidad

\begin{tabular}{|l|c|c|c|}
\hline Participación en la producción & $\mathbf{2 0 0 7}$ & $\mathbf{2 0 0 9}$ & $\mathbf{2 0 1 3}$ \\
\hline Sustentador principal 12 meses o más parado & 3,5 & 5,6 & 5,9 \\
\hline Sustentador principal con un oficio de exclusión & 0,8 & 1,7 & 1,4 \\
\hline Hogares con sustentador principal sin cobertura de la seguridad social & 0,6 & 1,1 & 1,2 \\
\hline Hogares sin ocupados, sin pensiones ni prestaciones contributivas & 8,8 & s.d. & 8,5 \\
\hline Hogares con algún parado y sin formación ocupacional & 8,2 & 23,2 & 23,9 \\
\hline Todos los activos en paro & 5,9 & 13,9 & 12,3 \\
\hline Participación del producto social & $\mathbf{2 0 0 7}$ & $\mathbf{2 0 0 9}$ & $\mathbf{2 0 1 3}$ \\
\hline Pobreza extrema & 4,9 & 3,5 & 4,4 \\
\hline Carece de bienes básicos & s.d. & s.d. & 2 \\
\hline
\end{tabular}

Fuente: EINSFFOESSA 2007, 2009 y 2013.

al alza en hogares con alguna persona desempleada y sin formación ocupacional $(8,2 \%$ en 2007 y $23,9 \%$ en 2013$)$, con todas las personas activas en paro $(5,9 \%$ en 2007 y I 2,3\% en 20I3) y en los que el sustentador principal lleva I 2 meses o más parado $(3,5 \%$ en 2007 y $5,9 \%$ en 2013).

En comparación con el conjunto de hogares, la representación de los hogares con algún miembro con discapacidad es especialmente relevante (uno de cada cinco hogares en el año 20I3) en aquellos que tienen carencia de bienes básicos, en los que todas las personas activas están en paro y en los que no tienen a nadie ocupado, con pensión o prestación contributiva.

7. La experiencia de la discriminación en el ámbito de la discapacidad

El Eurobarómetro sobre discriminación (European Commission, 20I2) muestra que la discapacidad es el segundo motivo de discriminación percibido por la ciudadanía en el conjunto de la Unión Europea (46\%), y también en el Estado Español (40\%), donde hay síntomas de mejoría en la sensibilización (Huete, 20I3b: 2I). Asimismo, es considerada uno de los principales obstáculos en el acceso al empleo. Para el $38 \%$ de las personas encuestadas en España, y el $40 \%$ en la Unión Europea, la discapacidad es una desventaja "cuando una empresa quiere contratar a alguien y puede elegir entre dos candidaturas con las mismas habilidades y cualidades" (European Commission, 20I2).

En la más reciente encuesta realizada por el CIS sobre discriminación (CIS, 20I3), también se observa que la discriminación por discapacidad se sitúa en los primeros puestos en cuanto a la percepción que la ciudadanía tiene sobre su extensión, y con unos porcentajes aún superiores a los obtenidos en el Eurobarómetro. Destaca especialmente la "discapacidad psíquica", que ocupa el segundo lugar con casi un $59 \%$ de personas que consideran muy o bastante frecuente la discriminación por este motivo (únicamente superada por la discriminación por origen étnico o racial). En cuanto a la “discapacidad física”, el porcentaje se sitúa casi en el $50 \%$. 


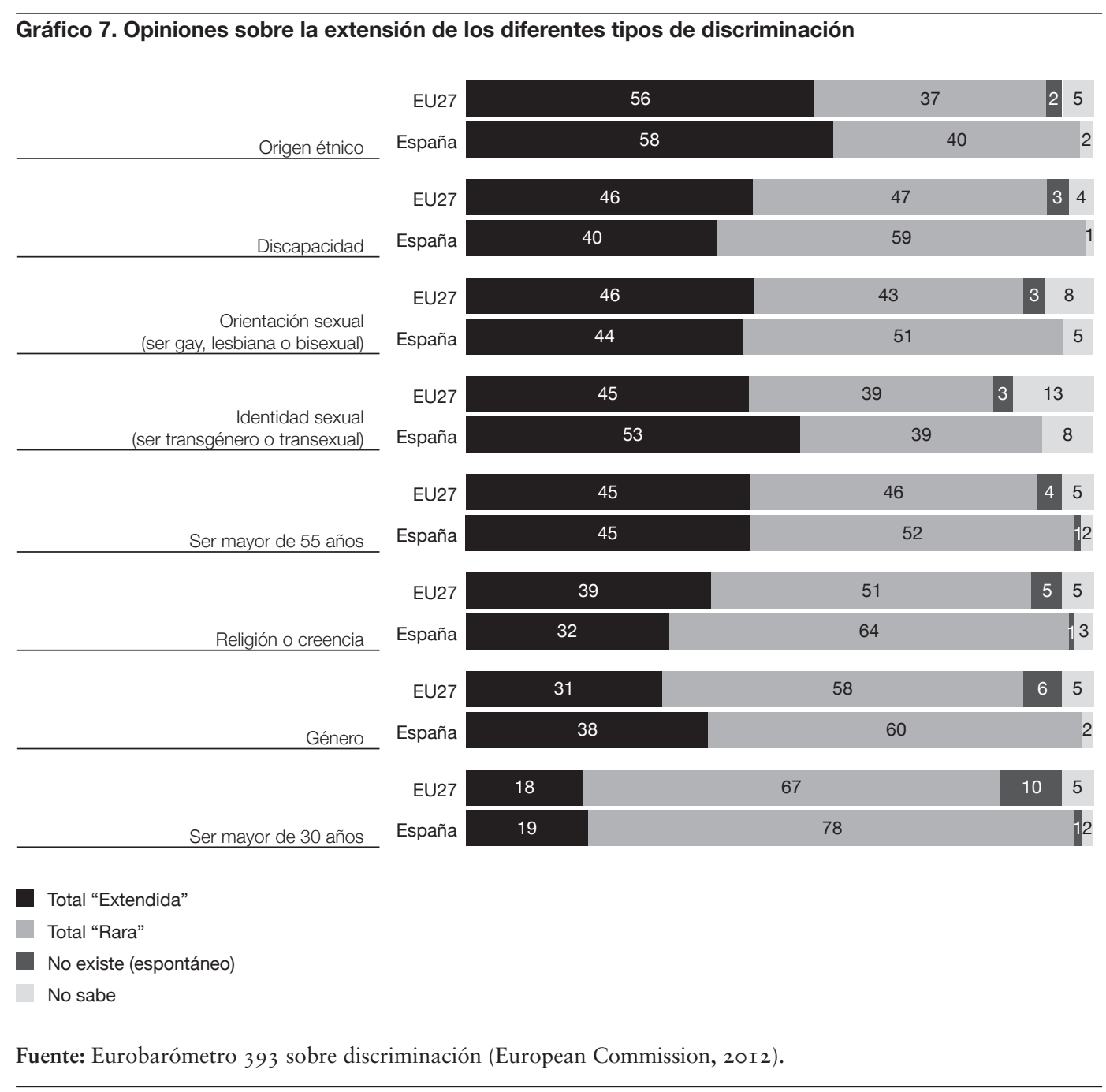

Esta importante incidencia en la percepción de discriminación por discapacidad, parece no corresponderse con una alta presencia en la sociedad de actitudes de rechazo hacia las personas con discapacidad. En la encuesta ya mencionada sobre discriminación (CIS, 20I3), apenas se detectan personas que declaren sentirse molestas ante la vecindad de una persona con discapacidad física (el 95,6\% señalan la opción "nada”). En el caso de la discapacidad intelectual, aunque el porcentaje de personas que indican la opción "nada" sigue siendo mayoritario $(84,7 \%)$, también se detecta un pequeño grupo al que les molestaría "algo", "bastante" o "mucho" la vecindad de estas personas ( $8 \%$ en total). No obstante, también debemos señalar que las preguntas incorporadas en el cuestionario quizás no sean suficientes para detectar uno de los tipos de actitudes propiciatorias de la discriminación en el caso de la discapacidad, como son las vinculadas al paternalismo o la desconfianza en las capacidades de estas personas (Arza, 20I4: I34-I37).

Se observa también falta de correspondencia entre la alta percepción respecto a la presencia en la sociedad de la discriminación por discapacidad y el relativamente bajo porcentaje de personas que declaran sufrirla. Así, la 
Gráfico 8. Proporción de población que cree que la discriminación es muy o bastante frecuente en cada tipo

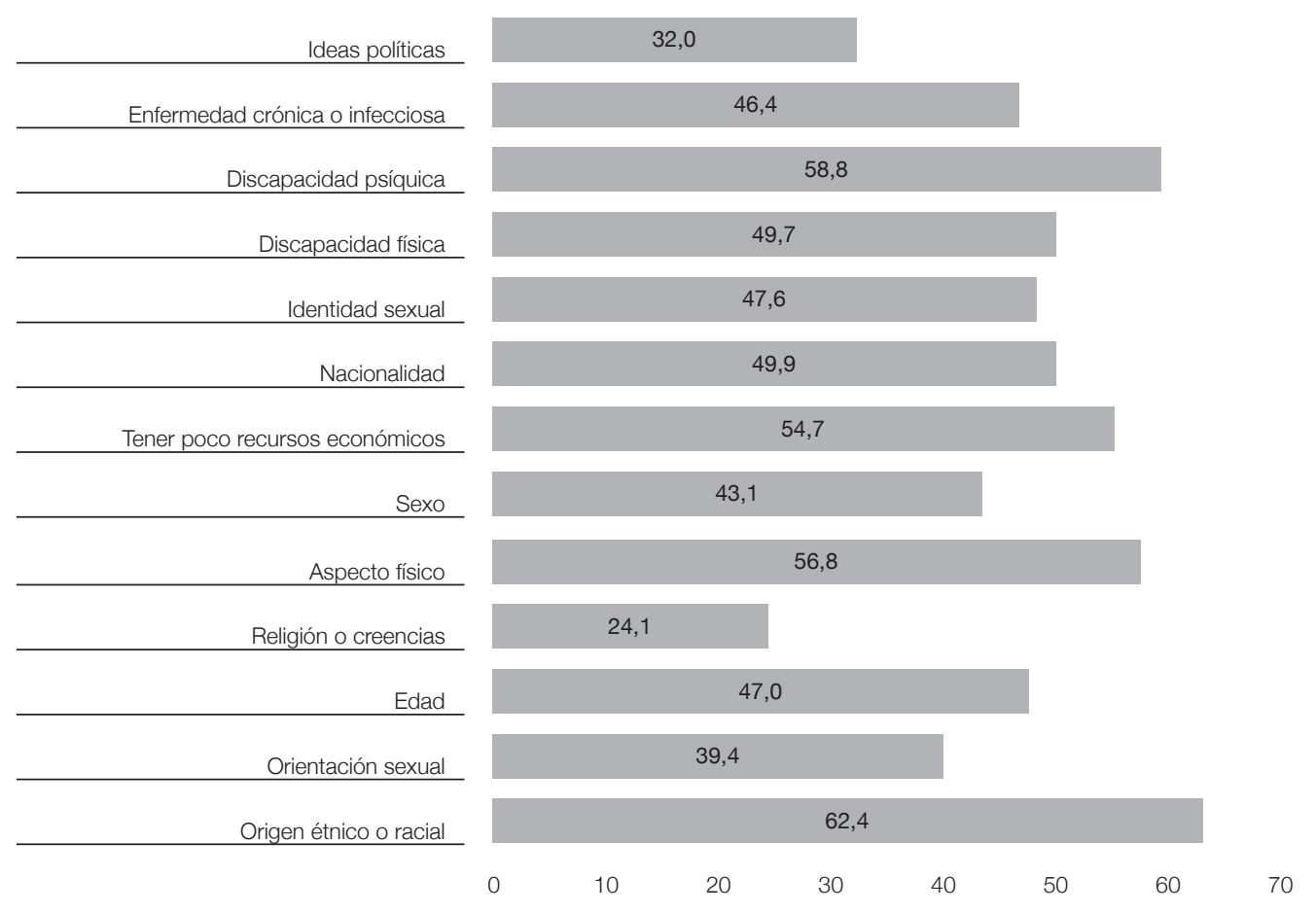

Fuente: Elaboración propia a partir de encuesta 3000 sobre discriminación (CIS, 20I3).

encuesta EDAD (INE, 2008) señala que el I $2 \%$ de las personas con discapacidad se han sentido discriminadas por ello, mientras que el $88 \%$ declaran no haberse sentido así nunca.

En el caso de la encuesta 3000 sobre discriminación (CIS, 20I3), no se puede establecer el porcentaje de personas con discapacidad que se han sentido discriminadas, ya que no se planteó ninguna pregunta que permitiera identificar a las personas con discapacidad. No obstante, disponemos de un dato: el porcentaje de personas que en los últimos doce meses ha sido testigo (ha visto $\mathrm{u}$ oído) alguna discriminación por discapacidad sufrida por alguna persona cercana: $8,4 \%$. Como podemos observar, y como venimos insistiendo, el porcentaje dista mucho de la percepción sobre la presencia de la discriminación por discapacidad en nuestra sociedad.
En una publicación del CERMI (Jiménez y Huete, 2003: 24) se establece una diferenciación entre dos tipos de discriminación. La primera es la que sufre directamente la persona con discapacidad, que en muchos casos está vinculada con aspectos socio-relacionales y tiene como consecuencia que se sienta infravalorada, menospreciada, invisibilizada, temida, etc., en su relación con otras personas. La segunda es un tipo de discriminación de tipo contextual y podemos vincularla con los conceptos de accesibilidad y diseño para todas las personas. Estos conceptos plantean que todos aquellos entornos y productos que no estén diseñados para permitir la participación, el acceso, el uso, a todo tipo de personas, son entornos y productos discriminatorios.

Puede considerarse, a modo de hipótesis, que el primer tipo de discriminación es más fácil de 
detectar, mientras que el segundo requiere un mayor nivel de concienciación, por lo que es más difícil que pueda ser detectado en este tipo de encuestas. De hecho, desde una concepción tradicional de la discapacidad, cuando una persona tiene dificultades para acceder a un entorno o usar un producto, se tiende a pensar que el problema está en la "falta de capacidad" de la persona. Sin embargo, los conceptos de accesibilidad y diseño para todas las personas plantean que el problema está en que los entornos y los productos, al ser diseñados pensando en un supuesto patrón medio de persona, son discriminatorios e incapacitantes. Vinculando esta reflexión con el estudio de la discriminación, y para lograr incrementar la capacidad de detección de las encuestas, sería necesario incorporar preguntas que faciliten a la persona la vinculación de este tipo de situaciones contextuales con la discriminación por discapacidad (Arza, 20I4: I34-I37).

En relación con el perfil de la persona con discapacidad que se ha sentido discriminada, debemos acudir de nuevo a la encuesta EDAD (INE, 2008). En ella se plantea que el perfil es el de un varón, menor de 65 años, desempleado y con "deficiencias mentales o del sistema nervioso". Respecto a los ámbitos o situaciones en las que ha sufrido la discriminación, destaca especialmente el de las relaciones sociales, seguido de la participación social y el acceso a la atención sanitaria. Finalmente, en la práctica totalidad de los casos $(92,3 \%)$ no denunciaron la situación de discriminación sufrida. Este escaso porcentaje de situaciones denunciadas, además de responder al desconocimiento, falta de canales de denuncia o insuficiente información que las personas afectadas tienen sobre los procedimientos que se deben seguir, también puede estar relacionado con la necesidad de incrementar la conciencia en este colectivo respecto a sus derechos de ciudadanía (Arza, 20I4: I34-I37).

\section{Reflexiones finales}

Han trascurrido casi cuatro años desde la anterior EINSFFOESSA (2009). Desde entonces la crisis económica se ha agudizado hasta límites impensables. La nueva fotografía que traslada la EINSFFOESSA (2013) no es alentadora en términos generales. Entre sus conclusiones destaca la socialización de la exclusión social. En este marco, las personas con discapacidad y los hogares en los que residen no parecen haberse visto tan duramente golpeados, lo que no encubre su situación de desventaja endémica.

El colectivo de personas con discapacidad ha descendido en un punto entre 2009 y $20{ }_{3}$ (del $8,2 \%$ al $7,3 \%$ ), cuando se esperaba un cierto repunte como efecto del sobre-envejecimiento de la población. Mantiene, en cambio, la sobrerepresentación de las personas mayores de 65 años (por encima del $40 \%$ ), la feminización ( $5 \mathrm{I} \%$ ) y los bajos niveles de estudios $(50 \%$ alcanza niveles de ESO y superiores) y ocupación ( $52 \%$ son pensionistas y I $2 \%$ empleados). Esta estabilidad del perfil de las personas con discapacidad corre paralela a la recogida en materia de discriminación, pobreza y exclusión social. La rigidez al cambio en un contexto de fuertes desajustes solo puede entenderse desde la comprensión de una apariencia epidérmica o bien de las dificultades para detectar cambios en el corto plazo cuando el empeoramiento más intenso ya se había producido (2007-2009).

Ciertamente, al analizar en las tres EINSFFOESSA la evolución de la situación de las personas con discapacidad y los hogares en los que viven, se han observado variaciones en cuanto al impacto de la exclusión social en la discapacidad. Así, se ha recogido el estancamiento de la pobreza relativa, pero en niveles altos. Además, queda constatada una leve reducción de la integración, a costa del incremento en la integración precaria y de un pequeño aumento de la exclusión severa, aunque teniendo en cuenta que se parte de una importante extensión de la exclusión. Muy distinto ha sido el impacto entre quienes 
no tienen una discapacidad, ya que se ha incrementado notablemente la pobreza relativa y la exclusión social en muy pocos años.

Si bien los datos indican que disponer de un certificado de discapacidad no ha sido suficiente para reducir los niveles de pobreza y exclusión alcanzados en 2009, su generalización entre los hogares encuestados puede explicar que no hayan repuntado más. Lo mismo podría decirse de la percepción de una pensión o de un empleo protegido. Es decir, el mantenimiento, en unos casos, y el refuerzo, en otros, de prestaciones sociales han demostrado su capacidad para prevenir el deterioro de la situación social e incluso el agravamiento de la precariedad social. Este efecto protector que el sistema les podía aportar ha sido reconocido por las personas con discapacidad y sus hogares de modo que se ha incrementado, de manera notable, el porcentaje de personas con certificado de discapacidad.

Sin embargo, parece claro también que el sistema de prestaciones técnicas, materiales y económicas tiene importantes limitaciones en cuanto a su capacidad para modificar, realmente, los desequilibrios, la falta de accesibilidad, de los diferentes entornos en los que se desenvuelven las personas con discapacidad y sus hogares.

En términos comparativos, en suma, los efectos de la crisis en los últimos cuatro años han sido menos dramáticos entre quienes tenían una discapacidad reconocida que entre quienes no la tenían. Es decir, se perciben ritmos distintos entre unos sectores de población y otros, pero no puede perderse de vista que las diferentes dimensiones de la exclusión social han seguido empeorando entre quienes tienen una discapacidad. 
Referencias bibliográficas

Abellán, A. (2000): "Nuevo modelo del funcionamiento y de la discapacidad". Revista Multidimensional de Gerontología, 3: I89-I92.

Alonso, Ma. J. y De Araoz, I. (20I I): El impacto de la Convención Internacional sobre los Derechos de las personas con discapacidad en la legislación educativa española, Madrid: CERMI, Ediciones Cinca. Colección Convención ONU, n ${ }^{\circ} 6$.

Anaut-Bravo, S. et al. (2010): "El impacto de la crisis económica sobre los hogares con personas con discapacidad”, en Laparra, M. et al. El primer impacto de la crisis en la cohesión social en España (Vol. 32), Madrid: Fundación FOESSA-Cáritas Española.

Anaut-Bravo, S. et al. (20I2): "Discapacidad: modelos y discursos hacia un enfoque de Derechos Humanos“, en Raya, E. et al.: Atención social a personas con discapacidad. Hacia un enfoque de Derechos Humanos, Buenos Aires: Lumen-Humanitas.

Arza, J. (20I4): "La discriminación por discapacidad”. En Laparra, M. et al. Estudio sobre percepción de la discriminación en España. Ministerio de Sanidad, Servicios Sociales e Igualdad: Madrid.

Ayala, L. (20I4): “Desigualdad y pobreza en España en el largo plazo: la continuidad de un modelo", en VII Informe FOESSA, Documento de Trabajo 2.I, Madrid: Fundación FOESSACáritas.

Barton, L. (I998): Discapacidad y sociedad, Madrid: Ediciones Morata, Fundación Paideia.

Béland, F. y Zunzunegui, M.V. (I995): “La salud y las incapacidades funcionales. Elaboración de un modelo causal”. Revista de Gerontología, 5: 232-244.

Belzunegui, A. et al. (2OI4): "Discapacidad y pobreza en España en el periodo 2006-20II. El impacto de las transferencias sociales". Sistema. Revista de Ciencias Sociales.
Benach, J. y Muntaner, C. (coords.) (2010): Empleo, trabajo y desigualdades en salud. Una visión global, Barcelona: Icaria.

Bermejo, Ma . L. et al. (2002): "El aprendizaje de las ciencias en niños ciegos y deficientes visuales". Integración: Revista sobre ceguera y deficiencia visual, 38: 25-34.

CIS (2013). Encuesta 3000. Percepción de la discriminación en España (en línea). http:// www.cis.es/cis/export/sites/default/-Archivos/ Marginales/3000_3019/3000/es3000mar.pdf,, acceso de ro febrero de 2015.

Colectivo Ioé (20I2): Discapacidades e inclusión social, Barcelona: Obra Social "La Caixa", Colección Estudios Sociales, $\mathrm{n}^{\circ} .33$.

Comisión sobre Determinantes Sociales en la Salud (CSDH) (2008): Closing the gap in a generation. Health equity through action on the social determinants of health, Ginebra: Organización Mundial de la Salud.

De Lorenzo, R. y Pérez Bueno L. C. (dir.) (2007): Tratado sobre Discapacidad, Pamplona: Thomson Reuters-Aranzadi.

Díaz, E. (20I0): “Ciudadanía, identidad y exclusión social de las personas con discapacidad". Politica y Sociedad, vol. 47 (I)

Esteban, R. y Gutiérrez, D. (20I4): “La incentivación del empleo de las personas con discapacidad en el medio ordinario de trabajo". Revista Española de Discapacidad, 2 (I): 7-32.

Etxebarría, X. (2008): La condición de ciudadanía de las personas con discapacidad intelectual, Bilbao: Universidad de Deusto.

España. Ley 26/20I I, de I de agosto, de adaptación normativa a la Convención Internacional sobre los Derechos de las Personas con Discapacidad, Boletín Oficial del Estado, núm. I 84, de 2 de agosto de 20 I I, pp. 87478 a 87494 .

España. Ley 39/2006, de I4 de diciembre, de Promoción de la Autonomía Personal y Atención 
a las personas en situación de dependencia, Boletín Oficial del Estado, núm. 299, de I 5 de diciembre de 2006, pp. 44I42 a 44I56.

España. Real Decreto Legislativo I/20I3, de 29 de noviembre, por el que se aprueba el Texto Refundido de la Ley General de derechos de las personas con discapacidad y de su inclusión social, Boletín Oficial del Estado, núm. 289, de 3 de diciembre de 2013, pp. 95635 a 95673 .

European Commission (2012). Discrimination in the EU. EBS 393. http://ec.europa.eu/public_ opinion/archives/ebs/ebs_393_en.pdf, acceso de 10 febrero de 2015.

Huete, A. (20I3b): "La exclusión de la población con discapacidad en España. Estudio específico a partir de la Encuesta Social Europea”. Revista Española de Discapacidad, I (2): 7-24.

Huete, A. (20I3a): Pobreza y exclusión social de las mujeres con discapacidad en España, Madrid: Ediciones Cinca-CERMI.

Huete, A. y Quezada, M. (20I 2): La discapacidad en las fuentes estadísticas oficiales. Examen y propuestas de mejora. Análisis formal y de contenido sobre discapacidad en las referencias del Instituto Nacional de Estadística (INE). Madrid: Ediciones Cinca-CINCA.

IMSERSO (I997): La discapacidad en el siglo XXI. Plan de acción. Una propuesta de futuro, Madrid: IMSERSO.

INE (2OI4): El salario de las personas con discapacidad. Explotación de la Encuesta Anual de Estructura Salarial y de la BEPD, Notas de Prensa, 5 de junio de 20I4, Madrid: INE.

INE (2013): El empleo de las personas con discapacidad. Explotación de la EPA y de la $B E P D$, Notas de Prensa, 9 de diciembre de 20I3, Madrid: INE.

Jiménez, A. y Huete, A. (2003): La discriminación por motivos de discapacidad. Madrid: CERMI.

Jiménez, A. y Huete, A. (20I0): "Estadísticas y otros registros sobre discapacidad en España”. Sociedad y Política, vol. 47 (I).

Malgesini, G. (coor.) (20I3): Informe de la vulnerabilidad social 2OII-2OI2, Madrid: Cruz Roja Española.
INE (2008). Encuesta sobre discapacidades, autonomía personal y situaciones de dependencia. EDAD 2008 (en línea). http:// www.ine.es/jaxi/menu.do?type=pcaxis\&path= $\%_{2} \mathrm{Ft}_{\text {I }} \% \%_{2} \mathrm{Fp}_{4}$ I $8 \&$ file=inebase, acceso de ı febrero de 2015 .

Marbán, V. et al. (20I2): El sector de la discapacidad: realidad, necesidades y retos futuros. Análisis de la situación de la población con discapacidad y de las entidades del movimiento asociativo y aproximación a sus retos y necesidades en el horizonte de 2020 , Madrid: Ediciones Cinca-CERMI, Fundación ONCE. Col. CERMI, n ${ }^{\circ} 59$.

Martínez, J. L. (2005): Exclusión social y discapacidad, Madrid: Fundación Promi, Universidad Pontificia de Comillas.

Martínez, B. (20I3): "Pobreza, discapacidad y derechos humanos”. Revista Española de Discapacidad, I (I): 9-32.

Martínez, B. (20I I): Pobreza, discapacidad y derechos humanos. Aproximación a los costes extraordinarios de la discapacidad y su contribución a la pobreza desde un enfoque basado en los derechos humanos, Madrid: CERMI, Ediciones Cinca. Col. Convención ONU, $n^{\circ} 4$.

Medina, J. A. et al. (2012): "Trabajadores pobres y empobrecimiento en España”. Zerbitzuan: Gizarte zerbitzuetarako aldizkaria/Revista de servicios sociales, 52: II9-I 28.

Observatorio Estatal de la discapacidad (2OI 5 ): Informe Olivenza 20I4, sobre la situación de la discapacidad en España. Madrid: Ministerio de Sanidad, CERMI.

Organización Mundial de la Salud (20II): World Report on Disability, Ginebra: OMS-Banco Mundial.

Palacios, A. (2008), El modelo social de discapacidad. Orígenes, caracterización y plasmación en la Convención Internacional sobre los Derechos de las Personas con Discapacidad, Madrid: Cinca.

Palacios, A. y Romañach, J. (2006): El modelo de la diversidad. La Bioética y los Derechos 
Humanos como herramientas para alcanzar la plena dignidad en la diversidad funcional, Santiago de Compostela: Ediciones DiversitasAIES.

Panadero, S. y Pérez-Lozao, M. (20I4): "Personas sin hogar y discapacidad”. Revista Española de Discapacidad, 2 (2): 7-26.

Puga, Ma D. y Abellán, A. (2004): El proceso de discapacidad. Un análisis de la Encuesta sobre discapacidad, deficiencias y estado de salud, Alcobendas: Fundación Pzifer.

Querejeta, M (2004): Discapacidad/dependencia. Unificación de criterios de valoración y evaluación, Madrid: IMSERSO.

Raya, E. et al. (201 2): Atención social a personas con discapacidad. Hacia un enfoque de Derechos Humanos, Buenos Aires: LumenHumanitas.

Raya, E. y Caparrós, N. (20I3): "Derechos Humanos y discapacidad: estrategias de empoderamiento", en Vega, A. $\mathrm{M}^{\mathrm{a}}$ (coor.): Derechos Humanos: Elementos para un nuevo marco conceptual, Pamplona: Thomson Reuters-Aranzadi.
Rodríguez, V. (20I3): "Fuentes de información sobre discapacidad y empleo en España”. Revista Española de Discapacidad, I (I): 73-95.

Seelman, C. C. (2004): “Tendencia en la Rehabilitación y en la Discapacidad: Transición desde un Modelo Médico a un Modelo de Integración”. Disabiliy Word, vol. 22.

Trujillo, M. (20I4): "Diseño muestral de la Encuesta sobre integración social y necesidades sociales", en VII Informe FOESSA, Documento de Trabajo 3.Io, Madrid: Fundación FOESSACáritas.

Verdugo, M. A. et al. (1994): Actitudes hacia las personas con minusvalia, Madrid: Ministerio de Asuntos Sociales, Instituto Nacional de Servicios Sociales.

VERDUGO, M. A. (edt.) (2000): Familias y discapacidad intelectual, Madrid: Colección FEAPS, $\mathrm{n}^{\circ} 2$.

Whitehead, M. y Dahlgren, G. (2006): Concepts and principles for tackling social inequities in health, Copenhage: World Health Organization. 


\title{
Las personas con discapacidad en España: inserción laboral y crisis económica
}

\author{
People with disabilities in Spain: job \\ placement and economic crisis
}

\section{Resumen}

El presente trabajo centra su objetivo en analizar la situación laboral de las personas con discapacidad en España, y la evolución que dicha situación ha experimentado durante la reciente crisis económica. Para ello, se establece una comparativa de datos macroeconómicos referidos a inserción laboral, de población con y sin discapacidad en el periodo 2008-20I2. Los resultados muestran que las personas con discapacidad se enfrentan a una peor situación en términos de inserción laboral y salarios. Durante la crisis, sin embargo, si bien los efectos de la recesión han sido severos para ambos grupos de análisis, estos se han acentuado más entre la población general.

\section{Palabras clave}

Discapacidad, mercado de trabajo, inserción laboral, políticas públicas, crisis económica.

\section{Abstract}

This paper explores the current employment situation of people with disabilities in Spain and how it has changed during the recent economic crisis. Macroeconomic data on the employment of disabled and nondisabled populations from 2008 to $20 \mathrm{I} 2$ are compared. The results show that people with disabilities face a worse situation in terms of both job placement and wages. While the economic crisis has had serious effects on both groups, the effects on the non-disabled population have been more pronounced.

\section{Keywords}

Disability, labour market, job placement, public policy, economic crisis.

\section{Joydi Hernández Díaz <joydihd@gmail.com> \\ Universidad de Huelva}

José María Millán Tapia <jose.millan@dege.uhu.es>

Universidad de Huelva

\author{
Para citar: \\ Hernández, J. y Millán, J. M. (20I 5): \\ "Las personas con discapacidad en \\ España: inserción laboral y crisis \\ económica", Revista Española de \\ Discapacidad, 3 (I): 29-56.
}

Doi: <http://dx.doi.org/IO.5569/23405104.03.01.02>

Fecha de recepción: 20-IO-20I4 Fecha de aceptación: IO-O4-20I 5 


\section{Introducción}

En el mundo más de r.૦oo millones de personas, el I $5 \%$ de la población mundial, viven con algún tipo de discapacidad reconocida, cifra esta que aumenta debido al progresivo envejecimiento de la población. Hablamos de r.ooo millones de personas que, con frecuencia, no pueden participar plenamente en la sociedad a causa de barreras físicas y económicas, prejuicios sociales, sistemas educativos que no las contemplan y empresas que no están preparadas para recibirlas. Así pues, en plena sociedad del conocimiento, el talento de un $15 \%$ de la población mundial está en riesgo de ser desperdiciado.

Construir una sociedad que incluya a todos no es un acto de caridad, ni debe ser visto únicamente como un derecho ${ }^{\mathrm{I}}$, sino que también sirve para ofrecer oportunidades de mercado y promover la innovación. Así, crear y ofertar productos y servicios accesibles para todos no es solo socialmente deseable sino que puede ser atractivo empresarialmente, dado el crecimiento en el número de consumidores.

En este sentido, la incorporación a un puesto de trabajo proporciona a la persona (con y sin discapacidad) un entorno fundamental de socialización y permite mayores niveles de independencia económica. Por tanto, garantizar el acceso al mercado laboral de las personas con discapacidad se presenta como requisito ineludible en el camino hacia una plena integración en la sociedad del colectivo.

I. La Convención sobre los derechos de las personas con discapacidad de las Naciones Unidas, primer instrumento internacional jurídicamente vinculante en el ámbito de los derechos humanos del que son Partes la UE y sus Estados miembros, exige a los Estados Partes que protejan y salvaguarden todos los derechos humanos y libertades fundamentales de las personas con discapacidad. Asimismo, la Carta de los Derechos Fundamentales de la Unión Europea establece en su artículo 26 que «la Unión reconoce y respeta el derecho de las personas con discapacidad a beneficiarse de medidas que garanticen su autonomía, su integración social y profesional y su participación en la vida de la comunidad». En España, el derecho a la igualdad de oportunidades de las personas con discapacidad está recogido en los artículos 9.2, Io, I4 y 49 de la Constitución Española.
Los esfuerzos en esta materia en nuestro país no son desdeñables. Así, cabe destacar que España recibió en $20 \mathrm{I} 2$ el premio Franklin D. Roosevelt International Disability Rights, la mayor distinción que puede recibir un estado en el ámbito de la discapacidad, reconociendo los avances en políticas de inclusión de las personas con discapacidad. Sin embargo, en 20I 2 , exclusivamente el $25 \%$ de aquellos que tienen reconocida una discapacidad y se encuentran en edad de trabajar (I 6-64 años) contaban con empleo, frente al $58 \%$ de los que no tiene discapacidad, evidenciándose así el largo camino que aún queda por recorrer en la materia que nos ocupa.

Precisamente este trabajo trata de analizar la situación laboral de las personas con discapacidad en España, y su evolución durante la reciente crisis económica ${ }^{2}$. Como colectivo más vulnerable, es necesario conocer cómo les ha afectado laboralmente la recesión, y si los efectos y consecuencias negativas exceden a los sufridos por nuestro grupo de control, que será, como es lógico, el conjunto de la población sin discapacidad. Para ello, comparamos datos macroeconómicos sobre inserción laboral para ambos grupos y su evolución durante el periodo 2008-20I2.

\section{Metodología}

\subsection{Datos}

Este trabajo hace uso de dos operaciones estadísticas de reciente creación: (i) el Empleo de las Personas con Discapacidad (EPD); y (ii) el Salario de las Personas con Discapacidad (SPD). Ambas operaciones surgen a raíz de la firma de un convenio de colaboración entre el Comité Español de Representantes de Personas con Discapacidad (CERMI), la Fundación

\footnotetext{
2. Otros trabajos que analizan la situación de las personas con discapacidad en el mercado laboral español son Albarrán y Alonso (2010), Malo (2003), Pagán y Marchante (2004), Villa-Fernández (2003) y Verdugo et al. (2007).
} 
ONCE, el Instituto de Mayores y Servicios Sociales (IMSERSO) y el Instituto Nacional de Estadística (INE), con la finalidad de obtener información sobre discapacidad y mercado laboral a través de la integración de registros administrativos con encuestas ya existentes.

El EPD proporciona información sobre la situación laboral de las personas con discapacidad en España para el periodo 2008-I3, siendo sus fuentes de información principales la Encuesta de Población Activa (EPA) y la Base de Datos Estatal de Personas con Discapacidad (BEPD). Por su parte, el SPD ofrece datos salariales relativos al colectivo de personas con discapacidad en España para el binomio 20I0-20I I, haciendo uso de la Encuesta de Estructura Salarial (EES) y la BEPD como fuentes de información principales. Ambas operaciones también incorporan datos provenientes de la Tesorería General de la Seguridad Social (TGSS), que proporciona información sobre las medidas para fomentar el empleo de los trabajadores con discapacidad.

\subsection{Muestra}

La operación EPD toma como población objeto a las personas residentes en España de I 6 a 64 años (es decir, a las que están en edad laboral) que residen en viviendas familiares principales (es decir, las utilizadas todo el año o la mayor parte de él como vivienda habitual o permanente). Por su parte, la operación SPD toma como ámbito poblacional a los asalariados por cuenta ajena que cotizan a la Seguridad Social.

Estas poblaciones bajo estudio incorporan personas con y sin discapacidad. La población con discapacidad es la incluida en la BEPD, esto es, aquellos que han solicitado el procedimiento de valoración de la discapacidad habiendo sido reconocidos con un grado de discapacidad igual o superior al $33 \%$ (requisito para acceder a determinadas prestaciones, beneficios fiscales, bonificaciones en las cotizaciones sociales, tarjetas de estacionamiento y otros). ${ }^{3}$

3. El art. I punto 2 de la Ley $5 \mathrm{I} / 2003$, de 2 de diciembre,

\subsection{Métodos}

En coherencia con la tipología del trabajo presentado, este estudio está basado en el análisis descriptivo de los datos macroeconómicos mencionados anteriormente. ${ }^{4}$ Con el objetivo de destacar algunos aspectos relevantes de nuestra muestra, además de la distinción entre personas con y sin discapacidad, utilizamos otras variables de clasificación tales como género, edad, nivel de estudios, comunidad autónoma de residencia y situación laboral. Para las personas ocupadas, distinguimos también por su situación profesional, sector de actividad, y duración del contrato o relación laboral. Por último, para el colectivo de personas con discapacidad, hacemos uso además de variables que nos informan del tipo y grado de discapacidad, percepción de prestaciones, y de si el empleo (si lo hubiere) está impulsado por alguna medida para incentivar el acceso al mercado laboral.

\section{Las personas con discapacidad}

Sobre la base del texto de la Convención sobre los derechos de las personas con discapacidad (Nueva York, I 3 de diciembre de 2006), el Estado español entiende como personas con discapacidad a aquellas que tengan deficiencias físicas, mentales, intelectuales o sensoriales a largo plazo que, al interactuar con diversas barreras, puedan impedir su participación plena y efectiva en la sociedad, en igualdad de condiciones con las demás.

de Igualdad de Oportunidades, No Discriminación y Accesibilidad Universal de las personas con discapacidad (LIONDAU) establece que tendrán la consideración de personas con discapacidad aquellas a quienes se les haya reconocido un grado de discapacidad igual o superior al $33 \%$. 4. La reducida longitud de nuestras series de datos desaconseja el uso de técnicas más complejas para el análisis de series temporales. Del mismo modo, el no disponer de microdatos individuales impide el uso de algunas técnicas de regresión econométricas. 


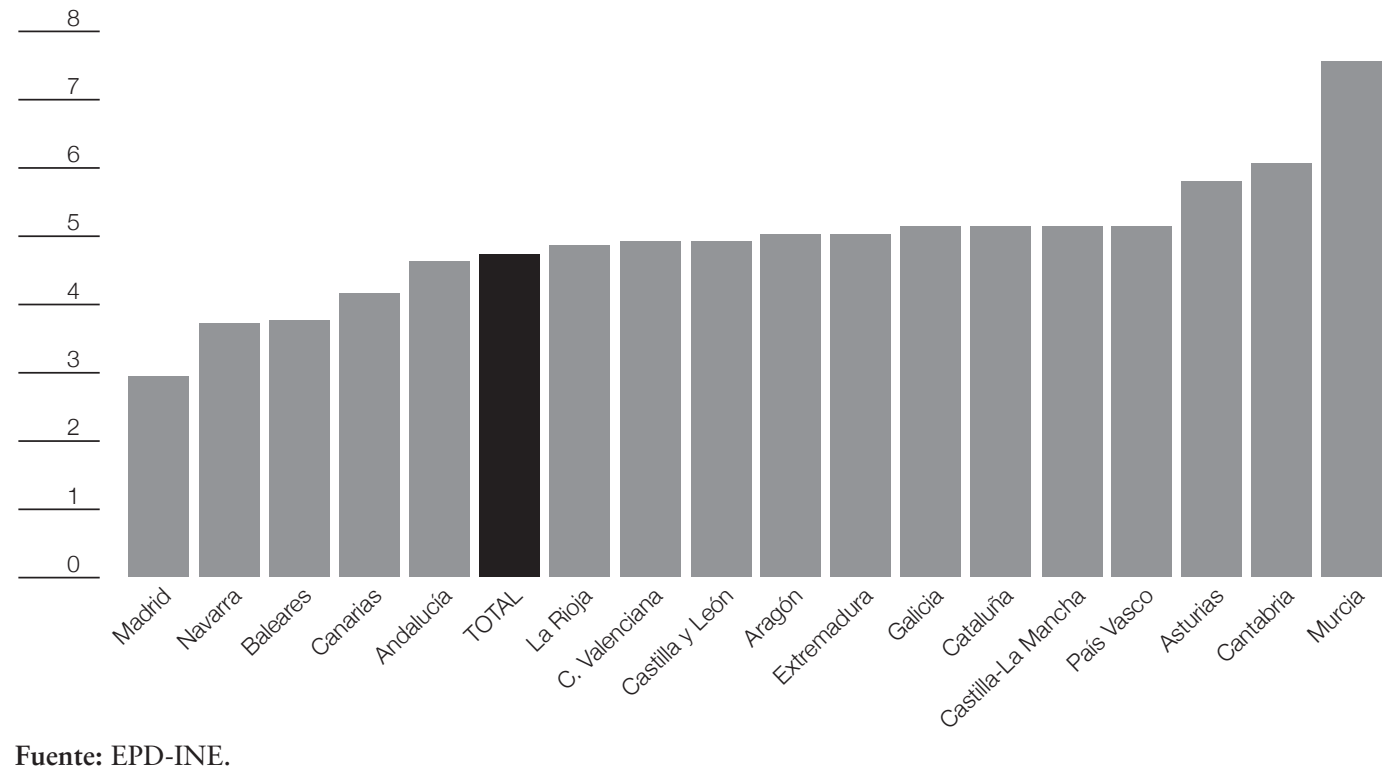

Desde un punto de vista laboral, el número de personas con discapacidad reconocida en España en edad de trabajar (I 6-64 años) ascendió en 2OI 2 a I.450.800, siendo este colectivo el $4,8 \%$ de la población en edad de trabajar. El Gráfico I nos muestra como varía este porcentaje por comunidades autónomas.

Así, vemos como Murcia, Cantabria y Asturias son las regiones que presentan un mayor peso de la población con discapacidad reconocida sobre el total de la población en edad de trabajar en dichas comunidades $(7,6 \%, 6, \mathrm{I} \%$ y $5,8 \%$, respetivamente), mientras que Madrid, Navarra y Baleares son las comunidades que presentan menores porcentajes sobre el total de su población ( $3 \%, 3,7 \%$ y 3,8 \%, respectivamente).

El Gráfico 2 muestra, para el año 20I2, la distribución de la población con discapacidad según el tipo de discapacidad.

Vemos como casi la mitad de la población con discapacidad en edad de trabajar en España tiene algún tipo de discapacidad física, pudiendo afectar a los sistemas osteoarticular,

\section{Gráfico 2. Distribución de la población con discapacidad según tipo de discapacidad, 2012}

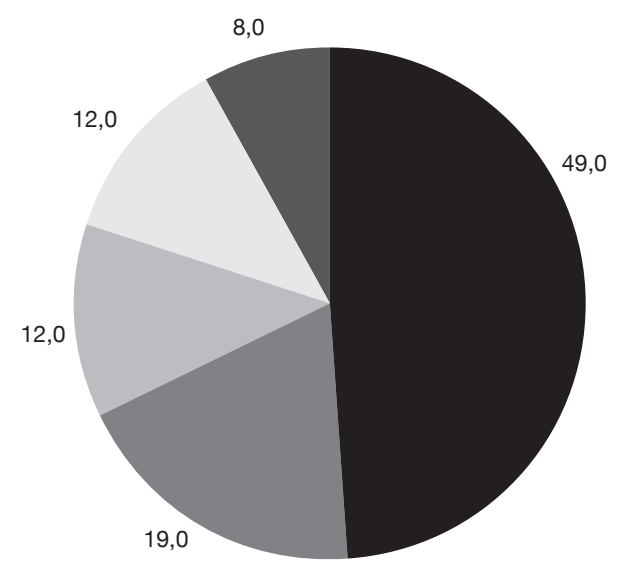

Discapacidad física

Discapacidad mental

Discapacidad intelectual

Discapacidad sensorial

Otras discapacidades

Fuente: EPD-INE. 
neuromuscular, cardiovascular o respiratorio. La discapacidad mental, por su parte, supone el I9 \% del total e incluye aquellas alteraciones de tipo psicótico (como la esquizofrenia) que producen variaciones en pensamientos, sentimientos, percepción o conducta. Tanto la discapacidad intelectual (que se caracteriza por un funcionamiento intelectual significativamente inferior a la media) como las sensoriales (principalmente auditivas o visuales) representan cada una el I $2 \%$ del total. Finalmente, el resto de discapacidades se agrupan en la categoría genérica otras, que tiene un peso del $8 \%$.

Además de por tipos, las discapacidades pueden clasificarse según su grado se severidad expresado en porcentaje. La valoración del grado de discapacidad se realiza mediante la aplicación de una serie de criterios técnicos unificados, teniendo la consideración de personas con discapacidad aquellas a quienes se les haya reconocido un grado de discapacidad igual o superior al $33 \%$. Del grado de discapacidad reconocida dependerá el acceso o no a una serie de beneficios, de ahí su relevancia. 5 El Gráfico 3 presenta la distribución de la población con discapacidad según el grado de discapacidad durante el periodo 2012.

Como vemos, el 4I \% de las personas con discapacidad en edad de trabajar en España tienen un grado igual o superior a un $65 \%$, que es la frontera que define la discapacidad considerada como severa.

A continuación, en el Gráfico 4 mostramos la evolución de la población con discapacidad reconocida en edad de trabajar para el periodo 2008-20I2, según su tipología.

Podemos observar cómo la población con discapacidad reconocida ha aumentado

\footnotetext{
5. Entre los posibles beneficios del reconocimiento del grado de discapacidad, pueden señalarse los siguientes: (i) acceso a las medidas de fomento del empleo para personas con discapacidad; (ii) adaptación del puesto de trabajo; (iii) adaptación de pruebas selectivas en el acceso al empleo público; (iv) jubilación anticipada; (v) acceso a la vivienda de protección pública; (vi) prestaciones económicas y sociales para personas con discapacidad; y (vii) beneficios fiscales.
}

\section{Gráfico 3. Distribución de la población con discapacidad según grado de discapacidad, 2012}

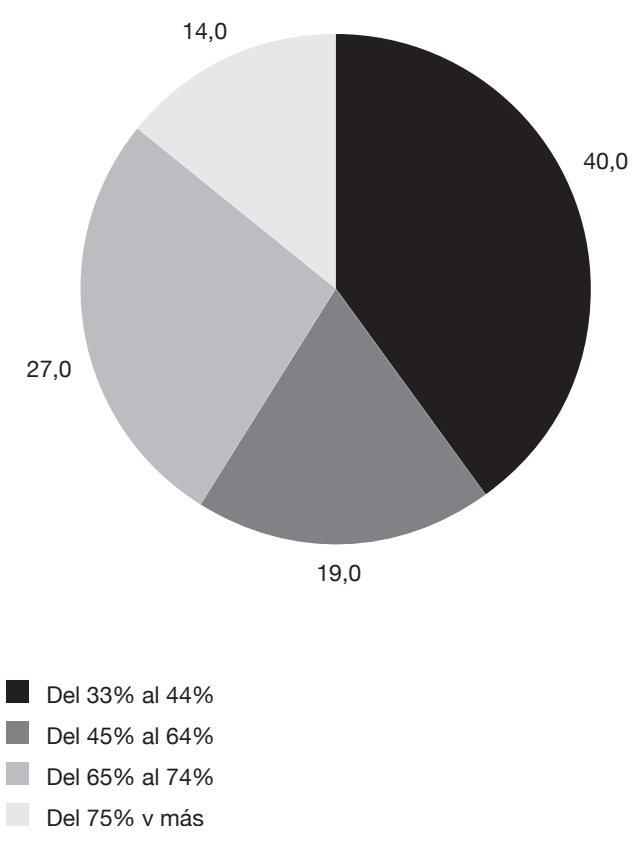

Fuente: EPD-INE.

significativamente durante los últimos años. Destaca el aumento del número de personas con discapacidad física, cuyas cifras en 2008 no alcanzaban las 400.000 personas y en 2012 han superado las 700.000. También llama la atención la evolución de las cifras referidas a discapacidad mental, que se han elevado en más de un $90 \%$ en el periodo considerado. Los datos de personas con discapacidad sensorial y otros tipos de discapacidad han experimentado aumentos considerables del $57 \%$ y $66 \%$, respectivamente. Por último, la discapacidad intelectual presenta el menor incremento, siendo este del I $5 \%$.

Entre las posibles causas de este aumento de la población con discapacidad reconocida, se encuentran las siguientes: (i) la aprobación en 2006 de la Ley de Promoción de la Autonomía Personal y Atención a las personas en situación de dependencia y a las familias de España, más conocida como «ley de 
Gráfico 4. Evolución de la población con discapacidad según tipo de discapacidad

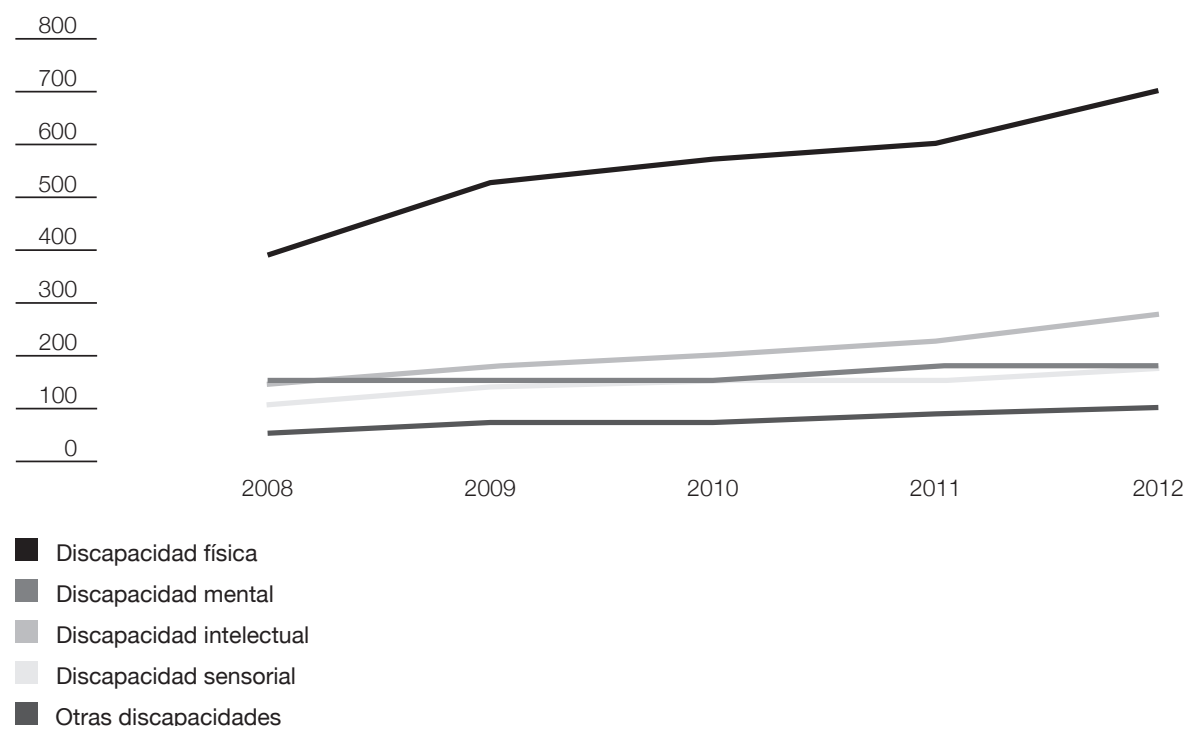

Fuente: EPD-INE; Datos expresados en miles de personas.

dependencia", que pudo animar a las personas con discapacidad a solicitar la valoración de su grado de discapacidad con el objetivo de acceder a determinados beneficios; (ii) los propios esfuerzos de la administración a la hora de transmitir el conjunto de derechos de la población con discapacidad (junto al trabajo de las asociaciones y profesionales del tercer sector); y (iii) la propia crisis económica que ha empujado a solicitar ayudas a personas con discapacidad que antes eran independientes económicamente al disponer de ingresos procedentes del trabajo.

Resultan interesantes también las cifras en cuanto a la percepción de prestaciones por parte del colectivo en edad de trabajar. Así, en 20I2, más del $54 \%$ de la población con discapacidad recibió algún tipo de prestación. ${ }^{6}$ De este colectivo, el $83 \%$ (el $45 \%$ de la población total) recibió prestaciones que estaban asociadas de

6. De la población que recibió alguna prestación, más del $96 \%$ recibió prestaciones contributivas. El resto, menos del $4 \%$, recibió prestaciones únicamente no contributivas. forma directa con una incapacidad laboral. ${ }^{7} \mathrm{El}$ Gráfico 5 a continuación muestra información acerca de la percepción de prestaciones de la población con discapacidad en el año 2012 según el tipo de discapacidad.

Como vemos, el porcentaje de población que recibió prestaciones siempre se mantuvo por encima del $40 \%$ independientemente del tipo de discapacidad. En este sentido, destacan las personas con discapacidad mental que, en más del $60 \%$ de los casos, recibieron algún tipo de prestación. En cuanto al porcentaje de población que recibió prestaciones asociadas a situaciones de incapacidad laboral, las cifras varían desde un $29 \%$ para las personas con discapacidad intelectual hasta un $52 \%$ para las personas con discapacidad mental.

\footnotetext{
7. Las prestaciones se refieren a incapacidad laboral, no a discapacidad. La incapacidad se deriva de la relación entre las condiciones de salud de la persona y el trabajo, mientras que la discapacidad lo hace de la relación entre dichas condiciones de salud y el medio ambiente en el que la persona desarrolla su vida (Vicente-Herrero et al. 2010). Así pues, la incapacidad laboral puede venir o no determinada por la discapacidad.
} 


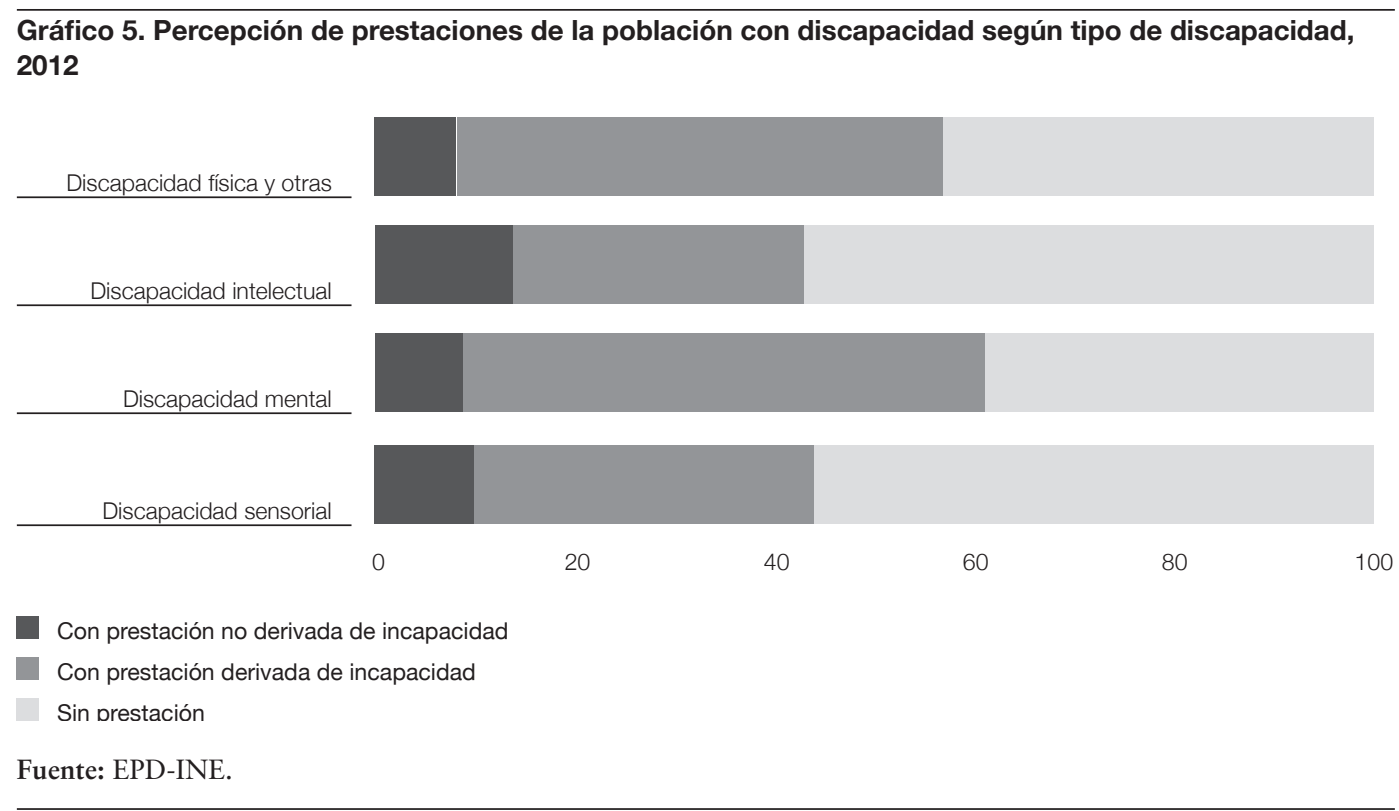

Gráfico 6. Población con discapacidad según tipo de discapacidad y género, 2012

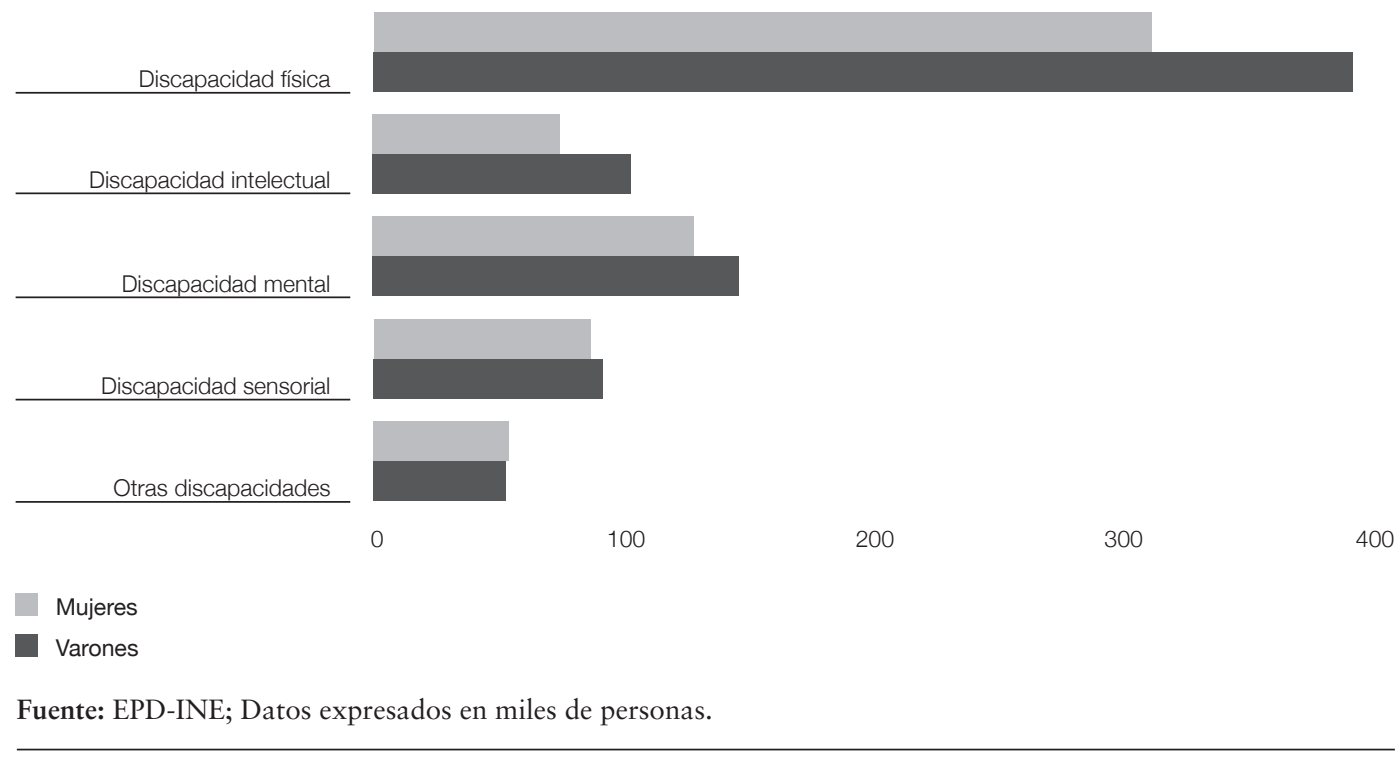

Las diferencias por género también son llamativas. El Gráfico 6 muestra las cifras de población con discapacidad en edad de trabajar según tipo de discapacidad y género.

Observamos como los varones presentan un mayor peso que las mujeres entre la población con discapacidad certificada en edad de trabajar (aproximadamente un 54,5\%). Sin embargo, otras fuentes como la Encuesta sobre Discapacidad, Autonomía personal y Situaciones de Dependencia (EDAD; INE) muestran para el año 2008 una mayor presencia de mujeres dentro del conjunto de personas 
con discapacidad en edad de trabajar (un $52,5 \%$ ). Estas diferencias surgen por el modo en que se define la población objeto de estudio. Así, mientras la EPD identifica las personas con discapacidad de entre aquellas que han solicitado un procedimiento de valoración, la EDAD incorpora a todas aquellas personas con limitaciones importantes para realizar las actividades de la vida diaria que tengan su origen en una deficiencia. Por tanto, sería relevante identificar las razones de un mayor porcentaje de varones con discapacidad certificada que no parece corresponderse con lo que ocurre en la población global de personas con discapacidad (certificadas o no).

La edad es también un factor que influye significativamente en el colectivo, pues muchas discapacidades no surgen de forma congénita sino que se desarrollan durante la vida (como podrían ser algunas discapacidades mentales o sensoriales) o a través de un accidente (como podrían ser muchas discapacidades físicas). Así, tan solo el $6 \%$ de la población con discapacidad en edad de trabajar pertenece al intervalo de edad I6-24 años, mientras que el 3 I \% forma parte del intervalo $25-44 \mathrm{y}$, finalmente, el $63 \%$ restante pertenece al intervalo 45-64. De este modo es factible afirmar que existe una relación directa entre edad y presencia de discapacidad. El Gráfico 7 a continuación nos muestra, con datos del año 20I2, cómo cambian las distribuciones según el tipo de discapacidad para tres bandas de edad diferentes del intervalo I664 años.

En consonancia con lo apuntado anteriormente, observamos como el peso de la discapacidad física sobre el total varía del $28 \%$ para el intervalo de menor edad (16-24) al $55 \%$ para el intervalo más sénior (45-64).

Finalmente, la comparativa entre población con y sin discapacidad, en cuanto a niveles de formación reglada, nos pueden apuntar información relevante sobre la integración social del colectivo. Con esa idea, el Gráfico 8 muestra la distribución para ambos targets, según nivel de estudios en $20 \mathrm{I} 2$.

Vemos como el colectivo de personas con discapacidad con educación primaria o inexistente se acercan al $40 \%$ del total, mientras que este porcentaje apenas supera el I $5 \%$ en el caso de la población general. Asimismo, los niveles de educación superior entre ambos

\section{Gráfico 7. Distribución de la población con discapacidad según tipo de discapacidad y bandas de edad,} 2012

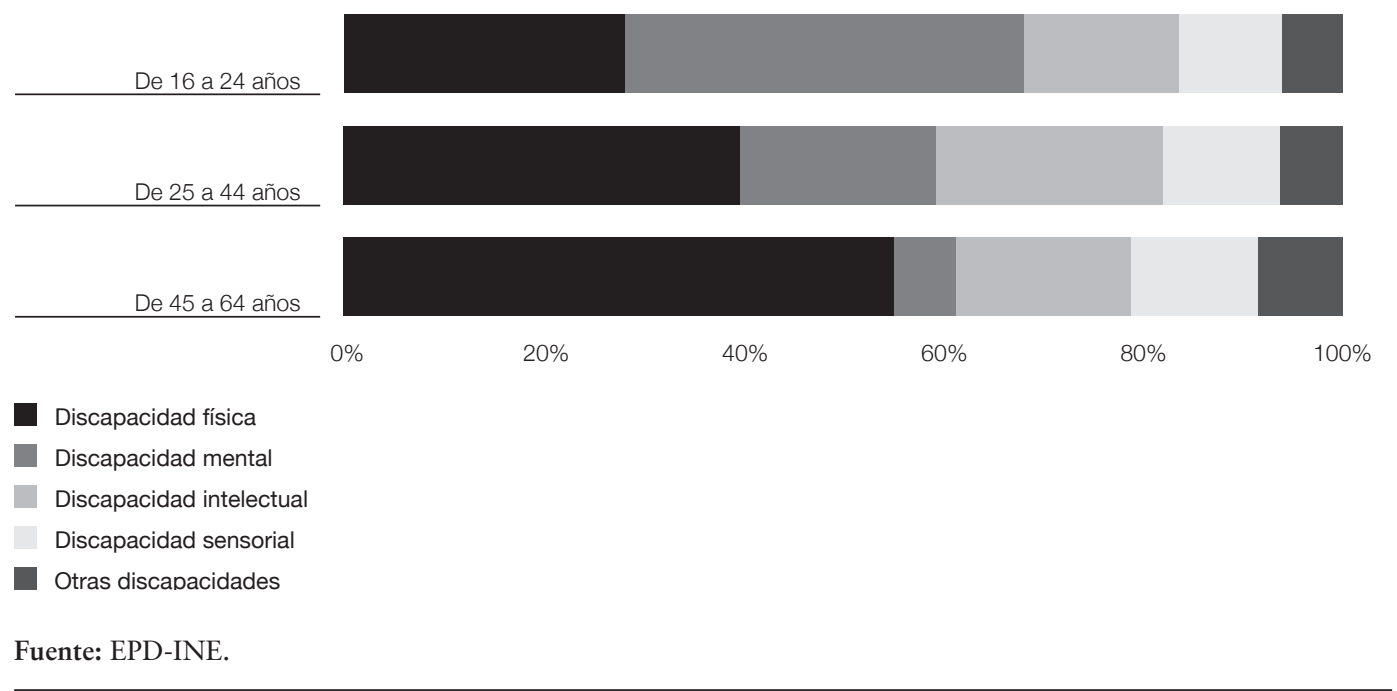




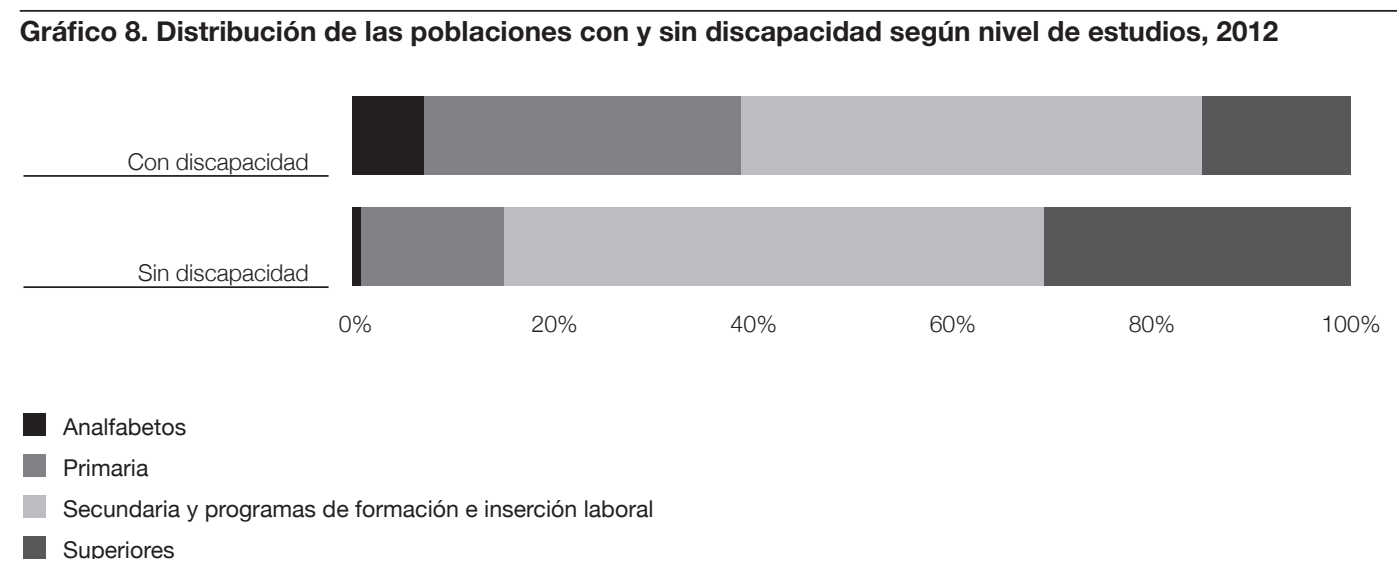

Fuente: EPD-INE.

grupos presentan diferencias significativas. Así, la presencia de estudios superiores entre la población sin discapacidad, duplica a las cifras referidas a personas con discapacidad $30 \%$, frente al $15 \%$. Quedan patentes, por tanto, las mayores dificultades del colectivo en su acceso al sistema educativo.

\section{Las personas con discapacidad en el mercado de trabajo}

\subsection{Medidas de apoyo a la integración laboral}

Las medidas de apoyo a la integración laboral de las personas con discapacidad en España pueden agruparse en tres grandes categorías. ${ }^{8}$

La primera categoría aglutina medidas destinadas a fomentar la integración en el sistema ordinario de trabajo. En ella se incluye, en primer lugar, la cuota de reserva, en virtud de la cual las empresas públicas y privadas con más de 50 trabajadores fijos están obligadas a emplear un número de trabajadores con

8. La tabla A.I en el Anexo muestra un cuadro resumen de la normativa vigente sobre bonificaciones y reducciones a

la contratación laboral así como de las medidas de fomento al empleo por cuenta propia de personas con discapacidad, Febrero 20I4. discapacidad no inferior al $2 \% .{ }^{9} \mathrm{El}$ segundo bloque dentro de esta primera categoría lo conforman una serie de subvenciones, incentivos, reducciones y bonificaciones de cuotas a la seguridad social que pretenden incentivar la contratación por cuenta ajena utilizando modalidades contractuales como los contratos indefinidos, temporales de fomento de empleo o formativos. En la misma línea, se incluyen también medidas de fomento del empleo por cuenta propia en este colectivo, como son subvenciones, capitalización de las prestaciones por desempleo y bonificaciones de cuotas a la seguridad social. Por último, se contemplan también en esta categoría una serie de acciones de orientación y acompañamiento individualizado en el puesto de trabajo, que tienen como objetivo facilitar la adaptación laboral y social de aquellas personas con discapacidad, con especiales dificultades de inserción laboral.

La segunda categoría contempla medidas destinadas a mejorar la integración en el sistema protegido de trabajo, a través de los denominados Centros Especiales de Empleo (CEE), empresas promovidas principalmente por asociaciones de personas con discapacidad

9. Existe una serie de excepciones a esta obligación, así como un conjunto de medidas alternativas a la misma como puede ser la realización de donaciones y acciones de patrocinio. 
o sus familiares cuyo objetivo principal es ofrecer al colectivo un trabajo productivo y remunerado, adecuado a sus características personales y que facilite su integración en el mercado ordinario de trabajo. Las ayudas en este ámbito incluyen subvenciones para financiar proyectos generadores de empleo, para apoyo al mantenimiento de los puestos de trabajo y para unidades de apoyo a la actividad profesional. ${ }^{1 \circ}$

Por último, la tercera categoría se centra en las medidas para favorecer el tránsito desde el empleo protegido al ordinario, a través de los enclaves laborales. Se trata de un contrato entre una empresa del mercado ordinario de trabajo -empresa colaboradora- y un CEE para la realización de obras o servicios que guarden relación directa con la actividad principal de la empresa. Implica el desplazamiento de un grupo de trabajadores con discapacidad del CEE de forma temporal al centro de trabajo de la empresa colaboradora. Considerado como un instrumento para la creación de empleo para el colectivo y su posible inserción en el mercado ordinario y en línea con las medidas anteriores, supone ayudas en forma de subvenciones y bonificaciones de cuotas a la seguridad social para la empresa colaboradora.

A continuación analizamos la efectividad de alguna de estas medidas. En primer lugar, prestamos atención a la cuota de reserva. El Gráfico 9 a continuación muestra cómo ha evolucionado en los sectores público y privado el peso de los asalariados con discapacidad con respecto al total de asalariados en las empresas de más de 50 trabajadores durante el periodo 2008-I2.

Gráfico 9. Evolución del porcentaje de asalariados con discapacidad respecto del total de asalariados en empresas de más de 50 trabajadores en el sector público y privado

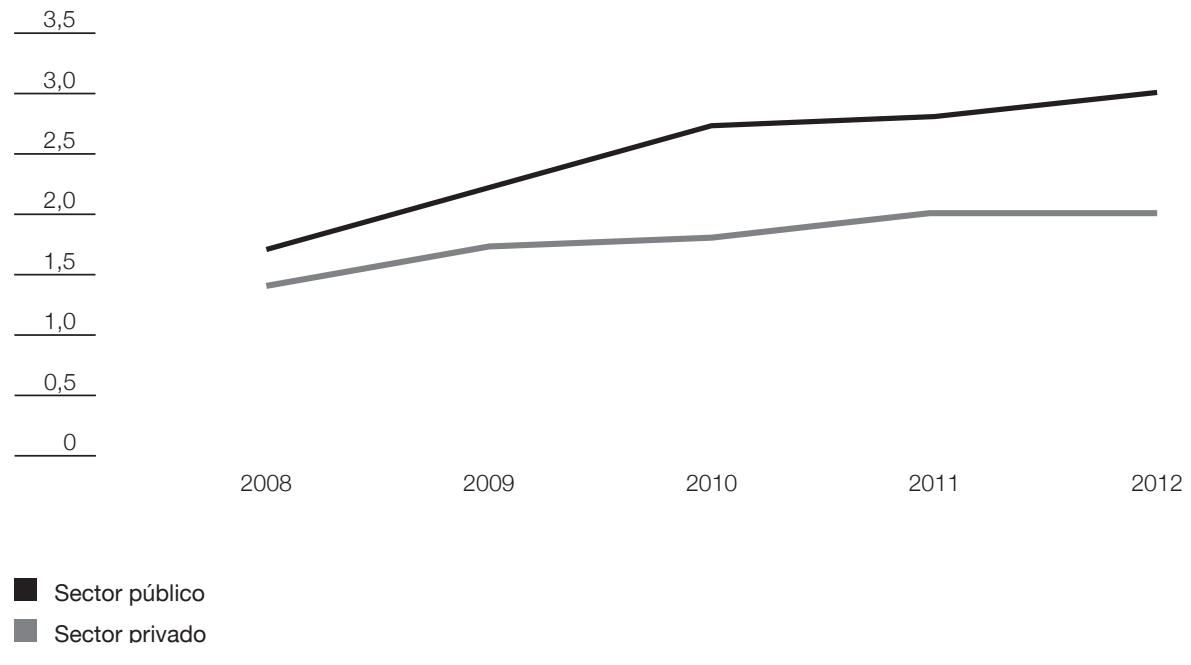

Fuente: EPD-INE.

Io. Las unidades de apoyo a la actividad profesional son equipos multiprofesionales dentro de los CEE que ayudan a las personas con discapacidad a superar las dificultades a las que se enfrentan tanto al incorporarse a un puesto de trabajo, como para conseguir la permanencia en el mismo. 
En este sentido vemos como, a pesar de la crisis económica, el porcentaje de asalariados con discapacidad en empresas de más de 50 trabajadores ha aumentado en ambos sectores, público y privado, alcanzando el $3 \%$ en el sector público y el $2 \%$ en el privado, lo cual es sin duda positivo, en términos de la inserción laboral de personas con discapacidad.

Con respecto a las bonificaciones o reducciones en las cuotas de la seguridad social que pretenden tanto incentivar la contratación por cuenta ajena como fomentar el empleo por cuenta propia, el Gráfico ro a continuación nos muestra datos de su cobertura sobre la población ocupada con discapacidad, distinguiendo por género.
Podemos observar cómo el $35 \%$ de los varones ocupados con discapacidad se beneficia de algún tipo de bonificación o reducción en las cuotas de cotización, mientras que este porcentaje disminuye al i $5 \%$ en el caso de las mujeres.

En relación con el uso de contratos específicos para la contratación de asalariados con discapacidad, el Gráfico I I arroja información acerca del peso de estas modalidades de contratación sobre el total de la población asalariada con discapacidad.

Análogamente a lo que observamos en relación con las bonificaciones y reducciones en las cuotas de cotización, vemos como también los hombres son contratados bajo formatos

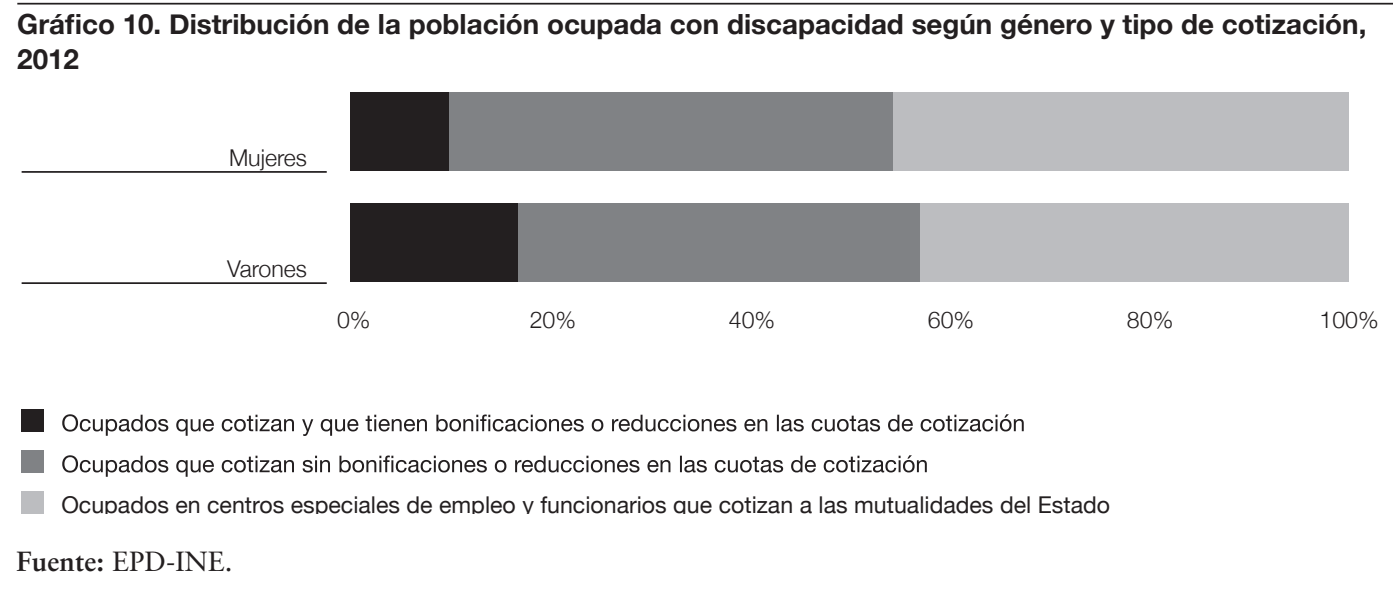

Gráfico 11. Distribución de la población asalariada con discapacidad según género y tipo de contrato, 2012

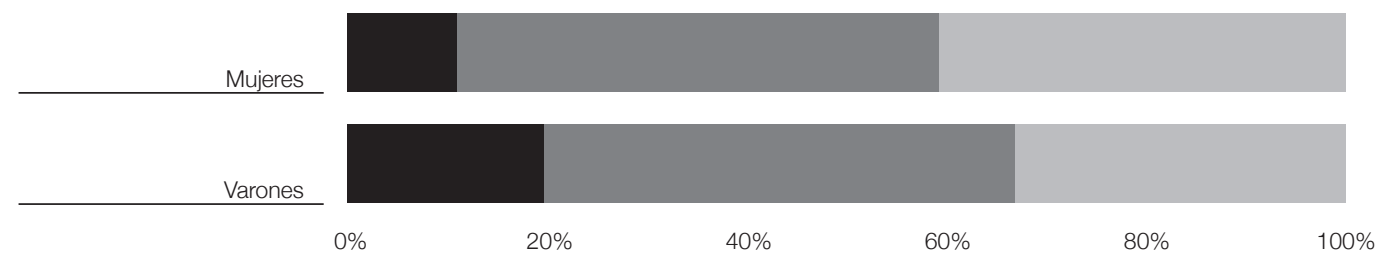

Contrato específico de discapacidad

Otros contratos

Asalariados en centros especiales de empleo v funcionarios que cotizan a las mutualidades del Estado

Fuente: EPD-INE. 


\begin{abstract}
Gráfico 12. Distribución de la poblaciones ocupada con y sin discapacidad según tiempo de permanencia en la misma empresa, 2012
\end{abstract}

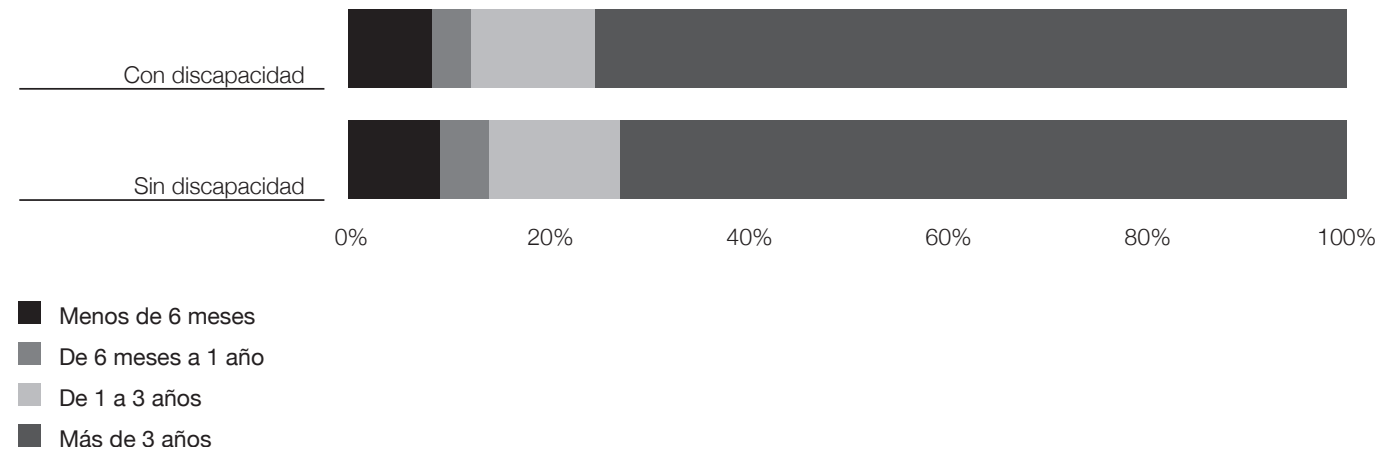

Fuente: EPD-INE.

específicos para personas con discapacidad en mayor proporción que las mujeres (un $20 \%$ frente a un I I \%). Este resultado es sin duda sorprendente, pues las ayudas a la contratación de mujeres con discapacidad superan en cuantía a la contratación de varones.

Por último, la figura 4.4 a continuación nos muestra las diferencias en cuanto al tiempo de permanencia en la misma empresa entre ambos grupos, lo que nos permite evaluar los niveles de seguridad en el empleo en clave comparada.

Si bien las diferencias entre ambos grupos son mínimas, podemos observar como la permanencia en la misma empresa durante más de 3 años, es ligeramente superior en el caso de las personas con discapacidad. Del mismo modo, una permanencia inferior a 6 meses, es más probable en el caso de la población general. Por tanto, las relaciones laborales para la población con discapacidad parecen ser, en media, algo más duraderas que para la población sin discapacidad. Estos datos podrían estar explicados por la necesidad de cumplir una duración mínima igual o superior al año en los contratos de personas con discapacidad para que las empresas contratantes puedan beneficiarse de ciertas ayudas y subvenciones. En ese caso, los datos estarían reflejando también la efectividad de estas medidas de apoyo a la inserción laboral del colectivo.

\subsection{Situación actual del mercado de trabajo}

Según su situación laboral, las personas pueden clasificarse en ocupados, parados e inactivos. ${ }^{\mathrm{II}}$ El Gráfico I 3 nos muestra, para el año 20I2, el peso de estos grupos dentro de las poblaciones con y sin discapacidad en edad de trabajar.

Podemos observar cómo la población con discapacidad ocupada tan solo representa el $24,5 \%$ del total de la población en edad de trabajar, mientras que para la población sin discapacidad, la misma cifra se eleva hasta el $58 \%$. Por el contrario, vemos como el $63 \%$ de las personas con discapacidad es inactivo mientras que ese grupo tan solo supone el $23 \%$ de la población general. Estos datos confirman que, sin perjuicio de la importancia de combatir el desempleo, el verdadero reto para el colectivo es el acceso al mercado laboral, esto es, la transición de la situación de inactividad a la de población económicamente activa. Persiguen ese objetivo las medidas encaminadas a la adaptación del puesto de trabajo: eliminación de barreras y modificación de las condiciones del

I I. Personas ocupadas son aquellas de I 6 o más años que trabajan a cambio de una retribución (salario, jornal, beneficio empresarial, etcétera) en dinero o especie. Se consideran paradas aquellas personas de 16 o más años sin trabajo, disponibles para trabajar y buscando activamente empleo. Finalmente, son personas inactivas aquellas de 16 o más años no incluida en ninguna de las categorías anteriores. 
Gráfico 13. Distribución de las poblaciones con y sin discapacidad según situación laboral, 2012

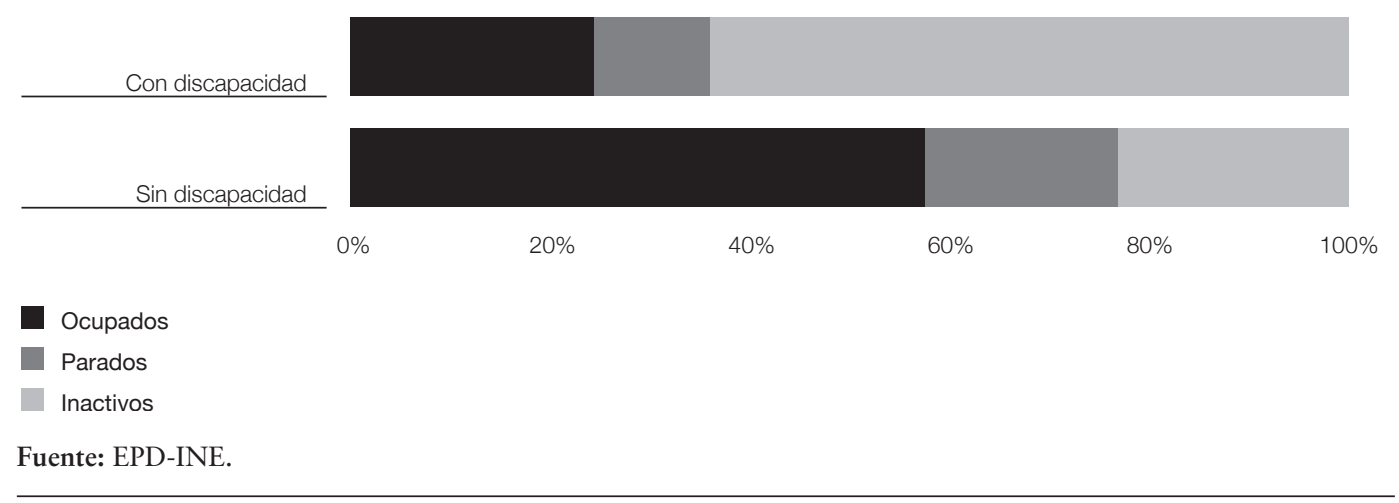

Gráfico 14. Distribución de la poblaciones ocupada con y sin discapacidad según situación profesional, 2012

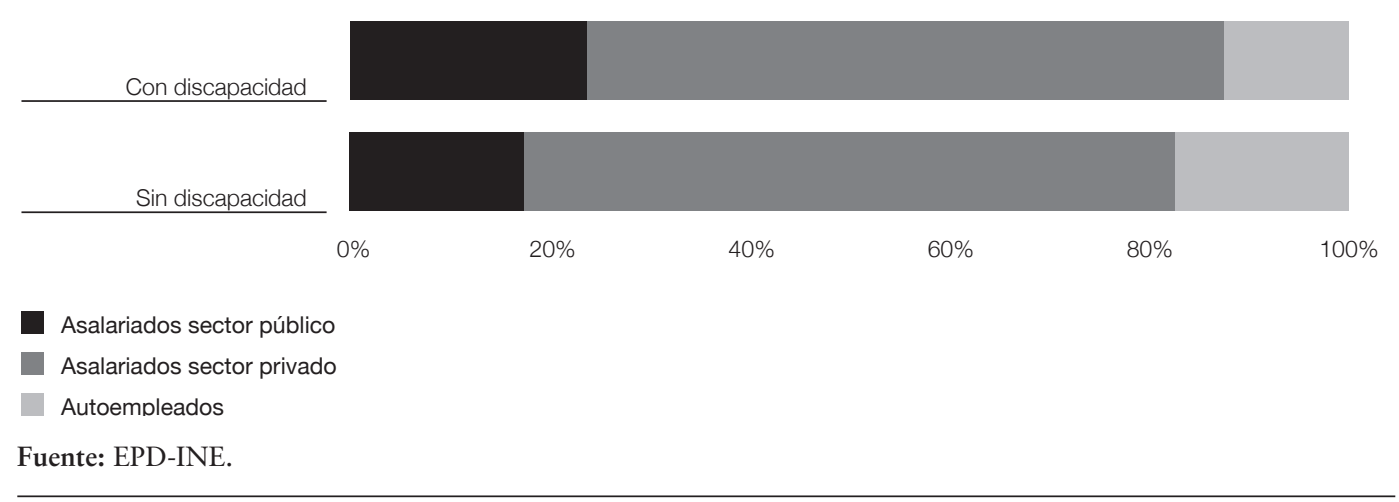

proceso de trabajo para que pueda ser realizado por una persona con discapacidad.

En cuanto a la distribución de ocupados según su situación profesional, el Gráfico I 4 nos muestra las diferencias para ambas poblaciones durante el periodo 2012.

Vemos como para ambos grupos se presenta un escenario similar. Así, los asalariados del sector privado pesan para ambos grupos aproximadamente el $65 \%$. Encontramos diferencias aunque mínimas, en el trabajo por cuenta propia ( $12 \%$ para la población con discapacidad, frente al I $7 \%$ de la población general) y en el empleo en el sector público, donde las personas con discapacidad tienen una mayor presencia, con un $23,5 \%$ de su ocupación, frente al i $7 \%$ del conjunto de las personas sin discapacidad.

También se observan diferencias entre ambas poblaciones en términos del sector de actividad en el que desarrollan su actividad. El Gráfico I 5 a continuación captura la información correspondiente para el periodo $20 \mathrm{I} 2$.

Vemos cómo en los sectores agrícola, industrial y de la construcción, el peso de la población con discapacidad es ligeramente inferior al de la población general (entre I y 3 puntos porcentuales). Estas diferencias son de esperar, pues las actividades correspondientes a estos sectores comprenden con frecuencia tareas 


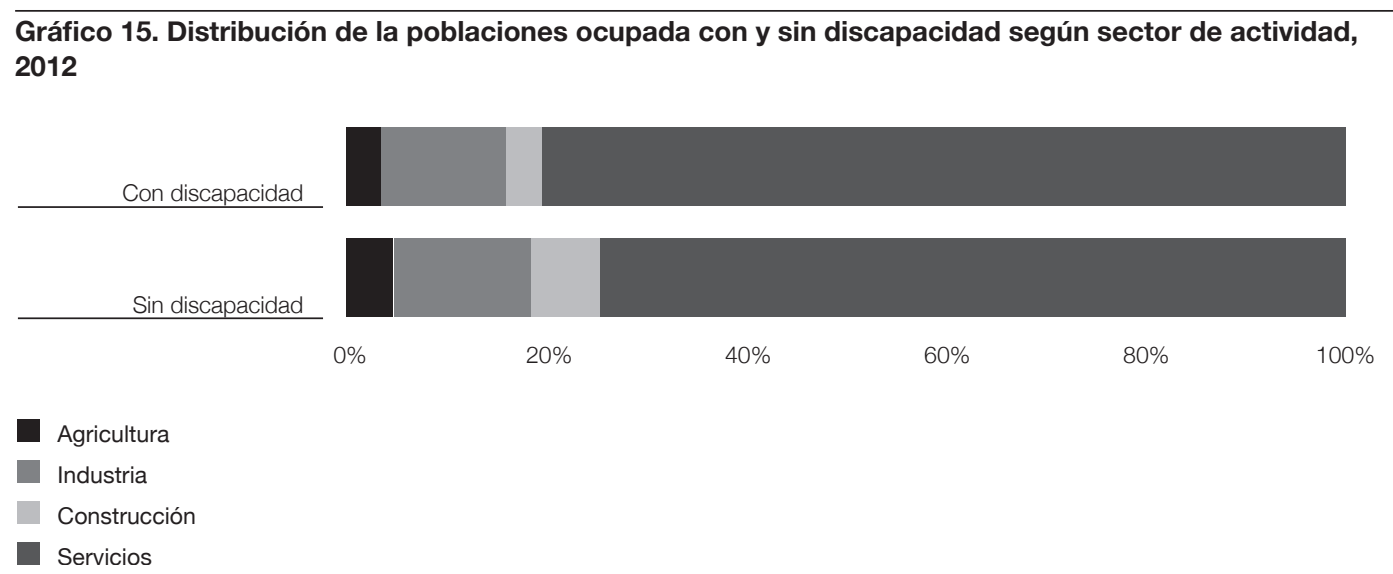

Fuente: EPD-INE.

Gráfico 16. Distribución de la poblaciones ocupada con y sin discapacidad según nivel de estudios, 2012

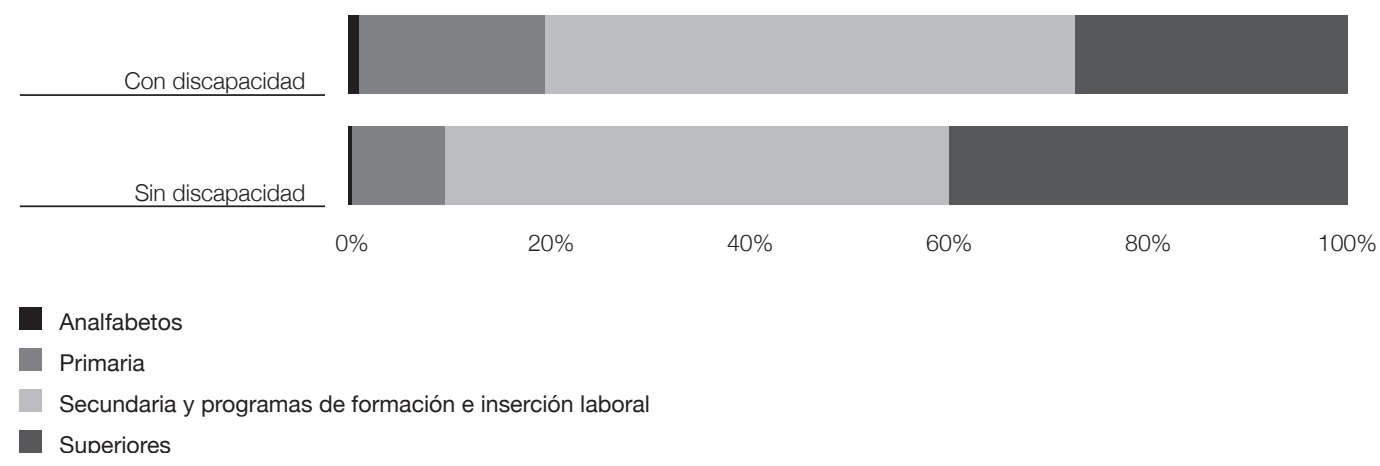

Fuente: EPD-INE.

de elevado esfuerzo físico y nivel de riesgo, lo que dificulta el acceso a estos sectores para el colectivo.

Atendiendo al nivel de educación formal entre los ocupados con y sin discapacidad, encontramos igualmente diferencias notables entre ambos grupos. El Gráfico I 6 muestra las disparidades existentes para el periodo $20 \mathrm{I} 2$.

Entre la población con discapacidad, el porcentaje de personas sin estudios y/o primarios, se sitúa en el $20 \%$. Dicho dato para la población general, apenas supera el
I० \%. Igualmente encontramos diferencias relevantes respecto a la formación superior. Así, la población con discapacidad ocupada con formación universitaria representa el $27,5 \%$ del total de ocupados con discapacidad. El mismo dato para la población general se eleva hasta el $40 \%$

Si bien las diferencias para la población ocupada son notables, estas se han reducido con respecto a las mismas cifras para la población total en edad de trabajar que presentamos en la sección 3 de este trabajo (fig. 3.8; pág. Io). La lógica detrás de esta reducción es la siguiente: 
un mayor nivel de formación aumenta las posibilidades de encontrar un empleo. Así pues, es de esperar que las personas ocupadas (con o sin discapacidad) presenten mayores niveles de formación que la población desempleada o inactiva. Es precisamente esa formación adicional la razón de que sus opciones de incorporarse a un puesto de trabajo hayan aumentado.

A continuación, en el Gráfico I7, mostramos las tasas de actividad, empleo y paro de ambos grupos para el periodo $2012 .^{\mathrm{I} 2}$

Como ya advertimos al principio de esta sección, al hilo de la información suministrada en la figura 4.5 , el verdadero reto del colectivo con discapacidad es la transición de la población inactiva a la población económicamente activa. Podemos observar que la diferencia en la tasa de actividad entre ambos grupos es de 40 puntos porcentuales. En términos de desempleo, el camino por recorrer es también complejo para la población con discapacidad. Así, la tasa de desempleo para esta población se sitúa por encima del $33 \%$ mientras que para la población general el dato desciende 8 puntos porcentuales.

Por tipos de discapacidad, estas cifras muestran una gran variabilidad, lo que mostramos a continuación a través del Gráfico I 8, con datos del 2012.

Así, las personas con discapacidad mental e intelectual presentan las menores tasas de actividad con valores en torno al $28 \%$, mientras que la cifra se eleva al $39 \%$ para las personas con discapacidad física y otras tipologías de discapacidad, y al $49 \%$ en el caso de los sensoriales. En cuanto a las cifras

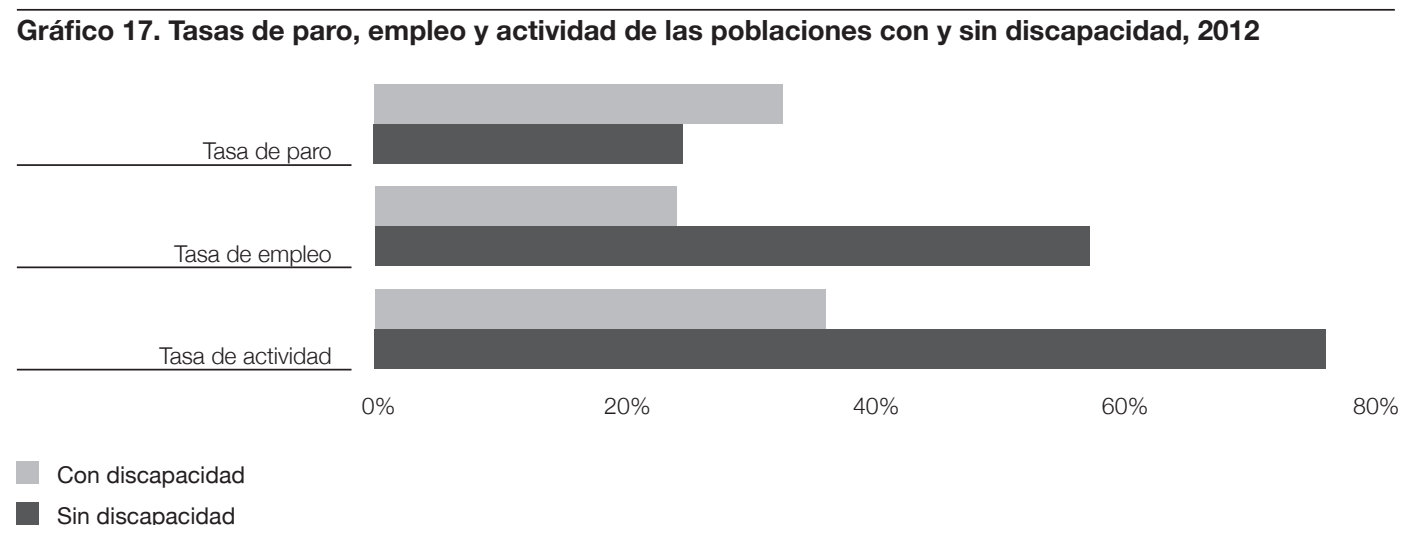

Fuente: EPD-INE.

I2. La tasa de actividad -o participación- es el porcentaje de la población económicamente activa -ocupados y paradoscomo proporción de la población en edad de trabajar -o población activa potencial-. Esta relación, es un indicador del tamaño relativo de la oferta laboral que realizan los trabajadores en la economía. La tasa de empleo -u ocupaciónes el porcentaje de la población ocupada como proporción de la población en edad de trabajar. Esta relación es un indicador del tamaño relativo de la demanda laboral que realizan las empresas en la economía. Finalmente, la tasa de paro -o desempleo- se define como la razón entre la población desempleada y la población económicamente activa. 

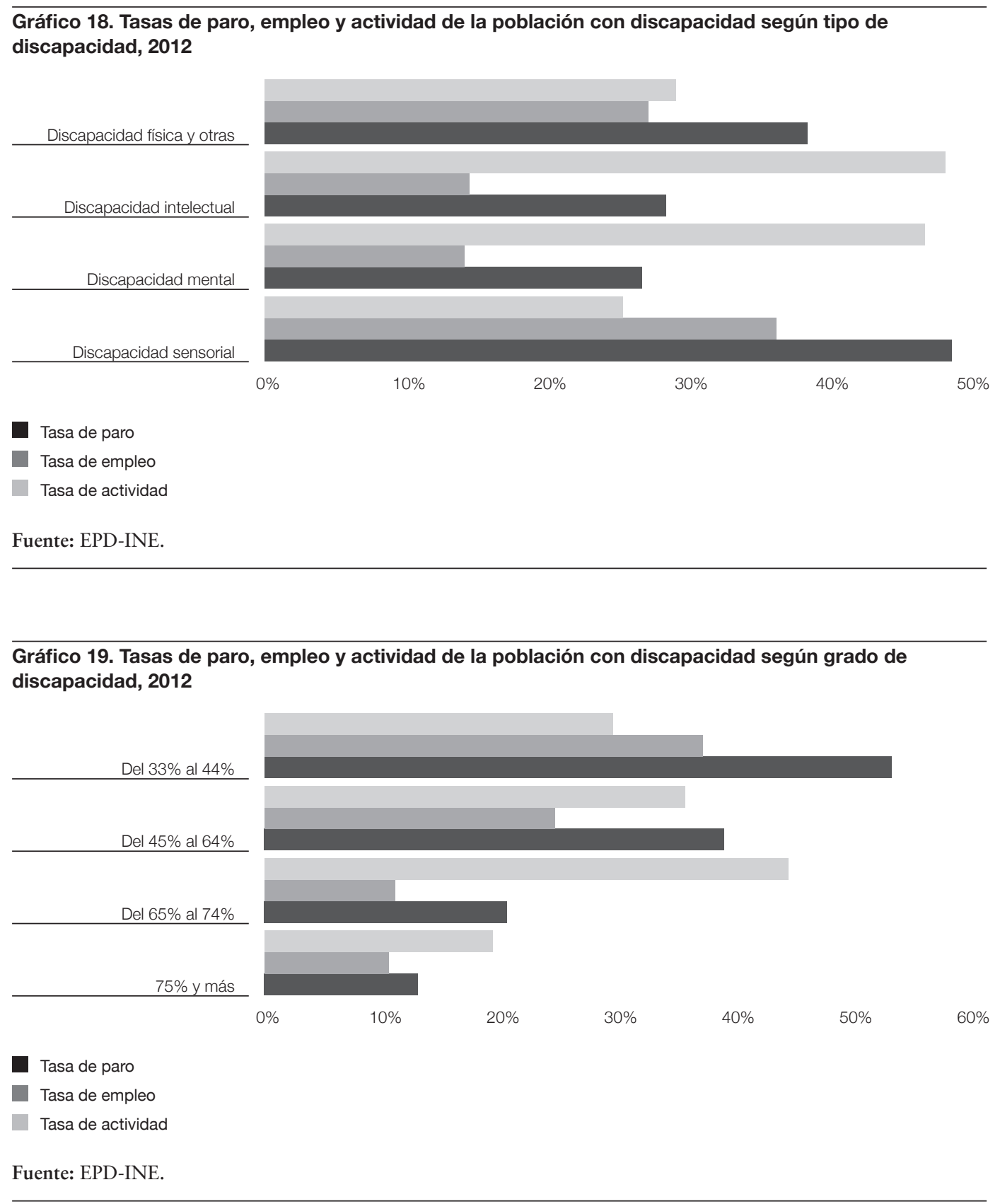

de paro, estas rondan el $48 \%$ para personas con discapacidad intelectual y mental mientras que descienden a valores por debajo del $30 \%$ para el resto de discapacidades. Son, por tanto, las discapacidades de tipo psíquico las que presentan mayores dificultades tanto de acceso al mercado laboral, como de inserción laboral.
El grado de discapacidad también genera divergencias en las tasas correspondientes al periodo 20I2, tal y como se observa en el Gráfico I9.

Como es lógico, la tasa de actividad presenta una relación inversa con el grado de 
discapacidad. Así, las discapacidades más leves $(33 \%-44 \%)$ presentan una tasa de actividad del $54 \%$ mientras esta tasa desciende para los grados más severos (75\% y más) hasta el I3 \%. La tasa de paro, por el contrario, aumenta a medida que lo hace el grado de discapacidad hasta alcanzar el $45 \%$ para discapacidades medias-altas $(65 \%-74 \%)$. No debe sorprender el descenso en la tasa de desempleo al $20 \%$ para las discapacidades más severas (75\% y más) pues para que una persona sea desempleada no basta con no trabajar, sino que es necesario que lleve a cabo una búsqueda activa de empleo, lo cual es complejo en situaciones de discapacidad severa. En estos casos, es más frecuente la inactividad laboral.

El nivel de educación formal también guarda una correspondencia con las tasas de actividad de ambas poblaciones, $y$ asumimos que hace lo propio con las tasas de empleo y paro. Lamentablemente, la EPD tan solo ofrece información acerca de actividad e inactividad (pero no de ocupación) de las personas con discapacidad al distinguir por niveles de ocupación. Por tanto, no es posible calcular, ni las tasas de empleo ni de desempleo del colectivo para los diferentes niveles educativos. Por ello, tan solo presentamos en el Gráfico
20 información del año 2012 sobre las tasas de actividad de las poblaciones con y sin discapacidad según su nivel de estudios.

Vemos como, a medida que aumenta el nivel educativo, también lo hacen las tasas de actividad para ambas poblaciones, lo cual tiene sentido. En el caso de personas sin discapacidad, sabemos que un mayor nivel de formación aumenta la propensión del individuo a incorporarse al mercado laboral. La misma lógica funciona para las personas con discapacidad, aunque podríamos incorporar un matiz en su redacción: si una persona ha superado las barreras para formarse, del mismo modo, podrá superarlas para acceder al mercado laboral.

Presentamos ahora, a través de la Tabla I a continuación, información acerca de las diferencias salariales existentes durante el periodo 20I I entre ambas poblaciones, y de si éstas persisten, cuando desagregamos por género y bandas de edad.

Podemos comprobar cómo, efectivamente, existen diferencias salariales entre ambas poblaciones en perjuicio de las personas con discapacidad y que estas diferencias son más

Gráfico 20. Tasa de actividad de las poblaciones con y sin discapacidad según nivel de estudios, 2012

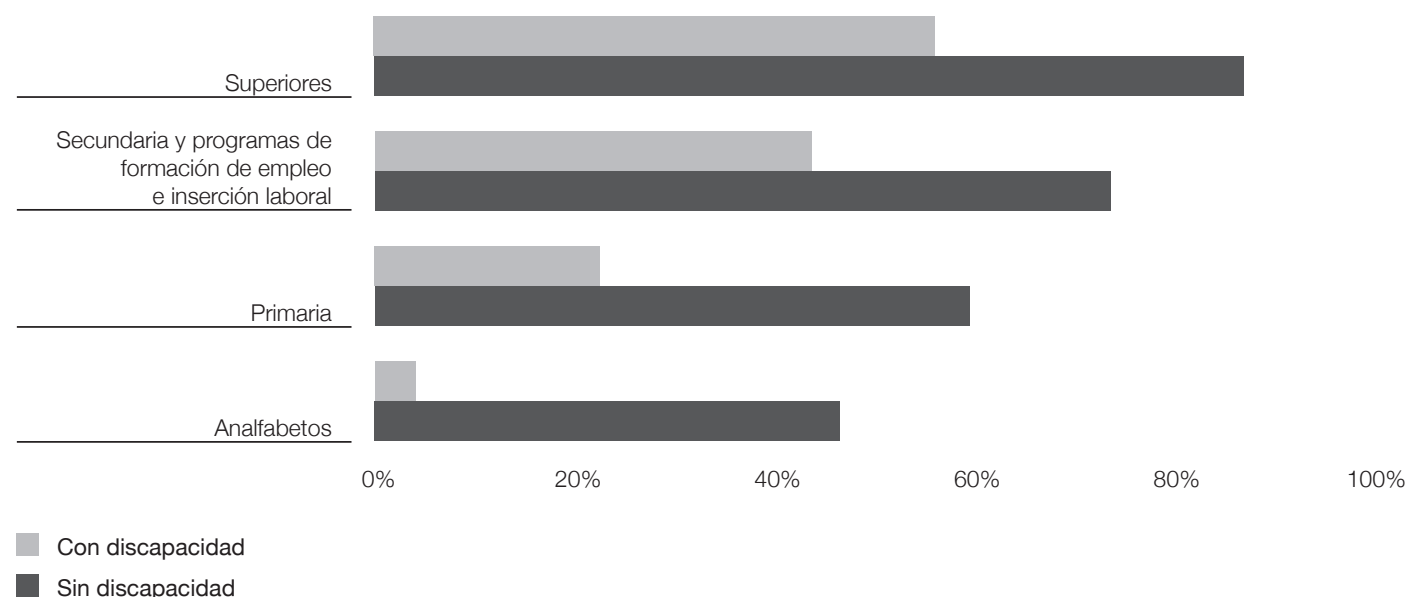

Fuente: EPD-INE. 
Tabla 1. Diferencias salariales entre las poblaciones con y sin discapacidad según género y bandas de edad, 2011

\begin{tabular}{|c|c|c|c|c|c|c|}
\hline & $\begin{array}{l}\text { Ganancia } \\
\text { bruta anual }\end{array}$ & $\begin{array}{c}\text { Diferencia } \\
\text { absoluta } \\
\text { CD-SD }\end{array}$ & $\begin{array}{l}\text { Diferencia } \\
\text { relativa } \\
\text { (CD-SD)/SD }\end{array}$ & $\begin{array}{c}\text { Ganancia } \\
\text { bruta por } \\
\text { hora }\end{array}$ & $\begin{array}{c}\text { Diferencia } \\
\text { absoluta } \\
\text { CD-SD }\end{array}$ & $\begin{array}{l}\text { Diferencia } \\
\text { relativa } \\
\text { (CD-SD)/SD }\end{array}$ \\
\hline \multicolumn{7}{|l|}{ Total asalariados } \\
\hline Con discapacidad & $20.337 €$ & \multirow{2}{*}{$-2.633 €$} & \multirow{2}{*}{$-11,5 \%$} & $13,2 €$ & \multirow{2}{*}{$-1,4 €$} & \multirow{2}{*}{$-9,6 \%$} \\
\hline Sin discapacidad & $22.970 €$ & & & $14,6 €$ & & \\
\hline \multicolumn{7}{|l|}{ Varones } \\
\hline Con discapacidad & $21.493 €$ & \multirow{2}{*}{$-4.308 €$} & \multirow{2}{*}{$-16,7 \%$} & $13,6 €$ & \multirow{2}{*}{$-2,1 €$} & \multirow{2}{*}{$-13,4 \%$} \\
\hline Sin discapacidad & $25.801 €$ & & & $15,7 €$ & & \\
\hline \multicolumn{7}{|l|}{ Mujeres } \\
\hline Con discapacidad & $18.539 €$ & \multirow{2}{*}{$-1.257 €$} & \multirow{2}{*}{$-6,3 \%$} & $12,5 €$ & \multirow{2}{*}{$-0,6 €$} & \multirow{2}{*}{$-4,6 \%$} \\
\hline Sin discapacidad & $19.796 €$ & & & $13,1 €$ & & \\
\hline \multicolumn{7}{|l|}{ De 16 a 29 años } \\
\hline Con discapacidad & $12.132 €$ & \multirow{2}{*}{$-3.398 €$} & \multirow{2}{*}{$-21,9 \%$} & $8,6 €$ & \multirow{2}{*}{$-1,6 €$} & \multirow{2}{*}{$-15,7 \%$} \\
\hline Sin discapacidad & $15.530 €$ & & & $10,2 €$ & & \\
\hline \multicolumn{7}{|l|}{ De 30 a 44 años } \\
\hline Con discapacidad & $18.155 €$ & \multirow{2}{*}{$-4.737 €$} & \multirow{2}{*}{$-20,7 \%$} & $11,5 €$ & \multirow{2}{*}{$-2,8 €$} & \multirow{2}{*}{$-19,6 \%$} \\
\hline Sin discapacidad & $22.892 €$ & & & $14,3 €$ & & \\
\hline \multicolumn{7}{|l|}{ De 45 y más años } \\
\hline Con discapacidad & $22.453 €$ & \multirow{2}{*}{$-3.637 €$} & \multirow{2}{*}{$-13,9 \%$} & $14,6 €$ & \multirow{2}{*}{$-2,1 €$} & \multirow{2}{*}{$-12,6 \%$} \\
\hline Sin discapacidad & $26.090 €$ & & & $16,7 €$ & & \\
\hline
\end{tabular}

Fuente: EPD-INE.

acusadas para los varones (frente a las mujeres), y para la banda de edad 30-44 años frente a otros tramos. Además, observamos que la diferencia relativa en términos de la ganancia bruta por hora es menor que la diferencia relativa en términos de la ganancia bruta anual, lo que se debe a jornadas laborales probablemente más cortas para el colectivo de personas con discapacidad.

Podríamos preguntarnos si las diferencias salariales detectadas persisten, independientemente de si centramos nuestra atención en la población con salarios bajos o altos. Esta información es capturada a continuación, a través del Gráfico 2I con datos del 20 II.
Comprobamos como, efectivamente, las diferencias salariales en perjuicio de la población con discapacidad son robustas a la consideración, tanto de los segmentos de la población con salarios bajos (percentiles bajos), como de los segmentos con salarios medios (percentil 50) y salarios elevados (percentiles elevados).

Del mismo modo, cabría cuestionarse si estas diferencias persisten según los grupos o categorías de ocupación. El SPD presenta tres grupos o categorías de ocupación diferentes: Alta, Media y Baja. La categoría Alta incluye directores y gerentes, técnicos y profesionales científicos, intelectuales y de apoyo. Por su parte, la categoría Media incorpora empleados, 
Gráfico 21. Distribución salarial de las poblaciones con y sin discapacidad por tramos salariales, 2011

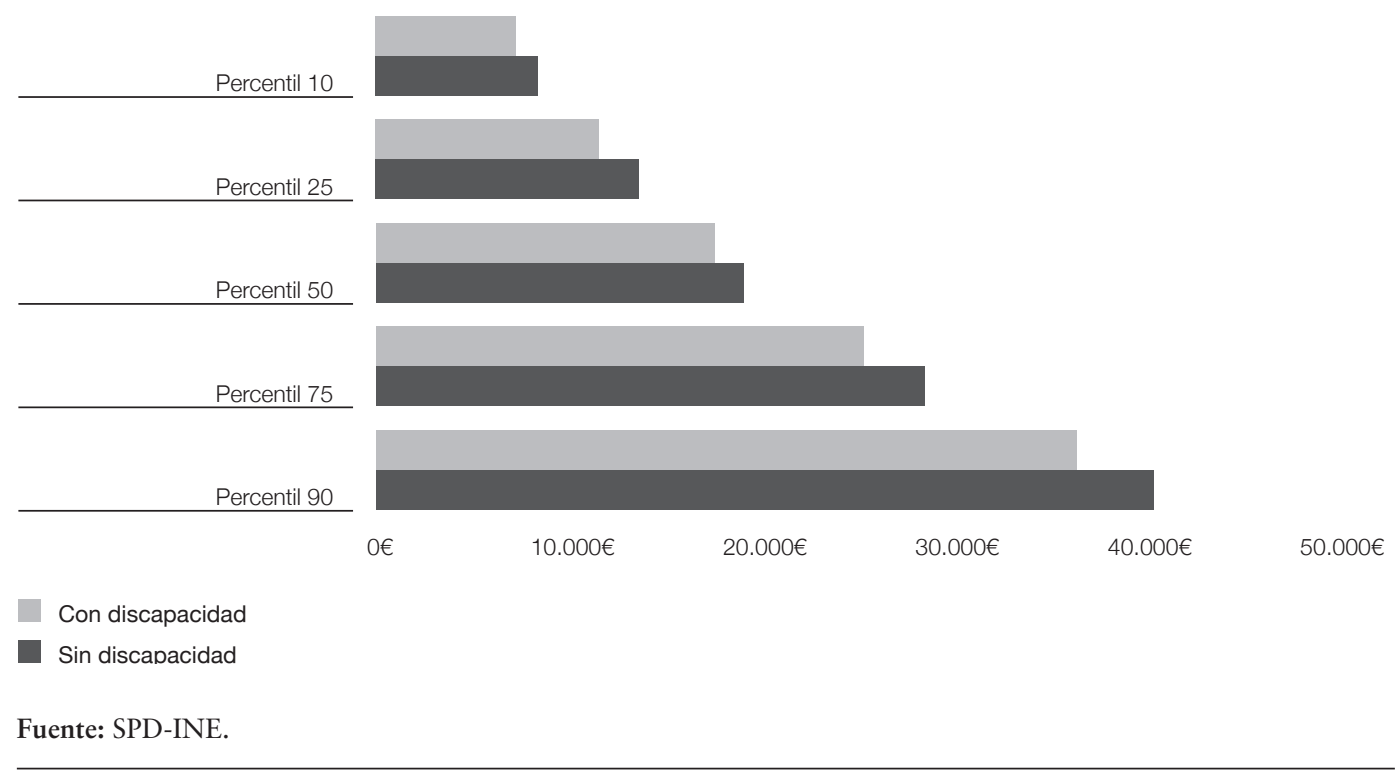

Gráfico 22. Distribución salarial de las poblaciones con y sin discapacidad por grupo de ocupación, 2011

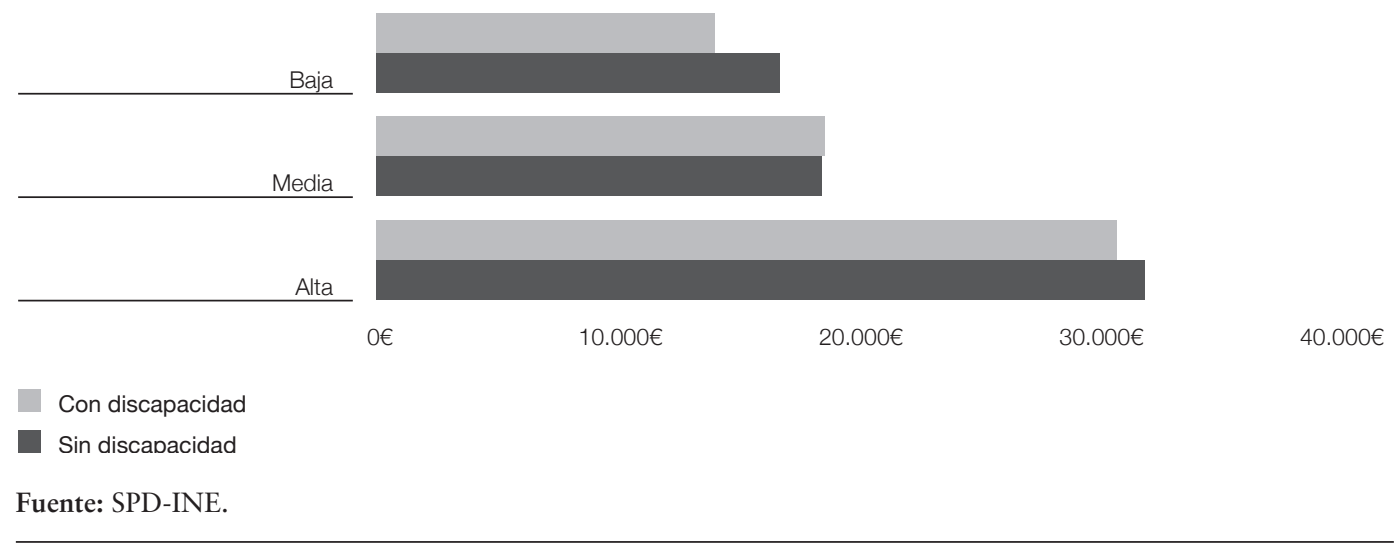

artesanos y trabajadores cualificados. Por último, la categoría Baja de destina a operadores y trabajadores no cualificados. El Gráfico 22 nos muestra estos datos para el periodo $20 \mathrm{II}$.

Observamos cómo no en todos los grupos los salarios son más elevados para las personas sin discapacidad. Así, mientras esto sí ocurre para los grupos de ocupación Alta y Baja, el salario de las personas con discapacidad en la categoría Media es algo superior ( ( $8.844 €$ frente a $18.629 €)$

A continuación nos cuestionamos sobre las posibles diferencias salariales que pueden emerger dentro de la población con discapacidad, según una serie de atributos tales como son el tipo y grado de discapacidad, la existencia de bonificaciones y reducciones en las cuotas de cotización, y el tipo de contrato. 
Utilizando datos del 20I I, estas diferencias son presentadas a continuación en la Tabla 2.

Podemos apreciar cómo las condiciones salariales menos favorables dentro de la población con discapacidad afectan a: discapacidades de tipo psíquico; discapacidades de tipo medio ( $45 \%-64 \%)$; aquellos que no se benefician de bonificaciones o reducciones en las cuotas de cotización a la seguridad social; y aquellos que no tienen contratos específicos para personas con discapacidad.

\subsection{Los efectos de la crisis económica}

Como primer objetivo de este apartado, tratamos de comprobar si el periodo de crisis ha afectado con igual virulencia a la situación laboral de ambos grupos de análisis. La Tabla 3 nos muestra la evolución de las tasas de paro, actividad y empleo de estas poblaciones durante el periodo 2008-I2, así como las variaciones absolutas y relativas de estos índices durante este periodo.

En términos de tasa de paro, vemos como la crisis afecta negativamente a ambos grupos. Para las personas con discapacidad, esta tasa aumentó en casi I 7 puntos durante el periodo, mientras que lo hizo en unos I4 puntos para el resto de la población. Desde esta perspectiva podría afirmarse que las personas con discapacidad se han visto más afectadas por la crisis en términos de pérdida de empleo. Esta es precisamente la información que nos muestra el Gráfico 23 a continuación, esto es, las variaciones absolutas de la tasa de paro, que presentamos como ilustración.

Como vemos, aunque las tasas de paro aumentan para ambas poblaciones, las curvas se alejan a partir del año 20Io, lo que parece indicar que el colectivo sufre más si cabe las

Tabla 2. Diferencias salariales en la población con discapacidad según tipo y grado de discapacidad, existencia de bonificaciones y reducciones en las cuotas de cotización y tipo de contrato, 2011

\begin{tabular}{|l|c|c|c|c|c|c|}
\hline & $\begin{array}{c}\text { Ganancia } \\
\text { bruta anual }\end{array}$ & $\begin{array}{c}\text { Diferencia } \\
\text { absoluta * }\end{array}$ & $\begin{array}{c}\text { Diferencia } \\
\text { relativa * }\end{array}$ & $\begin{array}{c}\text { Ganancia } \\
\text { bruta por } \\
\text { hora }\end{array}$ & $\begin{array}{c}\text { Diferencia } \\
\text { absoluta * }\end{array}$ & $\begin{array}{c}\text { Diferencia } \\
\text { relativa * }\end{array}$ \\
\hline Tipo discapacidad \\
\hline Física y otras & $21.470 €$ & $1.132 €$ & $5,6 \%$ & $13,9 €$ & $0,7 €$ & $5,3 \%$ \\
\hline Intelectual & $11.453 €$ & $-8.885 €$ & $-43,7 \%$ & $7,5 €$ & $-5,7 €$ & $-43,2 \%$ \\
\hline Mental & $17.640 €$ & $-2.698 €$ & $-13,3 \%$ & $11,9 €$ & $-1,3 €$ & $-9,8 \%$ \\
\hline Sensorial & $21.132 €$ & $795 €$ & $3,9 \%$ & $13,6 €$ & $0,4 €$ & $3,0 \%$ \\
\hline Grado discapacidad & \multicolumn{7}{|l}{} \\
\hline Del 33\% al 44\% & $20.953 €$ & $616 €$ & $3,0 \%$ & $13,5 €$ & $0,3 €$ & $2,3 \%$ \\
\hline Del 45\% al 64\% & $18.388 €$ & $-1.950 €$ & $-9,6 \%$ & $12,1 €$ & $-1,1 €$ & $-8,3 \%$ \\
\hline $65 \%$ y más & $20.170 €$ & $-168 €$ & $-0,8 \%$ & $13,3 €$ & $0,1 €$ & $0,8 \%$ \\
\hline Bonificaciones y reducciones \\
\hline Con & $22.741 €$ & $2.403 €$ & $11,8 \%$ & $15,1 €$ & $1,9 €$ & $14,4 \%$ \\
\hline Sin & $16.080 €$ & $-4.258 €$ & $-20,9 \%$ & $10,0 €$ & $-3,2 €$ & $-24,2 \%$ \\
\hline Tipo de contrato \\
\hline Discapacidad & $21.024 €$ & $687 €$ & $3,4 \%$ & $13,8 €$ & $0,6 €$ & $4,5 \%$ \\
\hline Otros & $18.075 €$ & $-2.262 €$ & $-11,1 \%$ & $11,4 €$ & $-1,8 €$ & $-13,6 \%$ \\
\hline
\end{tabular}

(*) Las diferencias absolutas y relativas son calculadas con respecto a los salarios medios anuales y por hora de la población con discapacidad Fuente: SPD-INE. 
Tabla 3. Evolución de las tasas de paro, actividad y empleo de las poblaciones con y sin discapacidad

\begin{tabular}{|l|c|c|c|c|c|c|c|}
\hline & $\mathbf{2 0 0 8}$ & $\mathbf{2 0 0 9}$ & $\mathbf{2 0 1 0}$ & $\mathbf{2 0 1 1}$ & $\mathbf{2 0 1 2}$ & $\begin{array}{c}\text { Variación } \\
\text { absoluta } \\
\mathbf{1 2 - 0 8}\end{array}$ & $\begin{array}{c}\text { Variación } \\
\text { relativa } \\
\mathbf{( 1 2 - 0 8 ) / 0 8}\end{array}$ \\
\hline Tasa de paro & & & & & \\
\hline Con discapacidad & $16,3 \%$ & $21,8 \%$ & $23,3 \%$ & $26,9 \%$ & $33,1 \%$ & $16,8 \%$ & $103,1 \%$ \\
\hline Sin discapacidad & $11,3 \%$ & $18,1 \%$ & $20,1 \%$ & $21,7 \%$ & $25,0 \%$ & $13,7 \%$ & $120,5 \%$ \\
\hline Tasa de actividad & $33,4 \%$ & $36,2 \%$ & $36,2 \%$ & $36,6 \%$ & $36,6 \%$ & $3,2 \%$ & $9,6 \%$ \\
\hline Con discapacidad & $74,9 \%$ & $75,4 \%$ & $75,9 \%$ & $76,4 \%$ & $77,0 \%$ & $2,1 \%$ & $2,8 \%$ \\
\hline Sin discapacidad & \multicolumn{7}{|l|}{} \\
\hline Tasa de empleo & $28,0 \%$ & $28,3 \%$ & $27,7 \%$ & $26,7 \%$ & $24,5 \%$ & $-3,5 \%$ & $-12,5 \%$ \\
\hline Con discapacidad & $66,4 \%$ & $61,8 \%$ & $60,6 \%$ & $59,8 \%$ & $57,8 \%$ & $-8,6 \%$ & $-13,0 \%$ \\
\hline Sin discapacidad
\end{tabular}

Fuente: EPD-INE.

Gráfico 23. Evolución de la tasa de paro de las poblaciones con y sin discapacidad
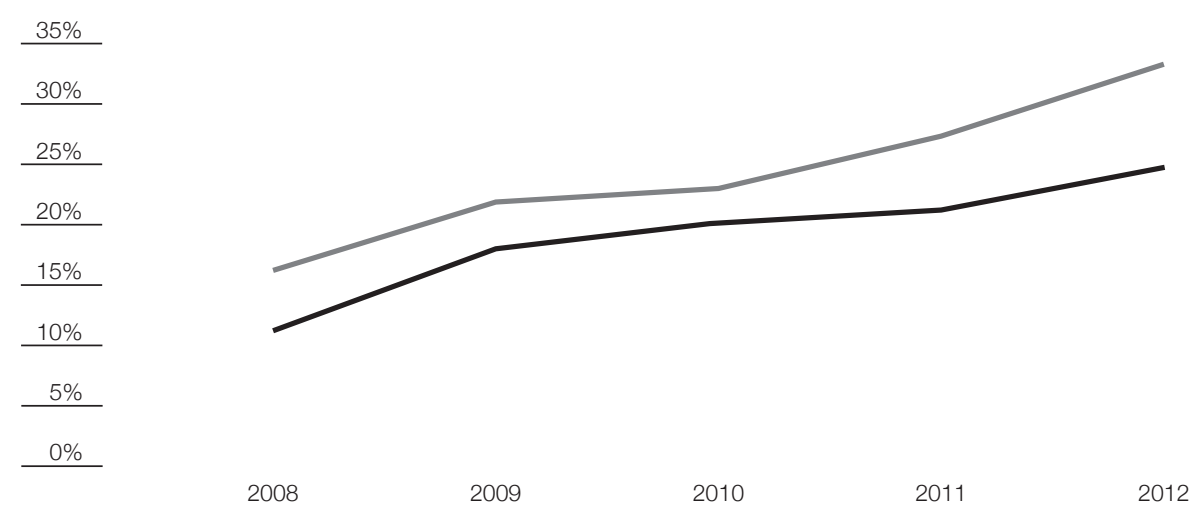

Sin discapacidad

Con discapacidad

Fuente: EPD-INE.

consecuencias de la crisis en términos de pérdida de empleo.

Volviendo a la información provista por la Tabla 3 , sin embargo, observamos como en términos relativos, la tasa de paro ha aumentado en un $103 \%$ para las personas con discapacidad y que lo hizo en un I $20 \%$ para aquellas sin discapacidad. Es decir, si atendemos a los datos relativos, deberíamos concluir que ha sido la población sin discapacidad las que más se ha visto afectada por el desempleo.

En cuanto a las tasas de actividad, vemos como estas han experimentado ligeros aumentos durante el periodo 2008-I 2 para ambas 
poblaciones, lo que indica que ambos grupos no solo mantienen, sino que aumentan su oferta de empleo durante la crisis. En términos relativos, sin embargo, este aumento ha sido mayor para la población con discapacidad (un $9.6 \%$ frente a un $2.8 \%$ ) lo cual contribuye a incrementar la participación del colectivo en la actividad económica del país.

Por último, con respecto a las tasas de empleo, vemos como ambas han sufrido descensos durante el periodo de análisis, lo que obedece a una reducción de la demanda de empleo por parte del tejido empresarial en el periodo de análisis. En términos relativos, observamos como la tasa de empleo se ha reducido en un $\mathbf{2} .5 \%$ para las personas con discapacidad y en un $\mathrm{I} 3 \%$ para la población general, lo que parece confirmar el dato apuntado anteriormente: en términos laborales, el colectivo de personas con discapacidad ha sufrido algo menos las consecuencias de la crisis que el resto de la población.

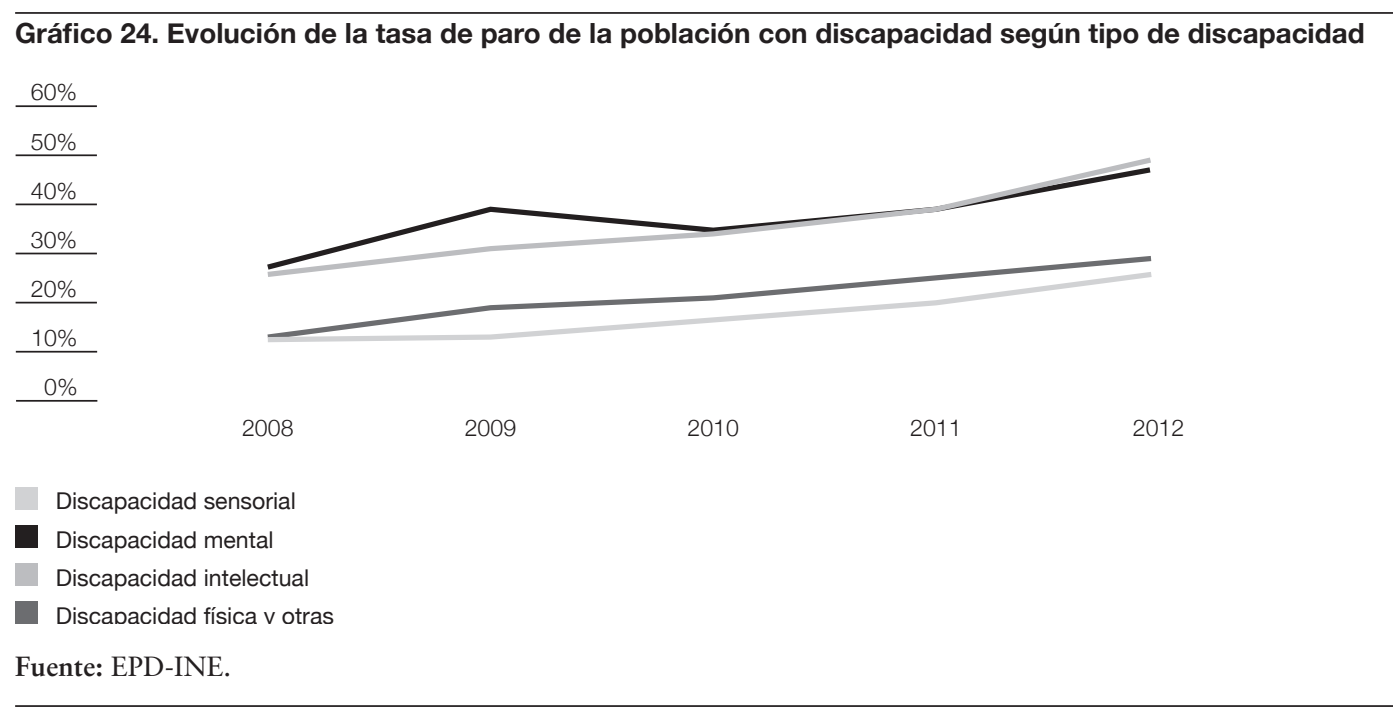

Gráfico 25. Evolución de la tasa de paro de la población con discapacidad según grado de discapacidad
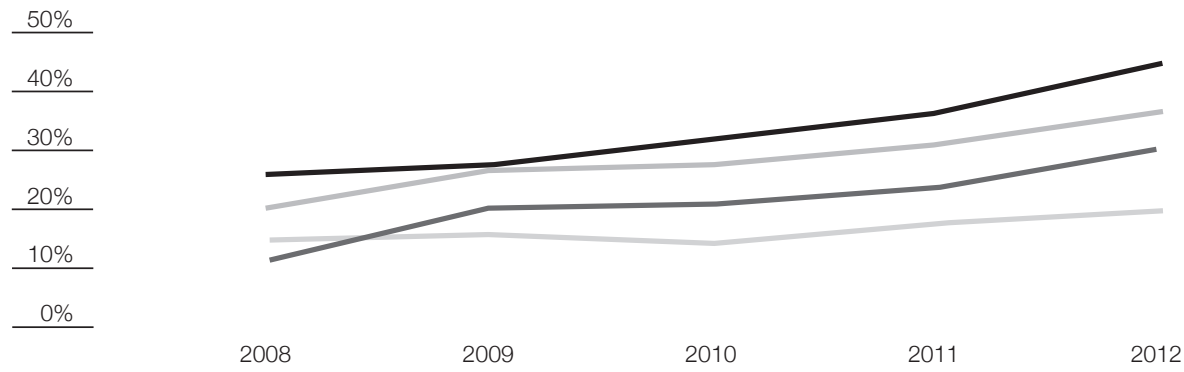

$75 \%$ y más

Del $65 \%$ al $74 \%$

Del $45 \%$ al $64 \%$

Del $33 \%$ al $44 \%$

Fuente: EPD-INE. 
Dentro del conjunto de personas con discapacidad, cabría preguntarse si el tipo o el grado de discapacidad han condicionado la severidad con que la crisis ha afectado al colectivo. Los gráficos 24 y 25 muestran la evolución de la tasa de paro de la población con discapacidad durante el periodo 2008 I 2 según el tipo y el grado de discapacidad, respectivamente.

Vemos como las tasas de desempleo han aumentado significativamente para todos los tipos de discapacidad. Sin embargo, existen diferencias entre estos grupos. Así, por ejemplo, las personas con discapacidad sensorial han incrementado su tasa de paro en I 2 puntos, pasando del I $3 \%$ en 2008 al $25 \%$ en 20 I 2 , mientras que las personas con discapacidad intelectual han visto incrementada su tasa de desempleo en 24 puntos, pasando del $25 \%$ en 2008 al $49 \%$ en 20 I 2 . En términos relativos, sin embargo, estas diferencias en el aumento del desempleo durante el periodo 2008-I 2 se disipan pues, para ambos grupos, las tasas de paro se han duplicado. En otras palabras, las tasas de paro han experimentado aumentos aproximados del I00\% en ambos casos.
También en términos relativos, observamos como la tasa de paro aumenta un $72 \%$ para la discapacidad mental (pasando de un $28 \%$ a un $47 \%$ ) y un I $20 \%$ para la discapacidad física y otras tipologías de discapacidad (pasando de un I3 \% a un $29 \%$ ). En términos de pérdida de empleo, este último grupo es el que parece haber sufrido en mayor medida los efectos de la recesión.

En cuanto al grado de discapacidad, podemos observar como los niveles más severos $(75 \%$ o más) tan solo experimentan un aumento de 5 puntos en su tasa de paro durante el periodo 2008-I 2; mientras que el resto experimenta incrementos de entre I 5 y 20 puntos. En números relativos, también surgen diferencias notables. Así, observamos como la tasa de paro aumenta un $39 \%$ para los casos muy severos y un $166 \%$ para los grados más leves (33\%-44\%), siendo estos los que parecen haber sufrido con más severidad las consecuencias de la crisis.

La distinción por género también arroja datos interesantes. El Gráfico 26 nos muestra la diferente evolución que ha seguido la tasa de paro del colectivo, atendiendo a dicha variable.

\section{Gráfico 26. Evolución de la tasa de paro de la población con discapacidad según género}

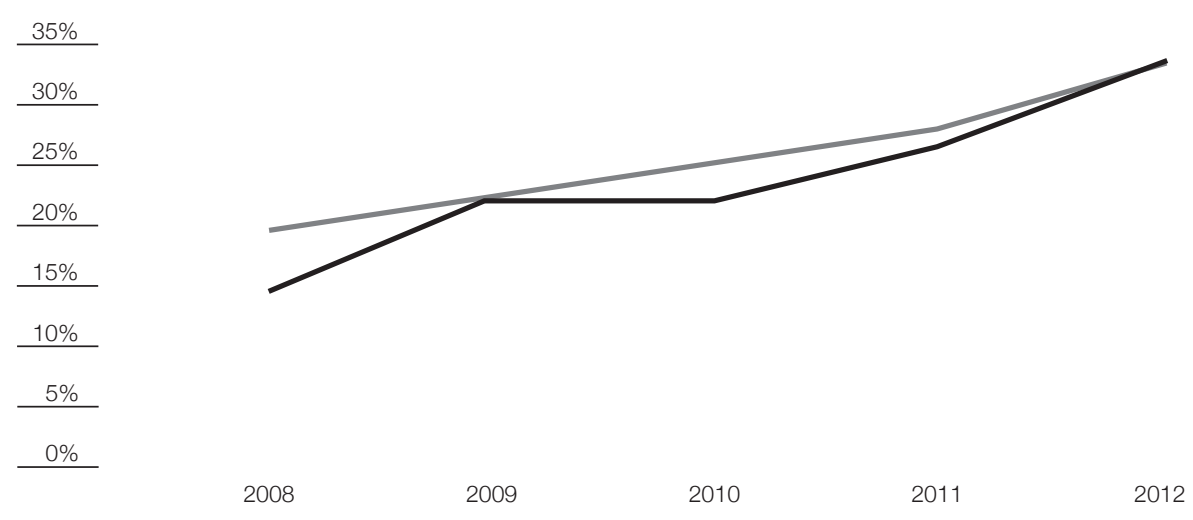

Fuente: EPD-INE. 
Podemos ver como los varones experimentan mayores subidas en su tasa de paro que las mujeres en el intervalo 2008-I2, tanto en términos absolutos como relativos. En este sentido, los varones sufren incrementos en sus tasas de paro superiores a los I9 puntos, pasando del $\mathrm{r} 4,5 \%$ al $33 \%$, lo que supone un incremento porcentual del I $30 \%$. Las mujeres, por su parte, tan solo experimentan aumentos en sus tasas de $\mathrm{I} 3,5$ puntos, lo que se traduce en un incremento porcentual del $70 \%$.

La edad de las personas con discapacidad también tiene su influencia en cuanto al nivel de afección de la crisis. El Gráfico 27 a continuación presenta la evolución de la tasa de paro del colectivo por bandas de edad.

Como puede apreciarse, en términos absolutos, los trabajadores de más edad sufren aumentos en su tasa de paro algo menores (I 6 puntos) que los que experimentan los trabajadores de la banda de edad intermedia (I9 puntos) y los más jóvenes (24 puntos). En términos relativos, sin embargo, ocurre justo lo contrario. La tasa de paro aumenta un $57 \%$ para los más jóvenes, mientras que para los de edad intermedia y de más edad esta tasa se incrementa un 108\% y un I $39 \%$, respectivamente.

Igualmente interesante hubiera resultado el poder contrastar si el nivel educativo de las personas con discapacidad condiciona la severidad con que se ven afectados por la crisis. Lamentablemente, ya advertimos en la sección 4.2 (al hilo de la información presentada en la figura 4.I2, págs. I9-20) que la EPD tan solo ofrece información acerca de actividad e inactividad (pero no de ocupación) de las personas con discapacidad al distinguir por niveles de ocupación.

En resumen, y atendiendo a los datos relativos (que son los realmente comparables) podemos afirmar que: (i) las personas con discapacidad han sufrido las consecuencias de la crisis en menor medida que las personas sin discapacidad; (ii) dentro del colectivo, las consecuencias de la crisis han sido más severas para las personas con discapacidad física, las que tienen una discapacidad leve (33\%-44\%), los varones y aquellos con edades comprendidas entre 45 y 64 años.

\section{Gráfico 27. Evolución de la tasa de paro de la población con discapacidad según bandas de edad}

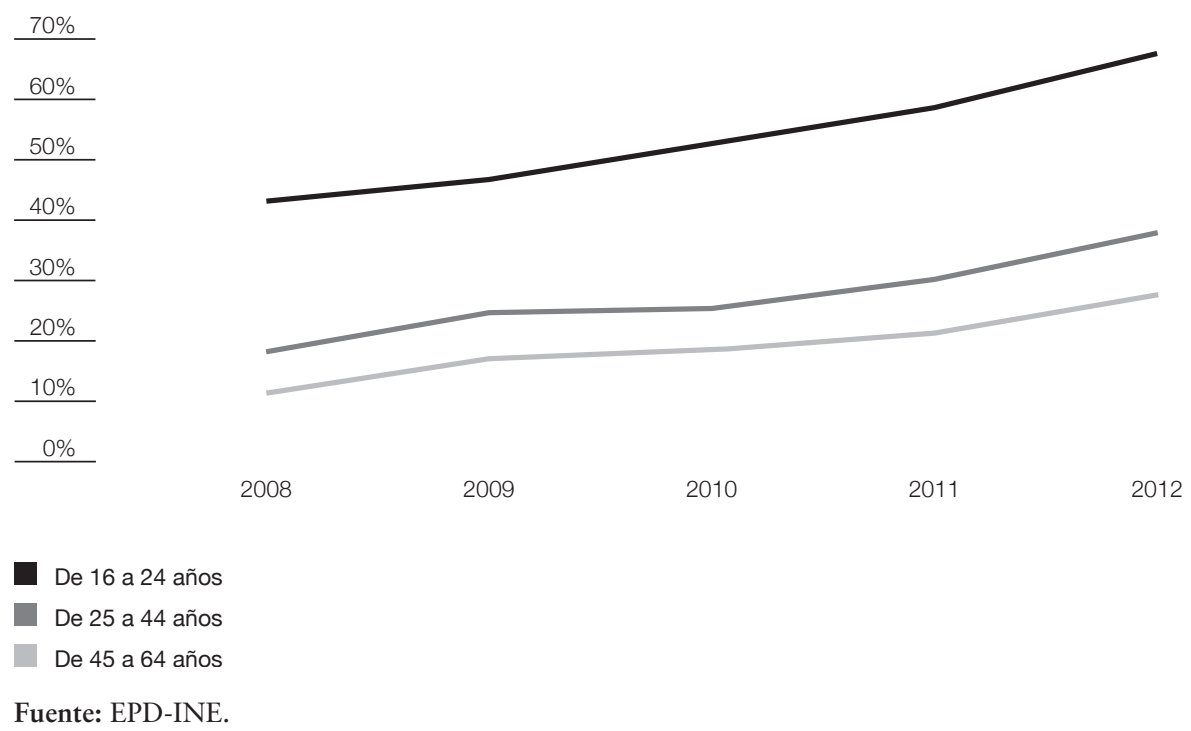




\section{Conclusiones}

La sociedad debe prestar a las personas con discapacidad la atención que merecen, no solo por su volumen poblacional (que alcanza el I $5 \%$ ) sino por su capacidad de para participar y transformar la sociedad si se eliminan ciertas barreras, y para crear oportunidades de beneficio (tan necesarias en la coyuntura económica actual) si el mercado es capaz de ofertar bienes y servicios accesibles para todos.

En línea con esta idea, el objetivo de este trabajo ha sido precisamente analizar los niveles de integración laboral (como pieza elemental para una integración en la sociedad plena) de las personas con discapacidad en España, y su evolución durante la reciente crisis económica. Nuestros resultados sobre inserción laboral y salarios revelan la existencia de importantes diferencias en detrimento del colectivo. Además, las consecuencias de la crisis en términos de pérdida de empleo han sido muy severas para las personas discapacitadas (si bien estas se han acentuado algo más entre la población general).

Este trabajo aspira a presentar sus resultados de manera rigurosa y contribuir al debate sobre la inserción laboral de las personas con discapacidad en España y, como es lógico, no está exento de limitaciones. El no disponer de series de datos más largas o microdatos impiden el uso de técnicas econométricas más complejas. Por otra parte, la ampliación de este trabajo a la esfera internacional resultaría de enorme interés pues mostraría la realidad de la población de personas con discapacidad en diferentes contextos, que podrían servir de referentes, tanto positivos como negativos.

Sin embargo, si bien la ampliación de los horizontes temporal, geográfico y metodológico de esta investigación resulta aconsejable para poder elevar el alcance de nuestros resultados e implicaciones, algunos de los pasos a seguir en el camino hacia la integración plena emergen con claridad a tenor del análisis realizado. De un lado, se confirma el papel de la educación formal como elemento indispensable para aumentar la participación laboral de las personas con discapacidad. Es crucial, por tanto, seguir rompiendo las barreras de acceso al sistema educativo. Del otro, observamos la efectividad de algunas medidas de impulso a la contratación de las personas con discapacidad como la cuota de reserva o la necesidad de cumplir una duración mínima en los contratos específicos para el colectivo para que las empresas contratantes puedan beneficiarse de ciertas ayudas y subvenciones. Seguir apostando por estas y otras medidas se revela como otro de los factores fundamentales en aras de la plena integración. 


\section{Referencias bibliográficas}

Albarrán, I. y Alonso, P. (20I0). "Participación en el mercado laboral español de las personas con discapacidad y en situación de dependencia”. Papeles de Población I6 (64): 217-256.

Comisión Europea, COM (2010) 636. Estrategia Europea sobre Discapacidad 2010-2020: un compromiso renovado para una Europa sin barreras.

Malo, M. A. (2003). "Las personas con discapacidad en el mercado de trabajo español". Revista del Ministerio de Trabajo y Asuntos Sociales 46, 99-I 26.

Pagán, R. y Marchante, A. J. (2004). “Análisis de las diferencias salariales por discapacidad en España: el caso de los varones”. Hacienda
Pública Española / Revista de Economía Pública I7I(4), 75-100.

Villa-Fernández, N. (2003). "Situación laboral de las personas con discapacidad en España”. Revista Complutense de Educación I4(2), 393424.

Verdugo, M. A. et al. (2007). Report on the employment of disabled people in European countries. Country: Spain. Academic Network of European Disability experts (ANED) $\mathrm{VT} / 2007 / 005$.

Vicente-Herrero, M. T. et al. (2010). "Minusvalía, discapacidad e incapacidad. Una revisión desde la legislación española”. SEMERGEN Medicina de familia 36(8), 456-46I. 


\section{Anexo}

Tabla A.1. Cuadro resumen de normativa vigente sobre bonificaciones y reducciones a la contratación laboral y medidas de fomento al empleo por cuenta propia de discapacitados, Febrero 2014

\begin{tabular}{|c|c|c|c|c|c|c|c|c|c|c|c|}
\hline $\begin{array}{l}\text { Tipo } \\
\text { Contrato }\end{array}$ & \multicolumn{5}{|l|}{ Colectivos } & \multicolumn{2}{|c|}{ Cuantía Anual } & Duración & \multicolumn{2}{|c|}{$\begin{array}{l}\text { Vigencia de } \\
\text { la medida }\end{array}$} & Normativa \\
\hline \multirow{7}{*}{$\begin{array}{l}\frac{0}{0} \\
\frac{0}{ \pm} \\
\frac{0}{0} \\
\underline{\underline{D}}\end{array}$} & \multirow{2}{*}{\multicolumn{2}{|c|}{$\begin{array}{l}\text { Menores de } 45 \\
\text { años }\end{array}$}} & \multicolumn{3}{|l|}{ En general } & \multicolumn{2}{|l|}{$4.500 €$} & \multirow{7}{*}{$\begin{array}{l}\text { Toda la } \\
\text { vigencia del } \\
\text { contrato }\end{array}$} & \multirow{7}{*}{\multicolumn{2}{|c|}{ Indefinida }} & \multirow{8}{*}{$\begin{array}{l}\text { Ley } \\
43 / 2006\end{array}$} \\
\hline & & & \multicolumn{3}{|c|}{ Discapacidad severa (1) } & \multicolumn{2}{|l|}{$5.100 €$} & & & & \\
\hline & \multirow{2}{*}{\multicolumn{2}{|c|}{ Mujeres }} & \multicolumn{3}{|l|}{ En general } & \multicolumn{2}{|l|}{$5.350 €$} & & & & \\
\hline & & & \multicolumn{3}{|c|}{ Discapacidad severa } & \multicolumn{2}{|l|}{$5.950 €$} & & & & \\
\hline & \multirow{2}{*}{\multicolumn{2}{|c|}{$\begin{array}{l}\text { Mayores de } 45 \\
\text { años }\end{array}$}} & \multicolumn{3}{|c|}{ En general } & \multicolumn{2}{|l|}{$5.700 €$} & & & & \\
\hline & & & \multicolumn{3}{|c|}{ Discapacidad severa } & \multicolumn{2}{|l|}{$6.300 €$} & & & & \\
\hline & \multicolumn{5}{|c|}{$\begin{array}{l}\text { * Contratación de un trabajador con discapacidad } \\
\text { por un C.E.E.(2) (Relación de carácter especial) }\end{array}$} & \multicolumn{2}{|c|}{$\begin{array}{l}\text { * } 100 \% \text { Cuotas Empresariales } \\
\text { por todos los conceptos }\end{array}$} & & & & \\
\hline 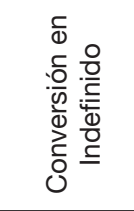 & \multicolumn{5}{|c|}{$\begin{array}{l}\text { * Conversión de contratos temporales de fomento } \\
\text { del empleo, así como de contratos formativos en } \\
\text { las empresas ordinarias } \\
\text { * Conversión de todos los contratos temporales } \\
\text { en C.E.E. }\end{array}$} & \multicolumn{5}{|c|}{$\begin{array}{l}\text { * Mismo régimen que las contrataciones indefinidas } \\
\text { iniciales } \\
\text { * } 100 \% \text { de las cuotas empresariales a la S. S. por todos los } \\
\text { conceptos y cuotas de recaudación en conjunto (C.E.E.) }\end{array}$} & \\
\hline \multirow{12}{*}{ 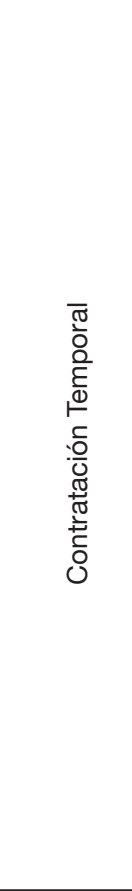 } & \multirow{2}{*}{$\begin{array}{l}\text { Contratos } \\
\text { formativos }\end{array}$} & $\begin{array}{l}\text { En } \\
\text { apre } \\
\text { la re }\end{array}$ & $\begin{array}{l}\text { ácticas y para f } \\
\text { hdizaje. (si no se } \\
\text { ducción de la Le }\end{array}$ & $\begin{array}{l}\text { ormación } \\
\text { ha optad } \\
\text { 3/2012) }\end{array}$ & $\begin{array}{l}\text { el } \\
\text { por }\end{array}$ & \multicolumn{2}{|c|}{$\begin{array}{l}50 \% \text { cuota empresarial por } \\
\text { contingencias comunes }\end{array}$} & $\begin{array}{l}\text { Toda la } \\
\text { vigencia del } \\
\text { contrato }\end{array}$ & Indefinida & ET & $\left(\right.$ D.A. $\left.2^{\mathrm{a}}\right)$ \\
\hline & & $\begin{array}{l}\text { Par } \\
\text { el a }\end{array}$ & $\begin{array}{l}\text { la formación y } \\
\text { rendizaje (3) }\end{array}$ & & & \multicolumn{2}{|c|}{$\begin{array}{l}\text { Reducción } 75 \% \text { o del } \\
100 \% \text { de las cuotas del } \\
\text { empresario(4) }\end{array}$} & $\begin{array}{l}\text { Toda la } \\
\text { vigencia del } \\
\text { contrato }\end{array}$ & Indefinida & Les & 3/2012 \\
\hline & \multicolumn{5}{|c|}{$\begin{array}{l}\text { Contratos de interinidad con desempleados } \\
\text { con discapacidad para sustituir a trabajadores } \\
\text { con discapacidad en situación de incapacidad } \\
\text { temporal }\end{array}$} & \multicolumn{2}{|c|}{$100 \%$ Todas las aportaciones } & $\begin{array}{l}\text { Toda la } \\
\text { vigencia del } \\
\text { contrato }\end{array}$ & Indefinida & & $\begin{array}{l}45 / 2002 \\
\left.\text { A. } 9^{a}\right)\end{array}$ \\
\hline & \multicolumn{5}{|c|}{$\begin{array}{l}\text { Contratación de un trabajador con discapacidad } \\
\text { por un C.E.E. (relación de carácter especial) }\end{array}$} & $100 \%$ Todas & s las aportaciones & $\begin{array}{l}\text { Toda la } \\
\text { vigencia del } \\
\text { contrato } \\
\end{array}$ & Indefinida & Les & 43/2006 \\
\hline & & & & & Menc & pres 45 años & $3.500 €$ & & & & \\
\hline & & & & varomes & Mayo & res 45 años & $4.100 €$ & & & & \\
\hline & & & 다 & $\Lambda$ & Menc & pres 45 años & $4.100 €$ & & & & \\
\hline & temporal & & & IVIu & Mayo & res 45 años & $4.700 €$ & Toda la & & & 43/2006 \\
\hline & fomento de & & & Varones & Menc & ores 45 años & $4.100 €$ & $\begin{array}{l}\text { Vigencia del } \\
\text { contrato }\end{array}$ & a & (D. & A. 1a) \\
\hline & & & Discapacidad & varutes & Mayo & res 45 años & $4.700 €$ & & & & \\
\hline & & & severa & & Menc & pres 45 años & $4.700 €$ & & & & \\
\hline & & & & Iviujeres & Mayo & res 45 años & $5.300 €$ & & & & \\
\hline
\end{tabular}




\begin{tabular}{|c|c|c|c|c|c|c|}
\hline $\begin{array}{l}\text { Tipo } \\
\text { Contrato }\end{array}$ & \multicolumn{2}{|c|}{ Colectivos } & Cuantía Anual & Duración & $\begin{array}{l}\text { Vigencia de } \\
\text { la medida }\end{array}$ & Normativa \\
\hline \multirow{2}{*}{ 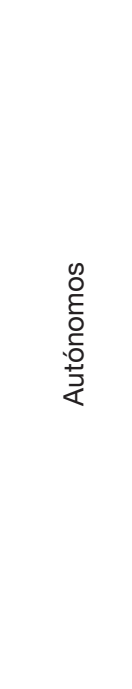 } & \multirow{2}{*}{ 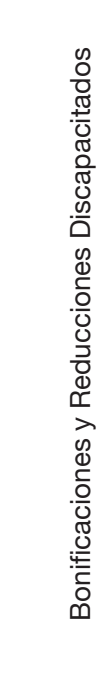 } & $\begin{array}{l}\text { Personas con un grado } \\
\text { de discapacidad igual } \\
\text { o superior al } 33 \% \text { que } \\
\text { causen alta inicial en } \\
\text { el R.E. de trabajadores } \\
\text { por cuenta propia o } \\
\text { Autónomos }\end{array}$ & $\begin{array}{l}\text { * Reducciones y } \\
\text { bonificaciones sobre la cuota } \\
\text { por contingencias comunes } \\
80 \% \text { durante } 6 \text { meses } \\
\text { (reducción) } \\
\text { * } 50 \% \text { durante } 5 \text { meses } \\
\text { (bonificación) }\end{array}$ & 5 años & & $\begin{array}{l}\text { Ley } \\
45 / 2012 \\
\left(\text { D.A. } 11^{a}\right)\end{array}$ \\
\hline & & $\begin{array}{l}\text { Personas con un grado } \\
\text { de discapacidad igual } \\
\text { o superior al } 33 \% \text { que } \\
\text { causen alta inicial o } \\
\text { no hubieran estado } \\
\text { dados de alta en los } 5 \\
\text { años inmediatamente } \\
\text { anteriores sin } \\
\text { trabajadores por cuenta } \\
\text { ajena. Menores de } 35 \\
\text { años de edad(5) }\end{array}$ & $\begin{array}{l}\text { * Reducciones y } \\
\text { bonificaciones sobre la cuota } \\
\text { por contingencias comunes } \\
80 \% \text { durante } 12 \text { meses } \\
\text { (reducción) } \\
\text { * } 50 \% \text { durante los } 4 \text { años } \\
\text { siguientes (bonificación) }\end{array}$ & 5 años & & $\begin{array}{l}\text { Ley } \\
45 / 2012 \\
\left(\text { D.A. } 11^{a}\right)\end{array}$ \\
\hline
\end{tabular}

Notas:

(I) Discapacidad severa: Personas con parálisis cerebral, enfermedad mental o discapacidad intelectual igual o superior al $33 \%$ y discapacidad física o sensorial igual o superior al $65 \%$.

(2) Centro Especial de Empleo.

(3) No se aplica límite de edad.

(4) Dependiendo que la plantilla sea inferior a 250 personas ( $100 \%)$ o igual o superior $(75 \%)$.

(5) También será de aplicación a los socios trabajadores de Cooperativas de trabajo Asociado que estén encuadradas en el Régimen Especial de la S. Social de los trabajadores por cuenta propia o autónomos. Fuente: Servicio Público de Empleo Estatal-Ministerio de Empleo y Seguridad Social. 


\section{El empleo de las personas con diversidad funcional en la prensa: ABC y El País $(1978-2012)^{1}$}

\section{Coverage of the employment of people with functional diversity in the press: $\mathrm{ABC}$ and $\mathrm{El}$ País newspapers (1978-2012)}

\begin{abstract}
Resumen
Este artículo presenta los resultados de los análisis realizados en relación con el conjunto de noticias relacionadas con el empleo ordinario y protegido de las personas con diversidad funcional, correspondientes a una muestra seleccionada en los periódicos ABC y El PAÍS entre I978 y 20I 2. El empleo es un tema muy presente en la prensa a través de noticias que ofrecen porcentajes de personas con diversidad funcional desempleadas, historias personales de éxito laboral, la opinión del empresariado, el incumplimiento de la legislación, las reivindicaciones del movimiento asociativo, los centros especiales de empleo, etc. Un argumento comúnmente repetido es la valoración del empleo como medio de integración social y normalización. En una sociedad capitalista esa "normalidad" pasa por producir un valor económico para conseguir un beneficio con el que poder consumir bienes y servicios. Los discursos hallados en las noticias han sido complementados con la legislación más relevante y han sido contrastados con los datos secundarios disponibles en materia de empleo.
\end{abstract}

\section{Palabras clave}

Diversidad funcional, discapacidad, empleo, legislación, medios de comunicación.

\begin{abstract}
This paper presents the results of analyses performed on news articles related to ordinary and protected employment for people with functional diversity in a sample taken from $\mathrm{ABC}$ and El País newspapers between I978 and 20I2. Employment is a common topic covered in the press and present in news that reports on percentages of unemployed people with functional diversity, personal stories of job success, opinions on the business sector, the failure of legislation, demands of associations, and special employment centers. A common theme is employment as a measure of social integration and normalization, which is understood in a capitalist society to mean the ability to produce an economic value to make earnings for acquiring goods and services. The speeches obtained have been supplemented with relevant legislation and have been contrasted with available secondary data on employment.
\end{abstract}

\section{Keywords}

Functional diversity, disability, employment, legislation, media.
I. Este artículo se basa en la comunicación presentada en el Congreso de la Red Española de Política Social, celebrado en Barcelona 5-6 de Febrero de 2015, en el panel "Políticas Sociales y Discapacidad", cuya coordinación estuvo a cargo de Eduardo Díaz y Ángel Belzunegui.

\section{Borja González Luna \\ <bgonlun@gmail.com>}

Universidad Complutense de Madrid

\section{Antonio láñez Domínguez <aiadom@upo.es>}

Universidad Pablo de Olavide, Sevilla
Para citar:

González, B. y Iáñez, A. (20I 5): “El empleo de las personas con diversidad funcional en la prensa: ABC y El País (I978-20I2)", Revista Española de Discapacidad, 3 (I): 57-76.

Doi: <http://dx.doi.org/IO.5569/23405 IO4.03.0I.03>

Fecha de recepción: I2-02-20I5 Fecha de aceptación: OI-O6-20I 5 


\section{Introducción}

La imagen de la diversidad funcional ha sido construida social y culturalmente a lo largo de los años desde diversos espacios (político, legislativo, asociativo, educativo, laboral, académico). En esa construcción, los medios de comunicación -como productores y generadores de estados de opinión- han jugado y juegan un papel importante. Los/as periodistas son conscientes de cómo influyen sus mensajes en la conformación de la idea que tienen las personas sobre un determinado fenómeno. Analizando e interpretando el tratamiento otorgado a la diversidad funcional en ese espacio comunicacional, se puede llegar a conocer cómo ha sido la representación de la misma y su evolución a lo largo del periodo analizado.

La importancia del papel de los medios de comunicación en la construcción de la realidad fue lo que nos llevó a realizar la investigación financiada por la Asociación Roosevelt con motivo de la XII Beca de investigación, que tuvo por objetivo analizar la imagen y el tratamiento dado a la diversidad funcional física en la prensa española, en concreto, a través del análisis de las noticias publicadas en dos periódicos nacionales: ABC y El País, en el periodo comprendido entre I 978 y 2012.

Del conjunto de noticias analizadas (un total de 435), para este artículo se han seleccionado las noticias concernidas con el empleo, relacionándolas con la legislación más relevante en la materia, y contrastándolas con datos secundarios obtenidos de diferentes fuentes documentales y estadísticas. Se quiere, por tanto, mostrar cuál ha sido la presencia de las políticas públicas sobre empleo y diversidad funcional en la prensa en las últimas décadas, a través de los dos periódicos seleccionados. Y cómo se han construido los discursos en torno a su integración laboral, en sentido general. Aunque el objeto y el diseño de la investigación partieron del grupo específico de personas con diversidad física, los resultados se pueden hacer extensibles, en la mayoría de los hechos al resto de diversidades funcionales.
Antes de pasar a exponer la metodología y los resultados, sirva esta introducción para aclarar el uso que hacemos -y que da título al artículodel término diversidad funcional. Tiene su origen en los debates generados entre los/as miembros del Foro de Vida Independiente y Divertad $^{2}$, y surge con la intención de crear un término que evite las connotaciones negativas y peyorativas que contemplan los utilizados hasta ese momento para denominar a este grupo (inválido, inútil, minusválido, discapacitado, etc.). "El término persona con diversidad funcional es definido desde dentro, siendo la primera denominación de la historia en la que no se da un carácter negativo ni médico a la visión de una realidad humana" (Iáñez, 20I0: 62). Según Romañach y Lobato (2005: 4) "el término diversidad funcional se ajusta a una realidad en la que una persona funciona de manera diferente o diversa de la mayoría de la sociedad". Es por todo ello que optamos por este término, aunque mantendremos todos aquellos otros tal cual aparecen en las noticias, las bases de datos, los discursos, etc., con objeto de ser fieles a las referencias que utilizamos y al contexto histórico en el que fueron empleados.

\section{Metodología}

Para realizar el análisis de la "representación de la diversidad funcional física en la prensa” se optó por elaborar una muestra de noticias ${ }^{3}$ de los periódicos nacionales ABC y El País, por considerarse que ambos periódicos representan los diarios de mayor tirada para el periodo analizado que comprende el intervalo de I978 a 2012.

2. Este Foro se crea en el año 200I, como una comunidad virtual que sirve para la reflexión, la ayuda mutua y la construcción de conocimientos acerca de todo lo relacionado con la diversidad funcional.

3. Las unidades de análisis no solo se correspondieron con noticias, en un sentido estricto, también han sido analizados editoriales, artículos de opinión, reportajes, y cartas al director. 
Para la búsqueda y selección de las unidades de análisis hemos utilizado los buscadores con los que cuenta cada periódico en su página web Para usar correctamente dichos buscadores y acercarnos al objeto de estudio de nuestra investigación definimos cuáles podrían ser, según un criterio que tuviera en cuenta la evolución terminológica, los «términos clave» para diversificar la forma de búsqueda a través de dichos buscadores. La idea era que diferentes términos nos remitirían a diferentes momentos históricos que se tenían que ver reflejados en la prensa analizada; los términos utilizados fueron: "disminuidos físicos", "minusválidos físicos", "discapacidad física" y "diversidad funcional". A continuación creamos una tabla con todas las unidades de análisis aparecidas en cada periódico por cada término clave y año, que nos sirvió para establecer la proporción de unidades de análisis que íbamos a seleccionar.

El criterio de selección de dichas unidades consistió en atender a un orden de jerarquía de los diferentes estilos periodísticos: editorial, artículo de opinión, reportaje, crónica y noticia, es decir, cada estilo periodístico, en el orden de jerarquía establecido, funcionaba de filtro para la selección de la cuota correspondiente a cada año. El principio de selección de las unidades de análisis fue optar, en primer lugar, por aquellas unidades de análisis que contienen un mayor contenido discursivo, frente a las noticias, en sentido estricto, que muestran un contenido más descriptivo y objetivista -aunque fueron estas últimas las unidades de análisis que obtuvieron mayor representación-. En el transcurso de la selección, decidimos incorporar también las cartas al director y las entrevistas a personas con diversidad funcional como unidades de análisis "extras", es decir, que no contabilizaron dentro de las cuotas establecidas de forma proporcional. La muestra quedó constituida por un total de 435 noticias: 202 en ABC y 233 en El País.

4. Para ABC: http://www.abc.es/ Para El País: http://elpais. com/
Tabla 1. Unidades de análisis seleccionadas por periódico (cada cuatro años)

\begin{tabular}{|l|c|c|c|}
\hline AÑo & ABC & EL PAís & Total \\
\hline $1978-1981$ & 18 & 13 & 31 \\
\hline $1982-1985$ & 11 & 15 & 26 \\
\hline $1986-1989$ & 28 & 11 & 39 \\
\hline $1990-1993$ & 32 & 11 & 43 \\
\hline $1994-1997$ & 25 & 31 & 56 \\
\hline $1998-2001$ & 23 & 44 & 67 \\
\hline $2002-2005$ & 20 & 38 & 58 \\
\hline $2006-2009$ & 25 & 36 & 61 \\
\hline $2010-2012$ & 20 & 34 & 54 \\
\hline Total & 202 & 233 & 435 \\
\hline
\end{tabular}

Fuente: elaboración propia.

Las noticias fueron analizadas desde dos perspectivas: (I) análisis del contenido y (2) análisis del discurso. Se definieron una serie de categorías específicas para ser identificadas en cada noticia y poder con ello obtener resultados representativos. Las principales categorías fueron: terminología, titular, sección, género periodístico, temática y modelos. El análisis de contenido ha permitido información más cuantitativa, registrándose la información en una base de datos Excel; y el análisis del discurso, utilizando el programa informático Atlas.ti, ha facilitado un análisis cualitativo de las disertaciones realizadas por representantes de entidades del sector, representantes políticos, de sindicatos, de periodistas, etc.

Para este artículo se han seleccionado concretamente todas las unidades de análisis que trataban sobre empleo ordinario y protegido: un total de 52 unidades de análisis. Si bien nuestra investigación ha estado centrada en la diversidad funcional física, un volumen importante de noticias trataba la diversidad funcional de forma genérica, esto es, no se hacía la distinción si era física, intelectual, sensorial y/o mental, sobre todo, cuando las noticias referían a cuestiones legislativas, estadísticas, etc. Es el caso del 
empleo, en el que el contenido de las noticias ha girado en torno a la presentación de las tasas de desempleo en la que se hallaba este grupo, casos particulares de personas que, por el contrario, tienen "éxito" laboral, sobre el incumplimiento de la LISMI, los debates sobre la reserva de cupo, sobre el empresariado, sobre los centros especiales de empleo, etc.

Para ofrecer una mayor consistencia a la información y los discursos hallados en las noticias, hemos recurrido a la legislación más relevante y a fuentes documentales y estadísticas en materia de empleo. En este sentido, queremos señalar que las reflexiones que exponemos a continuación tratan de hacer balance del tratamiento que ha tenido el empleo de las personas con diversidad funcional en la prensa durante las últimas décadas.

\section{Empleo ordinario en empresas privadas y públicas}

Para concretar mejor el análisis de las noticias seleccionadas en relación con el empleo ordinario hemos organizado la información en tres subapartados que comprenden la década de los 80 y 90 del siglo XX y primera década del siglo XXI.

\subsection{Década de los 80}

La década de los 80 se abre, en España, con una tasa de paro del I I, I \% de la población activa total, alcanza su máximo en 1985 con una tasa del 2 I \%, y dicha década se cierra con un I $7 \%$. En esta década, en algunas ofertas de trabajo se puede leer: "se excluirá todo aquel que reúna impedimento físico o psíquico"s.

5. "Los minusválidos y su conflictiva integración en las ciudades" (ABC 25/07/1982).
La primera noticia, en relación con el empleo, aparece el 22 de Febrero de $1979^{6}$. Este es un momento en el que sucede la reestructuración de organismos, instituciones y ministerios del Estado como consecuencia de las transformaciones democráticas que acontecen en España. Se disuelve la Asociación Nacional de Inválidos Civiles (ANIC) y sus trabajadores pasan a formar parte del Servicio de Recuperación y Rehabilitación de Minusválidos (SEREM) de la Seguridad Social. En dicho contexto de reestructuración del Estado español se aprobará la Ley de Integración Social de los Minusválidos, conocida con las siglas LISMI, el 7 de Abril de 1982, que será el texto de referencia en materia laboral durante las décadas de los 80 y 90 .

Durante la década de los 80 aparece reflejado en la prensa un conflicto en relación con la aparición de nuevas entidades que quieren gestionar cupones de lotería como forma de integración laboral. La ONCE se opone a que existan nuevas entidades que gestionen un nuevo cupón de loterías:

"El Consejo General de la Organización Nacional de Ciegos y la Coordinadora Estatal de Minusválidos Físicos han denunciado al Gobierno el desarrollo de formas fraudulentas del juego, así como la explotación de minusválidos y la insuficiencia del marco jurídico para paliar estos problemas” ${ }^{7}$.

En I986 acontece la desmantelación de la Red de Loterías de PRODIECU (Promoción y Difusión de Entidades Culturales) y APEM (Asociación para Promoción del Empleo al Minusválido). Según Pedro Fuentes, Jefe de prensa de PRODIECU y APEM:

"Dichas entidades no se fundaron con ánimo de ilegalidad, pues desde el mismo momento de su creación solicitaron el oportuno permiso de Loterías, primero en la Generalidad

6. Todas las noticias seleccionadas en el periódico El País durante la década de los 80 se corresponden con noticias sobre empleo protegido.

7. "La Once y los minusválidos denuncian las rifas ilegales" $\left(\mathrm{ABC}_{3} / \mathrm{IO} / \mathrm{I}_{985}\right)$. 
de Cataluña, después en los Ministerios pertinentes, pero siempre se les ha ido denegando" ${ }^{8}$.

En ese mismo año, el 24 de Abril, un periodista de ABC en la sección Zigzag, sección de opinión, plantea si los rumores que existen en relación con la posibilidad de que las personas con diversidad funcional física vendan tabaco en las calles no están relacionados con el conflicto antes mencionado:

"Aunque por el momento no lo confirman todas las fuentes consultadas, parece que el Gobierno está dispuesto a conceder a los disminuidos físicos la exclusividad de la venta de tabaco en la calle. Puede haber sido el controvertido sorteo de los minusválidos lo que haya propiciado este gesto de la administración"

El 24 de Diciembre de 1987 trabajadores de la ONCE se manifestaron contra la legalización de un cupón para las personas con diversidad funcional física. Las concentraciones fueron convocadas por UTO, sindicato mayoritario en la Organización Nacional de Ciegos:

“José Ignacio Rodríguez Rodríguez, secretario general de UTO-Madrid, manifestó que rechazaban la creación de nuevos cupones, ya que ello pondría en peligro la estabilidad de los puestos de trabajo de la ONCE, así como supondría un gran riesgo para la entidad. [...] Asimismo señaló que de los dos mil quinientos vendedores de cupones que hay en estos momentos en la Comunidad de Madrid, trescientos de ellos son minusválidos físicos" ${ }^{\circ}$.

Un hecho a destacar, quizás como consecuencia de los debates que se generaron, es la creación de la Fundación ONCE en I988:

"Esta nueva institución se configura como una entidad de ámbito estatal en las que

8. "Cupón del minusválido" (ABC 27/02/I986). 9. "Minusválidos" (ABC 24/04/I986).

Io. "Trabajadores de la Once rechazan la creación de un nuevo cupón para minusválidos" (ABC 24/I 2/I987). están representadas, además de la ONCE, las principales federaciones de minusválidos físicos, psíquicos y sordos. La Organización Nacional de Ciegos de España es la principal fuente de financiación de la Fundación, que recibe el 3 por roo de la venta del cupón para el desarrollo de proyectos en colaboración con centros, asociaciones, empresas y personas individuales" ${ }^{\mathrm{I}}$.

En 1991, La Asociación de Minusválidos Españoles (AME) anunció su intención de proceder a la recogida de firmas necesarias para llevar al Parlamento la solicitud de que «la ONCE se transforme en una entidad abierta al grueso de los minusválidos físicos trabajadores en esa entidad para que puedan participar en sus órganos de administración, dirección y gestión en igualdad de derechos con los afiliados a esa Organización»:

"En su comunicado, la AME recuerda que en el primer Consejo de Ministros del nuevo Gabinete se aprobó el real decreto 358/9I, de 15 de marzo, sobre reestructuración de la Organización Nacional de Ciegos, en el que «se sanciona definitivamente el monopolio antijurídico y antisocial que supone la tenencia en exclusiva de un cupón a favor del colectivo de invidentes, relegando cualquier referencia a otros colectivos de disminuidos a una pobre y desafortunada redacción, párrafo en el que se señala que la ONCE podrá formalizar convenios con el Ministerio de Trabajo para la atención de otros minusválidos. Esto nos hace suponer que el nuevo Gobierno se dispone a seguir en la línea de favorecer a una Organización hoy convertida en un poder fáctico propio de una multinacional»" ${ }_{\text {I2 }}$.

Una respuesta realizada por un portavoz de la ONCE en dicha noticia dice lo siguiente:

"La ONCE absorbió a 7.808 vendedores de

Prodiecu en julio de I988 y otros minusválidos

I I. "Crear empleo para minusválidos, objetivo de la Fundación ONCE” (ABC I $5 / 09 /$ I 988 ). I2. "Los minusválidos españoles quieren que la ONCE se transforme en una entidad abierta" (ABC 26/03/I99I). 
que se incorporaron en aquel momento por tener un grado de minusvalía superior al $30 \%$, el mínimo exigible por el INSERSO. Ese mismo año se creó la Fundación ONCE, dirigida especialmente a fomentar el empleo de minusválidos no ciegos.

En cuanto a la participación de minusválidos físicos en los órganos de difusión de la Organización, el portavoz subraya que sólo tienen entrada en los mismos los afiliados, «que son invidentes porque se trata precisamente de la Organización Nacional de Ciegos de España»" ${ }^{13}$.

Lo que acontece detrás de este conflicto es la gestión de las Loterías del Estado como un poderoso medio de financiación. Pero además, la defensa de un modelo de integración laboral, que perdura en nuestros días, y que tiene sus raíces en el tardo-franquismo. Es un modelo de integración que nace de la beneficencia, aunque el trabajo de vendedor de lotería no lo consideramos como tal, y que situamos en las representaciones sociales anteriores a la Ley de Integración Social del Minusválido. El conflicto narrado muestra la existencia de unos actores en pugna como evidencia de las re-configuraciones que acontecieron en el campo de la diversidad funcional (Ferreira, 2010) durante los 80 en España.

En un memorándum presentado, en el año I986, por la Comisión de las Comunidades Europeas al Consejo de Ministros de la CEE se plantea que "el problema del empleo y el desempleo de los minusválidos presenta gran complejidad. [...] La Comisión considera esencial dar mayor importancia a la capacidad de los minusválidos y subrayar que incluso las deficiencias más graves suponen una limitada serie de minusvalías" ${ }^{{ }^{4} 4}$. Veintiún millones de europeos en edad laboral, equivalentes a un ro \% de la población total, son personas con diversidad funcional según el estudio presentado por la Comisión de las Comunidades Europeas al Consejo de Ministros de la CEE.

I3. "La respuesta de la ONCE" (ABC 26/03/I99I). I 4. "CEE: Igualdad de oportunidades para los minusválidos" (ABC I4/og/I986).
Según las recomendaciones de dicha Comisión, los países miembros deberían establecer en unos compromisos numéricos la contratación de estas personas en empresas públicas y privadas. Esos compromisos numéricos ya fueron definidos en el texto de la LISMI (I982) ${ }^{\mathrm{I}}$ :

“Art. 38. Uno. Las empresas públicas y privadas que empleen un número de trabajadores fijos que exceda de cincuenta vendrán obligadas a emplear un número de trabajadores minusválidos no inferior al dos por ciento de la plantilla."

Además, dicha Ley establece, en su artículo I 2 (I), un sistema especial de prestaciones sociales y económicas para dichas personas que por no desarrollar una actividad laboral no estén incluidos en el campo de aplicación del sistema de la Seguridad Social. Además, la propia Ley prevé que:

Art. 4I. Uno. Los minusválidos que por razón de la naturaleza o de las consecuencias de sus minusvalías no puedan, provisional o definitivamente, ejercer una actividad laboral en las condiciones habituales, deberán ser empleados en Centros Especiales de Empleo, cuando su capacidad de trabajo sea igual o superior a un porcentaje de la capacidad habitual que se fijará por la correspondiente norma reguladora de la relación laboral de carácter especial de los trabajadores minusválidos que presten sus servicios en Centros Especiales de Empleo.

Art. 4I. Dos. Cuando la capacidad residual de los minusválidos no alcanzara el porcentaje establecido en el apartado anterior accederán en su caso a los Centros Ocupacionales previstos en el título VIII de esta Ley.

I 5. El Real Decreto I45I/I983, de I I de mayo, por el que en cumplimiento de lo previsto en la Ley I3/I982, de 7 de abril, se regula el empleo selectivo o las medidas de fomento del empleo de los trabajadores minusválidos, impone la obligatoriedad de reservar el $2 \%$ de los puestos de trabajo en las empresas con más de cincuenta empleados para personas con diversidad funcional. Y en relación con el empleo en las administraciones públicas, la Ley 30/I984 de Medidas para la Reforma de la Función Pública, establece, en su artículo I9, una reserva del $3 \%$ en las ofertas de empleo público. 
Art. 53. Uno. Los Centros Ocupacionales tienen como finalidad asegurar los servicios de terapia ocupacional y de ajuste personal y social a los minusválidos cuya acusada minusvalía temporal o permanente les impida su integración en una Empresa o en un Centro Especial de Empleo.

Pero el informe de la Comisión Europea platea un abanico más amplio de temas que va más allá de la reserva de cuotas: los avances tecnológicos como una esperanza y una amenaza, programas de desarrolla regional, iniciativas locales, cooperativas o pequeñas y medianas empresas, proyectos de formación para la creación de sus propios negocios, nuevos sistemas telefónicos, la jornada parcial, fondos públicos para la contratación y la formación específica, para la adecuación de la maquinaria, acceso al lugar de trabajo y costes suplementarios de personal, y consideraciones entorno al sistema de Seguridad Social.

Durante los 80 , observamos como la falta de aplicación, principalmente, de la cuota del $2 \%$ en empleo privado y del $3 \%$ en empleo público generará diferentes protestas y reivindicaciones desde el movimiento asociativo. En palabras de Matías Sainz, el presidente de la Coordinadora de Minusválidos Físicos de Cantabria, en I988:

\footnotetext{
"Sabemos que es una utopía el pleno empleo para todos los minusválidos, pero hay una ley de integración social del disminuido, y el primero que la incumple es el Gobierno. Un estudio señala que si el 2 por Ioo de los puestos de trabajo de la Administración estuviera ocupado por minusválidos, en tres años, el 80 por Ioo de este grupo estaría empleado" ${ }^{16}$.
}

\subsection{Década de los 90}

En la década de los 90 la tasa de paro en nuestro país alcanzará unos porcentajes históricos siendo del $22,4 \%, 23,9 \%, 22,7 \%, 22 \%$, y $20,6 \%$ en

I6. "Acusan al Gobierno de incumplir la ley de integración social del minusválido” (ABC Io/I I/I988). el arco que va de I993 a I997, respectivamente. La década se cierra con un descenso de dicha tasa que alcanza, en 1999, un I 5,6\%. La tasa de paro para el conjunto de personas con diversidad funcional, en I999, fue del 26, I \% $(\text { IO,5 puntos por encima de la población total })^{17}$.

Un acontecimiento relevante que reconfigura, una vez más, el campo de la diversidad funcional es la creación del CERMI (Comité Español de Representantes de Minusválidos) en el año I993. El CERMI adquirió personalidad jurídica el 9 de enero de I997, como una asociación de ámbito estatal creada al amparo de la Ley de Asociaciones de 1964. Sin embargo, por vía de hecho, el CERMI nació ya en I993, fruto del acuerdo de las seis principales organizaciones de ámbito estatal de personas con diversidad funcional (COCEMFE, FEAPS, CNSE, FIAPAS, ASPACE y ONCE), proyecto al que fueron sumándose otras entidades representativas.

En I994, coincidiendo con el Día Internacional de las Personas con Discapacidad, aparece tanto en ABC como en El PAÍs dos noticias donde la Confederación Coordinadora Estatal de Minusválidos Físicos de España (COCEMFE) hace público un manifiesto en el que informa de que son más de un millón las familias españolas que conviven con una persona con diversidad funcional física, de los que sólo un Io por ıoo dispone de un puesto de trabajo y menos de un tercio tiene algún tipo de pensión o subsidio ${ }^{\text {I8 }}{ }^{\text {19}}$.

Estamos ante algunas de las consecuencias de la LISMI, es decir, las medidas que dicha Ley establece en materia de empleo-que hemos enumerado en apartado anterior-. Por un lado, como veremos, las cuotas establecidas para la integración laboral en empleos ordinarios no se están cumpliendo 20 . Por otro lado, las pensiones

I7. Encuesta sobre Discapacidades y Deficiencias, I999. I 8. "Un millón de minusválidos físicos pide más atención social y laboral" (ABC 04/I2/I994).

I9. "Los discapacitados reclaman más ayudas y trabajo" (EL PAÍS 04/I 2/I994).

20. También es importante aclarar que en España no predominan empresas con plantillas superiores a 50 trabajadores. Más bien sucede lo contrario, es decir, tienen mayor presencia las pequeñas y medianas empresas que suelen tener plantillas inferiores a 50 trabajadores. 
y subsidios reconocidos en dicha ley no alcanzan a toda la población considerada (muchos y muchas no tienen el certificado que reconoce su diversidad funcional) y en la mayoría de los casos, dichas pensiones, no alcanzan el salario mínimo interprofesional.

En 1994 el número de personas con diversidad funcional física ronda el millón de habitantes, de los cuales I 24.970 personas ( I 2,5\%) cobran una pensión no contributiva por invalidez -lo que supuso un gasto bruto para el Estado, a Octubre de I994, de 5.OI4 millones de pesetas (30 millones de euros aproximadamente)-. En I996, el índice de paro entre las personas con diversidad funcional física es del $67 \%{ }^{21}$. En este contexto, la plataforma PREDIF (Plataforma Representativa Estatal de Personas con Discapacidad Física) va a proponer un discurso diferente a la LISMI. PREDIF propone una argumentación que se apoya en un análisis microeconómico del gasto que supone para el Estado una pensión no contributiva y el ahorro que supone mantener a una persona empleada. Llegan a la conclusión de un ahorro para el Estado de 9I4.000 pesetas al año por cada persona con diversidad funcional empleada (actualmente: 5.493,25 euros) ${ }^{22}$.

En I995 COCEMFE pidió al Gobierno -con motivo de la celebración del Día Internacionalque apruebe un plan de acción para personas con diversidad funcional. COCEMFE instó al Gobierno y a las Administraciones autonómicas a activar las medidas necesarias, para mejorar el sistema de contratación de dichas personas, puesto que la integración laboral «es la piedra angular de la normalización» ${ }^{23}$. También pidió al Parlamento la modificación de la Ley de Pensiones no Contributivas, ya que su contenido «no respeta al discapacitado físico como persona individual $»^{24}$.

2I. "El índice de paro entre los minusválidos físicos se acerca al 70 por ciento" (ABC 02/04/1996).

22. Una argumentación similar la veremos en la crítica del Foro de Vida Independiente en relación con el coste-plaza de una persona en una residencia y el presupuesto que esa misma persona necesita para contratar a un asistente personal. 23. "La COCEMFE pide al Gobierno la aprobación inmediata del plan de acción para los discapacitados" (EL PAIS 03/I 2/I995).

24. "La COCEMFE pide al Gobierno la aprobación inme-
Existe un modelo, que vincula educación-empleointegración. Este modelo se ha defendido durante mucho tiempo y se sigue defendiendo. Pero en la actualidad, algunas autores, empiezan a ser críticos con un eje tan lineal. Por ejemplo, Abberley (I998) plantea si la utopía de la integración a través del trabajo no encierra una cierta trampa y plantea qué pasa con aquellas personas que no son capaces de producir valor económico. Por su parte, Díaz Velázquez (20I0), desde el marco teórico de la ciudadanía, va a plantear que más allá de las dimensiones de la producción y el consumo existen otras áreas de la vida en la que las personas con diversidad funcional están excluidas (participación política, cultura, ocio, relaciones sociales, sexualidad, etc.).

En I997, el ministro de Trabajo Javier Arenas, junto con miembros del CERMI presentan a la Reina Doña Sofía un plan de empleo para personas con diversidad funcional ${ }^{25}$ que entre las principales medidas que contempla está hacer cumplir las famosas cuotas del $2 \%$ para las empresas privadas y del $3 \%$ para empresas públicas. En I998, coincidiendo con el día internacional de las personas con diversidad funcional, Javier Arenas anuncia sanciones para las empresas que no cumplan con dichos $\operatorname{cupos}^{26}$.

"Según Arenas «la autentica integración social de los disminuidos no se producirá hasta que no haya tenido lugar su integración laboral»" ${ }^{27}$.

Una vez más vemos repetidos los mismos hechos y discursos: falta de aplicación de las medidas legislativas contempladas en la LISMI y la defensa de la integración laboral como principal vía para la integración social. Un ejemplo más lo encontramos en una noticia que nos habla de la Confederación Andaluza de Minusválidos Físicos:

diata del plan de acción para los discapacitados" (EL PAIS 03/I 2/I995).

25. "Arenas presenta a la Reina el plan de empleo para discapacitados" (ABC 04/I I/I997).

26. "Siete de cada diez minusválidos en edad laboral están en paro” (EL PAÍS 04/I 2/I 998 ).

27. "Arenas presenta a la Reina el plan de empleo para discapacitados” (ABC 4/I I/I997). 
"Hoy por hoy, entre un $60 \%$ y $70 \%$ de los discapacitados no tienen empleo. El año pasado la CAMF recibió más de 200 millones del Instituto Andaluz de Servicios Sociales para el desarrollo de proyectos de formación y de empleo" ${ }^{28}$.

En la década del 2000 nacerá el Foro de vida independiente y las Oficinas de Vida Independiente, volviendo a reconfigurar el campo de la diversidad funcional y los discursos que obtienen mayor legitimidad. Comenzarán a aparecer críticas al gasto que implica las estructuras organizativas del movimiento asociativo de corte más tradicional, a la institucionalización en residencias y se defenderá la figura del «asistente personal». En este sentido, las Oficinas de Vida Independiente han denunciado el fracaso parcial de gastos en formación y estructuras organizativas, y defienden que la mayor parte del presupuesto asignado y recaudado debería ir destinado a programas de vida independiente que permitan a las personas con diversidad funcional disfrutar de los recursos comunitarios existentes.

Por otro lado, otra parte del movimiento asociativo sigue defendiendo la necesidad de recursos específicos ante la insuficiencia e ineficacia de los recursos comunitarios. Un ejemplo lo vemos en el texto de la siguiente noticia:

"Las medidas que lleva a cabo la Consejería de Economía [de la Comunidad de Madrid] a favor de las personas con discapacidad son insuficientes para la Federación de Asociaciones de Disminuidos Físicos de la Comunidad (FAMMA): «No realiza ninguna política activa de empleo y, además, sustituye los Servicios de Integración Laboral por pobres acciones de orientación que no contribuyen a los objetivos de la inserción laboral $»^{29}$.

28. "La Confederación de Minusválidos creará este año un millar de empleos" (EL PAÍ́S 24/04/I998).

29. "Los discapacitados critican la falta de políticas de empleo de la Comunidad de Madrid" (ABC 21/05/200I).

\subsection{Primera década del 2000}

La primera década del nuevo milenio se abrirá con un descenso prolongado de la tasa de paro que en su primer año se sitúa en el I 3,9\% (este descenso es una tendencia que se inicia en I998) y que culmina en el año 2007 (un año antes de la crisis económica internacional) con una tasa de paro del 8,3\%. En 2008, la tasa volverá a subir hasta el I I, 3 \%; en 2009, se disparará al I $8 \%$; en 20 IO alcanza nuevamente el límite del $20 \%$; y en 20 I 2 , se sitúa en el $25 \%$ (el porcentaje más alto del periodo analizado $)^{30}$. Para las personas con diversidad funcional legalmente reconocidas, en 2012 , la tasa de paro fue de 8 , I puntos superior, es decir, del $33, \mathrm{I} \%$.

La constatación del insuficiente grado de cumplimiento de la cuota del $2 \%-y$ otros intereses que este estudio no puede poner de manifiesto- dio lugar al establecimiento de medidas alternativas y mecanismos de control. Esta necesidad se hizo pública, por primera vez, en el año I 997 cuando se aprobó un plan específico a favor de la ocupación de las personas con diversidad funcional, con el objetivo de poner en práctica una serie de medidas urgentes para la promoción de la ocupación de estas personas. Pero no fue hasta el año 2000, mediante el Real Decreto 27/2000 de $\mathrm{I} 4$ de enero ${ }^{3 \mathrm{I}}$, cuando las empresas obligadas a cumplir el $2 \%$ pueden empezar a aplicar las medidas alternativas siguientes (artículo 2):

- Realización de un contrato mercantil o civil con un centro especial de empleo, o con un trabajador autónomo discapacitado, para el suministro de materias primas, maquinaria, bienes de equipo, o de cualquier otro tipo de bienes necesarios para el normal desarrollo de la actividad de la empresa que opta por esta medida.

30.Fuente: Banco Mundial. Databank (http://data.worldbank. org/).

3I. Real Decreto 27/2000, de I4 de enero, por el que se establecen medidas alternativas de carácter excepcional al cumplimiento de la cuota de reserva del 2 por 10 on favor de trabajadores discapacitados en empresas de 50 o más trabajadores. 
- Realización de un contrato mercantil o civil con un centro especial de empleo, o con un trabajador autónomo discapacitado, para la prestación de servicios ajenos y accesorios a la actividad normal de la empresa.

- Realización de donaciones y de acciones de patrocinio, siempre de carácter monetario, para el desarrollo de actividades de inserción laboral y de creación de empleo de personas con discapacidad, cuando la entidad beneficiaria de dichas acciones de colaboración sea una fundación o una asociación de utilidad pública cuyo objeto social sea, entre otros, la formación profesional, la inserción laboral o la creación de empleo en favor de los minusválidos que permita la creación de puestos de trabajo para los mismos $\mathrm{y}$, finalmente, su integración en el mercado de trabajo.

Estas medidas se vieron ampliadas con la regulación de los enclaves laborales, cuyo Real Decreto 290/2004 ${ }^{32}$ contempla entre sus objetivos facilitar a las empresas el cumplimiento de la cuota de reserva legal del $2 \%$. Los enclaves laborales se entienden como una subcontratación de obras o servicios entre un centro especial de empleo y una empresa ordinaria, siendo una medida de utilidad para favorecer el tránsito desde el empleo protegido al empleo ordinario.

En relación con el empleo público, el Real Decreto 227I/2004, de 3 de diciembre, aumentaba la cuota del $3 \%$ al $5 \%$. Posteriormente será modificada por la Ley 7/2007, de I2 de Abril, del Estatuto Básico del Empleo Público, donde se establece en su artículo 59 que en las ofertas de Empleo Público se reservará un cupo no inferior al $7 \%$.

En 2006, aparece en El PAÍS una noticia que vuelve a poner de relieve el incumplimiento por parte de las empresas de las cuotas establecidas:

32. Real Decreto 290/2004, de 20 de febrero, por el que se regulan los enclaves laborales como medida de fomento del empleo de las personas con discapacidad.
"Un total de 360 compañías de más de 50 trabajadores fueron investigadas en Cataluña al haberse detectado que incumplían la ley. De ellas, I 80 seguían vulnerando la norma pese al requerimiento de los inspectores. A causa de las actuaciones de Inspección de Trabajo, las empresas investigadas contrataron a 200 discapacitados o adoptaron alguna de las medidas alternativas que prevé la ley, como la contratación de servicios a centros especiales de ocupación" ${ }^{33}$.

En el último año del periodo analizado, 20I2, volvemos a observar como los incumplimientos de la LISMI, treinta años después de su aprobación, sigue siendo uno de los temas más recurrentes entre la administración y el movimiento asociativo:

"Ana Mato, Ministra de Sanidad, Igualdad y Servicios Sociales dice que «promoverá medidas como el cumplimiento de esta reserva del $2 \%$ y otras como contratos en el sector público" ${ }^{34}$.

"COCEMFE «advierte de que son necesarias aumentar las inspecciones»" ${ }^{35}$.

Seis días después del anuncio de la Ministra Ana Mato aparece una nueva noticia en $\mathrm{ABC}$ :

"Los inspectores de Trabajo se van a encargar de velar por que las empresas de más de 50 trabajadores cumplan con la ley vigente y reserven un $2 \%$ de sus puestos de trabajo a personas con algún tipo de discapacidad. Según informó a $\mathrm{ABC}$ el nuevo director general de Discapacidad, Ignacio Tremiño, desde el Ministerio de Sanidad, Igualdad y Servicios Sociales ya se está trabajando con el de Trabajo para que sus inspectores se involucren en esta tarea" ${ }^{36}$.

33. "Ocho de cada diez empresas incumplen la obligación de contratar a discapacitados" (EL PAIS 26/02/2006).

34. "Si me contratas te demostraré que tengo más ganas que nadie" (ABC 24/OI/20I2).

35. "Si me contratas te demostraré que tengo más ganas que nadie" ( $\mathrm{ABC} 24 / 0 \mathrm{I} / 20 \mathrm{I} 2$ ).

36. "Los inspectores de trabajo obligarán a contratar el $2 \%$ de discapacitados" (ABC 30/OI/20I2). 
En un informe realizado por la Organización Mundial de la Salud, en 2002, se destaca en relación con el empleo que:

\footnotetext{
"Las personas con discapacidad tienen entre dos y tres veces más posibilidades de estar desempleadas. Por ello, la deteriorada situación económica que sufren muchas de ellas está vinculada al difícil acceso que tienen al mundo laboral.
}

Una situación que se produce debido a una combinación de factores, entre los que se incluyen unos niveles formativos inferiores -muchos no poseen formación reglada alguna- así como una serie de prejuicios, como que no trabajan, que no pueden tener especialización o que sólo pueden desempeñar empleos marginales. Además, el informe señala que son contratadas para empleos en los que se les paga menos y en los que tienen pocas posibilidades de promoción profesional.

Una circunstancia que se produce a pesar de que las políticas de empleo para estas personas han experimentado un cambio importante en los últimos años. Así, una de las medidas adoptadas para favorecer la integración, como el sistema de cuotas -que obliga a las empresas a reservar un porcentaje de puestos para trabajadores con discapacidades generalmente incumplida en todos los países ante la pasividad de los gobiernos y autoridades. Tanto es así que la UE se está planteando la obligatoriedad del cumplimiento por parte de las empresas de las normas antidiscriminación existentes como uno de los condicionantes para optar a los concursos públicos" ${ }^{37}$.

En las últimas noticias analizadas, del año 20I2, comienzan a emerger discursos que alertan de la reducción del gasto público con motivo de la crisis de deuda pública que viven las administraciones públicas:

37. "Los discapacitados, ciudadanos de segunda en «prácticamente todos los países de la Tierra" ( $\mathrm{ABC}$ 22/I2/2002).
"Según la Fundación Ecom, que agrupa a más de 180 asociaciones que trabajan con personas con discapacidad física, el sector quedará «herido de muerte» por los recortes, en este caso impulsados por el Gobierno central, que afectarán a la partida sobre políticas activas de empleo. Las entidades aseguran que la Generalitat prevé que los 400 millones que el Servicio de Ocupación de Cataluña (SOC) destinó en 20I I a las organizaciones colaboradoras, entre ellas Ecom, queden reducidos en $\mathrm{I} 80$ millones” ${ }_{38}$.

Las noticias analizadas nos muestran, en materia de empleo ordinario, que tanto las esperanzas que generó la LISMI como su falta de aplicación es el tema que tiene más presencia. A su vez, las cuotas establecidas para empleo privado y público es el tema que genera más debate. En la primera década del año 2000, el movimiento asociativo exige mayores inspecciones para el cumplimiento de dichas cuotas y critica el elevado número de personas que permanecen inactivas y conformes con el sistema de prestaciones públicas. Sorprende la poca prensa que se tiene la LIONDAU (Ley de Igualdad, No Discriminación y Accesibilidad Universal, de 2 de diciembre del 2003). Al igual que tampoco se incida en otras medidas relacionadas con la integración laboral como los incentivos a los empleadores (fiscales, laborales o para la adaptación de los puestos de trabajo), que tienen por objetivo reforzar la contratación.

\section{4. Un breve apunte estadístico}

Aunque la tasa de paro en España es relevante tanto para las personas con diversidad funcional como para la población general, nos parece importante destacar que en la última década el porcentaje de personas con diversidad funcional que se muestran activas ha ido aumentando. En 20I2, según la Base Estatal de Datos de Personas con Discapacidad, había en España 3.478.395 registros correspondientes a personas que les ha sido valorado su grado de diversidad

38. "Uno de cada tres discapacitados perderá su empleo por los recortes" (EL PAÍS I/O5/20I2). 
funcional. De éstas, el grupo de personas que han resultado con un grado de diversidad funcional igual o superior al $33 \%$ y como tal con la consideración de personas en situación de

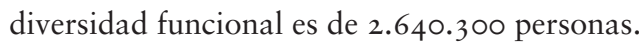
De dicho conjunto las personas en edad de trabajar, entre los I 6 y los 64 años, según el informe elaborado por el INE "El Empleo de las Personas con Discapacidad” en 20I2, fue de un total de 1.450 .800 personas, lo que supone un $4,8 \%$ de la población total en edad de trabajar. A continuación (Tabla 2) se muestra un desglose de dicho número de personas según su actividad:

El porcentaje de actividad de ambos sexos $(36,6 \%)$ todavía muestra grandes diferencias en relación con la población general, donde el mismo porcentaje es 40 puntos superior $(77,0 \%)$. A pesar del elevado número de personas con diversidad funcional que permanecen inactivas (9I9.200 personas en 20I2) observamos como en la serie revisada, 2008-20I2, el porcentaje de personas inactivas ha ido disminuyendo. En 20I3, la tasa de actividad aumentó al 37,4\%, lo que representa la noticia más positiva en las tres décadas analizadas.
Según los datos estadísticos del INE, antes mencionados, los asalariados con diversidad funcional en empresas de más de 50 trabajadores, exceptuando los Centros Especiales de Empleo, eran I34.700 -el 4I \% pertenece a personas empleadas en el sector público $(55.200)$ y el $59 \%$ pertenece a personas empleadas en el sector privado (79.500)-. Lo que representa un $37,9 \%$ de la población con diversidad funcional ocupada en 2012 (355.500) y un $43, \mathrm{I} \%$ de la población asalariada con dichas características (3 I 2.840), lo importante es destacar es que desde 2008 la tendencia ha sido positiva, a excepción del último año de la serie 2008-20I2 (Tabla 3).

Aunque se puede hacer una valoración positiva de los logros conseguidos por el sistema de cuotas en las tres décadas transcurridas desde que se estableció la LISMI, una conclusión que es compartida por diferentes actores sociales del sector de la diversidad funcional es que la medida de discriminación positiva establecida por la cuota del $2 \%$ es insuficiente. En primer lugar, porque en las tres décadas transcurridas desde la aprobación de la LISMI todavía existe un número desconocido de empresas

Tabla 2. Personas con discapacidad según sexo y situación de actividad

\begin{tabular}{|l|c|c|c|c|c|}
\hline \multirow{2}{*}{} & \multicolumn{2}{|c|}{ Valores absolutos en miles } & \multicolumn{2}{c|}{ Porcentajes (\%) } \\
\cline { 2 - 6 } & Total & Hombres & Mujeres & Hombres & Mujeres \\
\hline Total & $\mathbf{1 . 4 5 0 , 0 0}$ & $\mathbf{7 9 0 , 5}$ & $\mathbf{6 6 0 , 3}$ & $\mathbf{5 4 , 5}$ & $\mathbf{4 5 , 5}$ \\
\hline Activos & 531,6 & 310,2 & 221,4 & 58,3 & 41,7 \\
Ocupados & 355,5 & 297 & 148,5 & 58,2 & 41,8 \\
Parados & 176,1 & 103,2 & 72,9 & 58,6 & 41,4 \\
\hline Inactivos & 919,2 & 480,3 & 438,9 & 52,3 & 47,7 \\
\hline
\end{tabular}

Fuente: Instituto Nacional de Estadística.

Tabla 3. Asalariados con diversidad funcional en empresas, públicas y privadas, con más de $\mathbf{5 0}$ trabajadores. Unidades en miles de personas

\begin{tabular}{|l|c|c|c|c|c|}
\hline & $\mathbf{2 0 0 8}$ & $\mathbf{2 0 0 9}$ & $\mathbf{2 0 1 0}$ & $\mathbf{2 0 1 1}$ & $\mathbf{2 0 1 3}$ \\
\hline Asalariados con diversidad funcional & 86,3 & 115,5 & 132,3 & 138 & 134,7 \\
\hline
\end{tabular}

Fuente: Elaboración propia a partir de datos del INE. 
que incumplen dicha ley. En segundo lugar, por qué se desconoce el impacto que están teniendo las medidas alternativas al sistema de cuotas en el número de personas empleadas en el mercado ordinario. Lo que no quiere decir que dicho impacto sea negativo, pero si puede estar incidiendo en la calidad de los contratos realizados. Y en tercer lugar, el límite de tamaño de las compañías que establece la legislación española en lo que se refiere a las personas con diversidad funcional no tiene en cuenta las particularidades de la demografía empresarial española. Según el informe elaborado por la consultora KPMG (2OII):

$$
\begin{aligned}
& \text { "La cuota alemana, por ejemplo, alcanza al } \\
& 5 \% \text { de los empleados en compañias de más } \\
& \text { de } 20 \text { trabajadores. En el caso de España el } \\
& \text { tamaño de las compañias a las que aplica } \\
& \text { la cuota es de } 5 \text { empleados. Teniendo en } \\
& \text { cuenta que el tamaño medio de las compañias } \\
& \text { españolas es, en términos de empleados, la } \\
& \text { mitad de las alemanas, puede afirmarse que } \\
& \text { el potencial número de puestos de trabajo } \\
& \text { que podrían ser ocupados por personas con } \\
& \text { discapacidad en España están muy lejos del } \\
& \text { equivalente alemán” (49-50). }
\end{aligned}
$$

Otra medida establecida por la LISMI son las ayudas públicas a las personas con diversidad funcional. Según una nota de prensa elaborada por el INE sobre el informe "El empleo de las personas con discapacidad", en 2012 , "en el caso específico de las personas con discapacidad el sistema público de prestaciones benefició a 788.400 ( 54 de cada I00). De ellas, un I 8,6\% (I46.400 personas) eran activas” (I I). En 20I3, "el sistema público de pensiones benefició a 822.600 ( 57 de cada I00) personas con discapacidad. De ellas, un 2I,7\% (I 78.800 personas) eran activas" (2OI3: II).

Esto supone que el número de personas en edad laboral con dichas características que perciben una prestación sigue siendo muy elevado. Y de éstas, las que permanecen en activo, el porcentaje es pequeño. Por lo que el modelo de la LISMI, en relación con las prestaciones sociales, supone un gasto social muy elevado. Según KPMG (20II):
"Desde el punto de vista del gasto público, conviene recordar asimismo el carácter permanente de las ayudas públicas a las personas con discapacidad. Tal y como muestran los estudios desarrollados al efecto por organizaciones internacionales como la OCDE, la salida de una persona con discapacidad del mercado laboral tiene carácter casi permanente. Esto es, la probabilidad de que una persona que recibe subsidios por discapacidad se reincorpore al mercado laboral es reducida. De este modo, las iniciativas y el apoyo público al empleo de las personas con discapacidad tiene como contrapartida una disminución que podríamos denominar estructural y de largo plazo sobre el gasto social y reduce las presiones sobre el estado del bienestar" (34).

En relación con los incentivos para el fomento de la contratación, el informe del INE para $20 \mathrm{I} 2$ nos dice que "el $25 \%$ de las personas con discapacidad ocupadas que cotizaron a la Seguridad Social tenía algún tipo de deducción en las cotizaciones. Estas deducciones, tuvieron mayor efecto sobre los asalariados que sobre los trabajadores por cuenta propia. Y el $24,9 \%$ de los asalariados con discapacidad tenía la modalidad de contrato específico de discapacidad" (2013: IO). En 2013, dichos porcentajes aumentaron a un $26,6 \%$.

A pesar del alto porcentaje de personas con diversidad funcional que permanecen inactivas los datos muestran tendencias positivas en la tasa de actividad, en el número de asalariados que trabajan en empresas de más de 50 trabajadores, en el número de personas que permanecen activas aún percibiendo una prestación y en el número de personas que se ven beneficiadas por las medidas de fomento del empleo para el colectivo de personas con diversidad funcional. Si estas tendencias se ven modificadas en los últimos años analizados, parece ser, no se ha constatado, que se debe a la incidencia de la crisis económica internacional, a la recepción económica, a la deuda pública de las administraciones y a los recortes presupuestarios acontecidos en los últimos años. 


\section{Empleo protegido.}

La LISMI (I982) establece que son Centros Especiales de Empleo aquellos que, participando regularmente en operaciones de mercado, tengan como objetivo principal, junto con el de realizar un trabajo productivo, el asegurar el empleo remunerado y la prestación de aquellos servicios de ajuste personal y social a estos trabajadores con diversidad funcional, procurando a la vez constituir el medio de integración del mayor número de ellos al régimen normal de trabajo en empresas ordinarias.

"El Servicio Técnico del Fondo de Solidaridad, antiguo Fondo Nacional de Protección al Trabajo, califica a los Centros Especiales de «instrumentos de integración e instrumentos de paso hacia una empresa ordinaria»" 39 .

"González de Lena, subdirector de Negociación Colectiva y Condiciones de Trabajo del Ministerio de Trabajo y artífice principal del real decreto que regula la relación laboral del minusválido, afirma que «el trabajo es una de las formas de integración habituales, por lo que los Centros Especiales constituyen el medio idóneo para aprender a trabajar»" ${ }^{40}$.

La LISMI tendrá como consecuencia más directa la creación de Centros Especiales de Empleo y Centros Ocupacionales. Según el informe sobre centros especiales de empleo de KPMG (20II: 4-5) se observan cuatro momentos clave en la creación de este tipo de centros:

I. En el año i982 con la publicación de la LISMI I3/I982, en la que se definía por primera vez el centro especial de empleo.

2. Se observa un ligero crecimiento en los años I 986 y 1987 que podría deberse a la publicación de dos Reales Decretos,

39. "La integración laboral del minusválido tropieza con la falta de dinero para hacer cumplir la ley" ( $\left.\mathrm{ABC}_{3} / \mathrm{IO}_{1} / \mathrm{I} 85\right)$. 40. "La integración laboral del minusválido tropieza con la falta de dinero para hacer cumplir la ley" ( $\mathrm{ABC}_{3} / \mathrm{IO}_{\mathrm{I}} 985$ ). el 2273/I985 y el I368/I985, que desarrollaban la legislación que regula los centros especiales de empleo.

3. Hacia el año I 998 se publicó la Orden del Ministerio de Trabajo y Asuntos Sociales que establecía las bases reguladoras para la concesión de las ayudas y subvenciones públicas destinadas a la integración laboral de las personas con discapacidad. Este puede ser un factor de explicación en la creación de centros especiales de empleo.

4. El cuarto de ellos se produjo en el año 2000 y pudo deberse a la publicación del Real Decreto 27/2000, por el que establecían medidas alternativas de carácter excepcional al cumplimiento de la cuota de reserva del $2 \%$ a favor de trabajadores discapacitados de empresas de 50 o más trabajadores.

Otra novedad, a partir del Real Decreto 290/2004 de 20 de Febrero, son los Enclaves Laborales que se regulan como medida de fomento del empleo de las personas con diversidad funcional. Los Enclaves Laborales -como comentábamos con anterioridad- se conciben como «medio de transición» hacia el empleo ordinario y como medio para que las empresas del sector público y privado conozcan mejor las capacidades y aptitudes reales de los trabajadores con diversidad funcional, como paso previo a su eventual incorporación a la plantilla de la empresa4 ${ }^{\mathrm{I}}$.

En 2004, en El PAÍS, aparecerá una noticia que hemos querido destacar por sostener un discurso diferente a los expuestos más arriba.

"La comunidad foral [de Navarra] cuenta con un total de $\mathrm{I} 3$ centros especiales que acogen en régimen de empleo protegido a I.500 trabajadores. Se dedican a actividades

4I. Aunque esta nueva medida del gobierno central se encuentra en una frontera difusa entre el trabajo ordinario y el empleo protegido hemos querido comprenderla dentro de este apartado porque su discurso guarda cierta semejanza con los testimonios presentados en relación con los centros especiales de empleo en la década de los 80 . 
subcontratadas de montaje industrial y al sector servicios (jardinería, limpieza, hostelería). Creados en la mayoría de los casos por fundaciones y asociaciones sin ánimo de lucro, estos centros reciben importantes subvenciones públicas y cumplen una notable labor social, pero el modelo, asegura José Elizalde (portavoz del sindicato CCOONavarra y autor del informe), "ha fracasado como medio para la progresiva inserción de los trabajadores en el mercado ordinario»".

“La reserva para minusválidos del $2 \%$ de los puestos de trabajo en empresas ordinarias resultó ser un mecanismo totalmente insuficiente para promover la integración de los discapacitados. En 2000, la ley se cambió y desde ese momento se permitió a las industrias sustituir esa cuota por la subcontratación de tareas con los centros de empleo protegido. «Con el tiempo esa modificación se ha convertido en un mecanismo perverso", dice Elizalde”.

“Además, los centros resultan deficitarios en su mayoría. Sus pérdidas oscilan entre los 48.000 y los 240.000 euros. Para tapar los agujeros, la Administración foral, que ya paga el $50 \%$ del salario mínimo por trabajador y bonifica y exime las cuotas patronales de la Seguridad Social, debe subvencionar el déficit para equilibrar las cuentas de empresas fundadas por instituciones de apoyo a disminuidos físicos y psíquicos y personas en riesgo de exclusión social como Aspace, Anfas o Anasaps" ${ }^{42}$.

Sobre una población activa total en España que se sitúa alrededor de los 22 millones de personas, en $20 \mathrm{II}$, los centros especiales de empleo suponen un $0,4 \%$ del total: 70.000 trabajadores (de los cuales 64.39I son personas con algún tipo de diversidad funcional). Lo que supone un porcentaje de $5, \mathrm{I} \%$ en relación con la población con diversidad funcional en edad de trabajar en 20 I I (I.450.800), un I $4 \%$ en relación con la población activa con diversidad funcional (46I.600) y un I9 \% en

42. "Condenados a la exclusión social" (EL PAÍS 2I/04/2004). relación con la población ocupada con las mismas características (337.300). El informe de KPMG (20II) nos muestra que dichos centros han destruido menos empleo que el mercado ordinario desde que comenzó la crisis internacional. Algunos actores defienden la necesidad de los centros especiales de empleo para aquellas personas que necesitan más apoyos y tienen menos capacidades para producir valor económico en el mercado ordinario. Pero desconocemos qué función están cumpliendo en relación con el tránsito de personas del mercado protegido al mercado ordinario.

La LISMI estructuró las políticas públicas en materia integración laboral en tres espacios: empleo ordinario (cuota del $2 \%$ y el $3 \%$ ), centros especiales de empleo y centros ocupacionales. Tres espacios, que se vieron ampliados a cinco con la creación de los Enclaves Laborales (2004) y el programa de empleo con apoyo regulado por el Real Decreto $870 / 2007^{43}$. Y que está destinado a aquellas personas que cumplen con alguno de los siguientes requisitos:

Artículo 3. Destinatarios finales. I.

a) Personas con parálisis cerebral, personas con enfermedad mental o personas con discapacidad intelectual con un grado de minusvalía reconocido igual o superior a $33 \%$.

b) Personas con discapacidad física o sensorial con un grado de minusvalía reconocido igual o superior al $65 \%$.

Otro ejemplo de integración laboral lo encontramos en las empresas de inserción:

"En total hay cerca de 200 en España, donde trabajan unas 4.000 personas, en números redondos, sujetas al convenio colectivo del sector que corresponda. A pesar de que reciben subvenciones, generan retornos a

43. RD $870 / 2007$, de 2 de julio, por el que se regula el programa de empleo con apoyo como medida de fomento de empleo de personas con discapacidad en el mercado ordinario de trabajo. 
las arcas públicas. Un estudio de la Obra Social de Caixa Catalunya de hace unos años calculaba que estos empleos ahorraban al Estado 28 millones de euros. Y otro informe más reciente, elaborado para la Federación de Asociaciones Empresariales de Empresas de Inserción (Faedei) revelaba que comunidades, como Canarias, recibían en retornos más del $43 \%$ de lo empleado, y en otras, como Castilla y León, el dinero volvía duplicado" ${ }^{44}$

En las bases de datos analizadas no existen datos directos sobre el impacto de las diferentes medidas. Por ejemplo, desconocemos el número de empresas que no cumplen la cuota del $2 \%$, desconocemos el número de contratos que se han realizado en relación con las medidas de carácter excepcional a las cuotas del $2 \%$, el número de personas empleadas en enclaves laborales, el número de personas que se están beneficiando de los programas de empleo con apoyo, etc. La información de la que disponemos sólo nos permite hacer una valoración general del impacto de las diferentes medidas para la integración laboral de aquellas personas con un grado de diversidad funcional igual o superior al $33 \%$.

\section{La dimensión simbólica del empleo}

En dicho contexto, marcado por el desempleo, unas tasas de actividad, en general, que han ido en aumento desde principios del siglo XXI y una opinión pública cada vez más sensibilizada en torno a la integración laboral de las personas con diversidad funcional, constatamos una idea que aparece repetida en diferentes noticias y enunciada por diferentes actores sociales: $\mathrm{el}$ empleo es la vía principal para la integración social. Este discurso vincula la participación al eje de la producción y el consumo, es decir, se refuerza la idea de que la capacidad productiva resulta determinante para la inclusión social. La otra cara de este discurso son los riesgos de

44. "Las empresas de inserción resisten a la crisis en nuevos nichos de mercado" (El País 5/05/20Io). exclusión social, que se ven contrarrestados con medidas de prestaciones públicas y recursos familiares:

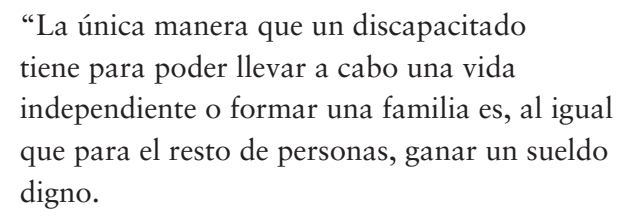
tiene para poder llevar a cabo una vida independiente o formar una familia es, al igual que para el resto de personas, ganar un sueldo digno.

Lo que podría parecer una obviedad es un asunto grave teniendo en cuenta que los discapacitados tienen unas necesidades especiales, con lo que si no ganan el dinero suficiente para cubrirlas se convierten en personas dependientes. Esa dependencia tiene un doble impacto.

El primero, para sus familiares, que deben hacerse cargo de ellos. El segundo, un impacto psicológico para los propios discapacitados, que llegan a considerarse como una carga o un estorbo para sus familiares y amigos, lo que acarrea serios problemas psicológicos" ${ }^{45}$.

Pero la población activa (con diversidad funcional) se enfrenta también a prejuicios a la hora de ser contratados. Como consecuencia de ello, acontecen en la prensa opiniones que al querer sensibilizar constituyen, al mismo tiempo, un juicio sobre el propio grupo. Vemos muy repetido en relación con la integración laboral lo que se podría denominar «la carga de la prueba», es decir, cuando las personas con diversidad funcional se enfrentan a un empleo tienen que demostrar que son capaces de hacerlo mejor que nadie:

"En este tiempo de trabajo en común he aprendido mucho de los minusválidos -que hoy son más de la mitad de una plantilla de 150 personas- $y$ he podido constatar su perfecto rendimiento" (Francisco Carabel, profesor de Balcarsa: fábrica gallega de joyería para disminuidos físicos ${ }^{46}$.

45. "Sólo uno de cada diez discapacitados tiene trabajo estable" (ABC 4/I 2/2006).

46. "Minusválidos, oficiales de oro" (ABC 7/02/I983). 
“Tenemos que convencer [a los empresarios] de que no sólo son rentables, sino que rinden un poco más" (José Gómez Amate, presidente de CAMF: Confederación Andaluza de Minusválidos Físicos) ${ }^{47}$.

"Francisco Mesonero, director general de la Fundación Adecco, expresa a ABC que «el trabajo de una persona discapacitada no sólo no menoscaba, si no que en muchos casos favorece la actividad de la empresa", porque suelen trabajar con más ilusión, esfuerzo y aprovechan una oportunidad que, saben, no se les presenta a menudo" ${ }^{48}$.

“ «Si me contratas, voy a tener la oportunidad de demostrarte que voy a hacer el trabajo igual que cualquier otra persona, que voy a tener más ganas que nadie y que le voy a dar un aire nuevo a tu empresa. Si más empresarios hacen lo que tú, entre todos vamos a hacer un mundo mejor». Esta es la llamada de Luis Castro, el nombre supuesto de un joven con síndrome de Down, realiza en un «video curriculum» colgado en internet que ha logrado cerca de I00.000 visitas en cuatro días" ${ }^{49}$.

En este mismo contexto, las noticias analizadas nos hablan de la emergencia de nuevos discursos entorno a las posibilidades de integración que las nuevas tecnologías pueden permitir:

\begin{abstract}
"La peculiar experiencia formativa, única en España, parte del convencimiento de que las comunicaciones generadas a través de la red suponen un espacio laboral inmejorable en donde el minusválido podrá competir en igualdad de condiciones si se prepara adecuadamente" (Carlos Mauricio Bernal, coordinador del departamento de Trabajo y Formación de la Asociación) $)^{50}$.
\end{abstract}

"Éste puede hacerse desde casa, o sin la obligación diaria de desplazarse a otro lugar

47. "Los discapacitados accederán en dos años a una bolsa de empleo regional" (EL PAÍS 8/09/I998).

48. "Discapacitados frente a la crisis" ( $A B C 2$ I/08/2009).

49. "Si me contratas te demostraré que tengo más ganas que nadie" ( $\mathrm{ABC} 24 / 0 \mathrm{I} / 20 \mathrm{I} 2)$.

50. "Una experiencia inédita" (EL PAÍS 8/I I/200I). y el teletrabajo puede aplicarse a todas las tareas de externalización de empresas: contabilidad, mailing... basta con tener un equipo informático”. (Ma Jesús Sanz, Jefa de Programas de Discapacidad de los Servicios Sociales de la Comunidad de Madrid) ${ }^{5}$.

Todos los tópicos identificados están relacionados con lo que actualmente muchos autores y autoras denominan ideología de la normalidad (Brogna, 2006; Ferreira y Caamaño, 2007; Palacios y Buffini, 2007). En este marco de referencia, los individuos con insuficiencias están obligados a asumir tantas funciones «normales» como puedan, y de la mejor forma posible.

Según Mark Oliver (I998), las personas con discapacidad se vieron discriminadas por la emergente sociedad industrial y ha sido ésta la que ha definido las capacidades que eran válidas para la misma. En relación con la producción, como reconoce Finkelstein (citado por Abberley, I998: 87) "es posible que una sociedad esté dispuesta, y en determinadas circunstancias llegue a ansiarlo, a absorber en el mercado laboral a una porción de su población con insuficiencias, pero esto puede producir el efecto de mantener y quizá de intensificar la exclusión del resto”. En palabras de Abberley (I998: 9I) "una teoría utópica alternativa puede ser la que ofrezca otro futuro en la medida en que rechace el «trabajo» como elemento esencialmente definitorio de la participación social”.

Sugiere Díaz Velázquez (20I0: I23) "la necesidad de reforzar necesariamente otros elementos sociales que vinculen a estas personas con la ciudadanía (la visibilidad en el entorno, la participación social y politica, la promoción de las virtudes cívicas basadas en la comunicación interpersonal), así como orientar el concepto de interdependencia y de aportación a la sociedad, bajo otras dimensiones más allá del cálculo de la aportación económica como productividad social".

5I. "Diez mil discapacitados físicos podrán trabajar desde casa a través de Internet" ( $\mathrm{ABC}$ I8/03/2003). 


\section{Conclusiones}

El empleo es un tema muy presente en la prensa, que ha generado diferentes posiciones discursivas en torno a cómo conseguir el acceso al mercado laboral por parte de las personas con diversidad funcional. Sobre todo, porque a pesar de las fluctuaciones de las tasas de desempleo, entre las personas con diversidad funcional, durante el periodo analizado -con especial relevancia a partir de 2007 con la crisis económica internacional- las tasas han sido siempre superiores a la media de la población general. De aquí, que se hayan hecho diferentes planteamientos, no exentos de polémicas en determinados momentos históricos: los intereses por la venta de cupones, como medio de financiación, enfrentó a diferentes organizaciones del sector; el incumplimiento de la reserva de cupo conllevó a la necesidad de establecer nuevas medidas para regular medidas alternativas; también se han definido medidas para el fomento de la contratación (contratos específicos, bonificaciones en las cotizaciones, subvenciones para la adecuación de los puestos de trabajo, etc.); se han creado los enclaves laborales como lugares de tránsito entre el empleo protegido y ordinario; se han aprobado programas de empleo con apoyo; se ha reconocido la figura del asistente personal; etc.

En materia laboral, la LISMI ha sido todo un referente durante los ochenta y noventa, generando una forma de entender la integración laboral a través de diferentes espacios: el empleo ordinario, los centros especiales de empleo y los centros ocupacionales. La falta de aplicación de la reserva de cupo, recogida en la ley, ha sido motivo de aparición de constantes noticias en la prensa, por parte del movimiento asociativo, de los diferentes partidos políticos, de los sindicatos, etc. De hecho, es el tema con más presencia en la prensa en lo referido al empleo y el que ha generado más debate y posiciones discursivas. Asimismo, un discurso comúnmente repetido y defendido es la consideración del empleo como vía para la integración social, siendo un mensaje que refuerza la idea de que la capacidad productiva resulta determinante para la inclusión social.

En relación con las medidas alternativas a las cuotas del $2 \%$, el principal argumento que se repite una y otra vez es que éstas se establecieron para hacer cumplir la Ley. Pero desconocemos por qué las correspondientes empresas eludían dicha Ley, por qué existen empresas que siguen sin cumplirla y, sobre todo, el impacto que dichas medidas han tenido en la primera década del 2000 , es decir, que se está viendo más beneficiado el empleo ordinario o protegido. Aún así, con los datos disponibles, la tendencia de personas con diversidad funcional empleadas en empresas, públicas y privadas, de más de 50 trabajadores ha sido positiva; representando, en 20I 2 , un 43 , I \% de la población asalariada con dichas características (3 I 2.840).

Un dato igualmente revelador es el aumento del número de personas con diversidad funcional activas, lo que significa un cambio en positivo en la concepción de pasar de sujetos pasivos a sujetos activos. Las personas receptoras de algún tipo de prestación (788.400) representaban, en $20 \mathrm{I} 2$, el $85,7 \%$ de la población inactiva (919.200). De las que reciben una prestación, un I 8,6\% ( 146.400 personas) eran activas. En algunos casos, con el cumplimiento de las políticas integración laboral, este gasto social puede ser revertido. En otros, este es un gasto social necesario para todas aquellas personas que se encuentran en una situación de incapacidad o no pueden producir valor económico.

El $25 \%$ de la población ocupada con diversidad funcional participó de las deducciones en las contrataciones y de contratos específicos. Desconocemos el impacto que dichas medidas está teniendo en la clase empresarial. Y pensamos que habría que estar atentos a la evolución de dichos datos en las próximas décadas. Por otro lado, señalar que las personas empleadas en centros especiales de empleo representan, en $201 \mathrm{I}$, un I $4 \%$ en relación a la población activa y un I9 \% en relación a la población ocupada. En estos tiempos de crisis, el empleo protegido ha destruido menos puestos de trabajo que el mercado ordinario. 
A nivel macrosocial, nos parece interesante poder saber que incidencia están teniendo las medidas de fomento del empleo en la clase empresarial, el número de personas que han conseguido un empleo ordinario gracias a las medidas de carácter excepcional a las cuotas de discriminación positiva, las personas empleadas en «enclaves laborales», cuántas personas participan de programas de empleo con apoyo y cuántas personas que disfrutan de una «asistente personal» se mantienen ocupadas. En un nivel microsocial se hace necesario hacer una apuesta por metodologías cualitativas que desvelen los "prejuicios", "estereotipos", "discriminaciones" y "violencias estructurales" que viven dichas personas en su día a día.

\section{Referencias bibliográficas}

Abberley, P. (I998): “Trabajo, utopía e insuficiencia”, en L. Barton (Comp.): Discapacidad y Sociedad (77-98). Madrid: Ed. Morata.

Brogna, P. (2006): El nuevo paradigma de la discapacidad y el rol de los profesionales de la rehabilitación, Argentina: Cisne.

Caamaño, M.J.R. y Ferreira, M.A.V. (2006): "Sociología de la Discapacidad: una propuesta teórica crítica". Nómadas: revista crítica de ciencias sociales y jurídicas, Vol. I3, no. I (2006), p. 243-249.

Díaz Velázquez, E. (2010). “Ciudadanía, identidad y exclusión social de las personas con discapacidad". Política y Sociedad, 47 (2): I I 5 I 35 .

España. Ley 7/2007, de I 2 de Abril, del Estatuto Básico del Empleo Público, Boletín Oficial del Estado, núm. 89, de I 3 de abril de 2007, pp. I6270 a I6299.

España. Ley I3/I982, de 7 de abril, de Integración Social de los Minusválidos (LISMI), Boletín Oficial del Estado, núm. I03, de 30 de abril de I982, pp. I I IO6 a IIII 2.

España. Real Decreto 27/2000, de I4 de enero, por el que se establecen medidas alternativas de carácter excepcional al cumplimiento de la cuota de reserva del 2 por 100 en favor de trabajadores discapacitados en empresas de 50 o más trabajadores, Boletín Oficial del Estado, núm. 22, de 26 de enero de 2000 , pp. 34 IO a $34 \mathrm{I} 2$.

España. Real Decreto 290/2004, de 20 de febrero, por el que se regulan los enclaves laborales como medida de fomento del empleo de las personas con discapacidad, Boletín Oficial del Estado, núm. 45, de 2I de febrero de 2004, pp. 8386 a 839 I.

España. Real Decreto 2271/2004, de 3 de diciembre, Boletín Oficial del Estado, núm. 303 , de I7 de diciembre de 2004, pp. 4I26I a 4I 264 .

Ferreira, M. A. (20I0): "De la minus-valía a la diversidad funcional: un nuevo marco teóricometodológico". Politica y Sociedad, 47 (2): $45-65$.

Iáñez, A. (20Iо). Prisioneros del cuerpo. La construcción social de la diversidad funcional. A Coruña, Diversitas.

IMSERSO. Base de datos Estatal de personas con discapacidad (en línea). http://www.imserso. es/imserso_or/documentacion/estadisticas/ bd_estatal_pcd/index.htm . 
Instituto Nacional de Estadística (2OI2). El Empleo de las Personas con Discapacidad. Serie 2008-20I2 (en línea). http://www.ine.es/ jaxi/menu.do? type $=$ pcaxis $\&$ path $=/ t_{22} /$ p $_{3} 20 /$ serie\&file=pcaxis .

Instituto Nacional de Estadística (201 2). El empleo de las personas con discapacidad. Informe de los datos para 20I I (en línea). http://www.ine. es/prensa/np753.pdf.

Instituto Nacional de Estadística (2013). El empleo de las personas con discapacidad. Informe de los datos para $20 \mathrm{I} 2$ (en línea). http://www.ine. es/prensa/np82I.pdf.

Instituto Nacional de Estadística (20I4). El empleo de las personas con discapacidad. Informe de los datos para 20I3 (en línea). http://www.ine. es/prensa/np883.pdf.
KPMG (20I3) "Presente y Futuro de los Centros Especiales de Empleo". Fundosa Galenas S.A.U. (en línea). http://www.feaps.org/files/ Documentos/CEEcompleto.pdf».

Oliver, M. (I998): “¿Una sociología de la discapacidad o una sociología discapacitada?”, en L. Barton (Comp.): Discapacidad y Sociedad. Madrid: Ed. Morata.

Palacios, A. y Buffini, F. (2007): La discapacidad como una cuestión de derechos humanos. Una aproximación a la Convención Internacional sobre los Derechos de las Personas con Discapacidad, Madrid: Ed. Cinca.

Romañach, J. y Lobato, M. (2005). Diversidad funcional, nuevo término para la lucha por la dignidad en la diversidad del ser humano (en línea). 〈http://www.forovidaindependiente.org/ node/ $45^{\prime}$. 


\title{
Relaciones interpersonales en niños y jóvenes con trastornos del espectro del autismo y discapacidad intelectual
}

\author{
Interpersonal relationships in children and \\ adolescents with autism spectrum disorders \\ and intellectual disability
}

\section{Resumen}

Las personas con discapacidad severa y profunda han sido un colectivo poco estudiado en el ámbito de la investigación y, menos aún, en las etapas de la infancia y adolescencia. Este estudio evalúa las relaciones interpersonales de una muestra de 55 personas con Trastorno del Espectro Autismo (TEA) y discapacidad intelectual (DI) entre 4 y 20 años. Para ello se utilizó la subescala de relaciones interpersonales de la Escala KidsLife (Gómez et al., en prensa) que evalúa calidad de vida. Las puntuaciones más altas se obtuvieron en los ítems relacionados con la comunicación, mientras que las más bajas se observaron en los ítems relacionados con las interacciones sociales. Además, las personas con DI profunda obtuvieron puntuaciones significativamente más bajas que aquellos con mayores niveles de funcionamiento. Se discute acerca de las implicaciones del estudio y se realizan recomendaciones específicas para mejorar las prácticas profesionales y organizacionales dirigidas a la mejora de la calidad de vida.

\section{Palabras clave}

Relaciones interpersonales, trastornos del espectro del autismo, discapacidad intelectual, calidad de vida, evaluación.

\section{Lucía Morán Suárez \\ <moranlucia@uniovi.es>}

Universidad de Oviedo

\section{Abstract}

People with severe and profound intellectual disabilities, and especially children and adolescents within these groups, have received little attention in research. This study assesses the interpersonal relationships of 55 people with Autism Spectrum Disorders (ASD) and Intellectual Disability (ID). We applied the KidsLife Scale (Gómez et al., in press) that assesses quality of life. The highest scores were obtained for those items related to communication, while the lowest ones were found for those related to social interactions. Additionally, people with profound ID obtained significantly lower scores than those with the highest levels of functioning. A discussion about the implications of the study is provided as well as some specific recommendations for bettering professional and organizational practices for the purpose of improving quality of life.

\section{Keywords}

Interpersonal relationships, autism spectrum disorders, intellectual disability, quality of life, assessment.

\section{Laura E. Gómez Sánchez <gomezlaura@uniovi.es> \\ Universidad de Oviedo}

\section{$M^{a}$ Ángeles Alcedo Rodríguez \\ <malcedo@uniovi.es> \\ Universidad de Oviedo}

Para citar:

Morán, L. et al. (201 5): "Relaciones interpersonales en niños y jóvenes con trastornos del espectro del autismo y discapacidad intelectual", Revista Española de Discapacidad, 3 (I): 77-9I.

Doi: <http://dx.doi.org/IO.5569/23405 I04.03.01.04>

Fecha de recepción: I I-OI-20I 5 Fecha de aceptación: 24-04-20I 5 


\section{Relaciones interpersonales en niños y jóvenes con trastornos del espectro del autismo y discapacidad intelectual}

Los intentos de conceptualización y medida de la calidad de vida (CV) de las personas con discapacidad intelectual (DI) han evolucionado desde una noción meramente sensibilizadora hasta convertirse en un constructo social, un área de investigación aplicada y un principio básico de prestación de servicios (Cuesta, 2009: 29; Gómez et al., 20ıоa: 454).

Una de las definiciones más conocidas y utilizadas en el ámbito de las discapacidades intelectuales y del desarrollo, es la propuesta por Schalock y Verdugo (Schalock y Verdugo, 2003, 2007, 20I2). Según esta concepción, la CV se entiende como un estado deseado de bienestar personal que: a) es multidimensional, formado por ocho dimensiones; b) tiene propiedades universales (etic) y ligadas a la cultura (emic); c) engloba componentes objetivos y subjetivos; y d) está influenciada por características personales y factores ambientales (Schalock et al., 2010:20).

Este concepto de CV se operativiza a través de dimensiones, indicadores y resultados personales, organizados en diferentes niveles. Las dimensiones básicas de CV se entienden como "un conjunto de factores que componen el bienestar personal” (Schalock y Verdugo, 2003: 34), y que se concretan en: inclusión social, autodeterminación, bienestar emocional, bienestar físico, bienestar material, derechos, desarrollo personal y relaciones interpersonales.

A su vez, estas dimensiones se definen a través de sus indicadores centrales (Schalock et. al, 2010: 20). Estos indicadores permiten la evaluación de resultados puesto que son "percepciones, conductas o condiciones específicas de las dimensiones de calidad de vida que reflejan el bienestar de la persona" (Schalock y Verdugo, 2003: 34). La evaluación de la situación personal o de las aspiraciones de la persona en estos indicadores se refleja en los resultados personales, es decir, aquellas aspiraciones definidas y valoradas personalmente (Schalock et al., 2009: 20).

En lo relativo a la evaluación del constructo de CV, la Ley de Promoción de la Autonomía Personal y Atención a las Personas en Situación de Dependencia recoge que los instrumentos que permitan la evaluación de la CV con suficientes garantías de validez y fiabilidad son, no ya recomendables, sino necesarios e indispensables (Ley de Promoción de la Autonomía Personal y Atención a las Personas en Situación de Dependencia, BOE de I 5 de diciembre de 2006: 44I 54).

Cabe destacar que los cambios que han tenido lugar en los últimos años en el ámbito de la atención a las personas con discapacidad se están restringiendo casi exclusivamente a aquellas personas que cuentan con suficientes capacidades y habilidades de comprensión y expresión que pueden contestar de un modo fiable a los autoinformes (Gómez et al., 20I4). Estos instrumentos de evaluación son considerados como la mejor forma de evaluar la $\mathrm{CV}$, sin embargo, los informes de otras personas son necesarios como información complementaria e, incluso, pueden llegar a sustituir a los autoinformes cuando no es posible obtener directamente la información de la persona (Sheldrick et al., 20I 2: 53).

Este estudio se centra en niños y jóvenes con DI y Trastornos del Espectro del Autismo (TEA), un continuo de trastornos del desarrollo neurológico que se caracterizan por déficits en la comunicación y la interacción social, así como por patrones restringidos y repetitivos de comportamiento, intereses y actividades (American Psychiatric Association, 2013: 28; Sheldrick et al., 20I 2: 53). Las puntuaciones medias de la CV en estos niños son menores en comparación con aquellos niños que presentan otras condiciones, tales como enfermedades crónicas (Kuhlthau et al., 20I0: 726) o niños sin discapacidad (Lee et al., 2008: I I 55 ). A su vez, los padres de los niños con TEA de menor edad informan de mayores puntuaciones en la CV que los padres de los niños de mayor edad. Resulta pues importante conocer los factores que 
pueden influir en el descenso de las puntuaciones al aumentar la edad del niño, de forma que permitan la puesta en marcha de estrategias de intervención eficaces (Kuhlthau et al., 20I0: 727).

Sin embargo, no sólo la CV del niño con TEA se ve comprometida, sino también la CV de sus familias. De esta forma, los familiares de niños y adolescentes con TEA presentan un mayor nivel de sobrecarga familiar, mayores posibilidades de renunciar a un trabajo, absentismo escolar, menor participación en eventos sociales y un menor uso de los recursos comunitarios, en comparación con las familias de niños que presentan otras condiciones o no presentan discapacidad (Lee et al., 2008: I I 55 ). Este decremento en las puntuaciones de CV de los niños, y de sus familias puede estar reflejando los problemas de comportamiento de muchos niños con TEA (Lee et al., 2008: I I 48). En este sentido, si bien la CV no está consistentemente relacionada con el diagnóstico de TEA o de DI, sí se asocia con las conductas estereotipadas, la reciprocidad social y la conducta adaptativa (Kuhlthau et al., 20I0: 72I), lo que sugiere que las intervenciones dirigidas a mejorar dichos comportamientos pueden mejorar la CV tanto de las personas con TEA, como de sus familias (Lee et al., 2008: I I 59).

Cabe destacar que gran parte de la literatura revisada sobre CV en las personas con TEA se centra en el uso de conceptos como el de CV relacionada con la salud (p. ej., WHOQOL Group, 2002: 3) y CV familiar (p. ej., Summers et al., 2005: 779), en los que, si bien se han llevado a cabo notables desarrollos del concepto de CV y modelos de importancia indudable, están más centrados en aspectos concretos. En este trabajo se parte de un concepto que va más allá y aborda la CV desde una perspectiva más amplia, que incluye las áreas más relevantes de la vida de una persona y propone su evaluación mediante elementos subjetivos y objetivos: la calidad de vida individual. Las dimensiones de este constructo adquieren especial relevancia a la hora de estimar el impacto del TEA (que puede no ser visible si se analizan de forma aislada los síntomas), así como a la hora de valorar la eficacia de las intervenciones.
Una de las dimensiones fundamentales de CV es la de Relaciones Interpersonales (RI), que tiene que ver con relacionarse con distintas personas, tener amigos y llevarse bien con la gente ( $\mathrm{p}$. ej., vecinos, compañeros y otros). Algunos de los indicadores más comúnmente elegidos para operativizar la son 'Comunicación', 'Relaciones familiares', 'Amigos', 'Compañeros' y 'Sociedad' (Gómez et al., en prensa).

En el caso de las personas con TEA, la alteración de la conducta social es uno de sus rasgos centrales (Tureck y Matson, 201 2: 608). Los niños con TEA emplean menos tiempo en las interacciones sociales, presentan una menor disposición a iniciar el contacto interpersonal (Deckers et al., 20I4: 449) y tienen dificultades para comprender las emociones de los demás en comparación con los niños sin TEA (Gillis et al., 2OII: 352).

Asimismo, los niños con TEA que presentan déficits sociales obtienen menores puntuaciones en desarrollo cognitivo y emocional (Gillis et al., 20I I: 352). Además, más del 50\% de las personas con TEA presentan también DI y un $40 \%$ un nivel de DI severo o profundo (Fombonne 2003 c.p. Walton e Ingersoll, 20I3: 594). Estas personas con TEA y DI muestran un menor nivel de habilidades sociales y más conductas desafiantes que las personas con similares niveles de DI sin TEA (p. ej., personas con síndrome de Down). Lo anterior pone de relieve que presentan otro tipo de necesidades que no pueden ser cubiertas por los programas diseñados para personas que tienen solamente DI. En definitiva, las dificultades en las RI hacen que esta dimensión cobre especial relevancia en la evaluación de la CV de las personas con TEA (Walton e Ingersoll, 20I 3:595).

Por todo ello, el presente trabajo tiene como objetivo evaluar las relaciones interpersonales en niños y jóvenes con TEA y DI, con el fin último de detectar las necesidades y puntos fuertes de este colectivo en esta dimensión, y guiar de este modo los apoyos, los programas y las prácticas profesionales dirigidas a mejora de la CV. Se ahondará además en el estudio de la posible influencia de variables señaladas como relevantes 
en la literatura como el género, la edad, el tipo de escolarización, el nivel de discapacidad y la presencia de problemas de comportamiento.

\section{Método}

\subsection{Participantes}

La muestra estudiada estuvo compuesta por 55 participantes con TEA que fueron evaluados por observadores pertenecientes a I9 organizaciones y entidades situadas en Andalucía (30,9\%), País Vasco (23,6\%), Comunidad Valenciana $(23,6 \%)$, Cataluña $(5,5 \%)$ y otras comunidades (Aragón, Cantabria, Castilla-La Mancha, Castilla y León, Extremadura y La Rioja) ( $6,2 \%$ ). La mayoría eran varones $(72,7 \%)$ y su rango de edad se situó entre 4 y 20 años, con una media de I 2,6 años $(D T=4,7)$.

En cuanto a la distribución de los participantes según su nivel de DI, el I, $8 \%$ presentaba un nivel leve, el $20 \%$ moderado, el $67,3 \%$ severo y el $10,9 \%$ profundo. La media del porcentaje de discapacidad fue del 70,3\%, en un rango que osciló entre $35 \%$ y $99 \%$. El nivel de dependencia en su mayoría correspondía a Grado III o Gran dependencia (67,3\%), y el resto a un Grado II o Severa (32,7\%). Respecto a la presencia de otras condiciones de la persona evaluada, un 32,7\% presentó problemas de comportamiento, un I $4,6 \%$ discapacidad física, un $\mathrm{I} 4,5 \%$ problemas de salud mental y/o trastorno emocional, un $\mathrm{I} 4,5 \%$ epilepsia, un І०,9 \% problemas de salud graves, un 9, I \% discapacidad visual, un $5,5 \%$ parálisis cerebral, un $3,6 \%$ discapacidad auditiva, un I, $8 \%$ TDAH y un I, $8 \%$ síndrome de Down.

En cuanto al tipo de escolarización, la mayoría acudían a centros de educación especial ( $80 \%$ ). Solo el I $2,7 \%$ cursaba sus estudios en centros ordinarios, y el resto lo hacía en una modalidad de educación combinada $(7,3 \%)$.

En cuanto a las personas que cumplimentaron los cuestionarios, se contó con 26 mujeres y 7 varones, entre 26 y 6I años $(M=44,7, D T=8,9)$. Respecto a la clase de relación entre el evaluador y la persona evaluada, un $54,5 \%$ fueron profesores y educadores, un $27,3 \%$ progenitores ( $16,4 \%$ madres y го,9 \% padres), un I0,9\% psicólogos, el 3,6\% orientadores escolares, un I, $8 \%$ cuidadores y un I, $8 \%$ directores de centros. El rango de edad se situó entre 4 y 20 años, con una media de 12,6 años ( $D T=$ 4,69). La duración media de la relación entre el informador principal y la persona evaluada fue de 6 años y 4 meses (el rango osciló entre 6 meses y I7 años). La frecuencia del contacto entre el informador principal y el evaluado fue, en un $92,7 \%$ de los casos, diaria o varias veces por semana, en un I, $8 \%$ una vez a la semana y en un $5,5 \%$ una vez cada dos semanas. En cuanto al número de personas que el informador principal necesitó consultar para completar la escala, osciló entre I y 4 .

\subsection{Instrumentos de medida}

El instrumento utilizado ha sido la subescala de RI de la escala KidsLife (Gómez et al., en prensa). La escala KidsLife evalúa resultados personales relacionados con la CV de niños y adolescentes con DI menores de $2 \mathrm{I}$ años (siempre que se encuentren en el sistema educativo). Puede ser completada por un observador externo que conozca bien a la persona (al menos desde hace 6 meses) y que tenga oportunidades de observarla durante largos periodos de tiempo en diferentes entornos. Por tanto, los respondientes más idóneos suelen ser familiares, profesores y profesionales proveedores apoyos.

La versión piloto de la escala KidsLife cuenta con I 56 ítems, distribuidos en ocho subescalas que se corresponden con las ocho dimensiones de CV (i.e., inclusión social, autodeterminación, bienestar emocional, bienestar físico, bienestar material, derechos, desarrollo personal y relaciones interpersonales). El formato de respuesta presenta cuatro opciones (i.e., nunca, algunas veces, frecuentemente y siempre). Todos ellos son ítems observables, concretos y fáciles de comprender. La escala también contiene una 
presentación de los objetivos de evaluación, una declaración de consentimiento informado, un apartado de datos sociodemográficos de la persona evaluada, del informador principal y de la organización o entidad en la que la persona recibe los servicios o apoyos, una apartado que recoge la valoración general del grado de satisfacción que la persona presenta con su vida tanto antes (grado de satisfacción inicial) como después de la cumplimentación de la escala (grado de satisfacción final) y, finalmente, un apartado para añadir cualquier otra información o sugerencia. Puesto que la escala KidsLife se halla en proceso de validación, no se cuenta aún con datos sobre las propiedades psicométricas del instrumento ni con baremos que permitan interpretar las puntuaciones.

En este estudio se ha utilizado la subescala de RI que cuenta con 20 ítems de valencia positiva. Con el fin de proporcionar evidencias de fiabilidad y validez de la escala en la muestra de estudio, en primer lugar se analizó la consistencia interna de los items mediante tres procedimientos: alpha de Cronbach $(\alpha=, 879)$, la división en dos mitades de Spearman-Brown $\left(r_{x x}=, 829\right)$ y los coeficientes lambda de Guttman $\left(\lambda_{1}=, 835, \lambda_{2}=, 886\right.$ y $\left.\lambda_{3}=, 879\right)$.

En segundo lugar, se analizó la fiabilidad de los items mediante el indice de fiabilidad y el indice de dificultad. Estos índices se representan en la Tabla I. La primera columna de la tabla representa la media del ítem, que se corresponde con el índice de dificultad (ID). La tercera columna representa el índice de fiabilidad $(I F)$, equivalente al producto resultante de la multiplicación de la $D T$ por el índice de homogeneidad corregida del ítem $\left(I H_{c}\right)$. Finalmente, la cuarta columna contiene los valores de alfa corregidos.

Tabla 1. Estadísticos de los ítems de la dimensión RI

\begin{tabular}{|l|c|c|c|c|}
\hline Ítems & M(ID) & DT & IHc & ac \\
\hline RI_01 & 3,18 & 0,772 & 0,334 & 0,878 \\
\hline RI_02 & 3,36 & 0,778 & 0,6 & 0,87 \\
\hline RI_03 & 3,18 & 0,772 & 0,479 & 0,873 \\
\hline RI_04 & 2,25 & 1,075 & 0,225 & 0,885 \\
\hline RI_05 & 2,25 & 0,907 & 0,442 & 0,875 \\
\hline RI_06 & 3,16 & 0,811 & 0,451 & 0,874 \\
\hline RI_07 & 3,67 & 0,546 & 0,341 & 0,877 \\
\hline RI_08 & 3,33 & 0,747 & 0,562 & 0,871 \\
\hline RI_09 & 3,53 & 0,573 & 0,6 & 0,871 \\
\hline RI_10 & 3,15 & 0,731 & 0,513 & 0,872 \\
\hline RI_11 & 3,4 & 0,683 & 0,617 & 0,87 \\
\hline RI_12 & 3,49 & 0,635 & 0,69 & 0,868 \\
\hline RI_13 & 3,49 & 0,605 & 0,72 & 0,868 \\
\hline RI_14 & 2,31 & 1,103 & 0,524 & 0,872 \\
\hline RI_15 & 3,4 & 0,596 & 0,586 & 0,871 \\
\hline RI_16 & 2,89 & 0,916 & 0,539 & 0,871 \\
\hline RI_17 & 2,44 & 0,996 & 0,521 & 0,872 \\
\hline RI_18 & 2,6 & 1,011 & 0,423 & 0,876 \\
\hline RI_19 & 3,18 & 0,722 & 0,727 & 0,866 \\
\hline RI_20 & 2,16 & 1,316 & 0,373 & 0,882 \\
\hline
\end{tabular}

Fuente: elaboración propia. 
En la Figura I se presentan los $I F$ y los $I H c$ de los ítems. Podemos observar como todos los IHc>, 200, por lo que el Io०\% de los ítems se pueden considerar adecuados.

Respecto a los ID de los ítems, los más próximos a las dificultades medias tienen mayor variabilidad (es decir, discriminan mejor entre personas), mientras los más extremos tienen menor variabilidad. En este sentido el ítem que obtiene las puntuaciones más bajas es el RI_2O ('Dispone de recursos que facilitan el contacto con sus seres queridos') $(I D=2, \mathrm{I} 6)$. Por otro lado, el ítem que obtiene las puntuaciones más altas es el RI_o7 ('Mantiene el contacto que desea con su familia') $(I D=3,67)$. Estos resultados se representan en la Figura 2.

\subsection{Procedimiento}

La selección de la muestra se realizó mediante muestreo de conveniencia. En primer lugar, se envió un correo electrónico explicando los objetivos del estudio y solicitando la participación de los centros que atienden a personas con discapacidad de las distintas comunidades autónomas del territorio español. Seguidamente se envió un nuevo correo electrónico a aquellas entidades que mostraron su interés en participar con información acerca del proyecto de investigación, un enlace para inscribirse y poder acceder a la escala y al manual de instrucciones. También se facilitó un número de teléfono y una dirección de correo electrónico para que pudiesen realizar las consultas, comentarios o sugerencias que consideraran oportunas. Finalmente se negoció con cada entidad un plazo para completar las escalas en línea. El periodo de aplicación duró desde octubre de 2013 hasta la primera semana de febrero de 2014.

El análisis de resultados se llevó a cabo a través del paquete estadístico SPSS I9.0 para Windows.

\section{Resultados}

\subsection{Descriptivos de las puntuaciones en RI}

La distribución de las puntuaciones obtenidas en la subescala RI muestra una ligera asimetría positiva (asimetría $=, 076 ;$ curtosis $=-, 975$ ). Cada uno los 20 ítems se puntúan de I a 4 , de forma que la puntuación mínima posible es 20 y la máxima 80 . En este sentido, el rango de las puntuaciones oscila entre 45 y 80 , la media alcanza una puntuación de 60,4 $(D T=9,2)$ y la mediana un valor de 6I. Ambos valores superan ampliamente el punto medio teórico de la subescala (Punto Medio Teórico $=40$ ). De hecho, este valor es ya superado por el percentil 25. Asimismo, la puntuación alcanzada con mayor frecuencia por los participantes es $60(n=49 ; \mathrm{I}, 87 \%)$.

Si analizamos los porcentajes válidos de respuestas dadas por los participantes a cada uno de los ítems, encontramos que las respuestas más positivas ('siempre o casi siempre' en los ítems con valencia positiva) se obtienen en los ítems: RI_7 ('Mantiene el contacto que desea con su familia') ya que el 70,9\% responde 'siempre o casi siempre', mientras que ninguno selecciona la opción 'nunca o casi nunca'. El resto de ítems que presentaron mayores porcentajes de respuestas más positivas (entre el 56,4\% y el 50,9\%) fueron los siguientes: RI_9 ('Se ha identificado la mejor forma de comunicarle información (i.e., visual, táctil, auditiva, olfativa, gustativa)'); RI_I3 ('Se toman medidas específicas para mejorar sus habilidades de comunicación'); RI_I2 ('Las personas que le proporcionan apoyos comprueban si les entiende correctamente mediante el análisis de sus reacciones'); RI_2 ('Celebra acontecimientos importantes para él/ella y sus personas significativas (p. ej., cumpleaños, aniversarios)') y el ítem RI_I I ('Cuando se interactúa con éllella, se le proporciona el tiempo necesario para que pueda responder'). Entre el 9, I \% y el $47,3 \%$ responden con la categoría positiva máxima en cada uno de los catorce ítems restantes, donde los porcentajes se encuentran más repartidos entre las categorías. Estos resultados se muestran en la Figura 3. 


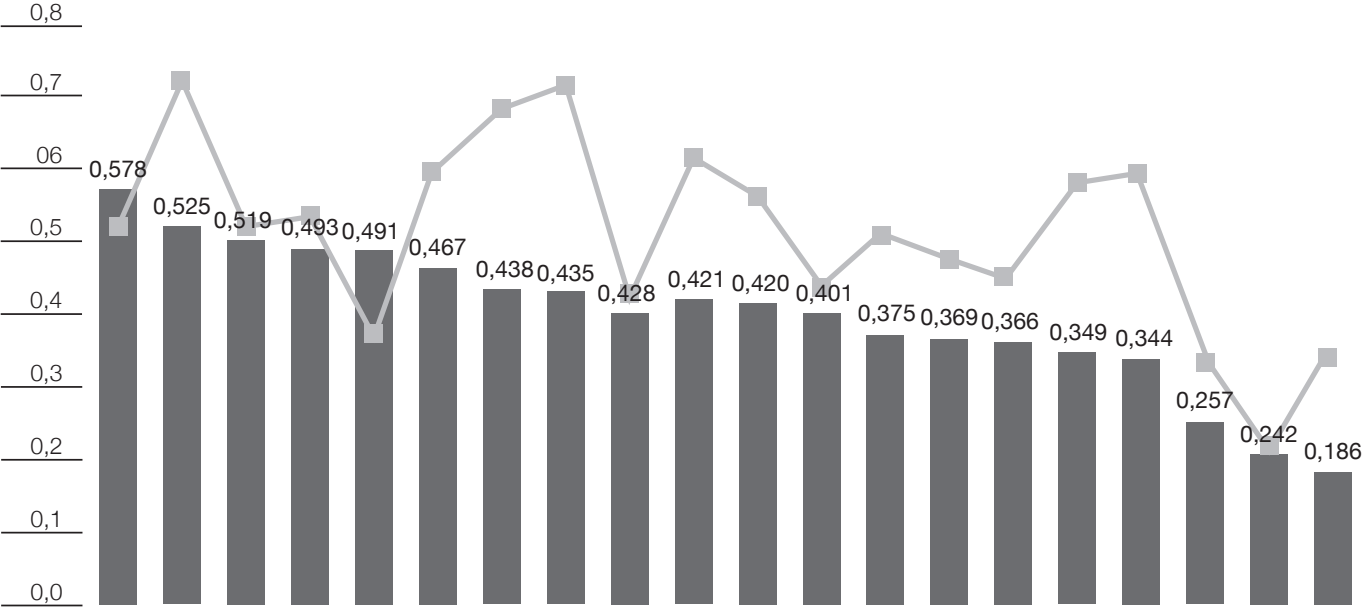

RI_14 RI_19 RI_17RI_16 R_20 RI_02 RI_12 Rl_13 RI_18 RI_11 Rl_08 RI_05 RI_10 Rl_03 RI_06 RI_15 Rl_09 RI_01 RI_04 RI_07

IF

Inc

Fuente: elaboración propia.

\section{Figura 2. Índices de dificultad de los ítems de la dimensión RI}

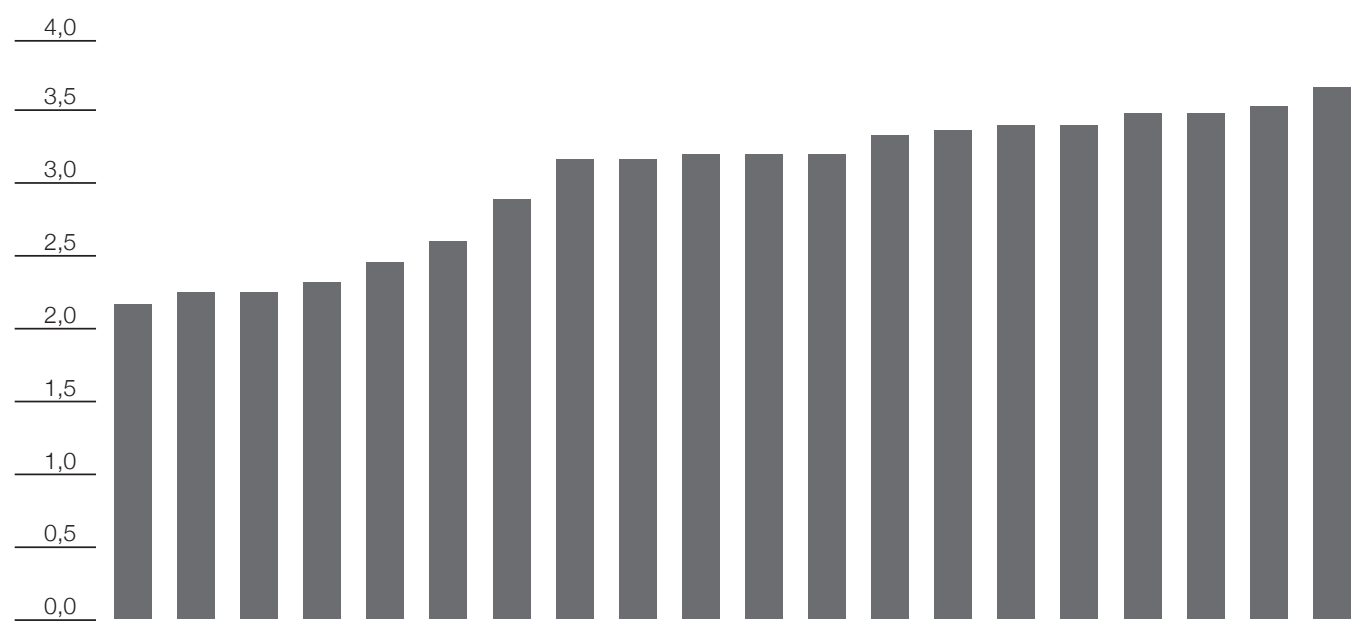

RI-20 RI-04 Rl-05 Rl-14 Rl-17 RI-18 Rl-16 Rl-10 RI-06 RI-01 Rl-03 Rl-19 RI-08 Rl-02 Rl-11 Rl-15 Rl-12 Rl-13 Rl-09 RI-07

Fuente: elaboración propia. 
En el otro extremo, las respuestas más negativas ('nunca o casi nunca') se obtienen en el ítem RI_2o ('Dispone de recursos que facilitan el contacto con sus seres queridos (p. ej., teléfono móvil, ayudas técnicas, internet'), al que el $50,9 \%$ responde 'nunca o casi nunca'. El resto de ítems que presentaron porcentajes de respuestas más negativas (entre el I 6,4 \% y el 29, I \%) fueron los ítems RI_4 ('Tiene oportunidades para estar a solas con sus amistades y personas conocidas), RI_I4 ('Tiene oportunidades para iniciar una relación de amistad si lo desea), RI_5 ('Se toman medidas especificas para mantener y extender sus relaciones sociales') y RI_I7 ('Utiliza un sistema de comunicación entendible en diferentes contextos).

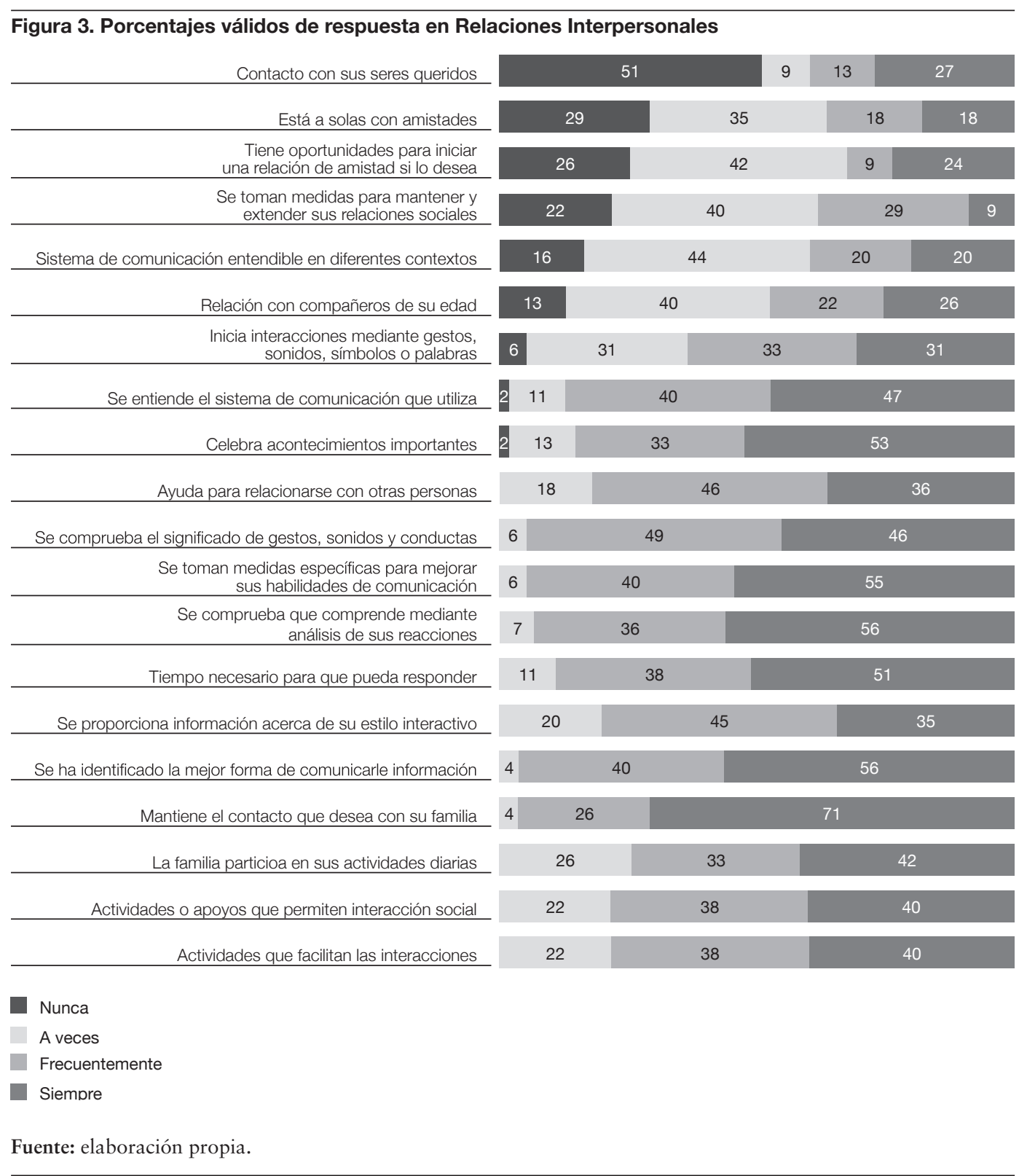




\subsection{Diferencias por variables sociodemográficas}

Para contrastar la relación entre la puntuación total obtenida en la subescala RI con la variable relativa al género, se ha utilizado la prueba $t$ para muestras independientes. Esta no dio lugar a diferencias significativas $\left.(t)_{53}\right)=-2, \mathrm{I}$; $p=, 8)$ : las puntuaciones fueron algo más positivas entre los varones $(M=60,6 ; D T=$ $9,8)$ que entre las mujeres $(M=60 ; D T=$ $7,8)$. Tampoco se encontraron diferencias significativas en función del género en ninguno de los 20 ítems.

En cuanto a las puntuaciones obtenidas por los participantes en la subescala RI en función de su $e d a d$, si atendemos a las medias observamos que son los participantes de 4 a 8 años los que obtienen el valor más alto $(M=63,4 ; D T=8,4)$, seguidos por los participantes entre 9 y I 2 años $(M=60,5 ; D T=9,2)$, los participantes entre I7 y 20 años $(M=60,6 ; D T=9,3)$ y, finalmente, con la puntuación más baja encontramos a los participantes entre I3 y I 6 años $(M=58,5$; $D T=9,8)$.

Los resultados del análisis de varianza (ANOVA) en la puntuación total de la dimensión RI no dieron lugar a diferencias significativas entre los grupos $\left(F_{(3)}=, 7 ; p=, 6\right)$. El mismo procedimiento se llevó a cabo para comprobar si existían diferencias por edad en cada uno de los veinte ítems que componen la dimensión RI. En dos de los ítems se encontraron diferencias estadísticamente significativas: RI_O5 ('Se toman medidas especificas para mantener $y$ extender sus relaciones sociales') $\left(F_{(3)}=5,5\right.$; $p=, 002 ; \eta^{2}=, 245$ ) y en el ítem RI_I4 ('Tiene oportunidades para iniciar una relación de amistad si lo desea') $\left(F_{(3)}=3, \mathrm{I} 25 ; p=, 034\right.$; $\eta^{2}=$, I 55 ).

Los resultados de las pruebas post hoc por ítems diferenciaron dos grupos en el ítem RI_05, así los participantes entre 4 y 8 años alcanzaron puntuaciones significativamente más altas que los participantes entre 9 y I 2 años $(p=, 029)$ y también mayores que los participantes entre I 3 y I 6 años $(p=, 005)$. En el ítem RI_I 4 la prueba $F$ de Scheffé no dio lugar a diferencias estadísticamente significativas.

Respecto a la puntuación total en la dimensión RI en función del tipo de escolarización, si atendemos a las medias observamos que son los participantes de educación combinada los que obtienen el valor más alto $(M=69,5$; $D T=8,3)$, seguidos de aquellos pertenecientes a la escolarización ordinaria $(M=62,7$; $D T=9)$ y, finalmente, con la puntuación más baja encontramos a los participantes de educación especial $(M=59,2 ; D T=8,99)$. Los resultados del ANOVA en la puntuación total de la dimensión RI no dieron lugar a diferencias significativas en función del tipo de escolarización $\left(F_{(2)}=2,660 ; p=, 079\right)$. El mismo procedimiento se llevó a cabo, posteriormente, para comprobar si existían diferencias por tipo de escolarización en cada uno de los veinte ítems que componen la dimensión RI. En tres de los ítems se encontraron diferencias estadísticamente significativas: en el ítem RI_05 ('Se toman medidas especificas para mantener $y$ extender sus relaciones sociales') $\left(F_{(2)}=5, \mathrm{IO}_{3}\right.$; $\left.p=, 009 ; \eta^{2}=, \mathrm{I} 64\right)$ ); en el ítem RI_I4 ('Tiene oportunidades para iniciar una relación de amistad si lo desea') $\left(F_{(2)}=3,67 \mathrm{I} ; p=, 032\right.$; $\eta^{2}=$, I 24) $y$ en el ítem RI_I 5 ('Se comprueba de forma sistemática el significado de sus gestos, sonidos y conductas') $\left(F_{(2)}=4, \mathrm{I} ; p=, 022\right.$; $\left.\eta^{2}=, \mathrm{I} 36\right)$.

Los resultados de las pruebas post hoc por ítems diferenciaron un grupo en el ítem RI_I4 y dos grupos en los ítems RI_05 y RI_I 5. En el ítem RI_05 los participantes de educación combinada alcanzaron puntuaciones significativamente más altas que los participantes de educación especial $(p=$, OI I $)$. En el ítem RI_I 5 las diferencias significativas se dieron también entre estos dos mismos grupos $(p=, \infty \circ)$.

El análisis de la puntuación total en la subescala RI según el nivel de DI (leve, moderada, severa o profunda) revela, en primer lugar, la diferencia en el número de participantes incluidos en cada categoría. Así encontramos que el grupo más numeroso es el conformado por personas con DI severa $(n=37)$, seguido del de personas con DI 
moderada $(n=\mathrm{II})$, y del grupo de personas con DI profunda $(n=6)$. Finalmente el nivel leve de DI es el menos numeroso de todos $(n=\mathrm{I})$. Puesto que dicho nivel cuenta con un solo participante no podemos realizar pruebas post hoc, por lo que se optó por eliminar esta categoría. De este modo, son los participantes con DI moderada los que obtienen el valor más alto $(M=65,9$; $D T=8,5)$, seguidos por los participantes con DI severa $(M=60,5 ; D T=8,7) \mathrm{y}$, finalmente, aquellos con DI profunda $(M=50,6 ; D T=6,6)$. El ANOVA puso de manifiesto la existencia de diferencias significativas en función del nivel de DI $\left(F_{(6)}=10,85 ; p=, 004 ; \eta^{2}=\right.$, I 98$)$ y la prueba de comparaciones múltiples constató la existencia de dos grupos. Las personas con DI profunda obtuvieron puntuaciones significativamente más bajas que aquellos con DI severa y aquellos con DI moderada.

También se encontraron diferencias por el nivel de DI en siete de los ítems. Los resultados de las pruebas post hoc por ítems diferenciaron dos grupos en cada uno de los ítems, excepto en el ítem RI_I4 ('Tiene oportunidades para iniciar una relación de amistad si lo desea') en el que no aparecieron diferencias estadísticamente significativas. En el ítem RI_O2 ('Celebra acontecimientos importantes para éll ella y sus personas significativas') las personas con DI moderada alcanzaron puntuaciones significativamente más altas que las personas con DI profunda $(p=, 039)$. En el ítem RI_o8 ('Las personas que le proporcionan apoyos entienden el sistema de comunicación que utiliza'), los participantes con DI profunda años alcanzaron puntuaciones significativamente más bajas que los participantes con DI severa ( $p=$, oI 9$)$ y que los participantes con DI moderada ( $p=$,oI9). En el ítem RI_I I ('Cuando se interactúa con éllella, se le proporciona el tiempo necesario para que pueda responder') los participantes con DI severa alcanzaron puntuaciones significativamente más altas que los participantes con DI profunda ( $p=$, o I 7 ). En el ítem RI_I 2 ('Las personas que le proporcionan apoyos comprueban si les entiende correctamente mediante el análisis de sus reacciones') las diferencias significativas se dieron también entre estos dos mismos grupos $(p=, 022)$ a favor del grupo con DI severa. A su vez, en el ítem RI_I6 ('Inicia interacciones mediante gestos, sonidos, simbolos o palabras') las personas con DI moderada alcanzaron puntuaciones significativamente más altas que las personas con DI profunda $(p=, 003)$.En el ítem RI_I7 ('Utiliza un sistema de comunicación entendible en diferentes contextos') los participantes con DI moderada alcanzaron puntuaciones significativamente más altas que los participantes con DI severa $(p=$ ,035) y profunda $(p=, 003)$. En el caso del ítem RI_20 ('Dispone de recursos que facilitan el contacto con sus seres queridos') $\left(F_{(2)}=6,907 ; p=\right.$ ,००2; $\eta^{2}=, 2 \mathrm{I} 3$ ) las personas con DI moderada alcanzaron puntuaciones significativamente más altas que las personas con DI severa $(p=, 002)$.

Para contrastar la relación entre la puntuación total obtenida en la subescala RI con la variable relativa a la presencia o no de problemas de comportamiento, utilizamos la prueba $t$ para muestras independientes. Ésta no dio lugar a diferencias significativas $\left(t\left(_{53}\right)=\mathrm{I}, 540\right.$; $p=, \mathrm{I} 29)$ las puntuaciones fueron algo más positivas entre los participantes sin problemas de comportamiento $(M=6 \mathrm{I}, 8 ; D T=9,6)$ que entre los que sí presentaban problemas de comportamiento $(M=57,7 ; D T=7,9)$. En cuanto a los ítems (Figura 4), sólo se encontraron diferencias significativas en el ítem RI_20 ('Dispone de recursos que facilitan el contacto con sus seres queridos').

\section{Discusión y conclusiones}

El objetivo general que ha guiado este trabajo ha consistido en analizar de forma exhaustiva las RI de los niños y jóvenes con TEA y DI. La distribución en la puntuación de la subescala RI resultó asimétrica negativa. Asimismo, la media, la moda y la mediana superaron el punto medio teórico de la escala RI. Por tanto, si bien las puntuaciones de niños y jóvenes con TEA en RI son positivas (por encima del punto medio teórico de la subescala), las puntuaciones 


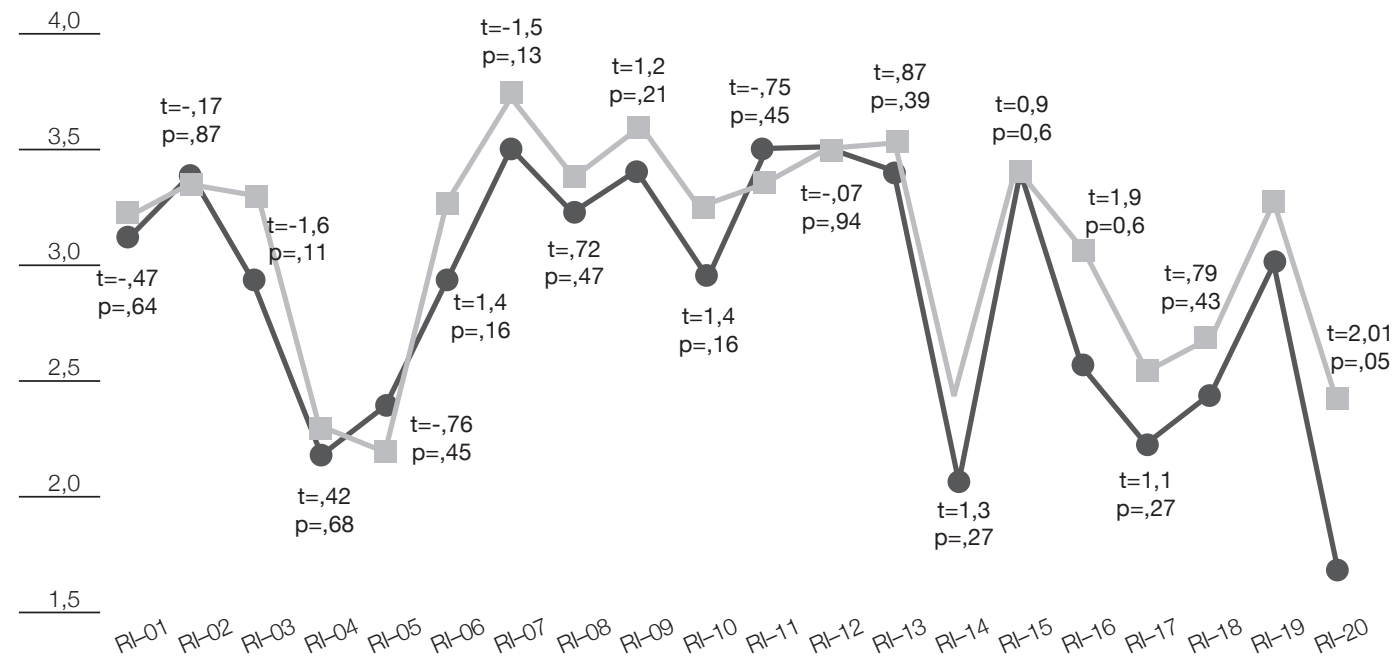

Sí

No

Fuente: elaboración propia.

son mejorables y se detectan necesidades importantes.

Respecto a los ítems, los participantes obtuvieron las mejores puntuaciones en el ítem RI_7 ('Mantiene el contacto que desea con su familia'), lo que no resulta sorprendente si tenemos en cuenta que el $72,73 \%$ de los participantes residen en el hogar familiar. También encontramos altas puntuaciones en algunos de los ítems relativos a la comunicación. En este sentido, parece que los esfuerzos y las prácticas por parte de las organizaciones destinadas a solventar los problemas de comunicación (uno de los rasgos centrales del TEA) son exitosos.

En cambio, las peores puntuaciones se obtuvieron en el ítem RI_2o ('Dispone de recursos que facilitan el contacto con sus seres queridos (p. ej., teléfono móvil, ayudas técnicas, internet'), lo que puede interpretarse como la no necesidad de tales recursos dado que la mayor parte de los participantes viven con sus familias.
También se obtuvieron bajas puntuaciones en los ítems relativos a fomentar las interacciones sociales. Estos resultados reflejan las dificultades que estos niños y jóvenes presentan a la hora de establecer contactos y relaciones sociales, lo que a su vez pone en entredicho la eficacia de los programas centrados en este ámbito, tal vez por no estar ajustados a las verdaderas necesidades de las personas (Walton e Ingersoll, 2013: 595). En cuanto al género, si bien la muestra de participantes con TEA estaba formada en su mayoría por varones $(72,7 \%)$, lo que se corresponde con la media de distribución del sexo en los TEA de una mujer por cada cuatro varones (Lee et al., 2008: I I 50), no se observan diferencias significativas, lo que concuerda con los resultados obtenidos en anteriores investigaciones (Gómez, 2010: 659).

Respecto a la edad aunque los análisis de varianza no dieron lugar a diferencias significativas en la puntuación total en RI, si atendemos a las medias los participantes de 4 a 8 años obtienen el valor más alto, seguidos 
por los participantes entre 9 y I 2 años. Por su parte, los jóvenes entre I 3 y I 6 años obtienen la puntuación más baja y, si bien se produce un aumento de las puntuaciones entre aquellos de edades comprendidas entre 17 y 20 años, no alcanzan los niveles encontrados en los participantes entre 4 y 8 años. El hecho de que no aparezcan diferencias significativas es una evidencia a favor de que la subescala RI puede ser válida para todas las edades. Sin embargo, sí aparecieron diferencias significativas en función de la edad en el ítem RI_05 'Se toman medidas especificas para mantener y extender sus redes sociales'; así ,los participantes entre 4 y 8 años alcanzaron puntuaciones significativamente más altas que aquellos de edades entre 9 y I 2 años y también mayores que los participantes entre I3 y I 6 años. Estos resultados concuerdan con los hallados en la literatura, en los que los padres de los niños con TEA de menor edad informan de mayores puntuaciones en la CV que los padres de los niños de mayor edad. Resulta pues importante conocer los factores que pueden influir en el descenso de las puntuaciones al aumentar la edad del niño, ya que permitirían identificar y poner en marcha estrategias de intervención eficaces (Kuhlthau et al., 2010: 727), lo que sería posible a través de un estudio longitudinal.

El análisis de la puntuación total en la dimensión RI en función del tipo de escolarización revela que la gran mayoría de los participantes $(80 \%)$ pertenecen al grupo de educación especial. Si bien los resultados del ANOVA en la puntuación total de esta dimensión no dieron lugar a diferencias significativas, si atendemos a las medias observamos que los participantes de educación combinada obtienen el valor más alto, seguidos por aquellos pertenecientes a la escolarización ordinaria y, finalmente, con la puntuación más baja encontramos a los participantes de educación especial. Además, en dos de los ítems, los participantes de educación combinada alcanzaron puntuaciones significativamente más altas que los participantes de educación especial. Estos resultados reflejan como la educación inclusiva mejora las RI y, por tanto, la CV de los niños y adolescentes con TEA. Sin embargo, también reflejan la dificultad para poner en práctica dicha inclusión en las escuelas ordinarias. Todo ello apunta a la necesidad de cambios profundos en la cultura de los centros, y así conseguir el mayor desarrollo posible de las capacidades personales, sociales e intelectuales de todos los alumnos, sin discriminación alguna (Gutiérrez, 2006: xiii).

Se encontraron diferencias significativas también en la puntuación total en RI en función del nivel de DI. Las personas con DI profunda obtuvieron puntuaciones significativamente más bajas que aquellos con DI severa y moderada. Asimismo, se encontraron diferencias estadísticamente significativas en ocho de los ítems. Estos resultados concuerdan con la bibliografía analizada, según la cual los niños con TEA que presentan déficits sociales obtienen menores puntuaciones en desarrollo cognitivo (Gillis et al., 20I I: 352). A pesar de ello, si bien es cierto que las investigaciones han demostrado que las personas con TEA de todos los niveles de funcionamiento intelectual pueden beneficiarse de intervenciones centradas en el aprendizaje de habilidades sociales que mejoran sus interacciones sociales (Walton e Ingersoll, 20I3: 6I2), estos hallazgos ponen de manifiesto que las personas con DI severa y profunda han sido el colectivo que ha disfrutado de estos avances en menor medida y para quienes la implementación de estos cambios ha resultado más compleja (Gómez et al., en prensa). Por tanto, las personas con TEA y DI severa y profunda presentan otro tipo de necesidades que no pueden ser cubiertas por los programas diseñados para las personas con TEA y DI moderada (Walton e Ingersoll, 20I3: 595), sino que deben ser específicos, es decir ajustados al nivel de funcionamiento que presenta la persona.

Respecto a la presencia o no de problemas de comportamiento, cabe destacar la alta prevalencia de problemas de comportamientos en la muestra $(32,7 \%)$, lo que corresponde con los hallazgos de la literatura especializada que señalan que una de cada tres personas con TEA presenta problemas de comportamiento (Emerson, 2003: 56). Si bien no aparecen diferencias significativas en la puntuación total 
en RI en función de la presencia de problemas de comportamiento, las puntuaciones fueron más positivas entre los participantes que no los presentan. Estos datos sugieren que las intervenciones dirigidas a la reducción y/o eliminación de dichos comportamientos pueden mejorar la CV tanto de las personas con TEA como la de sus familias (Lee et al., 2008: I I 59).

Los resultados de este estudio tienen importantes implicaciones en la intervención sobre las necesidades en las RI de niños y adolescentes con TEA. El nivel de habilidades sociales a lo largo de la vida es un importante predictor del bienestar psicológico. Por este motivo, la intervención temprana desde el momento en que las alteraciones en las RI son detectadas es fundamental para incrementar el funcionamiento social del niño y, por tanto, mejorar su CV (Tureck y Matson, 20I 2: 6I3). No obstante este estudio no está libre de limitaciones y entre ellas cabe destacar las características de la muestra (número reducido de participantes no seleccionados al azar), por lo que sus conclusiones no pueden generalizarse. Otro de sus puntos débiles es que si bien los informes de otras personas han sido utilizados casi en exclusiva para evaluar la CV de personas con TEA y reúnen los criterios de validez, han mostrado una baja-media correlación con los autoinformes de los niños con TEA, siendo estos últimos considerados como la mejor forma de evaluar la CV.

Con respecto a las líneas futuras de investigación, es mucho aun lo que desconocemos acerca de cómo las RI determinan la CV calidad de estas personas. Es imprescindible por tanto continuar con el estudio y análisis de las necesidades de los niños con TEA y las de sus familias, de forma que permitan la puesta en marcha de los servicios y apoyos necesarios para una vida de calidad. En este sentido este estudio constituye una primera aproximación a la evaluación de la CV de niños y jóvenes con TEA y DI, que facilita la implementación de prácticas basadas en la evidencia y el desarrollo de planes individuales de apoyo.

\section{Agradecimientos}

El equipo de investigación ha trabajado en el marco del proyecto de investigación del Ministerio de Economía y Competitividad PSI20I 2-33 I39. Los autores quisieran agradecer a las organizaciones, personas con discapacidad intelectual, profesionales y familiares el haber completado los cuestionarios. 
Referencias bibliográficas

American Psychiatric Association. (2013): Diagnostic and statistical manual of mental disorders ( $5^{\text {th }}$ ed.), Washington, D.C.: American Psychiatric Association.

Cuesta, J. L. (2009): Trastornos del espectro autista y calidad de vida. Guía de indicadores para evaluar organizaciones y servicios, Madrid: La Muralla.

Deckers, A. et al. (20I4): "Desire for social interaction in children with autism spectrum Disorders”. Research in Autism Spectrum Disorders, 8, 449-453.

Emerson, E. (2003): "Prevalence of psychiatric disorders in children and adolescents with and without intellectual disability". Journal of Intellectual Disability Research, 47, 5I-58.

España. Resolución de 2 de diciembre de 2008 , por la que se establecen criterios comunes de acreditación para garantizar la calidad de los centros y servicios del Sistema para la Autonomía y Atención a la Dependencia. Boletín Oficial del Estado, 17 de diciembre de 2008, núm. 303, pp. 50722-50725.

España. Ley 39/2006, de I4 de diciembre, de Promoción de la Autonomía Personal y Atención a las personas en situación de dependencia. Boletín Oficial del Estado, I 5 de diciembre de 2006, núm. 299, pp. 44 I4244 I 56.

Gillis, J. M. et al. (20I I): “Assessment of social behavior in children with autism: The development of the Behavioral Assessment of Social Interactions in Young Children". Research in Autism Spectrum Disorders, 5:35 I360.

Gómez, L. E. (2010):“Evaluación de la calidad de vida en servicios sociales: validación y calibración de la escala GENCAT" (Tesis doctoral) (en línea). http://gredos.usal.es/jspui/ handle/ı0366/76489', acceso 5 de mayo de 2014 .

Gómez, L. E. et al. (en prensa): "Escala KidsLife”. Salamanca: INICO.
Gómez, L. E. et al. (20I0a):“Calidad de vida individual: avances en su conceptualización y retos emergentes en el ámbito de la discapacidad". Behavioral Psychology/ Psicología Conductual, I 8(3): 453-472.

Gómez, L. E. et al. (20IOb): “A comparison of alternative models of individual quality of life". Social IndicatorsResearch, Iог: I09-I 26.

Gómez, L. E. et al. (2014): "El constructo de calidad de vida en niños y adolescentes con discapacidades múltiples y profundas: propuesta para su evaluación”. Siglo Cero, 45 (I): 56-69.

Gutiérrez, I. (2006): "Prólogo" en Aranda, R. E. (coord.):Educación especial: áreas curriculares para alumnos con necesidades educativas especiales, Madrid: Pearson-Prentice Hall.

Kuhlthau, K. et al. (2010): "Health-Related Quality of Life in Children with Autism Spectrum Disorders: Results from the Autism Treatment Network". Journal of Autism and Developmental Disorders, 40:72 I-729.

Lee, L. et al. (2008):“Children with Autism: Quality of Life and Parental Concerns. Journal of Autism and Developmental Disorders", 38 : I I 47-I I 60.

Schalock, R. L. et al. (2009): Quality of life for people with intellectual and other developmental disabilities. Applications across individuals, organizations, communities, and systems, Washington, DC: American Association on Intellectual and Developmental Disabilities (Orig. 2007).

Schalock, R. L. et al. (20Iо): "Quality of life model development in the field of intellectual disability, en R. Kober (dir.): Quality of life for people with intellectual disability. Nueva York: Springer.

Schalock, R. L. y Verdugo, M. A. (2003): Quality of life for human service practitioners. Washington, DC: American Association on Mental Retardation. (Orig. 2002). 
Schalock, R. L. y Verdugo, M. A. (2007):“El concepto de calidad de vida en los servicios y apoyos para personas con discapacidad intelectual”. Siglo Cero, 38:2 I-36.

Schalock, R. L. y Verdugo, M. A. (2012):“A conceptual and measurement framework to guide policy development and systems change". Journal of Policy and Practice in Intellectual Disabilities, 7: 7I-8I.

Sheldrick, R. C. et al. (20I2): "Quality of life of adolescents with autism spectrum disorders: concordance among adolescents' self-reports, parents' reports, and parents' proxy reports". Quality of Life Research, 2I: 53-57.

Summers, J. A. et al. (2005): “Conceptualizing and measuring family quality of life". Journal of Intellectual Disability Research, 49: 777-783.

Tureck, K. y Matson, J. L. (2OI 2): “An examination of the relationship between autism spectrum disorder, intellectual functioning, and social skills in children". Journal of Developmental and Physical Disabilities, 24:607-6I 5.

Verdugo, M. A. et al. (2007):“Construcción de escalas de calidad de vida multidimensionales centradas en el contexto: La escala Gencat”. Siglo Cero, 38(4): 57-72.

Walton, K. M. e Ingersoll, B. R. (2OI3): “Improving social skills in adolescents and adults with autism and severe to profound intellectual disability: a review of the literature". Journal of Autism and Developmental Disorders, 43: 594-61 5 .

WHOQOL Group (1998): “The World Health Organization WHOQOL-BREF quality of life assessment”. Psychological Medicine, 28: $55 \mathrm{I}-55^{8}$. 



\section{Evaluación de la calidad de vida en personas con discapacidades significativas: aplicación de la Escala San Martín en la Fundación Obra San Martín}

\section{Evaluating the quality of life of people with profound and multiple disabilities: Use of the San Martín Scale at the Obra San Martín Foundation}

\section{Resumen}

La Escala San Martín es un instrumento que permite evaluar la calidad de vida de personas con discapacidades significativas con evidencias adecuadas de fiabilidad y validez. En 20I 2 se administró la Escala San Martín a 85 personas con discapacidad intelectual que acudían a alguno de los centros de la Fundación Obra San Martín. El presente artículo recoge los resultados obtenidos agregados en el mesosistema, un ejemplo del microsistema y las líneas de trabajo puestas en marcha a partir de los resultados obtenidos.

\section{Palabras clave}

Calidad de vida, discapacidad intelectual, discapacidades múltiples y profundas, evaluación, apoyos.

\section{Abstract}

The San Martín Scale is an instrument used to measure the quality of life of people with significant disabilities with adequate levels reliability and validity. In 20I 2, the San Martín Scale was administered to 85 adults with intellectual disabilities who were provided supports at Obra San Martin Foundation (Santander). In this article, we describe the results obtained at the mesosystem level, an example at the microsystem level, and future areas of work identified from the results.

\section{Keywords}

Quality of life, intellectual disability, profound and multiple disabilities, assessment, supports.
Irene Hierro Zorrilla

<i.hierro@fundacionobrasanmartin.org>

Fundación Obra San Martín

\section{Miguel Ángel Verdugo Alonso \\ <verdugo@usal.es> \\ Universidad de Salamanca}

\section{Laura Elisabeth Gómez}

Sánchez

<gomezlaura@uniovi.es>

Universidad de Oviedo

\section{Sonia Fernández Ezquerra}

<coordinacion@fundacionobrasanmartin.org>

Fundación Obra San Martín

Patricia Cisneros Fernández $<$ p.cisneros@fundacionobrasanmartin.org>

Fundación Obra San Martín

Para citar:

Hierro, I. et al. (201 5): "Evaluación de la calidad de vida en personas con discapacidades significativas: aplicación de la Escala San Martín en la Fundación Obra San Martín”, Revista Española de Discapacidad, 3 (I): 93-IO5.

Doi: <http://dx.doi.org/IO.5569/23405104.03.01.05>

Fecha de recepción: 30-07-20I4 Fecha de aceptación: IO-O4-20I 5 
1. Aplicación de la Escala San Martín en la Fundación Obra San Martín

“¿Cómo valoramos la calidad de vida de los nuestros?" fue la pregunta más repetida en una mañana de noviembre de 20I0, en el salón de actos de la Fundación Obra San Martín (Santander), por un grupo de 35 profesionales (entre ellos, psicólogos, terapeutas, educadores, trabajadores sociales y auxiliares técnicoeducativos) que asistían a un curso de formación sobre el modelo de calidad de vida impartido por el Dr. M. A. Verdugo.

Al conocer escalas de evaluación de calidad de vida como la Escala INTEGRAL (Verdugo et al., 2009) o la Escala GENCAT (Verdugo et al., 2008), los profesionales de la Fundación Obra San Martín consideraron que algunos ítems no encajaban con las personas a las que prestaban apoyos y que no recogían aspectos que podían ser cruciales para el bienestar de las personas con discapacidades significativas.

En los últimos años se han producido importantes avances en el campo de la discapacidad intelectual: nueva definición de discapacidad intelectual de la Asociación Americana sobre Discapacidades Intelectuales y del Desarrollo (American Association on Intellectual and Developmental Disabilities, AAIDD), operativización del concepto de calidad de vida propuesto por Schalock y Verdugo (2002/2003, 2008, 20I2), programas de intervención basados en evidencias, desarrollo de instrumentos de evaluación con evidencias de validez y fiabilidad, cambios en los roles de los profesionales, apertura hacia la comunidad, y otros. Se ha evolucionado así desde una concepción basada en la beneficencia a una perspectiva centrada en los derechos, en la participación e inclusión en la vida de la comunidad, en la autodeterminación y en la planificación de apoyos centrados en la personas. Se ha desplazado el énfasis a conceptos como calidad de vida, autodeterminación, funcionamiento, inclusión social y educativa, planes de apoyo individualizados, derechos humanos y conducta adaptativa (Verdugo et al., 2OII).

Todos estos avances tienen un fin último, la mejora de la calidad de vida de las personas con discapacidad intelectual. Para ello, en nuestro país, se han desarrollado recientemente diversos instrumentos de evaluación de la calidad de vida con adecuadas evidencias de fiabilidad y validez, entre ellos: (a) la Escala INICOFEAPS, dirigida a evaluar la calidad de vida de adultos con discapacidad intelectual o del desarrollo desde la perspectiva de la persona y desde la perspectiva de otra persona que la conoce bien (Verdugo et al.,2013a, 2013b); (b) la Escala Integral (Verdugo et al., 2009), que permite la evaluación integral de la calidad de vida de personas con discapacidad intelectual; (c) la Escala GENCAT (Verdugo et al., 2008a, 2008b, 2009, 2010), que permite la evaluación de la calidad de vida de usuarios de servicios sociales (entre ellos, personas con discapacidad intelectual, personas con discapacidad física, personas mayores, personas con problemas de salud mental, personas con drogodependencias y personas con VIH/SIDA); (d) la Escala FUMAT (Verdugo et al., 2009), dirigida a la evaluación de la calidad de vida de personas mayores; (e) los Cuestionarios de Evaluación de la Calidad de Vida en la Infancia (CVI-CVIP) (Sabeh et al., 2009), dirigidos a niños con y sin discapacidad; y (f) el Cuestionario de Evaluación de la Calidad de Vida de Alumnos Adolescentes (CCVA), también dirigido a estudiantes con o sin discapacidad durante la etapa de la adolescencia (Gómez-Vela y Verdugo, 2009).

Sin embargo, mientras se han producido notables avances en la evaluación de resultados personales relacionados con la calidad de vida de aquellas personas con discapacidades intelectuales y del desarrollo con mayores niveles de funcionamiento, en España no existen instrumentos adecuados para evaluar la calidad de vida de las personas con discapacidades significativas, de tal modo que los escasos instrumentos existentes se han centrado tradicionalmente en la evaluación de la calidad de los apoyos que reciben. Parece pues fácil confundir la calidad de los cuidados y los 
apoyos que las personas reciben con sus metas y deseos, especialmente cuando nos referimos a las personas con graves afectaciones que presentan con frecuencia limitaciones en la comunicación.

Autores como Zijlstra y Penning (2004) afirman que todavía existe una falta de instrumentos de evaluación con propiedades psicométricas adecuadas para esta población. Las personas con discapacidades significativas conforman un grupo heterogéneo que tiene en común distintos aspectos, como la dependencia de otras personas en la mayoría de actividades de su vida diaria. Su bajo nivel de funcionamiento intelectual y sus dificultades a la hora de comunicarse hacen muy difícil utilizar escalas de calidad de vida autoinformadas. Por lo tanto, las escalas de calidad de vida se realizan mayoritariamente mediante informes de otras personas que conocen bien a la persona con discapacidades significativas.

Las escalas de evaluación de calidad de vida publicadas hasta la fecha están destinadas a personas con discapacidad intelectual con menor nivel de necesidades de apoyo, por lo que incluyen ítems que reflejan indicadores de calidad de vida que en ocasiones no son relevantes en la vida de las personas con grave afectación (e.g., ítems relativos a la situación laboral). Además, encontramos que otros aspectos que pueden ser cruciales en su vida no están recogidos en estas escalas (e.g., movilidad, productos de apoyo, comunicación).

En el año 2005, el equipo formado por Petry, Maes y Vlaskamp hizo un primer intento de operativizar la calidad de vida de las personas con discapacidades significativas. Estas autoras partieron del modelo de calidad de vida propuesto por Felce y Perry (I995). Para ello entrevistaron a padres y personal de atención directa con objeto de comprobar si las cinco dimensiones eran relevantes para las personas con discapacidades severas y múltiples. Encontraron que más del $50 \%$ de las personas entrevistadas encontraban de forma espontánea relevantes las cinco dimensiones. Cuando se les preguntaba de forma directa, entre el $80 \mathrm{y} \mathrm{el}$ I०० \% de personas las encontraba relevantes.
Como resultado de las entrevistas, desarrollaron un banco de 223 ítems, estructurado en torno a las cinco dimensiones, con sus correspondientes indicadores. Para comprobar la utilidad y validez del banco de ítems, en 2007, se realizó un estudio Delphi de dos rondas con 45 expertos que evaluaron el contenido y la estructura del banco de ítems. El resultado preliminar fue un conjunto de I05 ítems divididos en seis subescalas: bienestar material, bienestar físico, bienestar social, comunicación e influencia, desarrollo personal y actividades.

En 2009, realizaron un estudio para valorar las propiedades del instrumento desarrollado a partir del estudio Delphi anterior, denominado QOL-PMD. Para ello, se evaluó la calidad de vida de 49 personas con discapacidades significativas mediante I 47 informantes (Petry et al., 2009a, 2009b). Aunque el tamaño de la muestra no era lo suficientemente grande como para ser representativo, se redujo la escala casi en un $50 \%$ (se eliminaron 50 de los IO5 ítems).

En junio de 20I I la Fundación Obra San Martín y el INICO firmaron un convenio para la elaboración de una escala de calidad de vida para personas con discapacidades significativas: la Escala San Martín, que está llamada a llenar el vacío existente en lo relativo a herramientas adaptadas y específicas para estas personas. El proceso de creación de la escala piloto constó de un estudio Delphi realizado por I 2 jueces expertos, seleccionándose aquellos que obtuvieron una media igual o superior a $3 \mathrm{y}$ una desviación típica inferior a I,5. También se realizó un grupo de discusión que permitió la reformulación, modificación y explicitación de algunos de los ítems. Así la escala piloto se compuso de I 20 ítems. Esta escala piloto fue aplicada a I 770 personas con discapacidades significativas de distintas provincias españolas.

Se realizó un análisis de los índices de homogeneidad corregida (IHc) eliminándose 5 ítems cuyos valores eran inferiores a .20. De los restantes se seleccionaron aquellos con $\mathrm{IHc}$ más altos, en total I 20 ítems ( I 2 por dimensión, excepto Inclusión Social que quedó conformada por II). 
Respecto a la consistencia interna obtenida a través del coeficiente alfa de Cronbach la Escala obtuvo un valor total de .97 . La validez se comprobó a través de un análisis factorial confirmatorio (AFC) con LISREL v. 9.I. "dando lugar a índices de ajuste que indicaban la adecuación de dicha estructura: $\chi 00=2676.694$; $\mathrm{p}=.000 ; \mathrm{RMSEA}=.054 ; \mathrm{CFI}=.984 ; \mathrm{TLI}=.98 \mathrm{I}$; SRMR $=.044 "$ (Verdugo et al., 20I4b).

El presente artículo tiene como objetivo examinar los resultados obtenidos en la administración de la Escala San Martín (Verdugo et al., 20I4b) en la Fundación Obra San Martín, y valorar las implicaciones prácticas de los mismos en las prácticas profesionales y en el funcionamiento organizacional. Los resultados detallados son los agregados en el mesosistema y un ejemplo de resultados en el microsistema.

\section{Método}

\subsection{Participantes}

La Escala San Martín se administró en 2012 a un total de 85 personas con discapacidades significativas (e.g., personas con discapacidad intelectual que requieren apoyos extensos y generalizados, y en su mayoría con otras discapacidades asociadas) que recibían apoyos en uno o más de los centros de la Fundación Obra San Martín. De ellas, algo más de la mitad, el $59 \%(n=50)$ eran mujeres, frente a 35 varones, que suponían el 4I \% de la muestra. Las edades oscilaron entre 20 y 67 años (la media y la mediana se situaron en 42 años, mientras que la moda se situó en 46 ).

En cuanto a la intensidad de los apoyos prestados el $47 \%(n=40)$ de las personas recibían apoyos de tipo extenso y el $5 \mathrm{I} \%$ $(n=45)$ recibían apoyo de tipo generalizado. De las 85 personas a las que se administró la escala, 47 contaban con la evaluación de dependencia $(55 \%)$. De éstas, el $4 \%(n=2)$ tenían reconocido un Grado II, mientras que el $96 \%$ de las personas $(n=45)$ tenían reconocido un Grado III de Gran Dependencia. En cuanto al porcentaje de discapacidad reconocido, la media se situó en 82 , la mediana en 83 y la moda en 75 . El nivel de discapacidad más bajo se situó en $5 \mathrm{I} \%$ y el más alto en $99 \%$. El 91,76\% $(n=78)$ de las personas tenían reconocido un porcentaje de discapacidad igual o mayor al $66 \%$.

Otro dato que resulta importante destacar es su grado de institucionalización. De las 85 personas, sólo 7 ( $8 \%$ ) vivían en su domicilio familiar, el restante $92 \%$ vivía en alguno de los centros residenciales de la Fundación Obra San Martín. Respecto al tiempo que llevaban las personas viviendo en la Fundación Obra San Martín, la media se situó en I 9 años de estancia, encontrándose el periodo mínimo en I año y el máximo en 45 años.

Cabe destacar que 74 personas $(87 \%)$ presentaron alguna otra condición asociada a la discapacidad intelectual y $47(52 \%)$ presentaban dos o más condiciones asociadas. Las dos condiciones más frecuentes fueron epilepsia $(37,64 \%)$ y problemas de comportamiento $(35,3 \%)$. Dentro de la categoría "otras condiciones asociadas”, se incluyeron condiciones como deterioro cognitivo, enfermedad de Parkinson e hipercolesterolemia. El $80 \%$ de las personas $(n=68)$ tenía prescrito algún tipo de tratamiento farmacológico de carácter crónico. De ellas, 35 (5 I \%) recibían dos o más tipos de medicamentos. Los tratamientos farmacológicos más administrados eran antiepilépticos $(37,64 \%)$ y neurolépticos $(35,3 \%)$.

\subsection{Instrumento}

La Escala San Martín permite evaluar la calidad de vida de personas con discapacidades significativas a través de un informante que conoce bien a la persona (al menos desde hace tres meses) y que tiene oportunidades de observarla durante periodos prolongados de tiempo y en diversos contextos. La escala cuenta con una fiabilidad y validez constatadas, lo que permite recomendar su aplicación en personas 
con discapacidades intelectuales múltiples y profundas (Verdugo et al., 2013c; Verdugo et al., 2014a).

La Escala se cumplimenta con un formato de respuesta con cuatro opciones de frecuencia: siempre, frecuentemente, a veces y nunca. La escala consta de 95 ítems que se distribuyen en torno a las ocho dimensiones de calidad de vida, de modo que todas las subescalas constan de I 2 ítems, excepto la subescala inclusión social que consta de II.

Una vez corregida, la Escala San Martín proporciona puntuaciones estándar $(M=\mathrm{I} O$; $D T=3$ ) y percentiles para cada una de las ocho dimensiones de calidad de vida, así como una puntuación general, denominada Índice de Calidad de Vida ( $M=$ I००; $D T=$ I $\left._{5}\right)$. Todas estas puntuaciones se pueden representar gráficamente en un perfil de calidad de vida.

\subsection{Procedimiento}

El proceso de administración de la escala se inició en junio de 2012 y terminó en noviembre del mismo año. La Escala fue cumplimentada por nueve profesionales de la Fundación Obra San Martín adscritos a alguno de los cinco centros participantes: Centro Residencial de Atención Básica "Edificio Jado”, Centro Residencial de Atención 24 Horas "La Albarca", Centro Ocupacional "La Semilla", Centro de Día "San Martín” y Centro de Día "Jado".

De los nueve profesionales que cumplimentaron las escalas, el $78 \%$ fueron mujeres $(n=7)$ frente a dos hombres, que suponían el $22 \%$ de la muestra. Sus edades estaban comprendidas entre 27 y 55 años; la media y la mediana se situaron en torno a los 39. En cuanto a la profesión, casi la mitad eran psicólogos $(45 \%)$, maestros $(22 \%)$, educadores $(22 \%)$ y terapeutas ocupacionales ( I I \%). En cuanto a los años de experiencia en la prestación de apoyos a personas con discapacidad intelectual, oscilaba entre I y 20 años (la media se situó en ro años y la mediana en I2). Cada profesional evaluó a una media de 9,67 personas.
El tipo de relación entre el respondiente de la escala y la persona con discapacidad significativa fue en todos los casos de carácter profesional. Con respecto al tiempo de contacto con la persona evaluada, en el $5 \mathrm{I} \%$ de los casos el evaluador conocía a la persona desde hacía más de 5 años $(n=43)$, en el $36 \%$ de los casos $(n=3 \mathrm{I})$ lo hacía desde hacía 3-5 años, y en el I3 \% ( $n=\mathrm{II})$ la relación entre respondiente y la persona con discapacidad intelectual tenía un duración de I a 2 años. En ninguno de los casos la relación tuvo una duración menor a un año.

\section{Resultados}

\subsection{Resultados en el mesosistema}

En las Figuras I y 2 se muestra muestran gráficamente las puntuaciones medias obtenidas (directas y estándar) en cada una de las dimensiones en la Fundación Obra San Martín (e.g., datos agregados de las 85 personas evaluadas). Al analizar los datos agregados encontramos que ninguna de las puntuaciones medias alcanza el punto medio teórico de la escala $(M=$ Io en el caso de las puntuaciones estándar), por lo que podemos concluir que en términos generales las puntuaciones son bajas. Las dimensiones que alcanzan el percentil más alto $(P=25)$ son autodeterminación y bienestar físico. Las dimensiones que obtienen un percentil más bajo $(P=6)$ son inclusión social y relaciones interpersonales. Estos resultados ponen en evidencia que la calidad de vida de las personas con discapacidades significativas a las que se ha administrado la Escala San Martín está sustancialmente por debajo de la media obtenida por las I.788 personas con discapacidades significativas que conformaron la muestra de validación de la escala.

\subsection{Resultados en el microsistema}

El fin último por el que la Fundación Obra San Martín apostó por el proyecto de elaboración de la Escala San Martín era obtener evidencias sobre 
Figura 1. Perfil de calidad de vida de la muestra de la Fundación Obra San Martín

\begin{tabular}{|c|c|c|c|c|c|c|c|c|c|}
\hline \multicolumn{8}{|c|}{ Perfil de calidad de vida } & ICV & Percentil \\
\hline$A U$ & BE & BF & BM & $\mathrm{DE}$ & DP & IS & RI & $>128$ & 99 \\
\hline $16-20$ & $16-20$ & $16-20$ & $16-20$ & $16-20$ & $16-20$ & $16-20$ & $16-20$ & $118-121$ & 90 \\
\hline 14 & 14 & 14 & 14 & 14 & 14 & 14 & 14 & $\begin{array}{l}114-117 \\
112-113\end{array}$ & $\begin{array}{l}85 \\
80\end{array}$ \\
\hline 13 & 13 & 13 & 13 & 13 & 13 & 13 & 13 & 110-111 & 75 \\
\hline 12 & 12 & 12 & 12 & 12 & 12 & 12 & 12 & 106-107 & 65 \\
\hline 11 & 11 & 11 & 11 & 11 & 11 & 11 & 11 & $101-103$ & 55 \\
\hline 10 & 10 & 10 & 10 & 10 & 10 & 10 & 10 & $98-99$ & 45 \\
\hline 9 & 9 & 9 & 9 & 9 & 9 & 9 & 9 & $\begin{array}{l}90-91 \\
94-95\end{array}$ & $\begin{array}{l}40 \\
35\end{array}$ \\
\hline 0 & 8 & & 8 & 8 & 8 & 8 & 8 & $\begin{array}{l}92-93 \\
90-91\end{array}$ & 30 \\
\hline 7 & & 7 & & & & 7 & 7 & 86-89 & 20 \\
\hline 6 & 6 & 6 & 6 & 6 & 6 & 6 & 6 & $79-82$ & 10 \\
\hline 5 & 5 & 5 & 5 & 5 & 5 & 5 & 5 & $<70$ & 1 \\
\hline $1-41$ & $1-4$ & $1-4$ & $1-4$ & $1-4$ & $1-4$ & $1-4$ & $1-4$ & & \\
\hline
\end{tabular}

Figura 2. Resumen de puntuaciones: muestra de la Fundación Obra San Martín

\begin{tabular}{|c|c|c|c|}
\hline $\begin{array}{l}\text { Dimensiones de calidad } \\
\text { de vida }\end{array}$ & $\begin{array}{l}\text { Puntuaciones } \\
\text { directas totales }\end{array}$ & $\begin{array}{l}\text { Puntuaciones } \\
\text { estándar }\end{array}$ & $\begin{array}{l}\text { Percentiles de las } \\
\text { dimensiones }\end{array}$ \\
\hline Autodeterminación & 27,01 & 8 & 25 \\
\hline Bienestar emocinal & 29,93 & 7 & 16 \\
\hline Bienestar físico & 35,27 & 8 & 25 \\
\hline Bienestar material & 35,27 & 7 & 16 \\
\hline Derechos & 33,85 & 7 & 16 \\
\hline Desarrollo personal & 29,06 & 7 & 16 \\
\hline Inclusión social & 21,36 & 6 & 9 \\
\hline $\begin{array}{l}\text { Relaciones } \\
\text { interpersonales }\end{array}$ & 29,41 & 6 & 9 \\
\hline \multicolumn{2}{|c|}{ Puntuación estándar total (suma) } & 56 & \\
\hline \multicolumn{2}{|c|}{$\begin{array}{r}\text { Índice de Calidad de Vida } \\
\text { (puntuación estándar compuesta)) }\end{array}$} & 82 & \\
\hline \multicolumn{3}{|c|}{ Percentil del Índice de Calidad de Vida } & 11 \\
\hline
\end{tabular}


la calidad de vida de cada una de las personas con discapacidades significativas a las que presta apoyos. Disponer de un perfil de calidad de vida de cada una de las personas usuarias permite poder planificar los apoyos prestados de forma individualizada, haciendo hincapié en aquellos aspectos que la Escala San Martín pone de manifiesto como susceptibles de mejora.

El perfil de calidad de vida nos permite contrastar los resultados de calidad de vida de la persona en comparación con el resto de personas usuarias del centro al que acude y del resto de personas usuarias de la organización. Para ejemplificar cómo se realiza la interpretación de las puntuaciones individuales describimos a continuación un caso concreto.

Adela es una mujer de 46 años que presenta discapacidad intelectual de carácter profundo y necesidades de apoyo generalizado. Tiene asociados a la discapacidad intelectual problemas de comportamiento y de salud mental. Tiene reconocido un baremo de dependencia de Grado III y un porcentaje de discapacidad del $75 \%$.

Al comparar sus resultados individuales con los resultados obtenidos por la muestra (Figura 3), encontramos que su Índice de Calidad de Vida $(I C V=79)$ alcanza un percentil menor que el logrado por la muestra $(I C V=82)$, obteniendo la misma puntuación en derechos y bienestar físico, y más alta en bienestar emocional y relaciones interpersonales. La Figura 4 muestra las puntuaciones de Adela junto con las de la Fundación Obra San Martín y las del servicio en el que recibe prestación de apoyos: el Centro Residencial de Atención 24 horas "La Albarca". Sus resultados son más bajos al contrastarlos con su vivienda, destacando la diferencia que se produce en la dimensión inclusión social.

\section{Figura 3. Comparación entre las puntuaciones obtenidas por Adela y la Fundación Obra San Martín}

\begin{tabular}{|l|c|c|c|}
\hline $\begin{array}{l}\text { Dimensiones de calidad } \\
\text { de vida }\end{array}$ & $\begin{array}{c}\text { Puntuaciones } \\
\text { directas totales }\end{array}$ & $\begin{array}{c}\text { Puntuaciones } \\
\text { estándar }\end{array}$ & $\begin{array}{c}\text { Percentiles de las } \\
\text { dimensiones }\end{array}$ \\
\hline Autodeterminación & 26 & 7 & 16 \\
\hline Bienestar emocinal & 33 & 8 & 37 \\
\hline Bienestar fisico & 35 & 8 & 37 \\
\hline Bienestar material & 31 & 5 & 37 \\
\hline Derechos & 34 & 7 & 16 \\
\hline Desarrollo personal & 26 & 6 & 9 \\
\hline Inclusión social & 18 & 5 & 5 \\
\hline $\begin{array}{l}\text { Relaciones } \\
\text { interpersonales }\end{array}$ & 30 & 7 & 16 \\
\hline \multicolumn{2}{|c|}{ Puntuación estándar total (suma) } & $\mathbf{5 3}$ & \\
\hline \multicolumn{2}{|c|}{$\begin{array}{c}\text { indice de Calidad de Vida } \\
\text { (puntuación estándar compuesta)) }\end{array}$} & $\mathbf{7 9}$ \\
\hline \multicolumn{2}{|c|}{ Percentil del Índice de Calidad de Vida } \\
\cline { 1 - 1 }
\end{tabular}

\begin{tabular}{|l|c|c|c|}
\hline $\begin{array}{l}\text { Dimensiones de calidad } \\
\text { de vida }\end{array}$ & $\begin{array}{c}\text { Puntuaciones } \\
\text { directas totales }\end{array}$ & $\begin{array}{c}\text { Puntuaciones } \\
\text { estándar }\end{array}$ & $\begin{array}{c}\text { Percentiles de las } \\
\text { dimensiones }\end{array}$ \\
\hline Autodeterminación & 27,01 & 8 & 25 \\
\hline Bienestar emocinal & 29,93 & 7 & 16 \\
\hline Bienestar físico & 35,27 & 8 & 25 \\
\hline Bienestar material & 35,27 & 7 & 16 \\
\hline Derechos & 33,85 & 7 & 16 \\
\hline Desarrollo personal & 29,06 & 7 & 16 \\
\hline Inclusión social & 21,36 & 6 & 9 \\
\hline $\begin{array}{l}\text { Relaciones } \\
\text { interpersonales }\end{array}$ & 29,41 & 6 & 9 \\
\hline \multicolumn{2}{|c|}{ Puntuación estándar total (suma) } & 56 & 11 \\
\hline \multicolumn{2}{|c|}{$\begin{array}{c}\text { Indice de Calidad de Vida } \\
\text { (puntuación estándar compuesta)) }\end{array}$} & $\mathbf{8 2}$ \\
\hline \multicolumn{2}{|c|}{ Percentil del Índice de Calidad de Vida } \\
\hline
\end{tabular}

\begin{tabular}{|c|c|c|c|c|c|c|c|c|c|}
\hline \multicolumn{8}{|c|}{ Perfil de calidad de vida } & \multirow{3}{*}{$\begin{array}{c}\text { ICV } \\
>128 \\
122-128\end{array}$} & \multirow{2}{*}{$\begin{array}{c}\text { Percentil } \\
99\end{array}$} \\
\hline AU & $\mathrm{BE}$ & BF & Bм & DE & DP & is & RI & & \\
\hline $16-20$ & $16-20$ & $16-20$ & $16-20$ & $16-20$ & $16-20$ & $16-20$ & $16-20$ & & 90 \\
\hline 14 & 14 & 14 & 14 & 14 & 14 & 14 & 14 & $112-113$ & $\begin{array}{l}85 \\
80\end{array}$ \\
\hline 13 & 13 & 13 & 13 & 13 & 13 & 13 & 13 & $\begin{array}{l}110-111 \\
108-109\end{array}$ & 75 \\
\hline 12 & 12 & 12 & 12 & 12 & 12 & 12 & 12 & $106-107$ & 65 \\
\hline 11 & 11 & 11 & 11 & 11 & 11 & 11 & 11 & $101-103$ & 55 \\
\hline 10 & 10 & 10 & 10 & 10 & 10 & 10 & 10 & 98-99 & 45 \\
\hline 9 & 9 & 9 & 9 & 9 & 9 & 9 & 9 & 96-97 & 40 \\
\hline 8 & (8) & 8 & 8 & 8 & 8 & 8 & 8 & $92-93$ & 30 \\
\hline (7) & 7 & 7 & 7 & (7) & 7 & 7 & 7 & $86-89$ & 20 \\
\hline 6 & 6 & 6 & & 6 & (6) & 6 & 6 & \begin{tabular}{|l|l|}
$00-63$ \\
$79-82$
\end{tabular} & $\frac{15}{10}$ \\
\hline 5 & 5 & 5 & 5 & 5 & 5 & $(5)$ & 5 & $\begin{array}{c}71-78 \\
<70\end{array}$ & $\begin{array}{l}5 \\
1\end{array}$ \\
\hline $1-41$ & $1-4$ & $1-4$ & $1-4$ & $1-4$ & $1-4$ & $1-4$ & $1-4$ & & \\
\hline
\end{tabular}

\begin{tabular}{|c|c|c|c|c|c|c|c|c|c|}
\hline \multicolumn{8}{|c|}{ Perfil de calidad de vida } & ICV & \multirow{2}{*}{$\begin{array}{c}\text { Percentil } \\
99\end{array}$} \\
\hline AU & $\mathrm{BE}$ & BF & BM & DE & DP & is & RI & \multirow{2}{*}{$\begin{array}{c}>128 \\
122-128\end{array}$} & \\
\hline $16-20$ & $16-20$ & $16-20$ & $16-20$ & $16-20$ & $16-20$ & $16-20$ & $16-20$ & & 90 \\
\hline 14 & 14 & 14 & 14 & 14 & 14 & 14 & 14 & 112-113 & $\begin{array}{l}85 \\
80\end{array}$ \\
\hline 13 & 13 & 13 & 13 & 13 & 13 & 13 & 13 & 110-111 & 75 \\
\hline 12 & 12 & 12 & 12 & 12 & 12 & 12 & 12 & $106-107$ & 65 \\
\hline 11 & 11 & 11 & 11 & 11 & 11 & 11 & 11 & 101-103 & 55 \\
\hline 10 & 10 & 10 & 10 & 10 & 10 & 10 & 10 & 98-99 & 45 \\
\hline 9 & 9 & 9 & 9 & 9 & 9 & 9 & 9 & $96-97$ & 40 \\
\hline 8 & 8 & 8 & 8 & 8 & 8 & 8 & 8 & $92-93$ & 30 \\
\hline 7 & 7 & 7 & (7) & 7 & 7 & 7 & 7 & $86-89$ & $\begin{array}{l}25 \\
20\end{array}$ \\
\hline & & & & & & & & 83-85 & 15 \\
\hline 6 & 6 & 6 & 6 & 6 & 6 & (6) & (6) & \begin{tabular}{|l|l|}
$79-82$ \\
\end{tabular} & 10 \\
\hline 5 & 5 & 5 & 5 & 5 & 5 & 5 & 5 & $<70$ & 1 \\
\hline $1-41$ & $1-4$ & $1-4$ & $1-4$ & $1-4$ & $1-4$ & $1-4$ & $1-4$ & & \\
\hline
\end{tabular}


El fin último de la administración de la Escala San Martín es obtener resultados individuales de la calidad de vida de las personas con discapacidades significativas. Si estudiamos detenidamente los resultados de Adela encontramos que sus puntuaciones no alcanzan la media en ninguna de las dimensiones, como consecuencia su Índice de Calidad de Vida (ICV) logra un percentil 8 .

Si nos fijamos en las dimensiones en las que obtiene una puntuación más baja (bienestar material, inclusión social y desarrollo personal) y exploramos las respuestas dadas en dichas dimensiones hallamos que varios ítems reciben la puntuación "nunca": "Tiene un espacio físico con sus pertenencias personales a su alcance" (BM_40), "Aprende cosas que le hacen ser más independiente” (DP_64), "Tiene oportunidades de conocer otros entornos diferentes al lugar donde vive" (IS_73), "Disfruta de vacaciones en entornos inclusivos" (IS_74), "Participa en actividades fuera del centro con personas ajenas a su contexto de apoyos" (IS_76), "Participa en actividades inclusivas adecuadas para sus condiciones físicas y mentales" (IS_77), "Participa en actividades inclusivas que le interesan" (IS_78), "Las actividades en las que participa tienen en cuenta las instalaciones de ocio y cultura de la zona" (IS_79) y "Se toman medidas especificas para potenciar la participación de la persona en la comunidad" (IS_82).

A la luz de estos resultados, resulta necesario diseñar apoyos dirigidos a mejorar estos indicadores; principalmente habría que aunar esfuerzos para mejorar la inclusión social de Adela, ya que puntúa "nunca" en siete de los once ítems que componen esta dimensión.

\section{Discusión}

La finalidad de la Escala San Martín es "identificar el perfil de calidad de vida de la persona, con evidencias de validez y fiabilidad, 
para la puesta en marcha de prácticas basadas en la evidencia y el diseño de planes individuales de apoyo" (Verdugo et al., 20I4b). No obstante, además de ser utilizada para este objetivo, los datos recogidos mediante la aplicación de la Escala San Martín se pueden agregar con el fin de obtener información en el mesosistema (Gómez et al., 2012) y el macrosistema (véase Gómez et al., 2013).

La administración de la Escala San Martín puede considerarse el primer paso para la implantación de prácticas basadas en la evidencia en la Fundación Obra San Martín. Schalock, Verdugo y Gómez (20I I, p. 277) definen las prácticas basadas en la evidencia como:

“prácticas o intervenciones basadas en la mejor evidencia que puede obtenerse de fuentes creíbles (i.e., profesionales de los servicios que conocen bien a los usuarios y que tienen oportunidades de observar a las personas durante periodos prolongados de tiempo en varios contextos), que utilizan métodos válidos y fiables (i.e., la Escala San Martín) y que se basan en una teoría o marco conceptual claramente articulado y con suficiente apoyo empírico (i.e., el modelo de calidad de vida de ocho dimensiones propuesto por Schalock y Verdugo, 2002/2003)”.

La Escala San Martín permite la evaluación de resultados personales relacionados con la calidad de vida. Los resultados obtenidos pueden considerarse como el primer paso en el desarrollo de prácticas basadas en la evidencia para la mejora de la calidad de vida de las personas con discapacidades significativas que reciben servicios y apoyos en la Fundación Obra San Martín. Los perfiles de calidad de vida deben ser evaluados longitudinalmente para evidenciar los resultados de las prácticas sometidas a prueba. En el caso de la Escala San Martín se estima que la frecuencia debe ser cada dos años.

La participación en la financiación, construcción, administración y difusión de la Escala San Martín supone para la Fundación
Obra San Martín un punto de inflexión como organización de servicios sociales y educativos. La Fundación es una entidad con una amplia trayectoria, más de 65 años, que se ha ido transformando en función del avance de los modelos profesionales. Así, comienza a ser una entidad innovadora, que apuesta por el desarrollo de prácticas basadas en la evidencia, por profesionalizar la labor que hace y por poner de manifiesto resultados demostrables del trabajo que realiza. Cambiar es un proceso lento y no exento de dificultades pero, sobre todo, es un proceso enriquecedor, que a largo plazo consigue que los equipos se unan por el esfuerzo y las experiencias compartidas.

Además, la Escala San Martín ha supuesto que nos abramos, que dejemos de mirar hacia nosotros y difundamos cómo somos al resto de la comunidad autónoma de Cantabria y al resto de entidades prestadoras de apoyos a personas con discapacidad intelectual de España. Puede que la imagen que se tenía desde fuera de la Fundación haya cambiado pero, sobre todo, ha cambiado la imagen que tenemos desde dentro: somos un equipo de profesionales capaces de colaborar en un proyecto de investigación, formamos parte de una entidad que ha emprendido un camino de no retorno destinado a obtener una mejora real de la calidad de vida de las personas a las que prestamos apoyos, creemos en lo que hacemos y queremos hacerlo bien.

A través de la evaluación de la calidad de vida mediante la Escala San Martín se han propuesto modificaciones en los apoyos prestados de tal forma que redunden en la mejora de la calidad de vida de la personas usuarias. La información de carácter cuantitativo resulta relevante para establecer una línea base y poder hacer comparaciones en el futuro. La información cualitativa es la que ofrece orientaciones sobre las aplicaciones prácticas de mejora de los apoyos prestados.

Por todo esto, el análisis de los resultados de las 85 aplicaciones realizadas durante el año 20 I 2 supone obtener los resultados objetivos, analizar los mismos y comenzar a elaborar y poner en práctica propuestas de mejora. Los resultados 
generales obtenidos sobre la calidad de vida de las personas con discapacidades significativas a las que se ha aplicado la Escala San Martín ponen de manifiesto que ésta es más baja de lo que esperábamos. Ninguna de las puntuaciones estándar generales alcanzan la media $(P E=\mathrm{I} O)$ y la puntuación más alta se sitúa en el percentil 25 (el resto entre los percentiles 9-I6). Si analizamos los resultados individuales, sólo 6 personas obtienen un Índice de Calidad de Vida (ICV) que se sitúe por encima del percentil 50, además 66 personas obtienen un ICV por debajo del percentil 25 .

El perfil de calidad de vida refleja lo que, a priori, el equipo de profesionales esperábamos conociendo la realidad de nuestros centros y la circunstancias de las personas a las que prestamos apoyos. Debido alto grado de institucionalización que presentan las personas (una media de I9 años en la Fundación, con un mínimo de I y un máximo de 45) la escasez de red social (y, en demasiadas ocasiones, de la participación de la familia), unidas a las graves dificultades en la comunicación que presentan muchas de las personas y teniendo claro que el uso de sistemas de comunicación alternativa es un punto a mejorar, no resulta extraño que las puntuaciones más bajas sean las obtenidas en inclusión social y relaciones interpersonales. Lo mismo ocurre con la alta puntuación lograda en bienestar físico, ya que la Fundación Obra San Martín es una entidad que viene del modelo asistencial y en la que se presta especial atención a las condiciones de salud de las personas usuarias. El hecho de que la puntuación global obtenida en autodeterminación sea de las dos más altas era algo con lo que no contábamos, pero una vez obtenidos estos resultados vemos que sí concuerdan con la línea de trabajo iniciada en 2010 en todos los centros y que ha dirigido muchos esfuerzos en la prestación de apoyos alineada con el respeto a las elecciones de las personas, con el fomento de la toma de decisiones, con tener siempre presente las características, preferencias y deseos, y con la personalización de espacios, actividades, ritmos y rutinas.

$\mathrm{Al}$ analizar las respuestas dadas a cada uno de los ítems encontramos que ítems relativos a condiciones externas a la persona son respondidos con alta frecuencia "nunca" o "a veces” en más de un $80 \%$ de las ocasiones, es decir, indicadores que no dependen de las características de la persona si no que dependen del contexto en el que se encuentra:

- $\quad$ "Las personas que le proporcionan apoyos disponen de un listado de conductas observables que expresan sus estados emocionales" (BE_I3).

- "Tiene una ficha personal donde consta lo que le gusta, le tranquiliza, lo que no soportar y cómo puede reaccionar, que todo el personal conoce y debe cumplir" (BE_I9).

- “Las personas que le proporcionan apoyos ofrecen guía y apoyo acerca de su sexualidad" (BF_36).

- $\quad$ "Las personas que le proporcionan apoyos cuentan con formación en técnicas de Apoyo Conductual Positivo" (BE_2I).

- $\quad$ "Las personas que le proporcionan apoyos disponen de formación específica sobre ética y respeto de los derechos de las personas con discapacidad" (DE_49).

- "Disfruta de vacaciones en entornos inclusivos" (IS_74).

- “Tiene una ficha de apoyos personalizados que todo el personal conoce y debe cumplir" (IS_75).

- $\quad$ "Participa en actividades inclusivas adecuadas para sus condiciones físicas y mentales" (IS_77).

- "Participa en actividades sociales fuera del lugar donde recibe servicios y apoyos" (IS_8I).

- "Se toman medidas especificas para mejorar sus habilidades de comunicación” (RI_93).

- "Tiene la oportunidad de conocer a personas ajenas al contexto de apoyo" (RI_94).

- "Se toman medidas específicas para mantener y extender sus redes sociales" (RI_95).

Es decir, hay un gran número de ítems que dependen de los apoyos prestados desde la 
Fundación Obra San Martín, y no tanto de las características de las personas, por lo que será necesario diseñar y poner en marcha distintas acciones dirigidas a realizar:

- Actividades formativas en sexualidad y discapacidades significativas, ética, derechos y Apoyo Conductual Positivo.

- Procesos relativos a sintetizar todo el conocimiento que el personal de apoyo tiene sobre las personas con discapacidad intelectual en herramientas que faciliten la transferencia de toda esta información.

- Procesos destinados a la mejora de las habilidades comunicativas.

- Procesos diseñados para mejorar las relaciones interpersonales, el acceso a nuevos contextos de participación y a la inclusión real de las personas con discapacidades significativas.

Además, al analizar las respuestas dadas a cada uno de los ítems encontramos que, en menor número, hay ítems que reciben altos porcentajes (más del $80 \%$ ) de las categorías bajas de respuesta "nunca" y "a veces". Estos ítems describen indicadores que dependen de la interacción de condiciones personales y de condiciones ambientales:

- "Participa en la elaboración de su plan individual de apoyos" (AU_O2).

- “Aprende codas que le hacen ser más independiente" (DP_64).

- "Participa en actividades inclusivas que le interesan” (IS_78).

Las líneas de trabajo en este sentido tendrían que ir encaminadas a elaborar procesos de planificación de apoyos adaptados a los niveles de comprensión, fomento de actividades destinadas a la mejora de la autonomía y proporcionar nuevas experiencias que amplíen el campo de posibles intereses de la persona alineadas con el conocimiento que el personal de atención directa tiene sobre la persona.

No obstante, como toda investigación, ésta cuenta con algunas limitaciones. Una de ellas se centra en la realización de comparaciones de resultados atendiendo a variables sociodemográficas y a servicios. El reducido tamaño de la muestra (más concretamente, el reducido número de personas que compondrían cada grupo en el análisis por variables) limita el análisis de diferencias mediante contrastes paramétricos $(N=85)$. Tales análisis constituyen una línea futura de investigación que abordaremos en un futuro inmediato.

En la misma línea, otra limitación del proyecto se encuentra en el escaso número de evaluadores que participaron en la muestra $(N=9)$, por lo que la variabilidad es reducida y la subjetividad de cada uno de ellos puede estar teniendo bastante peso en el resultados final. De hecho, en aquellos centros en los que sólo participan dos evaluadores las puntuaciones son más extremas que en aquellos centros en los que intervienen mayor número de evaluadores en los que las puntaciones alcanzan valores centrales.

La principal línea futura de investigación de este proyecto tiene como objetivo general la puesta en marcha de prácticas basadas en la evidencia para la mejora de la calidad de vida de las persona usuarias en la Fundación. De este modo, tenemos previsto administrar la Escala San Martín en 20 I 5 a las mismas personas para valorar el impacto de los programas que se están desarrollando y los cambios que se están implementando a partir de este trabajo con el fin de constatar si se producen mejoras en la calidad de vida de las personas a las que prestamos apoyos. 
Felce, D. y Perry, J. (I995). "Quality of life: Its definition and measurement”. Research in Developmental Disabilities, I6(I), 5 I-74.

Gómez, L. E. et al. (2012). "An outcomes-based assessment of quality of life in social services". Social Indicators Research, 106, 8 I-93. doi: I0.I007/SI I 205-OI I-9794-9.

Gómez, L.E. et al. (2013). "The development and use of provider profiles at the organization and systems level”. Evaluation \& Program Planning, 40, 17-26. doi: го.Іог6/j. evalprogplan.20I3.05.00I.

Gómez-Vela, M. y Verdugo, M. A. (2009). CCVA: cuestionario de evaluación de la calidad de vida de alumnos adolescentes. Madrid: CEPE.

Petry, K. et al. (2005). "Domains of quality of life of people with profound multiple disabilities: The perspective of parents and direct support staff". Journal of Applied Research in Intellectual Disabilities, I8(I), 35-46.

Petry, K. et al. (2009a). "Psychometric evaluation of a questionnaire to measure the quality of life of people with profound multiple disabilities (QOL-PMD)". Research in Developmental Disabilities, 30, I326-I336.

Petry, K. et al. (2009b). "Measuring the quality of life of people with profound multiple disabilities using the QOL-PMD: First results”. Research in Developmental Disabilities, 30 , I394-I 405.

Sabeh, E. N. et al. (2009). CVI-CVIP: Cuestionario de evaluación de la calidad de vida en la infancia: manual de aplicación. Madrid: CEPE.

Schalock, R. L., Bonham G. S. y Verdugo M. A. (2008). "Quality of life conceptual and measurement framework: from concept to application in the field of intellectual disabilities". Evaluation and program planning, 3I, I8I-I90.

Schalock, R. L. y Verdugo, M. A. (2002/2003). Quality of life for human services practitioners.
Washington, DC: American Association on Mental Retardation [Traducido al castellano por M.A. Verdugo y C. Jenaro. Calidad de vida. Manual para profesionales de la educación, salud y servicios sociales. Madrid: Alianza].

Schalock, R. L. y Verdugo, M. A. (20I2). A leadership guide to redefining intellectual and developmental disabilities organizations: eight successful change strategies. Baltimore, MD: Brookes Publishing Company.

Schalock, R. L. et al. (20I I). "Evidence-based practices in the field of intellectual and developmental disabilities: An international consensus approach". Evaluation and Program Planning, 34, 273-282. 〈doi:10.IOI6/j. evalprogplan.20I0.10.004'.

Verdugo, M. A. et al. (2008a). Escala Gencat: Informe sobre la creació d'una escala multidimensional para avaluar la qualitat de vida de les persones usuàries dels serveis socials de Catalunya. Barcelona: Generalitat de Cataluña.

Verdugo, M. A. et al. (2008b). Escala Gencat. Formulari de l'Escala Gencat de qualitat de vida-Manual d'Aplicació de l'Escala Gencat de qualitat de vida. Barcelona: Generalitat de Cataluña.

Verdugo, M. A., Arias, B., Gómez L. E. y Schalock, R. L. (20IO). "Development of an objective instrument to assess quality of life in social services: Reliability and validity in Spain”. International Journal of Clinical and Health Psychology, IO(I): I05-I23. En «http://www. aepc.es/ijchp/articulos_pdf/ijchp-343.pdf).

Verdugo, M. A. et al. (2009). Evaluación de calidad de vida en personas mayores. La Escala FUMAT. Salamanca: INICO.

Verdugo, M. A. et al. (2009). Escala Integral de Calidad de Vida. Madrid. CEPE.

Verdugo, M. A. et al. (2013a). "Evaluación de la calidad de vida en personas con discapacidades 
intelectuales o del desarrollo: la escala INICOFEAPS”. Siglo Cero, 44(3), 6-20.

Verdugo, M. A. et al. (20I4a). "Measuring quality of life in people with intellectual and multiple disabilities; Validation of the San Martin Scale”. Research in Developmental Disabilities, $35,75-86$.

Verdugo, M. A. et al. (20I4b). Escala San Martín. Evaluación de la calidad de vida de personas con discapacidades significativas. Santander: Fundación Obra San Martin/ INICO. htttp:// inico.usal.es/33r/instrumentos-evaluacion/ escala-san-martin.aspx'.

Verdugo, M. A. et al. (20I3b). Escala INICOFEAPS. Evaluación integral de la calidad de vida de personas con discapacidad intelectual o del desarrollo. Salamanca: Universidad de Salamanca, Publicaciones del INICO, Colección Herramientas 7/2013.
Verdugo, M. A. et al. (20I3c). "Evaluación de la calidad de vida en personas con discapacidades significativas: la escala San Martín”. Siglo Cero, 44(4), 6-20.

Verdugo, M. A. et al. (20I I). Bases para el desarrollo de un modelo de evaluación para personas con discapacidad intelectual adultas que viven en servicios residenciales (en línea). http://sid.usal.es/idocs/F8/FDO25938/Bases_ modelo_de_evaluacixn_CdV_y_Apoyos.pdf .

Zijlstra, R. y Penning, C. (2004). “Mensen met ernstige verstandelijke en meervoudige beperkingen". En M. Kersten y D. Flikweert (Eds.): Onderzoek overgrenzen thematische rapportages en beschouwingen naaraanleiding van het 12 de IASSID, Montpellier 2004 (pp. 49-63). Utrecht: NGBZ en LKNG/NIZW. 



\section{Validez y fiabilidad del Sistema de Detección Precoz de los Trastornos del Desarrollo: 3 a 36 meses}

\section{The validity and reliability of the System for Early Detection of Developmental Disorders: 3-36 months}

\section{Resumen}

En este artículo se presenta el Sistema de Detección Precoz de los Trastornos del Desarrollo (SDPTD), desarrollado en trabajos anteriores (Rico, 20I3; Alonso, 20I4). Este sistema se compone de siete cuestionarios, uno para cada corte de edad $(3,6$, 9, I 2, I 8, 24 y 36 meses). Se han diseñado estos cuestionarios para ser contestados por los padres. Para estudiar su validez, se ha aplicado el SDPTD a una muestra de 728 niños/ as (aproximadamente roo niños/ as en cada una de las siete secciones de edad). Como prueba criterio se ha utilizado la Escala de Desarrollo Merrill-Palmer-Revisada (MP-R). Un año más tarde, se ha verificado el estado de desarrollo de los/as niños/ as. Los resultados muestran un alto acuerdo entre padres y profesionales. La validez concurrente es alta aunque varía con cada corte de edad. En cuanto a la validez diagnóstica de un año, las tasas de sensibilidad y especificidad son lo suficientemente altas como para considerar el sistema como fiable, válido y adecuado para los fines previstos.

\section{Palabras clave}

Detección, trastornos del desarrollo, validez concurrente, validez diagnóstica.

\begin{abstract}
This article introduces the System for Early Detection of Developmental Disorders (referred to as SDPTD for its abbreviation in Spanish), a system developed in previous papers. The SDPTD is a developmental screening test that includes seven questionnaires, one for each cutoff of age $(3,6,9,12,18,24$ and 36 months). These questionnaires have been designed to be answered by parents. To study its validity, SDPTD was administered to a sample of 728 children (approximately Io० children in each of the seven cutoff age groups). A development scale known as Merrill-Palmer-Revised (MP-R) was used as a criterion test. The development state of the children was tested again one year later. The results show a high level of agreement between parents and professionals. The concurrent validity is high although it varies by cutoff age. Regarding the diagnostic validity a year after the original evaluation, levels of sensitivity and specificity are high enough to consider the system reliable, valid and suitable for screening purposes.
\end{abstract}

Screening, developmental disorders, concurrent validity, diagnostic validity.

\section{Keywords}

\section{Francisco Alcantud Marín <francisco.alcantud@uv.es>}

Centro Universitario de Diagnóstico y Atención Temprana de la Universitat de Valencia

\section{Yurena Alonso Esteban <yurena.alonso@uv.es>}

Departamento de Psicología Evolutiva y de la Educación de la Universitat de Valencia

\section{Darío Rico Bañón \\ <dario.rico@uv.es>}

Centro Universitario de Diagnóstico y Atención Temprana de la Universitat de Valencia

Para citar:

Alcantud, F. et al. (20I 5): "Validez y fiabilidad del Sistema de Detección Precoz de los Trastornos del Desarrollo: 3 a 36 meses", Revista Española de Discapacidad, 3 (I): IO7-I2I.

Doi: <http://dx.doi.org/IO. 55 69/23405 I04.03.01.06>

Fecha de recepción: I I-I I-20I4 Fecha de aceptación: 25-05-20I 5 


\section{Introducción}

Se entiende como trastornos del desarrollo una disfunción permanente o transitoria (neurológica, psicológica o sensorial) que hace que se desvíe el desarrollo del niño/a de forma significativa del curso normativo. Generalmente se detecta cuando el niño/a no alcanza hitos significativos del mismo. En la literatura científica se utiliza tanto el término genérico "trastornos del desarrollo" como "retraso en el desarrollo" ${ }^{2}$ como termino transitorio en edades tempranas hasta avanzar o establecer un diagnóstico definitivo. Los trastornos del desarrollo se definen como "una tipología variada de problemas que tienen su origen en la infancia, la niñez o la adolescencia y que pueden perdurar a lo largo de toda la vida”. (García, I999, p.28).

Estos trastornos también fueron definidos como "crónicos, severos y atribuibles al retraso mental, parálisis cerebral, epilepsia o autismo, porque tales condiciones consisten en alteraciones similares del funcionamiento intelectual general y de la conducta adaptativa y requieren servicios y tratamientos similares a los requeridos por tales personas". (Schopler, I983, p. I20). Hoy en día podría referirse a ellos como trastornos del Neurodesarrollo. Es decir, aquellas alteraciones en el desarrollo de funciones vinculadas a la maduración del sistema nervioso central que se inician en la infancia y siguen un curso evolutivo estable (Artigas-Pallarés, 20I I). Sin embargo, cuando solo se tienen evidencias de un retraso en el desarrollo o un trastorno del desarrollo sin conocer las causas y por la edad, aun sin tener un diagnóstico específico, se suele mantener el término genérico de "trastornos del desarrollo".

Con independencia del diagnóstico, las evidencias de las mejoras producidas mediante los programas de Atención Temprana cuando se interviene antes de los tres años son abrumadoras

I. Del inglés "Developmental Disabilities". 2. Del Inglés "Developmental Delay".
(Barnett, I995; Reynolds, Temple, Robertson, \& Mann, 200I; McCormick, Brooks-Gum, Buka, Goldman, \& Yu, 2006; Casto \& Mastropieri, ı986; Shonkoff \& Hauser-Cram, I987; Guralnick \& Bennett, I987; Guralnick, I989,I997; Guralnick, I998). Sin embargo, hoy en día aún son muy numerosos los/as niños/ as que llegan a la edad escolar presentando un trastorno del desarrollo sin diagnóstico previo $y$, consecuentemente, sin haberse beneficiado de los servicios y programas de Atención Temprana. Así, por ejemplo, en USA, se constata que antes de entrar en la escuela infantil se identifican menos del $30 \%$ de los/as niños/as con trastornos del desarrollo (Glascoe \& Macías, 2003; Palfrey, Singer, Walker, \& Butler, I987). Las razones que se argumentan son diversas, por una parte unos apuntan hacia la carga asistencial de los servicios de pediatría en atención primaria. Consecuencia de la cual resulta difícil, por no decir imposible, desarrollar una exploración completa del desarrollo de todos los/as niños/ as atendidos. Otros apuntan hacia la falta de formación del pediatra que le llevaría a no utilizar sistemas normalizados (Smith, I978; Hamilton, 2006). La mayoría de ellos utilizan, como mucho, el juicio clínico, aunque se sabe que con este método no se detectan más del 30\% de niños/as con trastornos del desarrollo y menos del 50\% si se trata de problemas conductuales y emocionales (Alvarez \& Giner, 2007). Todo parece indicar, en definitiva, que solo se atiende sobre el $2 \%$ de niños/as menores de 3 años, frente al $5 \%$ de niños/as que se detectan con necesidades similares en preescolar (Sices, Feudtner, McLaughlin, Drotar \& Williams, 2003).

Este estado de conocimiento ha llevado a que las organizaciones profesionales y las entidades públicas responsables de la salud infantil, hayan desarrollado programas específicos de control del desarrollo en el/la niño/a, en los que se especifica la conveniencia de utilizar sistemas de screening o detección precoz de manera sistemática en diferentes momentos clave del desarrollo del niño/a. El problema parece radicar en la falta de accesibilidad a los instrumentos de detección y la falta de recursos para su administración. En nuestro país existen algunas experiencias en el caso de trastornos específicos, 
como es el caso del programa de detección de los Trastornos del Espectro Autista, desarrollado en Castilla-León (Canal, et al., 2006). Otro sistema desarrollado en nuestro país de uso extendido entre los especialistas en pediatría es la tabla Haizea-Llevant. Esta tabla derivada del Test de Denver consiste en un listado organizado de ítems representativos de los hitos evolutivos más significativos en el desarrollo del niño. Es el resultado de dos estudios o programas, el Estudio Llevant y el Programa Haizea, cuyos datos de referencia se obtuvieron de una muestra representativa de I.702 niños/as de Cataluña y 8I7 niños/as del País Vasco respectivamente. Esta tabla muestra el desarrollo cognitivo, social y motor de niños/as de o a 5 años (Fernández, I 988 y Fernández, E., Fernández, J., Fuentes, Rueda, I99I).

En los últimos años están tomando mucha fuerza el desarrollo de los sistemas de screening basados principalmente en las respuestas de los principales cuidadores del niño/a. En la mayoría de las investigaciones sobre la validez y fiabilidad de estos sistemas se informa de un acuerdo consistente entre las evaluaciones de profesionales y de padres/madres, en particular cuando estos últimos respondían a cuestiones sobre el desarrollo actual (Squires, Potter \& Bricker, I998). La información dada por los padres sobre el desarrollo de sus hijos/as ha sido utilizada en muchas de las escalas de desarrollo "clásicas" junto con la evaluación profesional (Inventario de Desarrollo Battelle -BDI-, Inventarios de Desarrollo Comunicativo MacArthur, Escala de desarrollo psicomotor de Brunet-Lézine, Escalas de desarrollo MerrillPalmer, Escala adaptativa Vineland, etc.). En este sentido, ya existen cuestionarios de cribado o detección precoz validados en Estados Unidos y España basados exclusivamente en la información recibida por la familia y con excelentes propiedades psicométricas (Parents' Evaluation of Developmental Status -PEDS-, The Modified Checklist for Autism in Toddlers -M-chat-, Ages \& Stages Questionnaires -ASQ-, y otros...).

Se entiende que los instrumentos de cribado están diseñados para identificar o detectar a niños/as que puedan necesitar una evaluación más exhaustiva. Suelen ser test o listas de chequeo breves (Aylward, I995; Hamilton, 2006; Melchers et al., 2003). La ventaja más obvia de este tipo de instrumentos es el coste reducido frente a la administración de este mismo tipo de pruebas por profesionales. Otra ventaja práctica que se les atribuye a este tipo de cuestionarios es que, según el estudio de Hickson et al., los padres/madres están más preocupados por el comportamiento y desarrollo de su hijo/a que por las cuestiones médicas y sin embargo no suelen consultar con su pediatra este tipo de preocupaciones (Hickson, Alteimer, \& O'connor, I983). De este modo cuando los/ as padres/madres contestan los cuestionarios de detección se consiguen efectos positivos adicionales, como por ejemplo, una mayor conciencia de la importancia del desarrollo evolutivo de sus hijos/as conociendo los hitos más importantes de su desarrollo.

Los sistemas de cribado del desarrollo son una medida preventiva (Hix-Small, Marks, Squires, \& Nickel, 2006) y en consecuencia son también competencia de los programas de Atención Temprana. Detectando de forma precoz permitimos también una intervención precoz que redundará en mayores beneficios para la familia y el niño/a a largo plazo y consecuentemente se rentabilizará la inversión económica necesaria para su implantación, desarrollo y mantenimiento de los programas de Atención Temprana (Rydz et al., 2006).

El Sistema de Detección Precoz de los Trastornos del Desarrollo (SDPTD) aquí presentado se basa en tres etapas o niveles. El primer nivel consiste en contestar un cuestionario adaptado a la edad del/la niño/a. Este cuestionario es auto-administrado por los propios padres/ madres. Estos cuestionarios pueden encontrarse en formato impreso o pueden administrarse por medio de un sistema web. El SDPTD se ha diseñado para ser administrado por medio de una aplicación web de forma que el coste de la administración por unidad es mínimo. Además, el sistema ofrece como beneficio añadido el uso de videos demostrativos de las conductas evaluadas con lo que la accesibilidad a los mismos se incrementa de forma significativa 


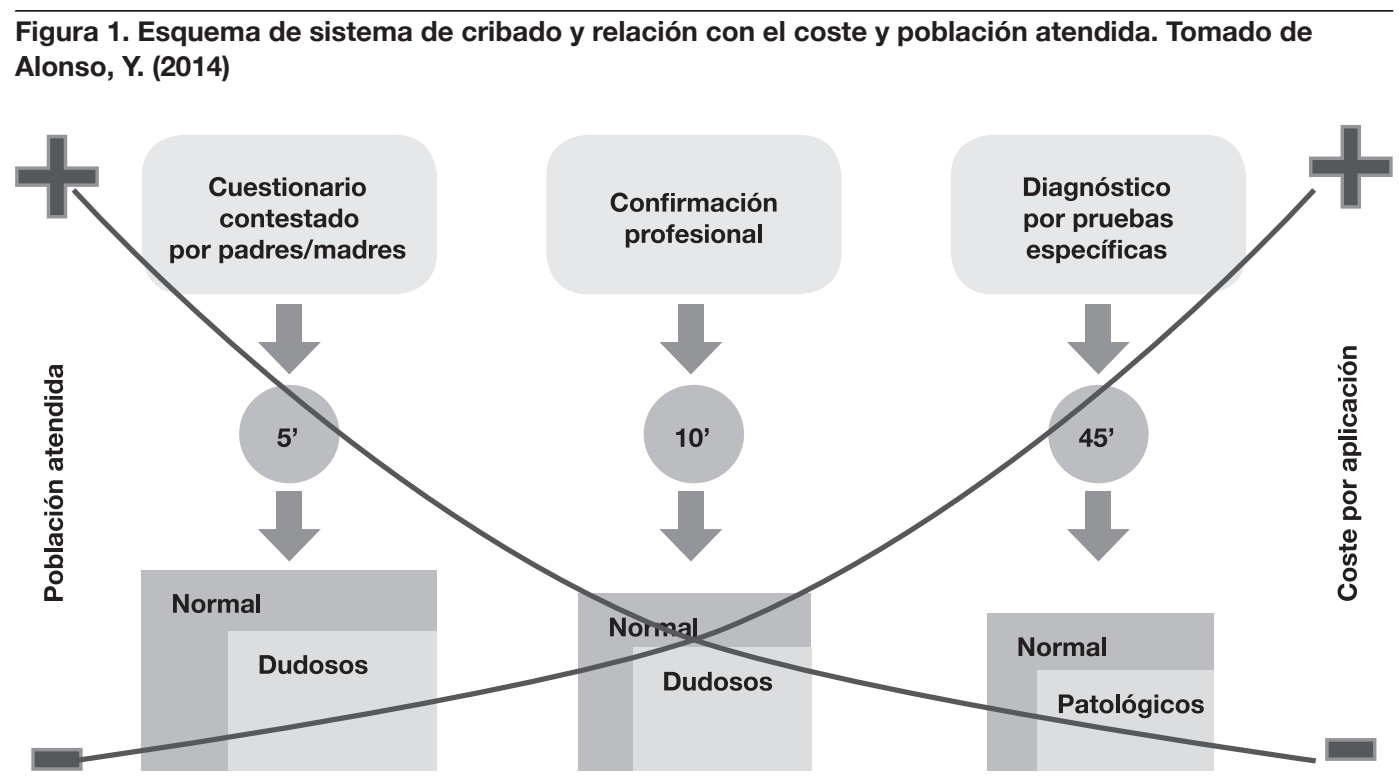

llegando al máximo de población. El segundo nivel del sistema es la confirmación profesional, que debería realizarse solo sobre los casos positivos del paso anterior y en la misma consulta del pediatra. Por último, el tercer paso sería la derivación a un centro especializado y solo recaería sobre una población mínima que hubiera sido detectada en los dos pasos anteriores. $\mathrm{La}$ imagen de la figura I, intenta evidenciar la relación inversa que debe haber entre el coste de la aplicación por familia evaluada y el número de familias que se deben evaluar.

El objetivo de este artículo es dar a conocer los resultados globales de la aplicación piloto realizada tras el proceso de construcción del SDPTD.

\section{Método}

\subsection{Instrumentos y cuestionarios}

La administración de un cuestionario de estas características debe ser obligatoriamente breve.
El objetivo del SDPTD es cubrir un periodo de edad en el que aún no existen instrumentos de detección de trastornos específicos. Del análisis de la literatura existente se ha detectado la falta de consenso en los cortes de edad más relevantes, así como sobre las áreas del desarrollo a describir. Así, encontramos en la literatura autores que diferencian el primer mes, como periodo neonatal, del resto del primer año de vida que dividen en tres periodos; los cuatro, los ocho y los doce meses. (Gesell, I974; Osofsky, I987; Horowitz, I989; Illingworth, I992). Por el contrario, otros autores presentan la información por meses o trimestres naturales (Aguirre, 200I) y por último, en el ámbito pediátrico, también existen autores que han hecho el esfuerzo de ajustar la exposición de hitos a las visitas de los programas de vigilancia del desarrollo del/la niño/a sano (Álvarez, Soria, \& Galbe, 2009; Olhweiler, Silva, \& Rotta, 2002).

Por otra parte, es importante caer en la cuenta que muchas conductas de las que se proponen observar son multidimensionales y en su desarrollo se ve implicada más de un área. En este sentido, solo se ha considerado el área 
Tabla 1. Número de ítems por cuestionario y área del desarrollo evaluada

\begin{tabular}{|l|c|c|c|c|c|c|c|}
\hline Áreas & $\begin{array}{c}\mathbf{3} \\
\text { meses }\end{array}$ & $\begin{array}{c}\mathbf{6} \\
\text { meses }\end{array}$ & $\begin{array}{c}\mathbf{9} \\
\text { meses }\end{array}$ & $\begin{array}{c}\mathbf{1 2} \\
\text { meses }\end{array}$ & $\begin{array}{c}\mathbf{1 8} \\
\text { meses }\end{array}$ & $\begin{array}{c}\mathbf{2 4} \\
\text { meses }\end{array}$ & $\begin{array}{c}36 \\
\text { meses }\end{array}$ \\
\hline Motriz & 6 & 4 & 6 & 4 & 4 & 2 & 4 \\
\hline $\begin{array}{l}\text { Audición } \\
\text { Lomunicación } \\
\text { Lenguaje }\end{array}$ & 3 & 3 & 2 & 5 & 2 & 3 & 4 \\
\hline Socio-Emocional & 1 & 3 & 2 & 4 & 3 & 4 & 3 \\
\hline Cognitiva & 2 & 1 & 4 & 3 & 2 & 2 & 1 \\
\hline Total & $\mathbf{1 2}$ & $\mathbf{1 1}$ & $\mathbf{1 4}$ & $\mathbf{1 6}$ & $\mathbf{1 1}$ & $\mathbf{1 1}$ & $\mathbf{1 2}$ \\
\hline
\end{tabular}

para asegurar la representatividad de los ítems seleccionados. Así se ha diseñado para cubrir un espectro de edades comprendidas entre los tres y los treinta y seis meses. Para ello se han construido un total de siete cuestionarios. Los cortes de edad han sido establecidos de forma convencional al estudiar los diferentes protocolos o programas de seguimiento de salud de los/as niños/as.

El número de ítems o hitos incorporados en cada cuestionario oscila entre los I I y los I6 ítems y oscila entre 5 minutos a los/as niños/as más pequeños y ro minutos en los preescolares. La selección de los ítems se ha realizado en base al principio de representatividad de la actividad dominante. Es decir, se han incluido los hitos evolutivos (ítems) que según los autores consultados el 90-95\% de los niños/as realizan al finalizar el periodo de tiempo analizado (Rico, 20I3; Alonso, 2014).

El SDPTD ${ }^{3}$ fue desarrollado con el principal objetivo de detectar cualquier problema que pudiera surgir en el desarrollo de un/a niño/a relacionado con un retraso en su desarrollo psicomotor con el objeto de comenzar las intervenciones necesarias lo antes posible

3. Sistema de Detección Precoz de Trastornos del Desarrollo.
(Alcantud, Alonso, \& Rico, 20I4). Se puede acceder a través del enlace http://acceso. uv.es/ProyectoC. Su desarrollo se realizó en U.I Acceso del Departamento de Psicología Evolutiva y de la Educación de la Universitat de València en colaboración con el CUDAP ${ }^{4}$ y la Conselleria de Sanitat de la Generalitat de Valenciana.

La mayoría de los ítems vienen acompañados de una breve explicación de la conducta que intenta evaluar el ítem. Complementariamente tiene un sistema de ayuda mediante el cual se presentan los ítems, con el complemento de un video donde un/a niño/a de edad normativa realiza la conducta objeto de la pregunta con el fin de facilitar la comprensión de la misma.

Al finalizar el cuestionario, automáticamente se genera un informe con los resultados obtenidos en formato PDF que se puede guardar o imprimir. Con este documento, una vez impreso, se puede acudir al pediatra para que verifique la información y, si se cree conveniente, se remita a los especialistas para una valoración más exhaustiva y si fuera necesario la remisión a un Centro de Atención Temprana para su evaluación y tratamiento.

4. Centre Universitari de Diagnòstic i Atencio Primerenca. 


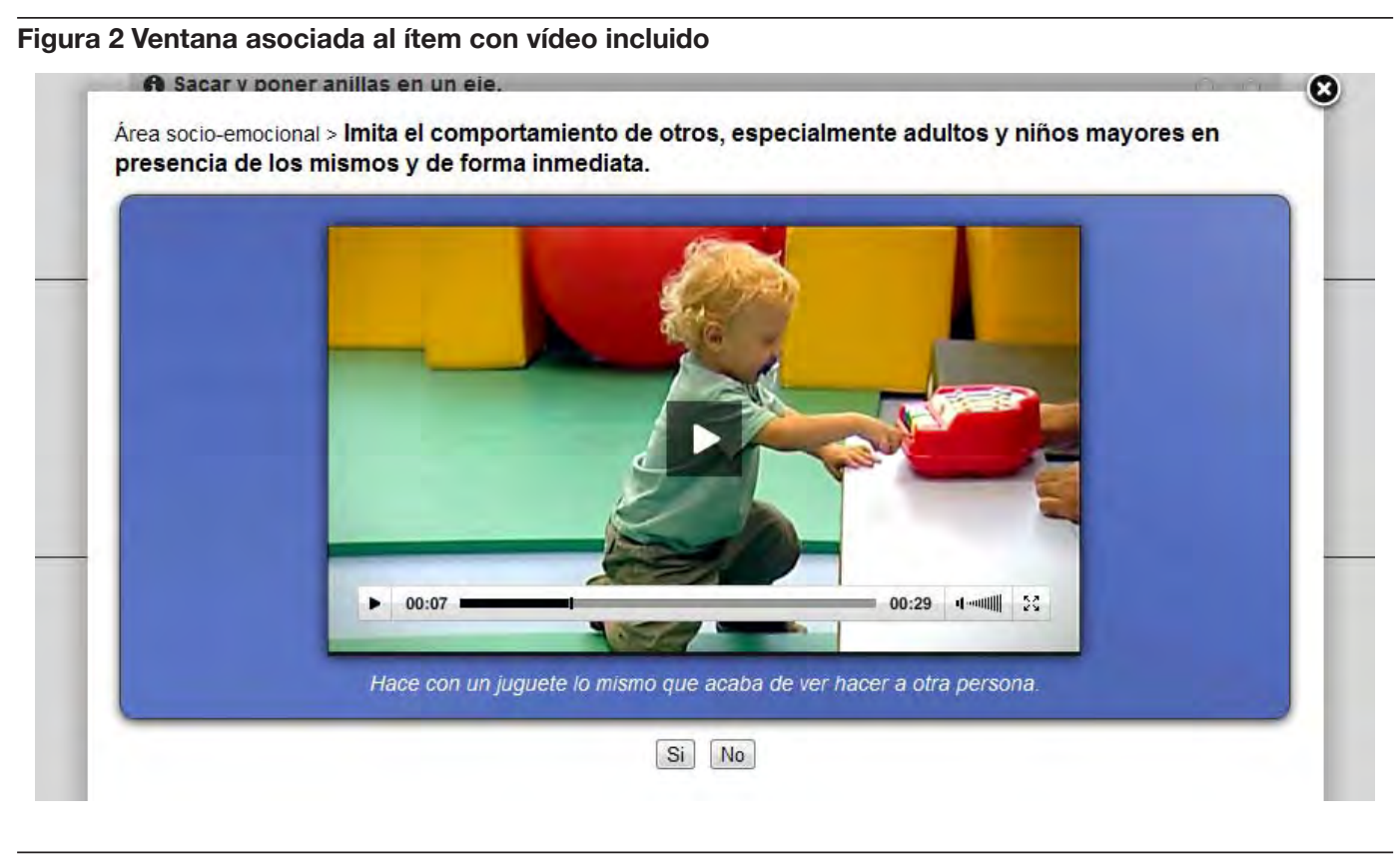

\subsection{Procedimiento}

Para el proceso de validación se contó con la colaboración de la Conselleria de Sanitat. El proyecto fue aprobado por el $\mathrm{CEIC}^{5} \mathrm{del} \mathrm{CSISP}^{6}$ el 27 de mayo del 20I I. El proceso de validación dada las grandes diferencias de edad se dividió en dos fases: en primer lugar, los cuestionarios de 18 meses hasta los 36 meses se administraron a una muestra de niños/as asistentes a centros educativos infantiles de la ciudad de Valencia (Rico, 20I3). En segundo lugar los cuestionarios de tres hasta los doce meses se aplicaron sobre una muestra de niños/as que acudieron en visita ordinaria a las consultas de Pediatría de Atención Primaria de los Centros de Salud de los departamentos del Hospital Clínico Universitario y Hospital Universitario de la Ribera en Alcira (Alonso, 2014).

En el primer caso se realizó una convocatoria a los centros infantiles de la ciudad de Valencia y acudieron a la misma un total de veinte centros educativos. Después de una acción formativa,

5. Comité Ético de Investigación Clínica.

6. Centro Superior de Investigación en Salud Pública. se instruyó a los profesionales para que distribuyeran los manuales de uso del sistema entre los padres/madres de los/as niños/as de la edad seleccionada invitándoles a participar. Una vez cumplimentados los cuestionarios, el documento demostrativo era entregado a los profesionales del centro que hicieron la verificación de la información (segundo nivel de cribado). Los/as niños/as que dieron positivo en las dos evaluaciones fueron derivados al CUDAP para realizar la evaluación por un especialista aplicándose como criterio "gold standard" la escala Merrill Palmer-R (Roid \& Sampers, 2004). Se constituyó un grupo control con niños/as de la misma edad y género a los que también se les aplicó la misma escala. Más detalles sobre el proceso de captación y muestreo se pueden encontrar en Rico (2013).

Para los cuestionarios de edades inferiores, dadas las dificultades de encontrar suficiente muestra en centros infantiles, se optó por acudir a los servicios de pediatría de los centros sanitarios de Atención Primaria. Los profesionales que colaboraron se encargaron de distribuir entre las familias atendidas los dípticos explicativos del sistema, solicitándoles 
que accedieran al mismo y contestaran al cuestionario de la edad de su hijo/a. Una vez realizada la primera evaluación por los/ as padres/madres, se les dio cita para que los propios pediatras se encargaran de validar las respuestas y, posteriormente, personal del equipo de investigación aplicó el test criterio o "gold standard". Igual que en la fase anterior, se eligió la escala de desarrollo Merrill-Palmer-R. El motivo de elegir este instrumento se debe a que la edad de aplicación se corresponde con la edad de aplicación del SDPTD, de forma que no es necesario utilizar más de un instrumento criterio en función de la edad, además, se trata de un instrumento de evaluación de espectro general que incluye todas las áreas del desarrollo.

\subsection{Participantes}

Aunque el objetivo de esta investigación no es un estudio poblacional ni un estudio epidemiológico, considerando que el proceso de captación no ha determinado la selección de los sujetos evaluados y por tanto, considerando la muestra como aleatoria, se ha estimado el error muestral a un nivel de confianza $\alpha=0,05 \%$. La aplicación de los cuestionarios de 3 a I 2 meses se realizó entre los meses de noviembre del 20 I I y julio del 20 I 2 y los cuestionarios de I 8 a 36 meses, se administraron desde marzo a Julio del 20I I.

Un año después de la aplicación, se realizó un seguimiento telefónico a las familias para conocer el estado de desarrollo de los/as niños/ as. Esta información, junto con la recogida en la anamnesis de cada caso, será utilizada para determinar la validez diagnóstica del SDPTD (Rico, 20I3; Alonso, 20I4).

\section{Resultados}

Los cuestionarios han sido analizados siguiendo un sistema de análisis psicométrico convencional (Tornimberi \& Perez, 2008; Muñiz, 2003; Muñiz, Fidalgo, Garcia-Cueto, Martinez \& Moreno, 2005). El criterio de calidad para estos cuestionarios se basa en el valor de diferentes indicadores psicométricos como la fiabilidad, validez, sensibilidad y especificidad entre otros (Camp, 2006; Johnson \& Marlow, 2006). Inicialmente y con la finalidad de determinar si los ítems cumplen el criterio de selección, es decir que representen conductas usuales en niños/as de la edad superior al 90\%, se calcularon los índices de dificultad $(\mathrm{P})$.

Como se puede observar en la tabla 3 , la mayoría de cuestionarios cumplen el criterio de que cada ítem representa un hito evolutivo que cumple como mínimo el 90-95\% de la población. El cuestionario que mejor cumple este criterio es el de tres y veinticuatro meses y el que peor lo cumple el de 36 meses.

\section{Tabla 2. Distribución de la muestra en función de la edad}

\begin{tabular}{|c|c|c|c|c|c|c|c|c|}
\hline & & \multicolumn{7}{|c|}{ Edad en meses } \\
\hline & & 3 & 6 & 9 & 12 & 18 & 24 & 36 \\
\hline \multirow{2}{*}{ 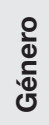 } & Varones & 47 & 47 & 59 & 57 & 44 & 84 & 34 \\
\hline & Mujeres & 56 & 45 & 38 & 37 & 49 & 86 & 45 \\
\hline & Total & 103 & 92 & 97 & 94 & 93 & 170 & 79 \\
\hline \multicolumn{2}{|c|}{ Error Muestral } & 0.0675 & 0.0715 & 0.0696 & 0.0707 & 0.0707 & 0.052 & 0.077 \\
\hline
\end{tabular}


Tabla 3. Porcentaje de ítems constantes y por debajo el criterio $\mathrm{p}=0,90$

\begin{tabular}{|l|c|c|c|c|c|c|c|c|}
\hline & \multicolumn{2}{|c|}{3 meses } & \multicolumn{2}{c|}{6 meses } & \multicolumn{2}{c|}{9 meses } & \multicolumn{2}{c|}{12 meses } \\
\hline \% Ítems & Padres & Prof & Padres & Prof & Padres & Prof & Padres & Prof \\
\hline $\mathrm{P}<0.90$ & 0 & 0 & 18,18 & 0 & 28,57 & 14,29 & 25,00 & 12,50 \\
\hline Constante & 33,33 & 25,00 & 18,18 & 54,55 & 28,57 & 21,43 & 6.25 & 18,75 \\
\hline
\end{tabular}

\begin{tabular}{|l|c|c|c|c|c|c|}
\hline & \multicolumn{2}{|c|}{18 meses } & \multicolumn{2}{c|}{ 24 meses } & \multicolumn{2}{c|}{36 meses } \\
\hline \% Ítem & Padres & Prof & Padres & Prof & Padres & Prof \\
\hline $\mathrm{P}<0.90$ & 0 & 6.66 & 0 & 0 & 0 & 0 \\
\hline Constante & 13.33 & 20.00 & 28.57 & 14.28 & 26.09 & 56.52 \\
\hline
\end{tabular}

\subsection{Fiabilidad}

La consistencia interna de los test se mide utilizando el coeficiente Alfa de Cronbach (Cronbach, I95I; Tornimberi \& Perez, 2008; Muñiz, 2003; Viladrich, Doval \& Prat, 2005).

En la tabla 4 se presentan una síntesis de los índices de fiabilidad calculados para los siete cuestionarios. Obsérvese como en general el cuestionario con las respuestas de los/as padres/madres corregidas por los profesionales tienen más fiabilidad que la de los/as padres/ madres, con excepción del cuestionario de 6 meses. Se observa que la fiabilidad es media y aceptable, con excepción del cuestionario de 3 meses (.44) y el de 6 meses (contestado por los profesionales). No obstante, debemos tener en cuenta que el Alfa de Cronbach mide consistencia interna y su valor se relaciona con el número de ítems (longitud de la prueba) y la dispersión de las puntuaciones. Como los ítems de los cuestionarios fueron seleccionados buscando que el 90-95\% de la población lo resolviera, la consecuencia es que existe poca dispersión en la respuesta lo que produce índices de fiabilidad más bajos. No obstante, está pendiente en una segunda aplicación (versión 2.o) la introducción de un mayor número de ítems en estos cuestionarios y el cálculo de fiabilidad por test-retest en los que esperamos que los resultados sean algo más elevados siguiendo la tendencia de las correlaciones entre los resultados de los padres y los profesionales.

El uso de herramientas de cribado por los/ as padres/madres, aunque claramente reduce coste, genera una preocupación general sobre la fiabilidad de las respuestas de los/as padres/ madres respecto al desarrollo de sus hijos/

Tabla 4. Valores de fiabilidad calculados por el Alpha de Cronbach para cada uno de los cuestionarios

\begin{tabular}{|l|c|c|c|c|c|c|c|}
\hline & 3 meses & 6 meses & 9 meses & 12 meses & 18 meses & 24 meses & 36 meses \\
\hline Padres & .44 & .66 & .54 & .68 & .82 & .797 & .584 \\
\hline Profesionales & .77 & .44 & .64 & .68 & .831 & .85 & .60 \\
\hline
\end{tabular}

Tabla 5. Correlaciones entre las respuestas de los padres y las puntuaciones de los profesionales

\begin{tabular}{|l|l|l|l|l|l|l|l|}
\hline$r_{x y}$ & 3 meses & 6 meses & 9 meses & 12 meses & 18 meses & 24 meses & 36 meses \\
\hline padres/prof & 0.846 & 0,903 & 0.872 & 0.900 & 0.98 & 0.93 & 0.459 \\
\hline
\end{tabular}


as (Sheehan, I988). Esta preocupación dio pie a muchas investigaciones alrededor de su validez. En la mayoría de las investigaciones se informa de un acuerdo consistente entre las evaluaciones de profesionales y de padres/ madres, en particular cuando estos últimos respondían a cuestiones sobre el desarrollo actual (Squires, Potter, \& Bricker, I 998). En este caso, las puntuaciones obtenidas por los profesionales, son el resultado de la evaluación de los resultados de los/as padres/madres, por tanto, no son dos evaluaciones totalmente independientes. No obstante, las correlaciones tal como se muestra en la tabla 5 son muy altas. Se puede concluir este punto diciendo que las observaciones de los profesionales pueden cambiar en magnitud pero no en dirección.

\subsection{Validez concurrente}

La validez hace referencia a la capacidad de un instrumento de medición para cuantificar de forma significativa y adecuada el rasgo para cuya medición ha sido diseñado (Viladrich, Doval, \& Prat, 2005; Garcia, I993; Tornimberi \& Perez, 2008). La constatación de la validez de un instrumento de detección no debería ofrecer mayores problemas si el criterio de contraste está bien definido. En general, dados los problemas de definición, se suele optar por utilizar diferentes criterios. En primer lugar, se presenta la validez concurrente (correlación entre el nuevo test y un test previamente validado), en segundo lugar se presenta la validez predictiva y por último la validez diagnóstica.

En el caso de la validez concurrente, el criterio utilizado en este estudio ha sido la escala de desarrollo MP-R (Roid \& Sampers, 2004). Si se observa la tabla 6 , salvo el caso del cuestionario de doce meses, las correlaciones entre las respuestas de los/as padres/madres y profesionales y los resultados de la MP-R son medios y mediosaltos y todos estadísticamente significativos.

\subsection{Validez predictiva/discriminante}

Para el estudio de la validez predictiva o discriminante se crearon dos grupos en cada nivel de edad, por una parte los/as niños/as que obtuvieron una puntuación superior al punto de corte de la MP-R en el Índice General, y por otro lado, los que obtuvieron una puntuación inferior a este punto de corte. (Criterio propio de la MP-R de tener una puntuación en el $\mathrm{IG}<85$ ).

Obsérvese que la bondad de clasificación sobre los resultados de la MP-R en base a los ítems del SDPTD es muy elevado en todos los casos. Este dato junto con el apartado anterior hace concluir que la aplicación del SDPTD equivaldría a la aplicación de la MP-R.

Tabla 6. Índices de correlación entre las puntuaciones dadas por los padres y profesionales y el Índice General Cognitivo obtenido de la MP-R

\begin{tabular}{|l|c|c|c|c|c|c|c|}
\hline & 3 meses & $\mathbf{6}$ meses & 9 meses & 12 meses & 18 meses & 24 meses & 36 meses \\
\hline$r_{x y}$ padres - MP-R & $0,521^{\star \star}$ & $0,300^{\star \star}$ & $0,735^{\star \star}$ & 0,168 & $0.804^{\star \star}$ & $0.727^{\star \star}$ & $0.461^{\star *}$ \\
\hline$r_{x y}$ prof - MP-R & $0,622^{\star \star}$ & $0,415^{\star \star}$ & $0,750^{\star \star}$ & 0,132 & $0.795^{\star \star}$ & $0.720^{\star \star}$ & 0.353 \\
\hline
\end{tabular}

Tabla 7. \% de clasificación correcta sobre los grupos definidos por el criterio de la MP-R en base a las funciones discriminantes calculadas a partir de las respuestas al SDPTD de los profesionales

\begin{tabular}{|l|c|c|c|c|c|c|c|}
\hline & $\mathbf{3}$ meses & $\mathbf{6}$ meses & $\mathbf{9}$ meses & $\mathbf{1 2}$ meses & $\mathbf{1 8}$ meses & $\mathbf{2 4}$ meses & $\mathbf{3 6}$ meses \\
\hline $\begin{array}{l}\text { \% clasificación } \\
\text { correcta con funciones } \\
\text { discriminantes }\end{array}$ & 99,00 & 98,9 & 96,9 & 96,8 & 100 & 96,1 & 96.0 \\
\hline
\end{tabular}




\subsection{Validez diagnóstica}

El concepto de validez predictiva o de pronóstico también hace referencia cuando el criterio no es una medida, que es un estado que queremos predecir con este test. En este caso sería el diagnóstico médico de padecer o pertenecer a alguna población de riesgo, en consecuencia se le suele denominar "Validez Diagnóstica” como la capacidad de predicción que tiene un test para predecir un diagnóstico como estado discreto.

En España, según la Encuesta sobre Discapacidades, Deficiencias y Estado de Salud realizada por el Instituto Nacional de Estadística, nos sitúan ante más de un $7 \%$ de niños/as que precisan seguimiento y/o tratamiento en los centros de atención temprana. En la aplicación piloto no sería esperable un porcentaje de detección superior al Io\% de la muestra. En un estudio sobre una población infantil de 472 niños/as nacidos entre I 996 y 2002 y seguidos en la consulta de Atención Primaria (Centro de Salud de Mendillorri) en la ciudad de Pamplona (Navarra), se encontró que el 8,68\% de niños/as tenían algún trastorno o riesgo de padecerlo (Galbe Sanchez-Ventura, 20I3). En el caso objeto de investigación se ha obtenido información de tres vías: por parte del cuestionario (contestado por padres/madres y profesionales), por el diagnóstico conocido recogido en la anamnesis y por último, el estado del niño/a un año después de la aplicación.
Los resultados obtenidos son diferentes en función de cada corte de edad, como se puede observar en la tabla 8. Para el corte de tres meses el porcentaje de población detectado por los profesionales (cuestionario de padres/ madres corregido por los profesionales) alcanza un $7,77 \%$ frente al $5,83 \%$ de casos conocidos y el $6,8 \%$ de casos conocidos un año después. Existe posiblemente una sobreestimación de casos detectados tanto por los/as padres/madres como por los profesionales. Se debe hacer una reflexión sobre esta cuestión. Es posible que, por el procedimiento de captación seguido, se haya producido un efecto llamada, de forma que acudieran más las familias que tenían niños/as con problemas y menos las de desarrollo típico (Alonso, 20I4).

En la misma línea, si observamos los valores de sensibilidad y especificidad de la clasificación con el criterio de diagnóstico (conocido un año después), se observa un comportamiento muy aceptable de las puntuaciones de los profesionales (acumula la de los padres/madres) y en algún caso, mejorado por las funciones discriminantes. Es importante recordar las diferencias procedimentales existentes en el proceso muestral entre los cuatro primeros segmentos de edad y los tres últimos. En estos tres últimos solo se aplicó la escala criterio a los/as niños/as con resultados positivos y a un grupo control, consecuentemente los índices de sensibilidad y especificidad se ven afectados y no tienen valor poblacional.

Tabla 8 Valores comparativos de resultados según segmentos de edad

\begin{tabular}{|l|c|c|c|c|}
\hline \multirow{2}{*}{} & \multicolumn{4}{|c|}{ \% casos positivos } \\
\cline { 2 - 5 } & Padres & Profesionales & Diagnóstico Previo & 1 año después \\
\hline 3 meses & 15,53 & 7,77 & 5,83 & 6,80 \\
\hline 6 meses & 27,17 & 14,13 & 4,35 & 4,35 \\
\hline 9 meses & 41,23 & 23,71 & 13,40 & 19,59 \\
\hline 12 meses & 63,83 & 46,81 & 15,96 & 15,96 \\
\hline 18 meses & 15,53 & 7,77 & 5,83 & 6,80 \\
\hline 24 meses & 27,17 & 14,13 & 4,35 & 4,35 \\
\hline 36 meses & 63,83 & 46,81 & 15,96 & 15,96 \\
\hline
\end{tabular}


Tabla 9 Tabla síntesis con los valores de sensibilidad y especificidad para el criterio de un año después

\begin{tabular}{|c|c|c|c|c|c|c|c|}
\hline & 3 meses & 6 meses & 9 meses & 12 meses & 18 meses & 24 meses & 36 meses \\
\hline \multicolumn{8}{|c|}{ Resultados para puntuación de padres } \\
\hline Sensibilidad & 0.714 & 0.75 & 1.00 & 1.00 & 1.00 & 0.875 & 0.80 \\
\hline Especificidad & 0.873 & 0.87 & 0.81 & 0.36 & 0.36 & 0.44 & 0.687 \\
\hline Valor Predictivo Positivo & 0.357 & 0.25 & 0.65 & 0.29 & 0.29 & 0.33 & 0.444 \\
\hline Valor Predictivo Negativo & 0.968 & 0.98 & 1.00 & 1.00 & 1.00 & 0.916 & 0.916 \\
\hline \multicolumn{8}{|c|}{ Resultados para puntuación de profesionales } \\
\hline Sensibilidad & 0.571 & 0.50 & 0.90 & 1.00 & 1.00 & 0.875 & 0.80 \\
\hline Especificidad & 0.971 & 0.94 & 0.98 & 0.59 & 0.59 & 0.44 & 0.562 \\
\hline Valor Predictivo Positivo & 0.666 & 0.33 & 0.94 & 0.39 & 0.39 & 0.33 & 0.363 \\
\hline Valor Predictivo Negativo & 0.958 & 0.97 & 0.96 & 1.00 & 1.00 & 0.916 & 0.90 \\
\hline \multicolumn{8}{|c|}{ Resultados función discriminante } \\
\hline Sensibilidad & 0.571 & 0.75 & 0.70 & 0.66 & 0.86 & 0.875 & 0.80 \\
\hline Especificidad & 1.00 & 0.90 & 0.98 & 0.94 & 0.77 & 0.44 & 0.687 \\
\hline Valor Predictivo Positivo & 1.00 & 0.30 & 0.93 & 0.77 & 0.50 & 0.33 & 0.444 \\
\hline Valor Predictivo Negativo & 0.959 & 0.98 & 0.90 & 0.91 & 0.95 & 0.916 & 0.916 \\
\hline
\end{tabular}

En otras publicaciones de mayor extensión (Alcantud, Alonso, \& Rico, 20I4), se presentan resultados de las Curvas ROC para la determinación de diferentes puntos de corte. De estos resultados se desprende que el sistema en su conjunto muestra un comportamiento adecuado, aunque como resulta obvio, mejorable. Para evitar el coste emocional que puede significar para una familia, la noticia de que su hijo/a dio positivo en un sistema de detección de trastornos del desarrollo y con la finalidad de garantizar el mínimo de falsos positivos, se propone aplicar puntos de corte múltiples. Se trata de calcular dos puntos de corte que determinen una zona de seguridad donde el impacto de los falsos positivos se aminore. En la tabla ıo se resume los resultados obtenidos para los siete cuestionarios. Obsérvese como los casos positivos sobre el criterio diagnóstico un año después, se distribuyen en la mayoría de los casos entre la categoría de Riesgo alto y Riesgo moderado. El número de falsos negativos es muy bajo, incluso en el cuestionario de doce meses es cero.

Tabla 10 Distribución del número de casos según riesgo calculado por las respuestas de los profesionales y el diagnóstico un año después

\begin{tabular}{|l|c|c|c|c|c|c|c|c|c|c|c|c|c|c|}
\hline & \multicolumn{2}{|c|}{3 meses } & $\mathbf{6}$ meses & \multicolumn{2}{|c|}{$\mathbf{9}$ meses } & \multicolumn{2}{|c|}{$\mathbf{1 2}$ meses } & $\mathbf{1 8}$ meses & \multicolumn{2}{|c|}{$\mathbf{2 4}$ meses } & \multicolumn{2}{c|}{$\mathbf{3 6}$ meses } \\
\hline RIESGO & SI & NO & SI & NO & SI & NO & SI & NO & SI & NO & SI & NO & SI & NO \\
\hline Alto & 4 & 0 & 2 & 6 & 13 & 0 & 7 & 2 & 5 & 2 & 2 & 4 & 2 & 3 \\
\hline Moderado & 0 & 2 & 1 & 4 & 5 & 1 & 8 & 24 & 2 & 3 & 5 & 10 & 2 & 2 \\
\hline Sin Riesgo & 3 & 69 & 2 & 78 & 2 & 57 & 0 & 30 & 0 & 1 & 1 & 11 & 1 & 10 \\
\hline
\end{tabular}




\section{Conclusión}

En definitiva, se puede concluir que el SDPTD es un sistema de detección para detectar los trastornos del desarrollo que muestra una adecuada fiabilidad y su validez. La validez ha quedado demostrada tanto al compararla de forma concurrente con la escala MP-R, como a nivel diagnóstico al comparar sus resultados con los diagnósticos conocidos y el seguimiento un año después. Esta es una primera versión de los cuestionarios que será mejorada en las siguientes revisiones. A nivel de la usabilidad, el sistema en general ha sido valorado como muy sencillo y accesible.

Como líneas de trabajo futuro, como ya se ha dicho en el texto, se deben mejorar los instrumentos, mejorando su redacción y los videos de apoyo a cada uno de los ítems. Se debe valorar también que además de ser un instrumento diagnóstico, también tiene un valor educativo, dando información a los padres sobre cuáles son los hitos evolutivos de sus hijos/as.

En cuanto a la forma de respuesta, es posible que la respuesta dicotómica provoque una respuesta forzada que en ocasiones no es del todo correcta. Se optó por esta solución por ser fácil de valorar, no obstante, muchos padres/ madres comunican que sus hijos/as lo hacían en ocasiones, pero no siempre, o simplemente decían que no lo habían observado. Se deben incorporar estas opciones de respuesta. Cuando se trata de responder si un/a niño/a "señala los objetos cuando se le nombran", la respuesta no solo será sí o no, bien podría ser "a veces" o "casi siempre". Este tipo de respuestas abren la posibilidad a utilizar la Lógica Difusa para un mejor procesamiento de la herramienta de evaluación. Se han desarrollado algunas herramientas para diagnosticar trastornos del desarrollo a edad temprana, tal es el caso del sistema KBS (Knowledge Based Screener) basado en reglas si-entonces. Por ejemplo, se ha desarrollado un sistema experto experimental que ayudan a identificar el/la niño/a con problemas (Veeraraghavan \& Srinivasan, 2007). En el caso de los Trastornos del Espectro Autista, existen estudios en los que se aplican estos principios basándose en una lista de supuestos y el MCHAT (Kannappan, Tamilarasi \& Papageorgiou, 20I I). Está en una línea de trabajo que linda entre el desarrollo metodológico, el desarrollo tecnológico y la aplicación diagnóstica.

Por último, la versión actual del SDPTD está abierta y lo único que se requiere es introducir la fecha de nacimiento y el distrito postal de residencia. Se debe cerrar el acceso y requerir un "login" controlado por nombre de usuario y contraseña. Esta opción se descartó en su momento puesto que obligaba, según la LOPD (Ley I5/I999 de I3 de diciembre), a publicar la base de datos y mantener unos sistemas de seguridad que para el proceso de investigación resultaban caros e innecesarios. Ahora, por el contrario, puesto a hacer público el uso de este instrumento, se cree necesario guardar los resultados de cada cuestionario e incluso arbitrar un sistema que, automáticamente, cuando la puntuación del/la niño/a esté en una zona de riesgo, avise a la familia cuando llegue la edad para cumplimentar el siguiente cuestionario o solicitar información de confirmación de diagnóstico. Una herramienta de estas características nos permitiría, con un coste razonable, poder plantearnos estudios incluso de ámbito nacional e internacional. 


\section{Referencias bibliográficas}

Aguirre, J. (200I). La actividad fisica del niño: de cero a tres años. Pamplona: Instituto Navarro de Deporte y Juventud.

Alcantud, F. et al. (2014). Sistema de Detección Precoz de Trastornos del Desarrollo (SDTP): Construcción, validación y manual de uso (versión I.O). Madrid: En prensa.

Alonso, Y. (20I4). Validación del Sistema de Detección Precoz de Trastornos del Desarrollo (SDPTD). 3 a I2 meses. Valencia: Universitat de València.

Alvarez, M. y Giner, A. (2007). “Desarrollo Psicomotor". Revista de Pediatria y Atención Primaria, 59-66.

Alvarez, M. et al. (2009). "Importancia de la vigilancia del desarrollo psicomotor por el pediatra de Atención Primaria: Revisión del tema y experiencia de seguimiento en una consulta de Navarra”. Revista Pediatrica de Atención Primaria, II (4I): 65-87.

Artigas-Pallares, J. (20II). “Trastornos del neurodesarrollo: Conceptos básicos”. En J. Artigas-Pallares, y J. Narbona: Trastornos del Neurodesarrollo, 3-I6. Barcelona: Viguera Ediciones.

Aylward, G. (I995). Bayley Infant Neurodevelopmental Screener. San Antonio: Psychological Corporation.

Barnett, S. (I995). "Long term effects of early childhood programs on cognitive and school outcomes". Future Child, 25-50.

Canal, R. et al. (2006) "La deteccion precoz del autismo". Intervención Psicosocial, I5 (I): 29-47. http://scielo.isciii.es/pdf/inter/vi 5 nI/ vi 5niao3.pdf>.

Camp, B. W. (2006). "What the clinician really needs to know: Questioning the clinicl usefulness of sesitivy and specificity in studies of screening test". Journal of Developmental and Behavioral Pediatrics, 27: 226-230.

Casto, G. y Mastropieri, M. (I986). “The Efficacy of Early Intervention Programs: A Meta-
Analysis". Exceptional Children, 52 (5):

Cronbach, L. (I95 I). "Coefficient alpha and the internal structure of tests". Psychometrika, 297-334.

Fernández, E. (1988). El desarrollo psicomotor de I.702 niños de o a 24 meses de edad. [Tesis doctoral]. Universidad de Barcelona.

Fernández, E. et al. ( I991). Tabla de desarrollo Haizea-Llevant. Servicio Central de Publicaciones del Gobierno Vasco: Vitoria.

Frankenburg, W. et al. (I992). "The Denver II: A major revision and restandardization of the Denver Developmental Screenig Test". Pediatrics, 89: 91-97.

Galbe, J. (2013). Atención orientada al desarrollo y supervisión del desarrollo psicomotor (en línea). 〈http://www.aepap.org/previnfad/ psicomotor.htm». Grupo Previnfand.

Garcia, E. (I993). Introducción a la Psicometría. Madrid: Alianza.

García, J. N. (I999): “Intervención Psicopedagógica en los Trastornos del Desarrollo. Conceptualización, ámbito y modelo Integral”. En García Sánchez, J. N. (Ed.): Intervención Psicopedagógica en los Trastornos del Desarrollo. Ed. Pirámide. Madrid.

Gesell, A. (I974). Psicología Evolutiva de I a I6 años. Buenos Aires: Paidos.

Glascoe, F. y Macías, M. (2003). "How you can implement the AAP's new policy on developmental and behavioural screening". Contemporary Pediatrics, 85-102.

Guralnick, M. (1989,I997). Recents developments in Early Intervention Efficacy Research:Implicantions for family involvement.

Guralnick, M. (I998). "The effectiveness of early intervention for vulnerable children: A developmental perspective". American Journal on Mental Retardation, IO2: 319-345. 
Guralnick, M. J. y Bennett, F. C. (1987). The effectiveness of early intervention for atrisk and handicapped children. New York: Academic Express.

Hamilton, S. (2006). Screening for developmental delay: Reliable, easy-to-use tools. Journal of Familiy Practice, 5 5: 4I 5-422.

Hickson, G. et al. (1983). "Concerns of mothers seeking care in private pediatric offices: Opportunities for expanding services". Pediatrics, 72: 619-624.

Hix-Small, H. et al. (2006). "Impact of implementing Developmental Screeningo at I 2 and 24 months in a Pediatric Practice". Pediatrics, $38 \mathrm{I}-388$.

Horowitz, F. (1989). "Using developmental theory to guide the search for the effects of biological risk factors on the developmental of children". American Journal of Clinical Nutrition, 50 : 589-95.

Illingworth, R. (I992). El desarrollo del lactante $y$ del niño. Churchill Livingtone. Edición Española Alhambra Longman.

Johnson, S. y Marlow, N. (2006). Developmental screen or developmental testing? Early Human Develpment, 82,I73-183.

Kannappan, A. et al. (20I I). "Analyzing the performance of fuzzy cognitive maps with nonlinear hebbian learning algoritm in predicting autistic disorder". Journal Expert Systems with Applications, 38 (3): I 282-I 292.

McCormick, M. et al. (2006). "Early intervention in Low Birth Weight Premature Infants: Results at I 8 years of age for the Infant Health and Development Program”. Pediatrics, I I 7 : 77I-780.

Melchers, P. et al. (2003). Erweterte Vorsorgeuntersuchung. Leiden : PITS.

Muñiz, J. (2003). Teoria Clasica de los tests. Madrid: Pirámide.

Muñiz, J. et al. (2005). Análisis de items. Madrid: La Muralla.

Olhweiler, L. et al. (2002). "Estudio del desarrollo psicomotor en pacientes prematuros durante el primer año de vida". Revista de Neurologia, $35(8), 727-730$.

Osofsky, J. (1987). Handbook of infant development. New York: Willey.

Palfrey, J. et al. (I987). "Early identification of children's special need: a study in five metropolitan communities". Journal of Pediatrics, 65 I-659.

Reynolds, A. et al. (200I). "Long term effects of an early childhood intervention on educational achievement and juvenile arrest". Journal of the American Medical Association, 2339-2346.

Rico, D. (2013). Construcción y Validación de un Sistema de Detección Precoz de los Trastornos del Desarrollo (SDPTD): I 8 a 36 meses. Valencia: Universitat de València.

Roid, G., y Sampers, J. (2004). Scales of MerrillPalmer-Revised. Wooddale,IL: Stoelting Co.

Rydz, D., y Col, E. (2006). “Screenig for developmental delay in teh settingo of a community pediatric clinic: a prospective assessment of parent-report questionnaires". Pediatrics, II78-II85.

Schopler, E. (1983). "New developments in the definition and diagnosis of autism". En Lahey, B.B. y Kazdin, A.E. (Eds): Advances in clinical child psychology, 6: 93-I 27. New York, Plenum Publishing Corporation

Sheehan, R. (I988). "Involvement of parents in early childhood assessment". En T. Wachs y R. Sheehan (Eds): Assessment of young developmentally disabled children, 75-90.

Shonkoff, J. P. y Hauser-Cram, P. (I987). "Early Intervention for Disabled Infants and Their Families: A Quantitative Analysis". Pediatrics, $80(5): 650-58$.

Sices, L. et al. (2003). "How do primay care physicians identify young children with developmental delays? A National Survey". Developmental Behavioral Pediatircs, 409-4I7.

Smith, R. (I978). “The use of developmental screening tests by primary care pediatricians". Journal of Pediatrics, 524-527.

Squires, J. et al. (I998). "Parent-completed Developmental questionnarires: Effectiveness 
with low and middke income parents". Early Childhood Research Quaterly, 345-353.

Tornimberi, S., y Perez, E. (2008). Introducción a la Psicometría. Buenos Aires: Paidos.
Veeraraghavan, S. y Srinivasan, K. (2007).

"Exploration of autism using expert systems". Information Technology ITNG'07, 26I-264.

Viladrich, C. et al. (2005). Psicometria. Barcelona: Universitat Oberta de Catalunya. 



\section{Las dificultades de clasificación diagnóstica en Atención Temprana. La experiencia en dos unidades de Galicia}

\section{Difficulties in diagnostic classification in early intervention. Experiences in two Galician units}

\section{Resumen}

En este artículo se ofrecen los resultados de aplicar un modelo de categorización diagnóstica a la población atendida en dos centros de atención temprana durante un período de 5 años. Se atendieron 4 I I niños y niñas con diversos tipos de trastornos del desarrollo, siendo los de comunicación y lenguaje los más frecuentemente diagnosticados $(39, \mathrm{I} \%)$, seguidos de los conductuales $(25,9 \%)$ y los afectivos ( $19,3 \%)$. Cabe destacar la escasa presencia de los trastornos motores $(6,6 \%)$ y de los de espectro autista (7\%). Los resultados del estudio muestran la complejidad de los problemas asistenciales y de procedimiento que en la actualidad enfrenta la atención temprana.

\section{Palabras clave}

Clasificación diagnóstica, atención temprana. evaluación de necesidades.

\begin{abstract}
This article shows the results of applying a diagnostic classification model to the population served by two early intervention units over a five year period. The units served 4 I I children with various types of developmental disorders. Language and communication problems were the most frequently diagnosed (39.1 \%), followed by behavioral disorders $(25.9 \%)$ and affective disorders (I9.3\%). Notably, motor disorders $(6.6 \%)$ and autism spectrum disorders (7\%) were less present. The results show the complexity of current care and procedural issues in the field of early intervention.
\end{abstract}

\section{Keywords}

Diagnostic classification, early intervention. needs assessment.

\section{Jaime Ponte Mittelbrunn \\ <jaime.ponte.mittelbrunn@xunta.es> \\ Coordinador de las Unidades de \\ Desarrollo Infantil y Apoyo Familiar (UDIAFS) de las comarcas de Deza y \\ Salnés (Ferrol)}

\author{
Para citar: \\ Ponte, J. (201 5): “Las dificultades de \\ clasificación diagnóstica en Atención \\ Temprana. La experiencia en dos \\ unidades de Galicia", Revista Española \\ de Discapacidad, 3 (I): I23-I39. \\ Doi: <http://dx.doi.org/IO.5569/2340- \\ 5I04.03.01.07>
}

Fecha de recepción: I4-09-20I 5 Fecha de aceptación: IO-O4-20I 5 


\section{Introducción}

La clasificación y organización diagnóstica de los trastornos del desarrollo y de los factores de riesgo que pueden generarlos ha sido y es una de las preocupaciones principales de los profesionales y las administraciones públicas que se ocupan de la Atención Temprana, todos ellos interesados en contar con un instrumento que sirva para estudiar su prevalencia, comprender los factores biopsicosociales que influyen en su aparición, diseñar, implementar y evaluar los recursos que se derivan de esa realidad epidemiológica.

Pero no por necesaria, esta tarea resulta sencilla. La complejidad de clasificar los trastornos del desarrollo deriva, por un lado, de su propio carácter multidimensional o de su dinamismo evolutivo y, por otro, de la heterogeneidad de las disciplinas profesionales que convergen en la Atención Temprana y de los cambios sociohistóricos que se dan en el itinerario o-6.

Durante años y aún ahora, la organización diagnóstica de los trastornos del desarrollo ha estado referenciada a sistemas de clasificación como la Clasificación Internacional de Enfermedades CIE ro (OMS ${ }^{\text {r }}$, 2008) o el Manual de Diagnóstico y Estadística de los Trastornos Mentales DSM IV ( $\mathrm{APA}^{2}$, I994) y V (APA, 20I3), pero estas clasificaciones fueron diseñadas desde una perspectiva diferente $y$ los profesionales consideran que no ofrecen un marco adecuado a las necesidades de la Atención Temprana. En relación al DSM IV se pone en cuestión que sus criterios sean aplicables a niños menores de 6 años pues no recogen de forma adecuada el dinamismo y peculiaridades evolutivas de dicha etapa. También se ha puesto de relieve la ambigüedad de alguno de esos criterios (como la utilización de adjetivos como "a menudo", "persistente", etc.). Así mismo se destaca el escaso énfasis sobre los factores contextuales (Mash \&

I. Organización Mundial de la Salud.

2. American Psychiatric Association.
Terdal, I997a). Por lo que se refiere al DSM $\mathrm{V}$ su reciente publicación ha generado una gran polémica en cuyo centro se sitúa la crítica al desdibujamiento de categorías y a la extensión sobrediagnóstica que pueda llegar a producir (Frances, 20I3). Respecto de la CIE Io, aunque se considera la clasificación idónea para organizar "enfermedades" y factores de riesgo basados en las mismas, también se cuestiona su utilidad para integrar aspectos clínicos, evolutivos y contextuales que son necesarios para obtener un perfil diagnóstico y un lenguaje útil para la Atención Temprana. Por otro lado, los intentos de incorporar estas dimensiones a los registros de las unidades y cultivar una mirada profesional más dinámica ante ellas todavía se encuentran en una fase experimental. A pesar de los avances realizados a través del desarrollo de la Clasificación Internacional del Funcionamiento en su versión para Infancia y Adolescencia (OMS, 20I I), todavía no contamos con instrumentos que estén reconocidos internacionalmente y que sean útiles en el trabajo cotidiano para describir y comunicar la situación funcional, evolutiva y relacional de los menores de o a 6 .

Mientras tanto, al hilo del consenso generado en torno al Libro Blanco de la Atención Temprana, en España, desde la Federación Estatal de Asociaciones de Profesionales de la Atención Temprana se fue desarrollando una propuesta de clasificación de síntesis, la Organización Diagnóstica en Atención Temprana ODAT (GAT, 2000). La ODAT importa muchos contenidos de otra aproximación específica para la primera infancia, la Diagnostic Classification of Mental Health and Developmental Disorders of Infancy and Early Childhood DC o-3 R (NICTD 3 , 2005), una fórmula multiaxial de clasificación realizada en Estados Unidos en la cual junto a tres ejes diagnósticos (el propio de salud mental, el relacional y el médicosindrómico), se enfatiza la importancia de tener en cuenta el funcionamiento socio emocional del niño (eje V) y los factores de riesgo/estrés (eje IV) que hay a su alrededor. La aproximación de la ODAT incorpora en su Eje IV (Trastornos

3. National Center for Infants and Toddlers and their Families. 
en el Niño) los diagnósticos sindrómicos y de salud mental infantil que la DC: $0-3 \mathrm{R}$ distribuye en sus ejes I y III; asume en su eje V (Familia) gran parte del eje II de la DC: $0_{-3} \mathrm{R}$ y, por fin, distribuye los estresores del eje IV de la DC: $0-3 \mathrm{R}$ en factores de riesgo biológico y psicosocial.

De tal modo que al final la ODAT se estructura en tres niveles (Nivel de riesgo, Nivel de disfunción/trastorno, Nivel de recursos/apoyos) y tres dimensiones que corresponden al Niño, a la Familia y al Entorno. Asimismo delimita unas y otras categorías mediante un glosario instrumentado a modo de guía clínica.

La ODAT cuenta con una primera versión que data de 2004 y con el respaldo de un trabajo de validación (EDIS, 2007) a partir del cual fue revisada en 2008. La Junta de Andalucía ha realizado también una tabla de equivalencias con la CIE ro (Pons, et al. 2012). Sin embargo, a pesar de tener ya casi diez años, la ODAT tiene todavía un escaso recorrido práctico como instrumento cotidiano de los centros, unidades y equipos profesionales de Atención Temprana. El lugar en que este recorrido parece estar más avanzado es Andalucía, en la cuál y en gran medida gracias al apoyo de nuevas herramientas de gestión informática su uso ya está generalizado como instrumento de registro en los procesos de detección y derivación en Atención Temprana. De momento, sin embargo, la Junta de Andalucía aún no ha ofrecido una publicación detallada de sus datos si bien ha presentado algunos aspectos parciales de los mismos en distintas reuniones profesionales (Pons, 20II).

Por lo que se refiere al conjunto del Estado y a las distintas Comunidades Autónomas la única referencia en que hallamos datos de uso de la ODAT es la publicación "La Realidad Actual de la Atención Temprana en España” elaborada por un grupo de trabajo de la Federación Estatal de Asociaciones de Profesionales de la Atención Temprana y editada por el Real Patronato sobre Discapacidad (GAT, 20I I). En dicha publicación se ofrecen datos por Autonomías que siguen el modelo clasificatorio de la ODAT pero no se precisa quiénes han valorado ni la forma de valorar utilizada. Se mezclan las situaciones de riesgo con los trastornos evolutivos. Y los resultados muestran un alto grado de dispersión que ofrece una imagen poco coherente en términos epidemiológicos para el conjunto de la población española. En las tablas adjuntas 2 y 3 se recogen esos datos resaltando los valores máximos y mínimos obtenidos en cada epígrafe diagnóstico.

\section{Tabla 1. Esquema de la ODAT}

\begin{tabular}{|l|c|c|c|}
\hline Dimensiones & Niño & Familia & Entorno \\
\hline Riveles & Eje I & Eje II & Eje III \\
\hline Disfunción/Trastorno & Eje IV & Eje V & Eje VI \\
\hline Apoyos/Recursos & Eje VII & Eje VIII & Eje IX \\
\hline
\end{tabular}


Tabla 2. Población 0-6 años asistida en centros de atención temprana según tipo de trastornos. España 2008

\begin{tabular}{|l|c|c|c|c|c|c|c|c|c|c|c|c|c|c|c|c|c|c|c|}
\hline C. Autónoma & $\begin{array}{c}\mathbf{N}^{*} \\
\text { casos }\end{array}$ & $\mathbf{A}$ & $\mathbf{B}$ & $\mathbf{C}$ & $\mathbf{D}$ & $\mathbf{E}$ & $\mathbf{F}$ & $\mathbf{G}$ & $\mathbf{H}$ & $\mathbf{I}$ & $\mathbf{J}$ & $\mathbf{K}$ & $\mathbf{L}$ & $\mathbf{M}$ & $\mathbf{N}$ & $\tilde{\mathbf{N}}$ & $\mathbf{O}$ & $\mathbf{P}$ & $\mathbf{Q}$ \\
\hline Andalucía & $5488^{*}$ & 9,92 & 2,51 & 1,42 & 8,78 & 1,35 & 3,01 & 10,7 & 10,51 & 7,0 & 23,72 & 0,64 & 1,33 & 4,79 & 6,58 & 3,94 & 2,86 & 0,47 & 0,47 \\
\hline Aragón & $634^{*}$ & 4,12 & 2,53 & 0,85 & 11,2 & 0,42 & 1,82 & 1,8 & 9,52 & 15,33 & 18,71 & 0,42 & 2,85 & 6,13 & 12,47 & 3,28 & 0,74 & 0,11 & - \\
\hline Asturias & $2487^{*}$ & 26,2 & 3,86 & - & 11,58 & - & 4,22 & - & 25,05 & 4,83 & 21,06 & 3,18 & - & - & - & - & - & - & - \\
\hline Baleares & $336^{*}$ & 18,45 & 6,55 & 2,08 & 8,33 & 0,6 & 1,49 & 4,17 & 14,58 & 4,76 & 18,15 & 0,0 & 2,08 & 3,27 & 5,06 & 3,58 & 6,55 & 0,3 & - \\
\hline Canarias & $262^{*}$ & 5,35 & 3,83 & 1,16 & 4,58 & 0,76 & 2,29 & 7,25 & 24,04 & 8,0 & 14,12 & 0,38 & 1,91 & 4,96 & 9,16 & 1,53 & 4,96 & 4,58 & 1,14 \\
\hline Cantabria & $342^{*}$ & 26,02 & 4,97 & - & 14,91 & 0,29 & 0,29 & - & 13,45 & - & 32,45 & - & - & 1,47 & 3,22 & 2,93 & - & - & - \\
\hline CLM & $1401^{*}$ & 18,1 & 2,85 & 1,28 & 11,5 & 1,21 & 0,57 & 15,2 & 7,92 & 8,57 & 17,84 & 0,29 & 0,29 & 1,86 & 5,85 & 3,5 & 2,79 & 0,22 & 0,0 \\
\hline CYL & $2524^{*}$ & 35,67 & 3,96 & 0,79 & 11,09 & 0,79 & 1,74 & 5,35 & 8,72 & 5,55 & 18,23 & 0,79 & 0,79 & 1,19 & 0,79 & 1,19 & 0,79 & 0,99 & 1,58 \\
\hline Cataluña & $9132^{*}$ & 3,37 & 1,63 & 1,51 & 8,52 & 0,2 & 0,35 & 1,29 & 14,43 & 3,14 & 25,24 & 1,53 & 16,39 & 6,95 & 4,2 & 0,98 & 8,37 & 1,4 & 0,5 \\
\hline Extremadura & $202^{*}$ & 19,3 & 0,99 & 0,0 & 6,43 & 0,49 & 2,97 & 5,94 & 21,78 & 3,96 & 10,4 & 1,49 & 0,5 & 2,48 & 7,43 & 9,4 & 6,44 & - & - \\
\hline Galicia & $229^{*}$ & 2,62 & 1,31 & 3,93 & 2,18 & 0,0 & 1,74 & 7,42 & 13,11 & 7,42 & 17,91 & 3,49 & 6,55 & 14,42 & 8,74 & 1,31 & 1,74 & 4,8 & 1,31 \\
\hline Murcia & $? ?$ & 10,65 & & 3,09 & 10,3 & - & 5,49 & 15,37 & 5,95 & 7,1 & 22,8 & 2,06 & 1,6 & 3,32 & 4,69 & 3,66 & 3,92 & - & - \\
\hline País Vasco & $507^{*}$ & 35,31 & 3,16 & 0,79 & 1,97 & 0,39 & 19,53 & 6,9 & 6,9 & 4,93 & 2,76 & 2,17 & 5,92 & 3,35 & 2,76 & 2,56 & 0,0 & 0,6 & 0,0 \\
\hline C.Valenciana & $1457^{*}$ & 23 & 3,0 & 2,0 & 8,6 & 0,8 & 1,9 & 3,7 & 15,8 & 9,3 & 11,9 & 0,5 & 2,0 & 1,4 & 7,3 & 3,0 & 0,6 & 3,2 & 2,0 \\
\hline
\end{tabular}

$\begin{array}{ll}\text { A. Factor biológ. riesgo } & \text { J. Trastorno comunica lenguaje } \\ \text { B. Factor familiar riesgo } & \text { K. Trastorno expresión somática } \\ \text { C. Factor ambiental riesgo } & \text { L. Trastorno emocional } \\ \text { D. Trastorno moto } & \text { M. Trastorno regulación comport. } \\ \text { E. Trastorno visual } & \text { N. Trastorno espectro autista } \\ \text { F. Trastorno auditivo } & \tilde{N} \text {. Pluridef. } \\ \text { G. Trastorno psicomotriz } & \text { O. Otros } \\ \text { H. Retraso evolutivo } & \text { P. Trastorno interacción familia-niño } \\ \text { I. Trastorno cognitivo } & \text { Q. Trastorno entorno }\end{array}$

* Número total de categorías diagnósticas identificadas. Cada caso puede aportar una o más categorías diagnósticas.

Fuente: La realidad actual de la Atención Temprana en España. GAT (20II). Real Patronato sobre Discapacidad. Elaboración propia.

Tabla 3. Población 0-6 años asistida en centros de atención temprana según tipo de trastornos. Rangos máximos y mínimos. España 2008

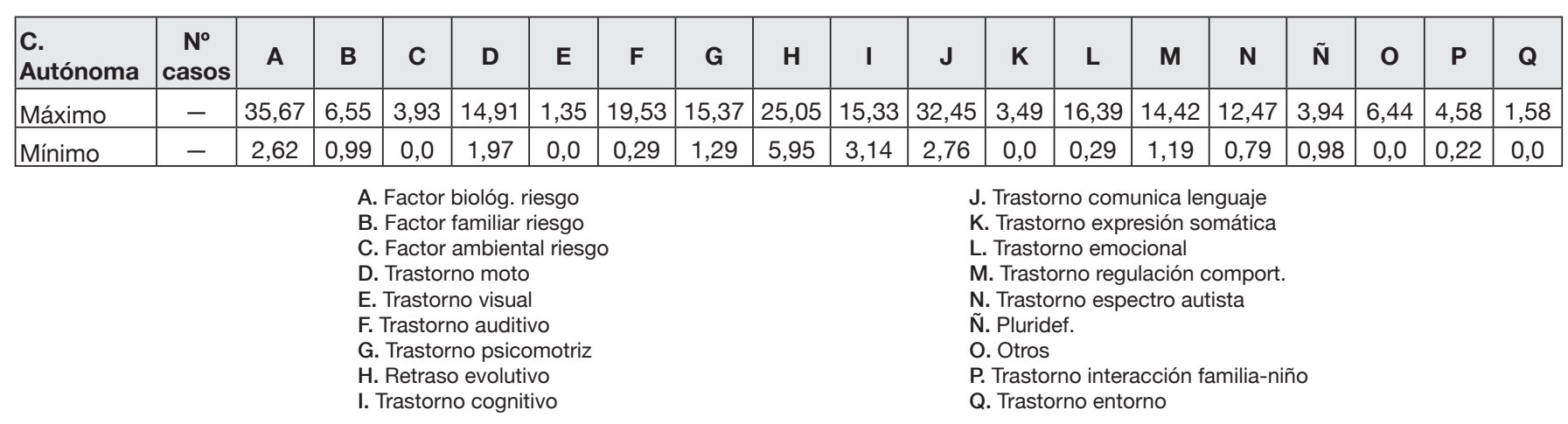

Fuente: La realidad actual de la Atención Temprana en España. GAT (20II). Real Patronato sobre Discapacidad. Elaboración propia. 
El objetivo de este estudio fue conocer la frecuencia de los trastornos diagnosticados y atendidos en dos unidades de atención temprana, utilizando la ODAT como criterio de clasificación.

Se presentan un total de 44 I casos de niños de $\circ$ a 6 años atendidos en dos servicios de Atención Temprana, las Unidades de Desarrollo Infantil y Apoyo Familiar de las comarcas del Deza y del Salnés (UDIAF), en Galicia, desde su inauguración en Junio de 2009 hasta diciembre de 20I3. Y que fueron categorizados en función de los ejes IV a VI de la ODAT, es decir según el tipo de trastorno del desarrollo, el tipo de disfunciones en la interacción entre niños y familias y el tipo de situaciones de exclusión social con las que pueda convivir el niño.

\section{Material y método}

La población de referencia fue la población infantil de o-6 años de la comarca del Deza (45.000 habitantes), ubicada en un área rural del centro de Galicia, y la comarca del Salnés (I00.000 habitantes), sita en la franja marítima de la Ría de Arosa. La población infantil de o a 6 años era de 2.000 y 7.000 respectivamente.

Las unidades de Atención Temprana en dichas comarcas comenzaron su actividad asistencial en Junio de 2009; el período de estudio se extiende desde ese momento hasta diciembre de $20 \mathrm{I} 3$

(Ponte, et al. 20IO, 20I I, 20I 2, 20I3)

Ambas unidades contaron con equipos interdisciplinarios formados por una psicóloga especializada en apoyo familiar, una psicomotricista y una logopeda, con experiencia o formación complementaria de postgrado en atención temprana y con una figura de coordinación de equipo con funciones de orientación, seguimiento y evaluación.

Los equipos y las unidades, han participado en diversos proyectos profesionales como el "Estudio sobre Atención Temprana y
Dependencia” (GAT y AGAT, 20I2), el diseño de una cartera de servicios de Atención Temprana para Galicia (en curso) o el desarrollo de la aplicación informática con la que gestionan su trabajo. Lo que les proporcionó una experiencia común. Actualmente los equipos son autónomos en sus procesos asistenciales.

Para la unificación de criterios en la categorización de los casos, mediante los ejes IV a VI de la ODAT, se realizaron además dos sesiones específicas de 8 horas cada una, la sesión de presentación de la clasificación y otra de consenso sobre una serie inicial de casos.

Se clasificaron todos los casos atendidos. La categorización definitiva se realiza en el momento del alta, y mientras son atendidos en la unidad se recogen las hipótesis diagnósticas que aportan los diferentes profesionales que participan en el proceso asistencial. Esta categorización, excepto allí donde lo marca la ODAT (hipoacusias, retrasos, trastornos cognitivos), no se plantea definir la intensidad o gravedad de los cuadros sino perfiles diagnósticos.

Entre las categorías analizadas se ha descartado incluir las situaciones de riesgo por factores biológicos, sociofamiliares o de entorno. $\mathrm{La}$ mezcla de situaciones de riesgo y problemas evolutivos parece inadecuada pues desdibuja la tipología de problemas que preocupa a las familias y que presentan los niños. Y confunde a los profesionales a la hora de clasificar pues se trata de dos niveles diferentes.

La aplicación informática que usan ambas unidades cuenta con un módulo de clasificación diagnóstica que, en cada expediente, permite seleccionar cualquiera de los diferentes epígrafes de los ejes IV a VI de la Organización Diagnóstica en Atención Temprana y consultar simultáneamente su contenido para comprobar si se ajusta o no al tipo de problemas evolutivos que presenta cada niño.

Los datos recogidos a través de la aplicación informática fueron exportados a Excel y de ahí al programa SPSS para su tratamiento estadístico. 


\section{Resultados}

En el período estudiado, se atendieron $44 \mathrm{I}$ casos, I 65 casos en la unidad de Deza y 276 casos en la de Salnés, que fueron clasificados en función de los ejes IV a VI de la ODAT, es decir, según el tipo de trastorno del desarrollo, el tipo de disfunciones en la interacción entre niños y familias y el tipo de situaciones de exclusión social con las que pueda convivir el niño.

Respecto de la frecuencia por sexo hay un claro predominio de niños sobre niñas, siendo el porcentaje de niños $(64,5)$ casi el doble que el de niñas $(35,5)$. La edad media en el momento de acceder al servicio fue de 3,3 años (mediana de 3). La distribución por intervalos de edad fue la siguiente: $3,4 \%$ de O-I años; 7,9\% de I-2; $20,4 \%$ de $2-3 ; 2$ I, $5 \%$ de $3-4 ; 24,0 \%$ de $4-5$; I $6,6 \%$ de 5-6 y 6, I \% de 6-7 pues en Galicia puede mantenerse la Atención Temprana hasta la finalización del curso escolar

Los niños llegaron a las unidades derivados desde las redes de servicios o desde la propia comunidad (orientados por otras familias): 3 I, $3 \%$ desde la comunidad; $23,6 \%$ desde la escuela infantil de $2^{\circ}$ ciclo; ז $1,2 \%$ desde la escuela infantil de $\mathrm{I}^{\mathrm{o}}$ ciclo; $25,4 \%$ desde los centros de salud y el 9,5\% desde los servicios sociales.
Las demandas manifestadas al pedir atención fueron muy variadas estando mayoritariamente relacionadas con la comunicación y el lenguaje, la conducta, los retrasos globales vinculados o no a síndromes específicos y los problemas afectivos: problemas de aprendizaje $4,8 \%$; situaciones afectivas I3,6\%; problemas de conducta 2 I, $8 \%$, problemas de lenguaje $27,0 \%$, problemas de hábitos $6,8 \%$; retrasos/síndromes $20 \%$ y problemas sensoriales $\mathrm{I}, \mathrm{I} \%$.

En el momento de cierre de este trabajo el $30,8 \%$ permanecían en las unidades como casos activos mientras que el resto habían sido dados de alta.

Los resultados se ofrecen en dos niveles de concreción a efectos de profundizar en los datos de ambas unidades:

- En primer lugar se recogen los datos siguiendo los epígrafes generales de los ejes IV, V y VI de la ODAT, mostrando tanto los resultados conjuntos de las dos unidades (Gráfico I) como los diferenciados (Gráfico 2) y el contraste estadístico de sus frecuencias (Tabla 4).

- En segundo lugar, y a continuación, en las tablas 5 a i 8, se muestra el detalle de los trastornos incluidos en cada uno de los epígrafes de los citados ejes.

\section{Tabla 4. Comparativa global de ambas unidades - Pruebas de chi cuadrado*}

\begin{tabular}{|c|c|c|c|c|c|c|c|c|c|c|c|c|c|}
\hline UDIAF & Motor & Visual & Auditivo & Psicomot. & R. Evolutivo & R. Mental & Leng. & Psicosom. & Afectivo & Regulación & TEA & Familia & Entorno \\
\hline No Deza & 10 & 11 & 3 & 16 & 7 & 9 & 61 & 29 & 35 & 22 & 8 & 32 & 9 \\
\hline No Salnés & 19 & 29 & 15 & 21 & 57 & 5 & 114 & 26 & 50 & 92 & 23 & 127 & 54 \\
\hline \% Deza & 6,06 & 6,67 & 1,82 & 9,7 & 4,24 & 5,45 & 36,97 & 17,58 & 21,21 & 13,3 & 4,85 & 19,31 & 5,45 \\
\hline$\%$ Salnés & 6,88 & 10,51 & 5,43 & 7,61 & 20,65 & 1,81 & 41,3 & 9,42 & 18,11 & 33,3 & 8,33 & 46,01 & 19,57 \\
\hline $\begin{array}{l}\text { Chi } \\
\text { cuad*. }^{*} \text {. }\end{array}$ & 0,848 & 0,174 & 0,063 & 0,444 & 0,000 & 0,035 & 0,368 & 0,012 & 0,425 & 0,000 & 0,166 & 0,000 & 0,000 \\
\hline Valor $p^{\star *}$ & 1,000 & 0,230 & 0,081 & 0,480 & 0,000 & 0,048 & 0,421 & 0,017 & 0,455 & 0,002 & 0,183 & 0,000 & 0,000 \\
\hline
\end{tabular}

* Chi cuadrado, sig. asint. bilateral, para tablas de contingencia $2 \times 2$

**Estadístico de Fisher, sig. exacta bilateral

Fuente: Trastornos del desarrollo según ejes IV, V y VI de la ODAT (Frecuencias y \%). Resultados de las unidades de Deza (I65 casos) y Salnés (276 casos). Elaboración propia 
Gráfico 1. Trastornos del desarrollo según ejes IV, V y VI de la ODAT (\%). Resultados agrupados de las unidades de Deza y Salnés. 441 casos

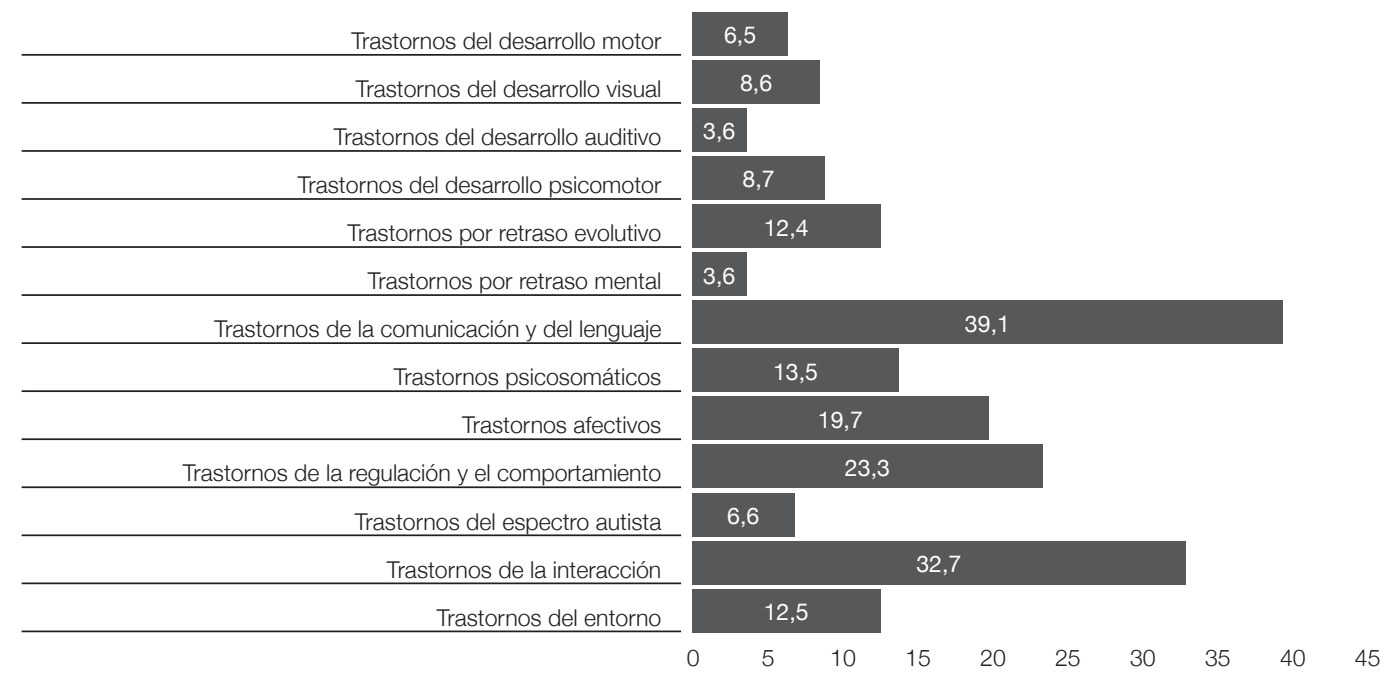

Fuente: Elaboración propia

Gráfico 2. Trastornos del desarrollo según ejes IV, V y VI de la ODAT (\%). Resultados diferenciados de las unidades de Deza (165 casos) y Salnés (276 casos)

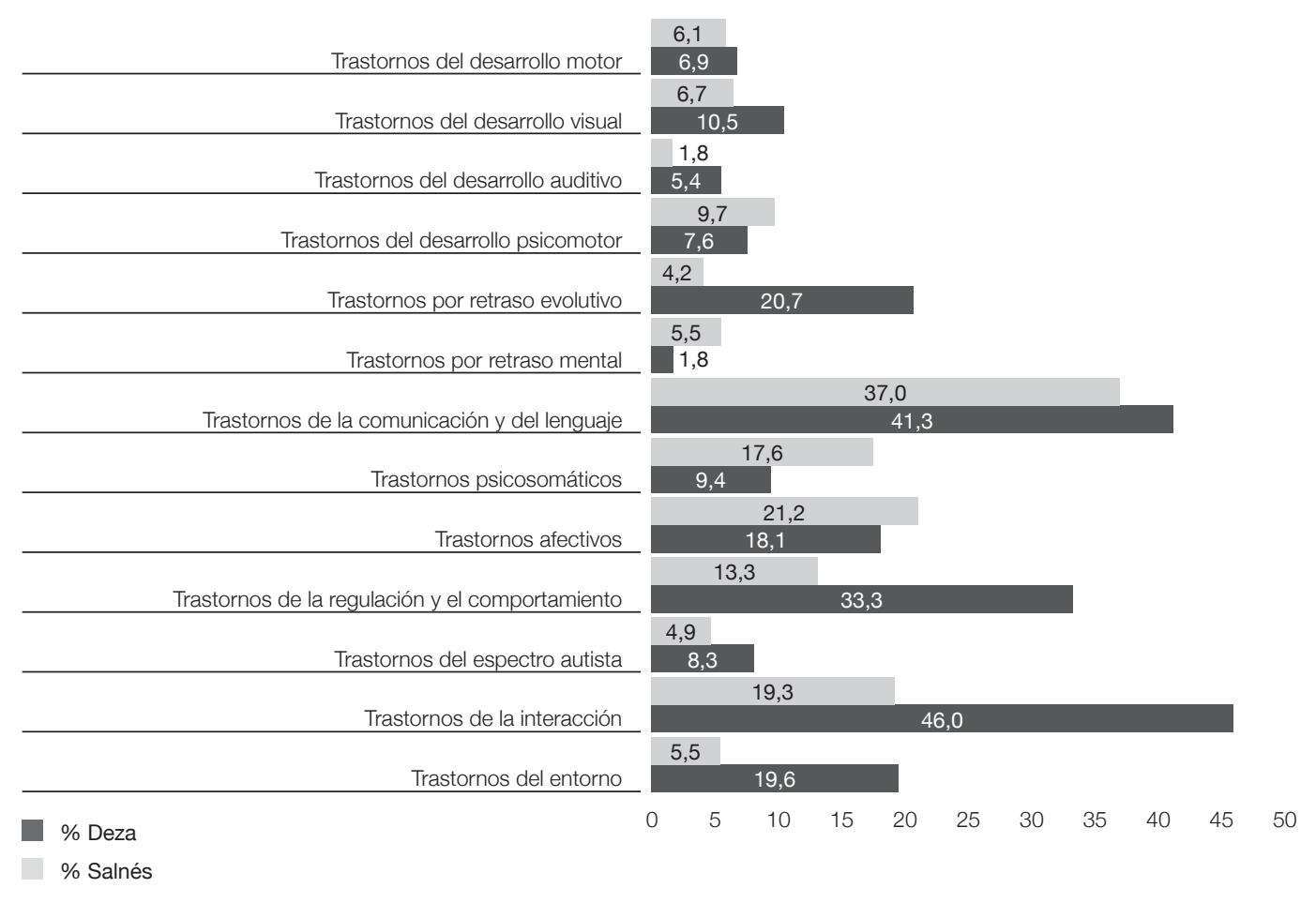

Fuente: Elaboración propia 
Como vemos en el gráfico I, con relación al Eje IV el tipo de problemas mayoritario entre los niños que acceden a las unidades son los trastornos de la comunicación y el lenguaje (39.I \%) seguidos de los conductuales $(25,9 \%)$ y los afectivos ( $19,3 \%$ ). Cabe destacar la escasa presencia de los trastornos motores $(6,6 \%)$ y de los de espectro autista $(7 \%)$.

A continuación, a través del gráfico 2 y de la tabla comparativa 4 podemos acercarnos a las semejanzas y diferencias en las clasificaciones de ambas unidades:

a) Respecto del eje IV de la ODAT las frecuencias obtenidas en ambas unidades son similares en el ámbito motor, visual, auditivo, psicomotor, comunicación y lenguaje, afectivo y TEA, mientras que divergen de manera significativa en el evolutivo y mental, psicosomático y de la regulación (pruebas chi cuadrado de la tabla 4). En el detalle de cada unidad se comprueba que las diferencias en los trastornos evolutivos y psicosomáticos se distribuyen a lo largo de casi todos los tipos de trastornos que incluyen dichas categorías, mientras que se centran en los trastornos 4.j.b. "Hipersensible negativo-desafiante", 4.j.m "Trastorno por comportamiento pertubador" y 4.j.h "Trastorno por TDAH tipo déficit de atención”, cuando observamos los trastornos de la regulación.

\section{Tabla 5. Trastornos del desarrollo motor}

\begin{tabular}{|l|c|c|c|c|}
\hline 4.a Trastornos en el desarrollo motor & $\mathbf{N}^{\circ}$ & \% Total & \% Deza & \% Salnés \\
\hline 4.a Trastornos en el desarrollo motor s.e. & 1 & 0,2 & $\mathbf{0 , 0}$ & $\mathbf{0 , 4}$ \\
\hline 4.a.a Parálisis cerebral infantil & 11 & 2,5 & $\mathbf{3 , 6}$ & $\mathbf{1 , 8}$ \\
\hline 4.a.b Trastorno de origen espinal & 2 & 0,5 & $\mathbf{0 , 6}$ & $\mathbf{0 , 4}$ \\
\hline 4.a.c Trastorno de origen periférico & 1 & 0,2 & $\mathbf{0 , 0}$ & $\mathbf{0 , 4}$ \\
\hline 4.a.d Trastorno de origen muscular & 1 & 0,2 & $\mathbf{0 , 0}$ & $\mathbf{0 , 4}$ \\
\hline 4.a.e Trastorno de origen óseo-articular & 2 & 0,5 & $\mathbf{1 , 2}$ & $\mathbf{0 , 0}$ \\
\hline 4.a.f Trastorno del tono no especificado & 10 & 2,3 & $\mathbf{0 , 6}$ & $\mathbf{3 , 3}$ \\
\hline 4.a.g Hábitos y Descargas Motrices & 1 & 0,2 & $\mathbf{0 , 0}$ & $\mathbf{0 , 4}$ \\
\hline Total & $\mathbf{2 9}$ & $\mathbf{6 , 6}$ & $\mathbf{6 , 1}$ & $\mathbf{6 , 9}$ \\
\hline
\end{tabular}

Tabla 6. Trastornos del desarrollo visual

\begin{tabular}{|l|c|c|c|c|}
\hline 4.b Trastornos del desarrollo visual & $\mathbf{N}^{\circ}$ & \% Total & \% Deza & \% Salnés \\
\hline 4.b.c Niños de baja visión & 6 & 1,4 & $\mathbf{0 , 6}$ & $\mathbf{1 , 8}$ \\
\hline 4.b.d Nistagmo & 4 & 0,9 & $\mathbf{1 , 2}$ & $\mathbf{0 , 7}$ \\
\hline 4.b.e Estrabismo & 20 & 4,5 & $\mathbf{4 , 8}$ & $\mathbf{4 , 3}$ \\
\hline 4.b.f Defectos de refracción & 10 & 2,3 & $\mathbf{0 , 0}$ & $\mathbf{3 , 6}$ \\
\hline Total & $\mathbf{4 0}$ & $\mathbf{9 , 1}$ & $\mathbf{6 , 7}$ & $\mathbf{1 0 , 5}$ \\
\hline
\end{tabular}




\section{Tabla 7. Trastornos del desarrollo auditivo}

\begin{tabular}{|l|c|c|c|c|}
\hline 4.c Trastornos del desarrollo auditivo & $\mathbf{N}^{\circ}$ & \% Total & \% Deza & \% Salnés \\
\hline 4.c.d Hipoacusia leve & 8 & 1,8 & $\mathbf{0 , 6}$ & $\mathbf{2 , 5}$ \\
\hline 4.c.e Hipoacusia moderada & 4 & 0,9 & $\mathbf{0 , 6}$ & $\mathbf{1 , 1}$ \\
\hline 4.c.f Hipoacusia grave o severa & 4 & 0,9 & $\mathbf{0 , 6}$ & $\mathbf{1 , 1}$ \\
\hline 4.c.g Hipoacusia profunda & 2 & 0,5 & $\mathbf{0 , 0}$ & $\mathbf{0 , 7}$ \\
\hline Total & $\mathbf{1 8}$ & $\mathbf{4 , 1}$ & $\mathbf{1 , 8}$ & $\mathbf{5 , 4}$ \\
\hline
\end{tabular}

\section{Tabla 8. Trastornos del desarrollo psicomotor}

\begin{tabular}{|l|c|c|c|c|}
\hline 4.d Trastornos del desarrollo psicomotor & $\mathbf{N}^{\mathbf{0}}$ & \% Total & \% Deza & \% Salnés \\
\hline 4.d.i Trastornos del control respiratorio & 1 & 0,2 & $\mathbf{0 , 0}$ & $\mathbf{0 , 4}$ \\
\hline 4.d.a Retraso psicomotor simple & 16 & 3,6 & $\mathbf{3 , 6}$ & $\mathbf{3 , 6}$ \\
\hline 4.d.b Trastornos de la coordinación dinámica & 17 & 3,9 & $\mathbf{4 , 2}$ & $\mathbf{3 , 6}$ \\
\hline 4.d.d Trastornos de la coordinación visomotora & 1 & 0,2 & $\mathbf{0 , 6}$ & $\mathbf{0 , 0}$ \\
\hline 4.d.e Trastornos de la estructuración espacial & 1 & 0,2 & $\mathbf{0 , 6}$ & $\mathbf{0 , 0}$ \\
\hline 4.d.f Trastornos de la organización temporal & 1 & 0,2 & $\mathbf{0 , 6}$ & $\mathbf{0 , 0}$ \\
\hline Total & $\mathbf{3 7}$ & $\mathbf{8 , 4}$ & $\mathbf{9 , 7}$ & $\mathbf{7 , 6}$ \\
\hline
\end{tabular}

\section{Tabla 9. Trastornos por retraso evolutivo}

\begin{tabular}{|l|c|c|c|c|}
\hline 4.e Trastornos por retraso evolutivo & No & \% Total & \% Deza & \% Salnés \\
\hline 4.e.a Retraso evolutivo leve & 30 & 6,8 & $\mathbf{3 , 0}$ & $\mathbf{9 , 1}$ \\
\hline 4.e.b Retraso evolutivo moderado & 21 & 4,8 & $\mathbf{1 , 2}$ & $\mathbf{6 , 9}$ \\
\hline 4.e.c Retraso evolutivo grave & 10 & 2,3 & $\mathbf{0 , 0}$ & $\mathbf{3 , 6}$ \\
\hline 4.e.d Retraso evolutivo profundo & 2 & 0,5 & $\mathbf{0 , 0}$ & $\mathbf{0 , 7}$ \\
\hline 4.e.e Retraso evolutivo no especificado & 1 & 0,2 & $\mathbf{0 , 0}$ & $\mathbf{0 , 4}$ \\
\hline Total & $\mathbf{6 4}$ & $\mathbf{1 4 , 5}$ & $\mathbf{4 , 2}$ & $\mathbf{2 0 , 7}$ \\
\hline
\end{tabular}

Tabla 10. Trastornos por retraso mental

\begin{tabular}{|l|c|c|c|c|}
\hline 4.f Trastornos por retraso mental & $\mathbf{N}^{\circ}$ & \% Total & $\%$ Deza & \% Salnés \\
\hline 4.f.a Retraso mental leve & 7 & 1,6 & 3,0 & 0,7 \\
\hline 4.f.b Retraso mental moderado & 2 & 0,5 & 0,6 & 0,4 \\
\hline 4.f.c Retraso mental grave & 2 & 0,5 & 1,2 & 0,0 \\
\hline 4.f.d Retraso mental profundo & 1 & 0,2 & 0,0 & 0,4 \\
\hline 4.f.f Altas habilidades & 2 & 0,5 & 0,6 & 0,4 \\
\hline Total & $\mathbf{1 4}$ & $\mathbf{3 , 2}$ & $\mathbf{5 , 5}$ & $\mathbf{1 , 8}$ \\
\hline
\end{tabular}


Tabla 11 Trastornos de la comunicación y del lenguaje

\begin{tabular}{|l|c|c|c|c|}
\hline 4.g Trastornos de la comunicación y del lenguaje & $\mathbf{N}^{\circ}$ & \% Total & $\%$ Deza & \% Salnés \\
\hline 4.g Trastornos en el desarrollo de la comunicación & 3 & 0,7 & $\mathbf{1 , 8}$ & $\mathbf{0 , 0}$ \\
\hline 4.g.a Dislalia. & 43 & 9,8 & $\mathbf{1 0 , 9}$ & $\mathbf{9 , 1}$ \\
\hline 4.g.b Retraso simple del habla. & 30 & 6,8 & $\mathbf{3 , 6}$ & $\mathbf{8 , 7}$ \\
\hline 4.g.c Disglosia. & 2 & 0,5 & $\mathbf{1 , 2}$ & $\mathbf{0 , 0}$ \\
\hline 4.g.d Disartria. & 2 & 0,5 & $\mathbf{0 , 6}$ & $\mathbf{0 , 4}$ \\
\hline 4.g.e Disfemia. & 10 & 2,3 & $\mathbf{4 , 8}$ & $\mathbf{0 , 7}$ \\
\hline 4.g.f Retraso simple del lenguaje. & 67 & 15,2 & $\mathbf{1 2 , 7}$ & $\mathbf{1 6 , 7}$ \\
\hline 4.g.g Disfasia (TEDL o TPDL). & 11 & 2,5 & $\mathbf{1 , 2}$ & $\mathbf{3 , 3}$ \\
\hline 4.g.h Afasia infantil congénita. & 6 & 1,4 & $\mathbf{0 , 0}$ & $\mathbf{2 , 2}$ \\
\hline 4.g.j Disfonías. & 1 & 0,2 & $\mathbf{0 , 0}$ & $\mathbf{0 , 0}$ \\
\hline Total & $\mathbf{1 7 5}$ & $\mathbf{3 9 , 7}$ & $\mathbf{3 7 , 0}$ & $\mathbf{4 1 , 3}$ \\
\hline
\end{tabular}

Tabla 12. Trastornos psicosomáticos

\begin{tabular}{|c|c|c|c|c|}
\hline 4.hTrastornos psicosomáticos & $\mathbf{N}^{\circ}$ & \% Total & \% Deza & $\%$ Salnés \\
\hline 4.h.a Afecciones somáticas. & 3 & 0,7 & 1,2 & 0,4 \\
\hline 4.h.b Trastornos psicofuncionales. & 5 & 1,1 & 2,4 & 0,4 \\
\hline 4.h.c Enuresis. & 14 & 3,2 & 5,5 & 1,8 \\
\hline 4.h.d Encopresis. & 9 & 2 & 0,6 & 2,9 \\
\hline 4.h.e Trastornos de la alimentación. & 13 & 2,9 & 3,0 & 2,9 \\
\hline 4.h.f Trastornos del sueño. & 8 & 1,8 & 3,6 & 0,7 \\
\hline 4.h.g Retraso psicógeno del crecimiento & 3 & 0,7 & 1,2 & 0,4 \\
\hline Total & 55 & 12,5 & 17,6 & 9,4 \\
\hline
\end{tabular}

\section{Tabla 13. Trastornos afectivos}

\begin{tabular}{|c|c|c|c|c|}
\hline 4.i Trastornos afectivos & $\mathbf{N}^{\circ}$ & $\%$ Total & \% Deza & $\%$ Salnés \\
\hline 4.i.e Trastorno mixto de la expresividad & 3 & 0,7 & 1,2 & 0,4 \\
\hline 4.i.a Trastorno por estrés traumático. & 1 & 0,2 & 0,6 & 0,0 \\
\hline 4.i.b Trastorno por ansiedad en la infancia & 19 & 4,3 & 4,8 & 4,0 \\
\hline 4.i.c Trastorno del estado de ánimo: reactivo al duelo & 6 & 1,4 & 0,6 & 1,8 \\
\hline 4.i.d Depresión en la infancia. & 3 & 0,7 & 0,6 & 0,7 \\
\hline 4.i.f Trastorno de la identidad genérica & 1 & 0,2 & 0,6 & \\
\hline 4.i.g Trastorno reactivo al vínculo. & 7 & 1,6 & 1,8 & 1,4 \\
\hline 4.i.h Trastorno adaptativo. & 38 & 8,6 & 9,7 & 8,0 \\
\hline 4.i.i Mutismo selectivo. & 6 & 1,4 & 1,2 & 1,4 \\
\hline 4.i.k Trastorno disocial. & 1 & 0,2 & 0,0 & 0,4 \\
\hline Total & 85 & 19,3 & 21,2 & 18,1 \\
\hline
\end{tabular}




\section{Tabla 14. Trastornos de la regulación y el comportamiento}

\begin{tabular}{|l|c|c|c|c|}
\hline 4.j Trastornos de la regulación y el comportamiento & $\mathbf{N}^{\mathbf{0}}$ & \% Total & \% Deza & \% Salnés \\
\hline 4.j.a Hipersensible temeroso-cauto. & 11 & 2,5 & $\mathbf{0 , 6}$ & $\mathbf{3 , 6}$ \\
\hline 4.j.b Hipersensible negativo-desafiante. & 30 & 6,8 & $\mathbf{0 , 0}$ & $\mathbf{1 0 , 9}$ \\
\hline 4.j.c Hiporeactivo. & 4 & 0,9 & $\mathbf{0 , 0}$ & $\mathbf{1 , 4}$ \\
\hline 4.j.d Desorganizado, motor-impulsivo. & 24 & 5,4 & $\mathbf{3 , 0}$ & $\mathbf{6 , 9}$ \\
\hline 4.j.e Otros. & 6 & 1,4 & $\mathbf{1 , 2}$ & $\mathbf{1 , 4}$ \\
\hline 4.j.f Trastorno por déficit de atención & 1 & 0,2 & $\mathbf{0 , 0}$ & $\mathbf{0 , 4}$ \\
\hline 4.j.g Trastorno por TDAH, tipo combinado & 3 & 0,7 & $\mathbf{0 , 0}$ & $\mathbf{1 , 1}$ \\
\hline 4.j.h Trastorno por TDAH, tipo déficit de atención & 14 & 3,2 & $\mathbf{0 , 6}$ & $\mathbf{4 , 7}$ \\
\hline 4.j.i Trastorno por TDAH, tipo hiperactivo & 3 & 0,7 & $\mathbf{0 , 6}$ & $\mathbf{0 , 7}$ \\
\hline 4.j.j Trastorno por TDAH, no especificado & 4 & 0,9 & $\mathbf{0 , 6}$ & $\mathbf{1 , 1}$ \\
\hline 4.j.I Trastorno negativista desafiante. & 2 & 0,5 & $\mathbf{1 , 2}$ & $\mathbf{0 , 0}$ \\
\hline 4.j.m Trastorno por comportamiento pertubador & 12 & 2,7 & $\mathbf{5 , 5}$ & $\mathbf{1 , 1}$ \\
\hline Total & $\mathbf{1 1 4}$ & $\mathbf{2 5 , 9}$ & $\mathbf{1 3 , 3}$ & $\mathbf{3 3 , 3}$ \\
\hline
\end{tabular}

\section{Tabla 15. Trastornos del espectro autista}

\begin{tabular}{|l|c|c|c|c|}
\hline 4.k Trastornos del espectro autista & $\mathbf{N}^{\circ}$ & \% Total & \% Deza & \% Salnés \\
\hline 4.k Trastornos del espectro autista & 2 & 0,5 & $\mathbf{0 , 0}$ & $\mathbf{0 , 7}$ \\
\hline 4.k.a Trastorno multisistémico. & 3 & 0,7 & $\mathbf{1 , 8}$ & $\mathbf{0 , 0}$ \\
\hline 4.k.b Trastorno autista. & 9 & 2 & $\mathbf{1 , 2}$ & $\mathbf{2 , 5}$ \\
\hline 4.k.d Trastorno desintegrativo infantil. & 2 & 0,5 & $\mathbf{0 , 6}$ & $\mathbf{0 , 4}$ \\
\hline 4.k.e Trastorno de Asperger. & 3 & 0,7 & $\mathbf{0 , 0}$ & $\mathbf{1 , 1}$ \\
\hline 4.k.f Trastorno generalizado del desarrollo & 12 & 2,7 & $\mathbf{1 , 2}$ & $\mathbf{3 , 6}$ \\
\hline Total & $\mathbf{3 1}$ & $\mathbf{7}$ & $\mathbf{4 , 8}$ & $\mathbf{8 , 3}$ \\
\hline
\end{tabular}

b) Con respecto al eje V, sus tablas (Tablas I6 y I7) nos indican que los profesionales han visto tanto problemas en la interacción como formas de relación inadecuadas en un elevado porcentaje de familias. Pero muestran unas tasas diferenciales significativamente diferentes en cuanto al número de familias que presentan trastornos en la interacción.
Mientras que en el Deza el número de familias con estos trastornos bordea el $20 \%($ I 9,4$)$ en el Salnés alcanza el $46 \%$. Y un análisis más detallado de los datos (Tabla I6, epígrafe 5.a.a) permite apreciar que casi 20 puntos de esa tasa diferencial se deben al diagnóstico de "relaciones inestables" que es de un I, $2 \%$ en el Deza y de un $\mathbf{2 0 . 7} \%$ en el Salnés. 
Tabla 16. Trastornos de la interacción

\begin{tabular}{|l|c|c|c|c|}
\hline 5.a Trastornos de la interacción. & $\mathbf{N}^{\circ}$ & \% Total & \% Deza & \% Salnés \\
\hline 5.- No especificados & 8 & 1,8 & $\mathbf{4 , 8}$ & $\mathbf{0 , 0}$ \\
\hline 5.a.a Relaciones inestables & 59 & 13,4 & $\mathbf{1 , 2}$ & $\mathbf{2 0 , 7}$ \\
\hline 5.a.b Relaciones alteradas & 56 & 12,7 & $\mathbf{9 , 1}$ & $\mathbf{1 4 , 9}$ \\
\hline 5.a.c Relaciones deterioradas & 21 & 4,8 & $\mathbf{1 , 8}$ & $\mathbf{6 , 5}$ \\
\hline 5.a.d Graves trastornos de la relación & 10 & 2,3 & $\mathbf{1 , 8}$ & $\mathbf{2 , 5}$ \\
\hline 5.a.e Relaciones negligentes & 5 & 1,1 & $\mathbf{0 , 6}$ & $\mathbf{1 , 4}$ \\
\hline Total & $\mathbf{1 3 9}$ & $\mathbf{3 6 , 1}$ & $\mathbf{1 9 , 4}$ & $\mathbf{4 6 , 0}$ \\
\hline
\end{tabular}

\section{Tabla 17. Tendencias en las relaciones}

\begin{tabular}{|l|c|c|c|c|}
\hline 5.b Tendencias en las relaciones & $\mathbf{N}^{\circ}$ & \% Total & \% Deza & \% Salnés \\
\hline Tendencias no especificadas & 212 & 51,9 & $\mathbf{4 3 , 1}$ & $\mathbf{5 7 , 3}$ \\
\hline 5.b.a Tendencia sobreprotectora & 104 & 23,6 & $\mathbf{1 5 , 8}$ & $\mathbf{2 8 , 3}$ \\
\hline 5.b.b Tendencia a la apatía o al de & 29 & 6,6 & $\mathbf{6 , 1}$ & $\mathbf{6 , 9}$ \\
\hline 5.b.c Tendencia al rechazo & 13 & 2,9 & $\mathbf{0 , 0}$ & $\mathbf{4 , 7}$ \\
\hline 5.b.d Tendencia agresivo-dominante & 6 & 1,4 & $\mathbf{0 , 0}$ & $\mathbf{2 , 2}$ \\
\hline 5.b.e Tendencia ambivalente & 72 & 16,3 & $\mathbf{2 0 , 6}$ & $\mathbf{1 3 , 8}$ \\
\hline 5.b.f Tendencia abusiva & 5 & 1,1 & $\mathbf{0 , 6}$ & $\mathbf{1 , 4}$ \\
\hline Total & $\mathbf{4 4 1}$ & $\mathbf{1 0 0}$ & $\mathbf{1 0 0 , 0}$ & $\mathbf{1 0 0 , 0}$ \\
\hline
\end{tabular}

c) Finalmente, respecto del Eje VI los profesionales han encontrado factores indicativos de exclusión social en alrededor del I $4,3 \%$ de los niños/familias, con diferencias significativas entre las dos unidades. En la UDIAF Deza, el porcentaje de niños con estas situaciones de entorno es de un $5,5 \%$, mientras que en el Salnés es de un I9,6. Nuevamente una aproximación al detalle nos permite comprobar que la categoría de "permanencia excesiva en guardería escuela" y la de "institucionalización prolongada" (Tabla I8, epígrafes 6.a.d y 6.a.e) son las que aportan casi toda esa cuota diferencial.

\section{Tabla 18. Trastornos del entorno}

\begin{tabular}{|l|c|c|c|c|}
\hline 6.a Trastornos del entorno - Exclusión social & $\mathbf{N}^{\circ}$ & \% Total & \% Deza & \% Salnés \\
\hline 6.a.a Ausencia de cuidadores sensibles & 35 & 7,9 & $\mathbf{5 , 4}$ & $\mathbf{9 , 4}$ \\
\hline 6.a.b Malos tratos y abusos & 3 & 0,6 & $\mathbf{0 , 0}$ & $\mathbf{0 , 1}$ \\
\hline 6.a.c Negligencia & 13 & 2,9 & $\mathbf{2 , 4}$ & $\mathbf{0 , 3}$ \\
\hline 6.a.d Institucionalización prolongada & 14 & 3,1 & $\mathbf{0 , 0}$ & $\mathbf{5 , 0}$ \\
\hline 6.a.e Permanencia excesiva en guardería o escuela & 17 & 3,8 & $\mathbf{0 , 0}$ & $\mathbf{6 , 2}$ \\
\hline 6.a.f Hacinamiento & 2 & 0,4 & $\mathbf{0 , 0}$ & $\mathbf{0 , 1}$ \\
\hline 6.a.g Chabolismo & 1 & 0,2 & $\mathbf{0 , 0}$ & $\mathbf{0 , 0}$ \\
\hline 6.a.h Violencia e inseguridad ambiental & 4 & 0,8 & $\mathbf{2 , 4}$ & $\mathbf{0 , 0}$ \\
\hline 6.a.k Confluencia de factores de exclusión & 15 & 3,4 & $\mathbf{3 , 0}$ & $\mathbf{3 , 6}$ \\
\hline Total & $\mathbf{6 3}$ & $\mathbf{1 4 , 3}$ & $\mathbf{5 , 5}$ & $\mathbf{1 9 , 6}$ \\
\hline
\end{tabular}




\section{Discusión}

Se presentan los resultados de la demanda asistencial de dos unidades de atención temprana de nueva creación, en comarcas de Galicia que carecían de dicho servicio. La clasificación de los problemas de los niños, de las familias y del entorno se ha realizado por equipos que iniciaban su experiencia asistencial en el mismo momento (2009), en un territorio delimitado, con muchas semejanzas en su composición (psicóloga, psicomotricista, logopeda), y que se han guiado por el mismo modelo de procesos asistenciales. Además se ha realizado una formación que trató de ayudar a perfilar una mirada diagnóstica común y minimizar una parte de los múltiples sesgos a que puede dar lugar la complejidad de la Atención Temprana.

Los resultados obtenidos y la comparación entre las dos unidades señalan tendencias pero también permiten apreciar la dificultad de obtener datos consistentes sobre la prevalencia de los trastornos evolutivos así como de unificar la mirada profesional ante cierto tipo de problemas y desde el soporte de algunos criterios diagnósticos.

Valorando la demanda conjunta, más de I de cada 3 niños atendidos presentan problemas de comunicación y de lenguaje, I de cada 4 problemas de regulación y comportamiento y I de cada 5 problemas afectivos. Una realidad que parecería apuntar a la creciente importancia de los factores contextuales en la génesis de los problemas evolutivos de los niños de hoy que frecuentan las unidades de Atención Temprana. Estos resultados contrastan con los datos que se habían aportado previamente, en particular en el ámbito de los trastornos de expresión somática, afectivo-relacionales y de la regulación y el comportamiento en la mayoría de las comunidades autónomas.

También en el terreno de las relaciones familiares nuestros datos se alejan de manera notable de las cifras ofrecidas anteriormente por el documento de la Realidad Actual de la Atención Temprana en España en 2008. En este documento el porcentaje más elevado de familias/niños con trastornos de la interacción era de un $4,8 \%$ en Galicia y el de niños viviendo en entornos de exclusión era de un I, $8 \%$ en Castilla y León. Mientras que en nuestras unidades la inadecuación de las formas de relación $(48, \mathrm{I} \%)$ y la presencia de trastornos de la interacción $(36, \mathrm{I} \%)$ en el seno de las familias es un acontecimiento frecuente, aunque un porcentaje elevado de esa cuota procede de problemas muy leves ("relaciones inestables") que la propia ODAT señala que no debe considerarse un trastorno.

Otro dato que se desprende de las cifras obtenidas en nuestras unidades es el bajo porcentaje de niños clasificados como niños con "trastorno de espectro autista" ( $7 \%$ en relación a población atendida) lo que no parece refrendar la impresión empírica de una situación "cuasiepidémica" que a veces se obtiene de otros países (European Commission, 2005) en revisiones profesionales (Lai, 20I3) y en los medios de comunicación, en los que se aportan tasas de prevalencia de I/I 60 y i/68 casos en relación a la población total del grupo de edad (CDC, 20I4).

En la evaluación comparativa de una y otra unidad podemos apreciar resultados bastante semejantes. Pero también diferencias notables en los retrasos evolutivos, psicosomáticos y de la regulación.

En los trastornos de la regulación los profesionales refieren muchas dificultades para distinguir el punto de corte entre lo "típico" y lo "atípico" a la hora de valorar manifestaciones tan habituales del curso evolutivo como son la impulsividad, la dificultad para admitir cambios, la desatención, o la hiperactividad. Dificultades ante las cuales cada equipo habría adoptado estrategias de clasificación diferentes. Por ejemplo los niños con perfil diagnóstico negativo-desafiante han sido clasificados en el epígrafe 4.j.b. en la UDIAF Salnés (I0,9\%) y en el 4 .j.m en la UDIAF Deza $(5,5 \%)$ pues ambos epígrafes admiten dicho perfil. 
En los retrasos evolutivos leves o moderados podría haber influido el deseo de evitar el "etiquetaje precoz" del retraso mental, de hecho el diagnóstico del retraso mental en el Salnés es de I, $8 \%$ (5,5\% Deza) mientras que el diagnóstico del retraso evolutivo alcanza el 20,7\% frente al 4,2 \% del Deza. Y, en los trastornos psicosomáticos, una minusvaloración (y en consecuencia falta de registro) de algunos síntomas como la enuresis o los trastornos del sueño cuando no ocupan el centro de la demanda familiar ni del proceso asistencial. Pero es difícil objetivar y ponderar el alcance de estos factores propios de la mirada profesional frente a otros como la eventual variación de la demanda y de la población a clasificar.

Las dificultades de clasificación alcanzan también a un fenómeno tan común en el curso del desarrollo como los desencuentros y conflictos que tienen lugar entre padres e hijos por las más diversas razones. El hecho de que la discordancia entre los datos de ambas unidades al clasificar los problemas del eje $\mathrm{V}$ se apoye en las diferencias de registro de las "relaciones inestables" (20,7 \% Salnés, I, $2 \%$ Deza), una categoría que según la ODAT agrupa problemas en las relaciones "de carácter puntual y/o contextual” parece ilustrar que hubo una manera diferente de valorar esos problemas.

Finalmente el análisis comparativo del eje VI parece orientarnos hacia una diversidad de realidades sociofamiliares en una y otra comarca. En la comarca del Deza, comarca rural de la Galicia interior, todavía hay un predominio neto de la familia tradicional y una presencia activa y generalizada de la familia extensa en la proximidad de la familia nuclear, mientras que en el Salnés, comarca marítima semiurbana, se da una mayor diversidad de familias y los abuelos y abuelas son un recurso menos accesible o inexistente para un buen número de ellas. Estas diferencias en el tipo de familias (más tradicional y extensa en el Deza, más diversa, nuclear y discontinua en el Salnés), podría explicar que en el Deza no se haya registrado ningún caso en los epígrafes 6.a.d "Institucionalización prolongada" y 6.a.e "Permanencia excesiva en guardería o escuela" mientras que suponen un I I,9\% de los casos del Salnés.

\section{Conclusiones}

Este estudio no hace sino confirmar que realizar clasificaciones diagnósticas es un asunto muy serio y complicado (Simeonsson, 2009) en el que hay que proceder con la mayor de las cautelas, procurando un alto control de las variables, población elegible, formación de los profesionales, composición de los equipos, procedimiento de clasificación, etc., máxime en un ámbito relativamente nuevo como es el de la Atención Temprana. Este trabajo tiene muchas de estas limitaciones y está referido a un territorio y una población muy restringida, por lo que no es posible hacer generalizaciones sobre sus resultados. Pero, desde esa constatación, consideramos que ofrece datos útiles para comprender mejor la complejidad de los problemas asistenciales y procedimentales con que hoy nos enfrentamos desde la Atención Temprana.

Los equipos de profesionales, si no disponen de herramientas con criterios bien definidos y contrastados pueden adoptar estrategias de clasificación diferentes. Sobretodo si los "trastornos del desarrollo" no se presentan como cuadros estructurales y funcionales muy evidentes y visibles. De hecho los datos obtenidos parecen apuntar a cierta evolución en la forma de clasificar con aumento de errores y omisiones e incluso una modificación activa de los criterios de clasificación, en particular en torno a aquellas categorías en las que los límites entre típico y atípico ("relaciones inestables"), los solapamientos respecto del epígrafe adecuado ("conductas negativistas") o los niveles de gravedad y criterios de inclusión ("trastornos psicomotores", "de la regulación y el comportamiento”) son más imprecisos o inexistentes.

Los equipos necesitan disponer de tiempo y ocasiones para hacer esta tarea, tan importante 
como otras. Y para hacerla bien tienen que disponer de oportunidades para evaluar su actuación, discutir y proyectar en el colectivo profesional su práctica cotidiana, su experiencia y sus dudas.

También sería interesante que se tomara la iniciativa de revisar a fondo, desde la práctica profesional y en el conjunto del Estado una herramienta como la ODAT, precisando mejor su objeto, enriqueciéndola con nuevas aportaciones y acercándola al conjunto de profesionales y recursos que hoy intervienen en la Atención Temprana, todos ellos necesitados de herramientas que faciliten su comunicación y coordinación.

Cabe decir, por último, que la no inclusión de los factores de riesgo en las variables a categorizar creemos que se ha mostrado como una decisión acertada y que ha ayudado a la participación e implicación de los profesionales. La recogida de todos los factores de riesgo y su registro se nos antoja una tarea que, por su amplitud, es difícilmente asumible por los equipos profesionales de Atención Temprana en la práctica diaria. Pero que, además, induce a confusión en la clasificación de los casos pues se mezclan los objetos de clasificación: la etiología con las limitaciones funcionales, los retrasos evolutivos, las manifestaciones conductuales y las relaciones personales. La limitación del ámbito de clasificación al nivel del "trastorno" facilita la tarea profesional y ofrecería, en nuestra opinión, resultados más precisos.

\section{Agradecimientos}

A los equipos de las Unidades de Desenvolvemento Infantil e Apoio Familiar del Deza y del Salnés por su trabajo, dedicación y constante colaboración. 


\section{Referencias bibliográficas}

American Psychiatric Association (20I4): DSM-5. Manual diagnóstico y estadístico de los trastornos mentales, Madrid: Editorial Médica Panamericana.

American Psychiatric Association (2002): DSM-IV. Manual diagnóstico y estadístico de los trastornos mentales, Barcelona: Masson.

Center for Disease prevention and Control (20I4): "Prevalence of Autism Spectrum Disorder Among Children Aged 8 Years Autism and Developmental Disabilities Monitoring Network, I I Sites, United States, 2010”. Surveillance Summaries, 63 (SSO2): I-2I. http://www.cdc.gov/mmwr/preview/ mmwrhtml/ss6302aI.htm?s_cid=ss6302a I_w〉.

Zero To Three (2005): Diagnostic classification of mental health and developmental disorders of infancy and early childhood (DC: ${ }_{-}-3 \mathrm{R}$ ). Washington, DC: Zero to Three Press.

Domenech, E. y Ezpeleta, L. (I998): "Las clasificaciones en psicopatología infantil”, en Rodríguez, J. (ed): La psicopatología del niño y del adolescente. Sevilla: Universidad de Sevilla.

Equipo de Investigación Sociológica EDIS (2007): Validación de la Organización Diagnóstica en Atención Temprana. Madrid: Real Patronato sobre Discapacidad.

European Commission Health \& Consumer Protection Directorate- General (2005): Some elements about the prevalence of Autism Spectrum Disorders (ASD) in the European Union. (En línea) http://ec.europa.eu/health/ ph_information/dissemination/diseases/ autism_I.pdf.

Federación Estatal de Asociaciones de Profesionales de Atención Temprana-GAT y Asociación Galega de Atención Temperá (2012): Atención Temprana y dependencia. Documento de trabajo. Real Patronato sobre Discapacidad.

Federación Estatal de Asociaciones de Profesionales de Atención Temprana-GAT (20I I): Organización diagnóstica para la atención
temprana-ODAT. Niveles I, II y III. Madrid: Real Patronato sobre Discapacidad.

Frances, A. (2013): Saving normal: An insider's revolt against out-of-control psychiatric diagnosis, DSM-5, big pharma, and the medicalization of ordinary Life. New York: HarperCollins Publishers.

Organización Mundial de la Salud (2008): CIE Io. Clasificación Internacional de Enfermedades. Madrid: Ministerio de Sanidad, Servicios Sociales e Igualdad.

Organización Mundial de la Salud (20II): Clasificación Internacional del Funcionamiento de la Discapacidad y de la Salud. Versión para la Infancia y la Adolescencia: CIF-IA. Madrid: Ministerio de Sanidad, Política Social e Igualdad.

Lai, M. et al. (20I3): “Autism”. The Lancet, 383 (9920): 896-910.

Mash, E. J. y Terdal, L. G. (I997a): “Assessment of child and family disturbance: A behavioralsystems approach”. En Mash, E. y Terdal, L. (Eds.): Assessment of childhood disorders. New York: Guilford Press.

Ponte, J. et al. (2010): Unidades de Desenvolvemento Infantil e Apoio Familiar. Informe de avaliación. Narón: Asociación Galega de Atención Temperá (en línea). http:// www.atenciontemprana.com/EIDocumentsAT/ UDIAF\% 2०MEMORIA.pdf\%.

Ponte, J. et al. (20I I): Memoria de actividades a avaliación das Unidades de Desenvolvemento Infantil e Atención Temperá. Documento de trabajo. Asociación Galega de Atención Temperá. Xunta de Galicia.

Ponte, J. et al. (2OI2): Memoria de actividades e avaliación das Unidades de Desenvolvemento Infantil e Atención Temperá. Documento de trabajo. Asociación Galega de Atención Temperá. Xunta de Galicia. 
Ponte, J. et al. (2013): Memoria e avaliación das Unidades de Desenvolvemento Infantil e Atención Temperá. Documento de trabajo. Asociación Galega de Atención Temperá. Xunta de Galicia.

Pons, A. et al. (2012): Tabla de equivalencias entre la Organización Diagnóstica de Atención Temprana (ODAT) y la Clasificación Internacional de Enfermedades (CIE).

Sevilla: Consejería de Salud de la Junta de Andalucía (en línea). http://www. repositoriosalud.es/bitstream/I0668/889/5/ TablaEquivalenciasODAT_CIE_2OI 2.pdf..
Pons, A. (20I I): "El programa Alborada”. Ponencia presentada en las IV Jornadas Interdisciplinarias de la Federación Estatal de Asociaciones de Profesionales de la Atención Temprana de Sevilla.

Simeonsson, R. J. (2009): "ICF-CY: a universal for documentation of disability". Journal of Policy and Practice in Intellectual Disabilities, 6 (2): 70-72.

VV.AA. (2000): Libro Blanco de la Atención Temprana. Madrid: Real Patronato de Prevención y Atención a personas con Minusvalía. 



\title{
La incidencia de los patronatos nacionales en la política educativa de las enseñanzas de sordos (1910-1978)
}

\author{
The influence of national boards on deaf \\ educational policy (1910-1978)
}

\section{Resumen}

El objetivo del trabajo es analizar la incidencia de los patronatos en las políticas educativas de las enseñanzas de sordos, desde el primer Patronato Nacional de Sordomudos, Ciegos y Anormales hasta el Real Patronato de Educación Especial (I910-I978). La metodología utilizada es la histórica, fundamentalmente el análisis de las fuentes documentales archivísticas y de normativa y la revisión de la obra bibliográfica existente, sobre los patronatos y las políticas educativas de los gobiernos y sus administraciones en las enseñanzas de personas sordas. El enfoque fundamental del trabajo se plantea desde la acción de los gobiernos y sus administraciones, es decir, desde sus políticas educativas. Las conclusiones se construyen sobre unos hechos y análisis que permiten entender la acción de los patronatos y su contribución en la evolución de las enseñanzas de sordos.

\section{Palabras clave}

Política educativa. patronatos nacionales. sordomudos. anormales. deficientes. minusválidos. discapacitados.

\begin{abstract}
The aim of this paper is to analyze the impact of national boards on educational policy related to the teaching of deaf individuals from the first Patronato Nacional de Sordomudos, Ciegos y Anormales (National Council for the Deaf, Blind and Abnormal) to the Real Patronato de Educación Especial (Royal Council of Special Education) (I9I0-I978). This study uses historical methodology, primarily the analysis of archival and documentary sources, legal documentation and existing bibliographic material on the national boards and educational policies related to the education of deaf or deaf-mute people carried out by governments and administrations. This paper focuses on the actions of governments and their administrations through their educational policies. The conclusions are drawn from facts and analyses which allows for the understanding of actions taken by the national boards and their contribution to the evolution of education for deaf people.
\end{abstract}

\section{Keywords}

Educational policy, national boards, deaf-mute people, disabled people, handicapped people.

\section{Alfredo Alcina Madueño <alfredo.alcina@madrid.org> Inspector de Educación, Comunidad de Madrid}

\section{Luisa Navarro Juárez <es@spreadthesign.com> \\ Coordinadora de Spread the Sign, España}

Para citar:

Alcina, A. y Navarro, L. (20I4): "La incidencia de los patronatos nacionales en la política educativa de las enseñanzas de sordos (I9IO-I978)", Revista Española de Discapacidad, 3 (I): I4I-I6O.

Doi: <http://dx.doi.org/IO. $5569 / 234$ O5 I04.03.01.08>

Fecha de recepción: 20-I I-20I4 Fecha de aceptación: 2I-05-20I5 


\section{Introducción. Precisiones, estado de la} investigación y temporalización histórica

La presencia y actividad de los patronatos nacionales como entidades en la historia de la educación especial en España se remonta a I9ro, lo que supone un periodo de más de roo años y haber estado presentes desde entonces en todos los regímenes políticos sucedidos hasta hoy. Desde el punto de vista histórico entre el Patronato Nacional de Sordomudos, Ciegos y Anormales de r9ro y el actual Real Patronato sobre Discapacidad hay una larga línea que evoluciona con continuidades en muchos aspectos y sin éstas en muchos otros y es en este ámbito donde se ubica el objeto de este estudio: analizar la incidencia de los patronatos entre I9I0 y I978 en la política educativa de las enseñanzas de sordos.

Procede hacer en este punto algunas apreciaciones semánticas de interés así como alguna precisión conceptual introductoria sobre las enseñanzas de sordos, pertinentes en tanto que este colectivo y su educación son también elementos protagonistas de este artículo.

Primera. Los términos que se utilizan en este trabajo, pongo por ejemplo el de anormales, deficientes o sordomudos se utilizan siempre con valor histórico, es decir, tal como se usaban en el periodo o periodos que se van a analizar y también la misma narración permite observar su evolución terminológica y conceptual. El caso del término sordomudo evoluciona hasta la expresión sordo en un número importante de idiomas por la incidencia de planteamientos educativos y sociales de naturaleza oralizadora que defienden que el sordo puede hablar y en consecuencia se pierde la parte de mudo. Sin embargo, esta evolución no tiene un correlato tan amplio en un importante número de lenguas de signos del mundo, cuyas configuraciones del signo del concepto sordo siguen haciendo referencia tanto a la sordez como a la mudez (Diccionario on line Spread the Sign), manteniéndose viva una idea que resurge en los tiempos de confrontación entre los enfoques o métodos educativos del siglo XIX y que significaba que el sordo "ni oía ni hablaba".

Segunda. La expresión enseñanzas de sordos utilizada tanto en el título del trabajo como en reiteradas ocasiones en el texto se recoge en plural con una fuerte intencionalidad connotativa, en tanto que a nuestro juicio la educación de las personas sordas en un contexto escolar desde sus inicios a finales del siglo XVIII hasta hoy, ha tenido enfoques educativos diferenciados que se orientaban por el uso (en mayor o menor grado) de los signos propios de las lenguas de signos o señas o bien se centraban en el uso de métodos y planteamientos que favoreciera el aprendizaje de la lengua oral nacional en su forma escrita y hablada, como eran el aprendizaje de la articulación, de la lectura labial o de la dactilología. Estos dos enfoques generales convivieron durante mucho tiempo, si bien no en armonía, sí con valores eclécticos compartidos en cuanto a procedimientos y técnicas y evolucionaron de forma específica cada uno dentro de sus modelos. En el último cuarto del siglo XIX en Europa y los Estados Unidos se produce una profunda confrontación de planteamientos que termina en que la educación de los sordos se plantee y ordene sin presencia de los signos y mucho menos de las lenguas de signos en los currículos educativos oficiales.

Consecuencia de la situación anterior, determinada línea de investigación considera que el enfoque oralizador hegemónico durante muchos años en la educación de los niños sordos presenta un fuerte componente ideológico, además de pedagógico, que se simboliza y define en un continuo de consideraciones, pensamientos y creencias de las cabezas y voces más significadas del Congreso Internacional de Profesores de Milán de I 880 y sus sucesores (Lane, I989:376-4I4).

Estos modelos educativos oralizadores con objetivos muy potentes como el de integrar al sordo en la sociedad y de resultados mediocres y muy desiguales que las administraciones educativas hacen suyo y lo imponen en sus políticas, empezarán a cambiar paulatinamente 
en la década de los años I970 al modificarse la concepción de la educación de los sordos y de sus derechos lingüísticos y civiles. En países como Suecia o EE.UU surgirán nuevas propuestas y el modelo educativo para los sordos se hará, también lentamente, plural y diverso dentro de la heterogeneidad propia de las personas sordas. Y en un mundo educativo cada día más globalizado surgirán universales educativos a escala internacional como la integración escolar del niño o joven sordo apoyada en una tecnología médica (implantes cocleares) que está provocando una revolución en la forma de abordar la sordera y también el reconocimiento de las lenguas de signos como idiomas de cultura y educación y que darán lugar a programas y planteamientos bilingües (lengua de signos y lengua oral). Hoy, los sistemas educativos más modernos, con fuertes valores de calidad y equidad, buscan respuestas que principalmente beneficien al alumnado sordo y a ello han contribuido, estamos convencidos, los patronatos más modernos en España o figuras similares en otros países.

Hechas estas consideraciones que van a favorecer la comprensión de la exposición se vuelve a la línea inicial y se plantean tres periodos con cierta unidad cada uno en el lapso I9IO-I978 para el análisis de la incidencia de los patronatos nacionales en las enseñanzas de sordos en España. El primero es el de la institucionalización I9Io-I936; muy diverso en cuanto a modelos y que recorre la Restauración y la República. Un segundo periodo, muy parco en cuanto a estas corporaciones y de funciones premodernas se circunscriben al régimen de Franco y un tercero, muy intenso en el tiempo, relativo al posfranquismo y la Transición política (I975-I978). Los patronatos reales que se crean a partir de la Constitución de I978: el Real Patronato Nacional de Atención a Deficientes, el de Prevención y Atención a Personas con Minusvalías y el actual Real Patronato sobre la Discapacidad, serán objeto de otro trabajo.

La bibliografía o trabajos de investigación específicos tanto sobre los patronatos nacionales de la educación especial como de las políticas sobre las enseñanzas de sordos en el marco temporal y del objeto del artículo se centran fundamentalmente en: Molina, I900,1903; Pereira, I904; López Núñez, I908; Orellana, I9I4; Navarro, I917,I926; Granell, I932; García Maroto, I935; Polaino-Lorente, I983; García Pastor y García Jiménez, I987; Herráiz, I992, I995, 2000; Cabada, I992; Molina y Gómez, I992; Del Cura, 20I 2. También y dadas las fuentes utilizadas en este trabajo hay que citar a la administración que a lo largo del periodo estudiado se ha expresado y manifestado a través de un conjunto de disposiciones, reglamentos y decretos y que han supuesto su contribución a la solución, ordenación y regulación de los distintos aspectos que se tratan en este artículo. Estas disposiciones se presentan de forma sucinta en notas a pie de página y en extenso en la sección de normativa de la bibliografía.

Las características estructurales más regulares a lo largo del tiempo de los patronatos que tenían y tienen como objeto de su actividad a los distintos colectivos de personas con deficiencias, minusvalías o discapacidades son:

A) Siempre han sido y siguen siendo instituciones oficiales, en consecuencia públicas y financiadas básicamente por los presupuestos del Estado. B) Su dependencia administrativa siempre se ha realizado en el ámbito ministerial, no siempre el mismo, y discurre desde los de instrucción pública o educación hasta los de naturaleza social-sanitaria. C) Estas instituciones no tuvieron personalidad jurídica salvo excepciones (Patronato Nacional de Sordomudos y Ciegos concedida por el Real Decreto de 3 I de diciembre de I926). D) Su objetivo siempre ha sido y es dar una respuesta global, comprensiva y coordinada a los colectivos a los que se dirigía en los ámbitos más significativos para éstos y que a lo largo del tiempo han sido el educativo, el sanitario y el social.

E) Los patronatos nacionales han sido siempre instrumentos en las políticas educativas, sociales y sanitarias de los gobiernos para los colectivos indicados, si bien, desde el punto de vista histórico no siempre desarrollaron las mismas competencias ni fue la misma la naturaleza de las acciones, lo 
que se correlaciona directamente con la evolución del Estado español en los campos manifestados. Así, durante muchos años los patronatos tuvieron la competencia de la inspección superior sobre los centros educativos de sordomudos, ciegos y anormales y sobre los programas o currículos que impartían éstos o también la selección y clasificación del alumnado de educación especial, entre otras muchas competencias, las cuales han evolucionado y se han transformado consecuencia de la misma evolución del Estado. Estas instituciones, expresado de manera simplificadora, han pasado de la realización específica de muchas de las acciones anteriores a su promoción, coordinación y difusión.

Los patronatos como elementos institucionales del Estado son una realidad adaptativa, en muchos casos paralela a la misma evolución que la sociedad tiene sobre los colectivos y personas objeto del artículo y que tiene un buen indicador en el cambio semántico de sus denominaciones: de anormales a deficientes y minusválidos y de éstos a discapacitados.

\section{Primera etapa: la institucionalización de los patronatos (1910-1936)}

La regeneración educativa en los primeros años del siglo XX se aborda gracias a la acción de los programas conservador y liberal, representados por los ministros de Instrucción Pública García Alix, que para Carr (2000:457) representa "el primer ensayo de regeneración desde la derecha...”, y por el liberal Álvaro de Figueroa.

\subsection{Las enseñanzas de sordomudos al inicio del siglo $\mathrm{XX}$}

El subsistema escolar de las enseñanzas de sordomudos es funcionalmente independiente y estanco en el conjunto del sistema educativo, siendo indicadores de esta situación que sus maestros no forman parte del Escalafón General o que la Inspección provincial de
Educación en su función de formación del magisterio no dedica ni una sola conferencia a estas enseñanzas en los principios del siglo XX (Ministerio de Instrucción Pública, I908:34-4I).

El secretario del Colegio Nacional de Sordomudos y de Ciegos de Madrid, Pedro Molina (I 900:3-5) considera que solo el 4, I $4 \%$ de los sordomudos y el I, $48 \%$ de los ciegos están escolarizados en los años finales del XIX y primeros del XX entre I4 establecimientos, unos son provinciales y locales sostenidos por diputaciones y ayuntamientos, un solo colegio estatal financiado por la Administración Central del Estado (Colegio Nacional de Sordomudos y de Ciegos) y los demás son privados. La población sordomuda en España en edad escolar a principios de siglo se estima entre las $9000 \mathrm{y}$ I I000 personas (Molina,I903:I0).

El aparato administrativo de estas enseñanzas está muy centralizado y es mínimo, una Sección de la Dirección General de Primera Enseñanza del Ministerio de Instrucción Pública y Bellas Artes que se completa con la estructura de la Comisaría Regia y su secretaría para el Colegio de Sordomudos y de Ciegos de Madrid.

\subsection{Las enseñanzas de sordomudos se modernizan}

Las enseñanzas de sordomudos también forman parte de las enseñanzas que se modernizan en el proceso de regeneración del sistema educativo iniciado a principios del siglo XX, y producto de esta iniciativa se asientan nominalmente los principios teóricos de estas enseñanzas que regirán básicamente hasta el último tercio del siglo XX.

El proceso de modernización se hace por dos vías, la primera, por la administración educativa del ministro Álvaro de Figueroa tomando como objeto el Colegio Nacional de Sordomudos y a través de su Reglamento de octubre de $1902^{\mathrm{I}}$, en

I. Exposición de Motivos del Real Decreto de I7 de octubre de I902 que aprueba el Reglamento del Colegio Nacional de Sordomudos y de Ciegos. 
el que se insertan un conjunto de principios cuya incidencia real en esos años es nula o mínima y que se pueden concretar en:

a. Un proceso de normalización de las etapas impartidas en el Colegio con respecto al régimen escolar general y de adaptación de sus currículos a los ordinarios.

b. La necesidad de establecer un nivel de educación especial inserto en el sistema educativo y armonizado con el ordinario y que permita el desarrollo de una red pública y privada, unificada, especializada y diferenciada de la ordinaria, con una organización de los centros escolares basada en grupos homogéneos y la clasificación rigurosa y científica del alumnado y aprendizaje del lenguaje oral, siguiendo los planteamientos del Congreso de Profesores de Milán de 1880 y una formación moderna del profesorado especial de sordomudos.

c. La necesidad de la escolarización del alumnado sordomudo por encima de lo existente.

La segunda vía de modernización o de reforma de esas enseñanzas se produce por la posición de los profesionales del sector a través de la Asamblea de Profesores de Sordomudos y de Ciegos de I906, que supone la crítica más sistemática, ordenada y coherente de los distintos sectores profesionales de las enseñanzas de sordomudos y de ciegos a las políticas educativas de la Ley de Instrucción Pública de I 8 57. Además, pretenden que sus conclusiones vertebren la acción y las políticas de la administración educativa en estas enseñanzas y entre las más significativas destacamos la confección de estadísticas, la formación del profesorado específico de sordomudos y de ciegos, la oralización del alumnado, la incorporación de talleres profesionales, las políticas de prevención de la sordera y ceguera o la financiación de la red escolar (Ministerio de Instrucción Pública, I908:46I-462).

Estas vías o medios no son distintos a los que se utilizan en otros países avanzados y las ideas, ideologías e iniciativas que sustentan son el magma en el que los miembros más progresistas de la administración educativa y los sectores profesionales más avanzados se mueven. En I9Io se crea el Patronato Nacional de Sordomudos, Ciegos y Anormales, producto o creación del regeneracionismo y de los postulados teóricos sobre estas enseñanzas. No hay salto en el vacío, los métodos experimentales y la extensión de las disciplinas educativas de la educación especial se han empezado a materializar en Francia, Alemania, Inglaterra o Bélgica, pronto algunos de estos países tendrán comisiones especiales que estudiaran la enseñanza especial y en no muchos años dictaran leyes sobre la nueva etapa (Francia e Inglaterra, I909 y I9I3). Aquí se hace de otra forma, se obvia la discusión parlamentaria y la acción puramente legislativa y se crea una Educación Especial por decreto.

Aún así, la administración educativa actúa bajo criterios de racionalidad y en I9 Io se intentan conseguir los recursos económicos necesarios para la implantación de la Educación Especial mediante un empréstito de I 500 millones de pesetas para la "Construcción de Edificios para Escuelas públicas, Colegios, Escuelasmodelos de niños sordo-mudos, ciegos y demás anormales" ${ }^{2}$. No nos consta que consiga la financiación ni que se construyan las escuelas. Ante esta imposibilidad la medida financiera que se toma por el gobierno es incrementar las partidas económicas de los Presupuestos del Estado para el Colegio Nacional de Sordomudos y de Ciegos 3 . Por este procedimiento, el nuevo Patronato Nacional de Sordomudos, Ciegos y Anormales, su sede, su personal y sus gastos administrativos son atendidos desde los presupuestos del Colegio de Sordomudos y de Ciegos y también el desarrollo de las enseñanzas

2. Real Decreto de I de octubre de I9 Io del Ministro de Hacienda, Gaceta de Madrid de 7 de octubre de I9Io. También hay una referencia de dicho Proyecto de Ley en el Diario de Sesiones de 6 de octubre de I9Io. Congreso de los Diputados. Diario de Sesiones. 29. Serie Histórica (I8I2-I936), I9IOI9I 5 .

3. Proyecto de Ley de los Presupuestos Generales del Estado para el año económico de I9I I, de 2 de julio de I9Io. Diario de Sesiones de 15 de octubre de I9ro. Congreso de los Diputados. Diario de Sesiones. 29. Serie Histórica (I 8I 2-I936), I9IO-I9I 5 . 
de anormales. Esta situación provocó siempre un fuerte conflicto entre las secciones o colectivos profesionales de los distintos patronatos.

2.3. Los patronatos en el periodo 1910-1936: su evolución y aportaciones a las políticas educativas de ámbito didáctico, de red escolar y de formación del profesorado especialista de sordomudos

En cuanto al diseño y creación del Patronato son gobiernos del Partido Liberal los que lo establecen en r9 Io a petición del ministro de Instrucción Pública, Barroso, del Gabinete José Canalejas ${ }^{4}$. Según el decreto de creación el Patronato inicia "la política intervencionista, vigente hoy en todas las legislaciones europeas" y se plantea bajo "una idea de unidad en la acción, y de esfuerzos y que deviniese en un prestigioso cuerpo consultivo que fuese constante asesor del Ministerio en todo lo referente a estos asuntos”.

El Patronato presenta un conjunto de atribuciones de naturaleza principalmente consultivas y también ejecutivas que abarcan toda la política educativa que la administración educativa quiere diseñar y aplicar ${ }^{5}$, pero pronto el Patronato va a ser el marco de una lucha política y gremial, que no es solo propia de España y que se lleva a cabo entre sectores de pedagogos, médicos y psicólogos, tanto para que sus visiones y argumentos determinen la organización del nuevo sector como para establecer su presencia en las direcciones de los

4. Real Decreto de 22 de enero de I9ro por el que se establece un Patronato Nacional de sordomudos, ciegos y anormales.

5. El Patronato Nacional de Sordomudos, Ciegos y Anormales es una corporación principalmente consultiva encargada de informar al Ministerio en todo lo referente a la protección higiénica, social y pedagógica de los colectivos a los que agrupa, estando el Ministerio obligado a realizar la consulta en determinados ámbitos (organización y reforma de planes y reglamentos de enseñanza. Exámenes, grados y cátedras. Subvenciones a instituciones protectoras o recursos de alzada). El Patronato tiene funciones ejecutivas en el ámbito educativo, en el del cuidado y prevención y en el de la tutela social: hacer la estadística de sordomudos, ciegos y anormales. La profilaxis y la higiene. La tutela social. La vulgarización de los conocimientos. La alta inspección de los establecimientos de enseñanza y de las instituciones protectoras (art. $\left.5^{\circ}\right)$. nuevos organismos y del sistema formativo que tendrá que crearse ${ }^{6}$. Además, los patronatos se constituyen en moneda de cambio entre los políticos conservadores y liberales.

Las incidencias en las enseñanzas de sordomudos del primer Patronato son de difícil cuantificación directa, y no porque no hubiera representantes cualificados en la sección de Sordomudos, ya que estaban el comisario regio del Colegio Nacional de Sordomudos y de Ciegos Bejarano y su director Granell. Tampoco en la sección de Anormales, para determinados miembros del sector médico, la actividad parece mejor:

"Este Patronato estuvo 4 años deliberando y discutiendo, sin llevar nada a cabo. Cuando llegó el Sr. Bergamín al ministerio hace dos años, y vio aquella obra estéril de 4 años, reformó el Patronato nombrando presidente al Sr. Barroso" (González, I9 I7:I2).

Del Pozo ( I980) considera que sí hubo avances o al menos la actividad del Patronato influyó en la normativa de I9I 3 que estableció secciones de anormales en las escuelas graduadas o la presencia de la inspección médica en la clasificación de los niños anormales. Parece razonable pensar que al menos sí hubo una acción difusa en el sector.

En I9I4 se reforma el Patronato Nacional de Sordomudos, Ciegos y Anormales a propuesta del ministro de Instrucción Pública, el conservador Francisco Bergamín, pasando a denominarse Patronato Nacional de Anormales 7 . Se crea para resolver el problema de la educación pública de los niños anormales y según la exposición del decreto porque “(...) la presencia de los niños anormales de distintas variedades entorpece la enseñanza de las clases

6. El Dr. Lafora dice sobre el Colegio Nacional de Sordomudos: "A costa de los niños anormales, sordomudos y ciegos, se está nutriendo una banda de aves de rapiña que ha caído sobre el Colegio...”. En Molina y Gómez, I992: 24I.

7. Real Decreto de 24 de abril de I9I4, reformando el

Patronato Nacional de Sordomudos, Ciegos y Anormales, disponiendo que en lo sucesivo se denomine Patronato Nacional de Anormales. 
ordinarias y perjudica así la educación de los niños normales" y también "porque las distintas variedades de niños anormales necesitan una pedagogía especial...”. Para el Ministerio de Instrucción Pública lo urgente es la creación de escuelas para los anormales mentales ${ }^{8}$.

En la nueva ordenación de la educación especial, el remodelado Patronato se concibe como un instrumento de ejecución e intervención centralizada de la administración con unas funciones definidas y novedosas que se dirigen a todo el alumnado anormal constituido por sordomudos, ciegos y anormales y que se centran en el reconocimiento de la anormalidad infantil y su tratamiento, además de la formación de los profesionales. También, el Patronato desarrolla funciones directivas tanto sobre los centros educativos especiales como en los nuevos organismos que se constituyen en ese periodo. El decreto contempla una organización territorial estable.

Para hacer posible las funciones estatutarias se crea un Instituto Central con un Laboratorio médico-psicológico que lleva a cabo el reconocimiento de la anormalidad y la organización de cursos de formación de maestros y médicos inspectores de esta especialidad. Se crea el cargo de secretario general del Patronato que también es el director de toda la obra y de los establecimientos para anormales, incluido el Colegio Nacional de Sordomudos y Ciegos. El Patronato está presidido por el anterior ministro de Instrucción Pública Barroso 9 .

Este Patronato tiene una incidencia importante tanto en las enseñanzas y organización del Colegio de Sordomudos de Madrid como en el sistema general de estas enseñanzas. En el caso del Colegio de Madrid el efecto se concreta en

8. En esa misma línea de pensamiento se encuentra el maestro de primera enseñanza Francisco Pereira, vocal de la Sección 3 del Patronato Nacional de Sordomudos, Ciegos y Anormales, promotor en España de las escuelas de anormales.

9. El diputado Vincenti señala que el nuevo patronato es presidido por el ministro que presentó o creó el anterior. Diario de Sesiones de I I de diciembre de I9I4 de Enmiendas al Proyecto de de Presupuesto del MIPyBA de I9I 5 . Esto no será la última vez en producirse. que la dirección y gobierno del Colegio pasa a la Comisión ejecutiva y al secretario general del Patronato $^{\text {10 }}$ y desaparece la Comisaria regia. Una vez que el Colegio está bajo la dirección del Patronato se inicia la transformación del centro en una organización de enseñanza graduada y se profundiza en el enfoque metodológico oralista, que como se indicó más arriba, son dos aspectos de la reforma de principios de siglo de las enseñanzas de sordomudos.

La graduación de las enseñanzas requiere la previa clasificación del profesorado, transformando a los profesores auxiliares (Reglamentos de I902) en profesores de sección o grados en que se dividen las enseñanzas (Reglamento del Colegio de I9I 5, Disposición Transitoria $\mathrm{I}^{\mathrm{a}}$ ). Todavía en I9I9, cuatro años después, la autoridad competente requiere a la dirección del Colegio que se lleve a cabo tal modelo organizativo ${ }^{\text {II }}$.

En cuanto a la oralización del alumnado sordomudo se concreta o tiene un buen indicador en las pruebas para acceder al profesorado especial de sordomudos, los aspirantes tienen que practicar ante dos alumnos de dicha sección procedimientos de lectura oral y labial, con exclusión de toda mímica artificiosa. En la educación del sordomudo se defiende la adquisición del lenguaje de la palabra, formulación mantenida por el profesorado más prestigioso, entre otros por María Luisa Navarro (I9I7:287), jefa de Estudios del Colegio de Madrid.

Procede hacer dos últimas consideraciones de este Patronato de naturaleza e intención más genérica, si bien con afectación en el Colegio Nacional de Sordomudos y de Ciegos de Madrid, la primera es la creación de colegios de anormales mentales, ubicando uno de éstos en las instalaciones del Colegio, si bien,

Io. Reales Decretos de 24 de abril de I9I4 y 2 de marzo de I9I 5 .

I I. Oficio de la Dirección del Instituto Nacional de Sordomudos, Ciegos y Anormales, Castellana, 69, de 3 de junio de I9I9, destinado a una serie de profesores de sección. Documento sin numerar. Carpeta ${ }^{\circ} 5$ María Luisa Navarro. Fundación Ortega y Gasset. CSIC, Madrid. 
previamente el presidente del Patronato pidió la opinión del Claustro que lamentablemente desconocemos $^{12}$. Los alumnos sordomudos del Colegio se amotinan ante la presencia de aquellos, situación que fue sofocada por la Guardia Civil según Yuste de Santos (2013:45). La segunda incidencia es la renovación del sistema formativo del profesorado especialista de sordomudos y de ciegos:

“[...] a partir de I9I5 a I9I6 se suprimirá la asignatura de Métodos y Procedimientos para la enseñanza de Sordomudos y de Ciegos, creada por Real orden de 25 de marzo de I 857 , pasando estas enseñanzas á formar parte de las que incumben al Instituto Central de Anormales para la formación de Maestros de esta especialidad" ${ }^{13}$.

Y se pone en funcionamiento el Seminario de Maestros del Instituto Central de Anormales que tiene como estructura física el Colegio de Sordomudos y de Ciegos (Art. $2^{\circ}$ del Reglamento del Colegio de Sordomudos de I9I 5).

El Patronato Nacional de Anormales realiza sus funciones durante dos años escasos, ya que el ministro de Instrucción Pública Burell en marzo de I9I 6 deshace lo hecho y la estructura vuelve a la conocida organización del Patronato de Sordomudos, Ciegos y Anormales de I9I0 ${ }^{14}$. En la exposición del real decreto de restablecimiento se justifica en estos términos:

“[...] para que cada uno permanezca y se mueva en sus respectivas esferas sin confusiones que esterilicen o entorpezcan los esfuerzos de todos... Conviene que la parte docente en el Instituto Nacional de Anormales y especial de Sordomudos y Ciegos proceda con independencia de todo otro fin, así como que la Administración mantenga su derecho de intervención".

I2. Documento sin numerar. Carpeta ${ }^{\circ} 5$ María Luisa Navarro. Fundación Ortega y Gasset. CSIC, Madrid.

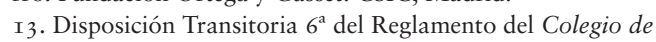
Sordomudos de I9I 5.

I4. Real Decreto de Io de marzo de I9I6 restableciendo la organización del Patronato de Sordomudos, Ciegos y Anormales.
Es una argumentación críptica y cuyo verdadero significado tienen que ver con el deseo del ministro de realzar la dirección pedagógica frente a la estructura profesional médica que para él ha copado el Patronato Nacional de Anormales. El presidente de la nueva forma es el conservador Bergamín, que fue el patrocinador del anterior Patronato de Anormales como ministro.

La estructura del Patronato Nacional de Sordomudos, Ciegos y Anormales de г9r6 mantiene las tres secciones de su creación entre marzo y agosto, pero en este mes mediante dos reales decretos de la misma fecha pero separados por cinco días en su publicación, el ministro cambia la estructura a dos secciones: Sordomudos y Ciegos por un lado y Anormales por otro y los inserta en un denominado y confuso Patronato del Instituto Nacional de Anormales y Especial de Sordomudos y Ciegos, con ro consejeros por cada una de las secciones. El segundo real decreto aprueba un nuevo reglamento para el Colegio Nacional de Sordomudos, Ciegos y Anormales en su instituto Nacional, reglamento para una nueva y creativa denominación que presenta entre otras novedades para el Colegio, que la dirección pedagógica y la alta inspección se adscriban al presidente del Patronato y el gobierno del establecimiento al director administrativo. El ministro se asegura el control del Colegio de Sordomudos y de Ciegos, sin bien la incidencia de la nueva fórmula en las enseñanzas de sordomudos es de difícil valoración.

Consecuentemente con la nueva denominación tanto del Colegio como del Patronato, el ministro Burell sí consolida las enseñanzas de anormales creando orgánicamente una Sección de Anormales bajo un director técnico y formada por dos escuelas y un seminario, con una regulación y organización notablemente moderna. Sección que “(...) tan pronto los alumnos anormales pasen a otro edificio (están en las instalaciones de Castellana del Colegio de Sordomudos y de Ciegos), se convertirá en Patronato independiente". En diciembre de I9I 6, estando todavía los alumnos anormales en las instalaciones citadas, el ministro Burell provoca la transformación del Patronato de dos 
secciones en dos patronatos independientes, el de Anormales y el de Sordomudos y Ciegos ${ }^{15}$. El motivo no está justificado ni es claro ${ }^{16}$.

Tras el cese en abril de I9I7 del conde de Romanones, jefe del Gabinete al que pertenece Burell como ministro de Instrucción Pública, el nuevo ministro de Instrucción Pública, el conservador Andrade Navarrete (abril-noviembre de I9I7) perteneciente al Gabinete Dato, decide que es más oportuno que el número de Patronatos que gestionan la educación especial sean 3 y no 2 , de tal manera que sordomudos y ciegos tuvieran cada uno el suyo independientemente. El ministro ha tardado 3 meses en hacer su reforma de la dirección institucional de la Educación Especial ${ }^{17}$ y se justifica en el decreto en que "(...) la intensidad de la vida de las instituciones sociales, está en razón directa de su especialización. A este fin parece prudente la formación de tres patronatos". Para Andrade el esfuerzo realizado por la administración y sus ministros de Instrucción Pública en estos últimos 7 años es importante y pueden darse por bien empleados.

Las atribuciones de cada uno de los Patronatos siguen siendo las conocidas pero aportan una idea original beneficiosa para el sistema educativo: “(...) interesa relacionar a los Patronatos con el Consejo de Instrucción Pública, mediante el ingreso de los Presidentes en el mencionado Cuerpo consultivo en calidad de vocales natos" (exposición del decreto). Además, en el mismo decreto se establece el compromiso de definir el significado real de la competencia de "la alta inspección", hecho que no tenemos constancia que se produjera.

I 5. Real Decreto de 22 de diciembre de I9I 6 por el que se establece que las dos secciones del Patronato se constituyan en dos patronatos independientes.

I6. En la prensa de aquellos días, el Dr. Lafora, enemigo acérrimo del ministro hace alguna consideración sobre la visita de éste al Colegio Nacional de Sordomudos y de Ciegos: “(...) encuentra algunas deficiencias en el primero y decide de un plumazo destituir al Patronato y nombra a un amigo suyo. Debemos hacer constar que la mayor parte de las deficiencias encontradas por el Sr. Borrell eran defectos de construcción del edificio y de la presencia de la Escuela de Ingenieros Industriales” (González, I9I7: I2).

I7. Real Decreto de 24 de agosto de I9I7 por el que se crean tres patronatos independientes.
El periodo de actuación de estos tres Patronatos se extiende hasta 1924 , y en cuanto a las aportaciones del de Sordomudos afirmamos que tiene incidencia en la oralización del alumnado, al promoverse y crearse una oferta específica de ortoepía (pronunciación correcta) en el Colegio de Sordomudos de Madrid por medio de una Sección de niños disártricos cuyo profesor fue Jacobo Orellana ${ }^{18}$.

No parece que tuviera el indicado Patronato Nacional repercusión en la creación de plazas escolares para los sordomudos ya que no sufren variación sensible a nivel general, a pesar de un crédito de $250.5 \mathrm{I} 7$ pesetas para las obras del nuevo edificio del Colegio de Sordomudos de Santiago de Compostela en su nueva sede. Tampoco estas enseñanzas se benefician de los acuerdos en I922 y 23, entre el Ayuntamiento de Madrid, Ministerio de Instrucción Pública y la Junta de Instrucción Primaria de Madrid, ya que no se llegó a realizar el grupo de sordomudos y de anormales de los seis grupos previstos (Del Pozo, I999:229 y 246).

La Dictadura de Primo de Rivera, a través de su Directorio Militar en I924, reorganiza los patronatos que funcionan desde I9I7 y los trasforma en dos, dando lugar al Patronato Nacional de Sordomudos y de Ciegos y al Patronato Nacional de Anormales. Se justifica porque los Patronatos no funcionan con regularidad. El nuevo Patronato ${ }^{19}$ ejerce un mayor control en la acción tutelar administrativa de los centros privados y en la inspección sobre los claustros y profesionales de los Colegios Nacionales de Sordomudos y de Ciegos.

Además, se determina que la responsabilidad máxima de los Colegios Nacionales recaiga en un comisario regio con el fin de conseguir la eficacia y unidad necesarias. Esta figura desaparecida de la escena de estas enseñanzas en

I 8. Hoja de Servicios de Jacobo Orellana. Archivo de Clases Pasivas. Ministerio de Hacienda. El profesor tuvo una gratificación de 2000 pesetas/año según los Presupuestos de I922, Real orden de 24 de agosto de I 922.

I9. Real Decreto de I3 de septiembre de I924, reorganizando el Patronato Nacional de Sordomudos y de Ciegos. 
I9I 5, al restablecerse provoca serios conflictos competenciales con el Patronato, cuya dirección de los Colegios Nacionales se ejerce a través de un administrador. En I930, en una situación máxima de centralización de las competencias, se ordena que la Comisaría regia concentre todas las atribuciones de dirección e inspección sobre estas enseñanzas (Real Decreto de 5 de abril de I930).

El Patronato Nacional de Sordomudos y de Ciegos, como los anteriores, profundiza en la acción oralizadora extendiendo al sistema escolar general las enseñanzas de ortoepía (pronunciación correcta), de tal forma que un profesor del Colegio de Sordomudos asista a otros colegios de Madrid en los que haya niños disártricos (Orden de I I de septiembre de I924). También, las enseñanzas de disártricos se hacen obligatorias en el sistema formativo del profesorado especial de sordomudo a partir de I 924 .

La aportación más sustantiva de la Dictadura a las enseñanzas de sordomudos es adscribir en I925 la formación especializada de sordomudos a la Escuela de Estudios Superiores del Magisterio conjuntamente con el Colegio Nacional de Sordomudos y de Ciegos, articulándose un nuevo Curso Normal de Profesores Especiales de Sordomudos y de Ciegos de dos años académicos de duración, uno más que en el anterior modelo y con contenidos modernos. Este modelo de formación desaparece en I930, en nuestra opinión por una decisión política que se debe entender dentro del proceso de máxima concentración de poderes del nuevo comisario regio (López Núñez), del cual dependerá la formación del profesorado especializado.

La política educativa relativa a las enseñanzas de sordomudos durante los años I923-I93 I, periodo relativo a la Dictadura de Primo de Rivera y del gobierno del general Berenguer (I930-3I), presenta una fuerte unidad con la del periodo anterior (I9IO-I923), si bien con la característica citada: su fuerte centralización en la dirección de las enseñanzas de educación especial (sordomudos, ciegos y anormales).
El último tramo de este periodo I9Io-I936 es el republicano, cuya política educativa se lleva a cabo por los ministros de Instrucción Pública Marcelino Domingo, Fernando de los Ríos y Domingo Barnés entre I93 I y I933. La política relativa a las enseñanzas de sordomudos tiende a conseguir modernizar las enseñanzas de sordomudos, extender su red escolar y proporcionar una organización moderna al Colegio Nacional de Sordomudos, el único de la Administración Central del Estado en su especialidad. Si bien, no son objetivos nuevos, ya que son los mismos que los formulados en las distintas fases de la Restauración, se conciben de forma más coherente e integrada en el sistema escolar, lo que no quita que determinadas decisiones políticas provoquen el cierre del Colegio Nacional de Sordomudos y de Ciegos de Madrid en I932.

En estos años el Patronato de Sordomudos y de Ciegos no ejerce más que funciones consultivas y además se le adscribe un delegado del gobierno, el comisario de la República en los Colegios Nacionales de Sordomudos y de Ciegos, Sidonio Pintado (El Magisterio Español de 9 de julio de I93I). En septiembre de I933 se promueve por Lerroux el único decreto que establece la organización de los Colegios de Sordomudos y de Ciegos de Madrid, y además deroga todos los reales decretos, reales órdenes y reglamentos que se dictaron por los gobiernos de Alfonso XIII para los Colegios Nacionales de Sordomudos y Ciegos, incluso las competencias del propio Patronato Nacional de Sordomudos y de Ciegos de 1924 sobre el Colegio.

En febrero de 1934 se crea el Patronato Central ${ }^{20}$ por el ministro de Instrucción Pública Pareja Yébenes que sustituye al anterior Patronato. Como justificación y en la exposición de motivos del decreto se hace alusión a "la organización y vida mezquina que llevan los centros de sordomudos, ciegos y maternales”. Sus funciones son las ya conocidas pero definidas con claridad en consonancia con el mandato que tiene: averiguar las causas del estado de

20. Decreto de I 6 de febrero de I934, por el que se crea el Patronato Central. 
estos centros. El texto del decreto entra en seria contradicción con las disposiciones del aludido decreto de I933 que contemplaba en el director de los Colegios Nacionales de Sordomudos y de Ciegos la inspección de las enseñanzas y centros $\left(\right.$ art. $\left.\mathrm{I}^{\circ}\right)$. Además, el Patronato Central incluye en su ámbito las escuelas de maternales pero no las de anormales.

Este Patronato no tiene incidencia práctica, el ministro Yébenes es sustituido en marzo de I 934 por Salvador de Madariaga que lo deroga y crea otro por Decreto de 3 de abril de ese mismo año, el Patronato Nacional de Cultura de los Deficientes $^{21}$. Esta institución se plantea bajo una consideración de organización flexible, sencilla y eficaz y tiene las funciones en el sentido cultural que la cuestión exija, se viene a decir en la exposición del decreto. Nominalmente las funciones del Patronato parecen ser las mismas que las de sus antecesores si bien expuestas en términos laxos: “(...), deben quedar afectos al Patronato todas las instituciones que se ocupen de las cuestiones culturales de los deficientes, así como la inspección de las de orden privado...".

Su terminología es atractiva y humanística y plantea ideas de interés como es la creación de un centro de recursos -como se llamaría hoy- para la educación especial con fonoteca y material en braille.

El ministro Madariaga cesa el 28 de abril de I934 y le sucede en el Ministerio de Instrucción Pública Filiberto Villalobos que no modifica ni sustituye el Patronato Nacional de Cultura de los Deficientes que hereda. Por otra parte no tenemos constancia de su incidencia en las enseñanzas de sordomudos, ni que participe en la política educativa sobre estas enseñanzas, y no porque la situación de las enseñanzas de sordomudos no lo requiriera, todavía el Colegio Nacional de Sordomudos seguía sin encontrar ubicación y por tanto clausurado y los grandes problemas de estas enseñanzas se mantienen. Los años I935 y 36 son un cúmulo de acontecimientos en estas enseñanzas: se

2I. Decreto de 3 de abril de I934 por el que se crea el Patronato Nacional de Cultura de los Deficientes. abre el Colegio Nacional de Sordomudos en condiciones muy precarias y separado definitivamente del de Ciegos, se crea una inspección del Estado e incluso se diseña una red de centros, pero todo se diluye en la situación política existente y luego la guerra civil.

\subsection{Conclusiones del periodo}

Procede, antes de planear las conclusiones del periodo I9IO-I936, hacer dos consideraciones, la primera es que con carácter general el conocimiento de partidos políticos, gobierno y Congreso de los Diputados sobre las enseñanzas de sordomudos (lo mismo ocurre con las de ciegos y anormales), no va más allá de la simpatía hacia estos colectivos y de la aprobación de los créditos para gastos del Colegio de Sordomudos y de Ciegos de Madrid establecidos en el Presupuesto del Estado, además de los principios generales de intervención en la educación o de la libertad de enseñanza que liberales y conservadores, respectivamente, defendían. Aunque, hay que decir que gracias al principio de intervención de los gobiernos en la educación defendido principalmente por liberales y también, de forma discontinua por conservadores, fue posible poner en pie tanto la reforma de las enseñanzas de sordomudos de principio de siglo XX como la creación de la educación especial y sus instituciones durante el primer tercio de éste.

La segunda consideración es que la actividad de los patronatos de sordomudos, ciegos y anormales, especialmente los de la Restauración y en menor medida en el periodo de la Dictadura y en menor todavía durante la República, está determinada por los grupos profesionales adscritos a la nueva etapa de la Educación Especial, es decir, por médicos, psicólogos y maestros, y un grupo heterogéneo de publicistas, juristas o defensores de estos colectivos. Muchos ministros de Instrucción Pública, que como tal son los responsables de la política educativa de las enseñanzas de educación especial, adaptarán su actividad a la influencia corporativa de aquellos para su pervivencia y justificación, porque además de la falta de unas ideas precisas 
y novedosas según se constata en el análisis de las funciones de la mayoría de los patronatos, la media de tiempo de los 39 ministros, algunos repiten cargo, entre I9IO-I936 es inferior a los 8 meses.

La conclusión es que ni la creación de estas instituciones ni su actividad se desenvolvieron de manera adecuada: un presupuesto bajo y mal distribuido, unas instituciones que se reconstituyen hasta en 8 o 9 ocasiones sin razones pertinentes como se ha expuesto más arriba y se plasma de forma comprensiva en un gráfico final, unas funciones o atribuciones de naturaleza diversa y muy amplias; muchas veces erráticas y cambiantes y un magma semántico confuso en cuanto a las denominaciones, hacen que su incidencia en las enseñanzas de sordomudos no tuvieran el rendimiento ni la consolidación institucional que hubiera sido deseable. Es cierto que los cambios de regímenes, las crisis sociales y económicas (I9I7 o I929), dos golpes de estado y una guerra civil, dificultan cualquier asentamiento.

3. Segunda etapa: los patronatos en el régimen de Franco (1939-1975)

Las políticas educativas de la administración franquista sobre estas enseñanzas así como sus patronatos tienen directa relación en su ejecución con un régimen que evoluciona desde la no intervención a la intervención declarada en las enseñanzas de educación especial (sordomudos, ciegos y anormales), y desde un régimen totalitario a otro tecnocrático con un fuerte control ideológico y político.

\subsection{Las políticas educativas de las enseñanzas de sordomudos}

El régimen en sus inicios toma dos decisiones de política educativa sobre las enseñanzas de sordomudos: no abrir el Colegio Nacional de Sordomudos cerrado por la Republica al inicio de la guerra, en tanto que dice no tener los recursos necesarios y mantener una política de no intervención en dichas enseñanzas. El Colegio se abre en 1947, posiblemente en atención a que la Ley de Instrucción Primaria de 1945 establece la existencia de centros de sordomudos y el de Madrid es el único financiado por la Administración Central del Estado.

En los años 50 y principio de los 60, la administración educativa tiene una intervención muy tímida en estas enseñanzas que se concreta en el aumento de las unidades del Colegio de Sordomudos de Madrid, la creación de unidades o secciones en el conjunto del país, la promoción de la construcción de centros de sordomudos con financiación social, fondos de diputaciones y ayuntamientos o el otorgamiento de interés social a los centros privados. También en I95 I inicia la formación del profesorado especialista en sordomudos con un curso de 3 meses.

El régimen empieza a ser consciente de que su discurso de la participación de la sociedad, de los padres afectados y de la beneficencia en la tarea de la educación especial, es insuficiente para dar respuesta a la necesidades escolares de un régimen que se titula social y cristiano e inicia la programación de su presencia y la participación de la administración en estas enseñanzas. Uno de los medios elegidos para este fin es a través de un patronato. En I953 el gobierno justifica la creación del Patronato Nacional de Educación de la Infancia Anormal, en tanto que:

\footnotetext{
"(...) todavía no se ha abordado con ímpetu y eficacia el problema total de la educación y de la rehabilitación moral y social de un sector importante de la infancia y juventud españolas que acusan deficiencias o taras que es necesario contrarrestar mediante tratamientos de carácter especial” ${ }^{22}$ (preámbulo del decreto).
}

22. Decreto de 6 de marzo de 1953 por el que se crea el Patronato Nacional de Educación de la Infancia Anormal. 
El nuevo Patronato concibe "la necesidad de atender a la educación de la infancia anormal...", desde una "solución cristiana a este problema" y bajo el peligro de orden social que entraña no hacerlo. Y para estos efectos tendrá la colaboración de los servicios correspondientes de los Ministerios de Gobernación y Justicia. La presidencia de este Patronato corresponde al ministro de Educación Nacional RuizGiménez. Sus competencias en general son las tradicionales de los patronatos pero sin contemplar las consultivas ni las de intervención directa en el sistema escolar.

En I955, las autoridades estiman que dicha organización se debe perfeccionar y ampliar para cumplir la Ley de Educación Primaria de I945, creándose una "nueva institución de título más comprensivo y discreto": el Patronato Nacional de Educación Especial ${ }^{23}$. Bajo esta nueva fórmula el gobierno plantea nominalmente que "Es misión del Estado, (...) la noble tarea de la educación, que rige desde un plano superior, la fomenta en la esfera privada y la suple y completa por los órganos de gobierno".

Este Patronato mantiene la dependencia del Ministerio de Educación Nacional y sus atribuciones son consecuentes con las del Patronato de I953: una actividad centrada en la propuesta, ya de centros escolares o de creación de consultorios para el diagnóstico precoz y en los tradicionales de la organización de la formación del personal especializado, la tutela o la propaganda. Para una mayor eficacia de las actividades del Patronato, en provincias las secciones de Educación Especial de los Consejos Provinciales de Educación Nacional, son constituidos como organismos delegados del Patronato. El Gobierno le asigna al Patronato Nacional de Educación Especial la elaboración de un Plan Nacional de Educación Especial que incluye la formación profesional y la adaptación social, de forma específica para el tema de sordomudos, semi-sordos y disártricos, susceptible de tener una gran incidencia en estos colectivos.

23. Decreto de 9 de diciembre de 1955 por el que se crea el Patronato Nacional de Educación Especial.
Aunque con modificaciones en su estructura a lo largo de sus 20 años, la realización de sus funciones presenta un conjunto de incidencias en las enseñanzas de sordomudos, ciegos y anormales, de las que destacamos las que creemos más significativas:

- $\quad$ En I956 se institucionaliza y generaliza la presencia en la Comisión Permanente del Patronato de los directores de las Escuelas de Anormales, María Soriano y de Sordomudos, Miguel Baena y del presidente de la Federación Nacional de Sociedades de Sordos Españolas (FNSSE) Marroquín.

- Polaino-Lorente ( 1983 ) hace referencia a un estudio epidemiológico de los deficientes mentales en España llevado a cabo por el Patronato.

- Otros autores citan “un plan del Patronato Nacional de Educación Especial para dejar en Io años debidamente atendidas esta especialidad de la enseñanza (sordomudos)" ${ }^{24}$, hecho que anticipamos no se llegó a cumplir.

En I964, el gobierno dispone que una Comisión Central dependiente del Patronato redacte una nueva ordenación de especialidades, formación y titulación de todo el personal afecto a la educación especial. Además, esa Comisión interviene en los preparativos técnicos de la ordenación del sector de 1965 , que se realiza por medio del Decreto 2925/I965 regulador de la Educación Especial, en el que se le confiere nuevos cometidos al Patronato, incluido el volver a elaborar un Plan Nacional de Educación Especial.

En la segunda parte de los 6o, el Patronato contempla como el todavía Ministerio de Educación Nacional empieza a entender como propia la definición de una serie de políticas que se traducen en la construcción y financiación de los colegios o la formación del profesorado especial, si bien dejando amplios márgenes de libertad a la iniciativa privada y a la Iglesia

24. Entrevista al profesor del Colegio Nacional de Sordomudos, Rico. Diario $A B C$ de 20 de enero de 1958. 
Católica, siempre bajo un profundo control ideológico y político.

A finales de la década, el Ministerio de Educación y Ciencia está preparado para afrontar el mayor cambio metodológico y de ordenación del sistema educativo. El Libro Blanco sobre la reforma de 1969 como la Ley de Educación de I970 plantea un conjunto de consideraciones sobre la educación especial relativas a principios de organización, de red escolar o de escolarización con un tono de coherencia apreciable (capítulo XIII, parte $2^{\mathrm{a}}$ de Bases).

El régimen, al iniciarse la década de los 70, centra la realización de su política con las enseñanzas de sordos en el Instituto Nacional de Pedagogía de Sordos, heredero del Colegio Nacional de Sordomudos, tanto por sus medios humanos considerables y profesorado especializado, autonomía funcional del centro en cuanto a organización y dirección e instalaciones modernas y amplias que incluye una residencia y permiten la escolarización de un gran número de alumnos sordos. La formación del profesorado de sordos sigue siendo una de las competencias básicas del Instituto, el cual constituye el mejor motor de la política del régimen.

\subsection{Conclusiones}

El régimen de Franco se vale de la figura de los patronatos para justificar su intervención en la ordenación, dirección y gestión de la educación especial, y por ende, en las enseñanzas de sordos. A partir de los años 60 estas enseñanzas se conciben con un cierto grado de unidad con la de anormales y ciegos, en aspectos tales como la formación de los maestros especialistas y titulaciones de éstos. El planteamiento de la Ley General de Educación de I970 sobre la educación especial y la puesta en funcionamiento del Instituto Nacional de Psicopedagogía de Sordos de Madrid son los dos hitos que el régimen marca como fundamentales en las enseñanzas de sordos. La evaluación del grado de incidencia de las políticas educativas en las enseñanzas de sordos, ciegos y anormales se pospone a unas líneas siguientes.

\section{Tercera etapa: el posfranquismo y la Transición hasta 1978}

La última etapa de este estudio está destinada a hacer un análisis introductorio de las principales actividades del Real Patronato de Educación Especial y su incidencia en las políticas educativas del posfranquismo y de los primeros gobiernos de la Transición política de 1975 a I978, relativas a las enseñanzas de sordos. El año 78 es el de la proclamación de la Constitución Española y a los efectos de este estudio, el año de la desaparición del último Patronato no constitucional contemporáneo.

Un órgano creado en 1975 siendo ministro de Educación Martínez Esteruelas ${ }^{25}$ se constituye en elemento central de las políticas educativas de los años I975-I978, el Instituto Nacional de Educación Especial (en adelante INEE). En I976 se completa el aparato administrativo de la educación especial con un nuevo patronato, el Real Patronato de la Educación Especial ${ }^{26}$, presidido por la Reina de España y con las funciones genéricas de impulsar la educación especial regulada por el artículo 49 de la Ley General de Educación de 1970 y que sucede al casi homónimo Patronato creado en 1955.

Este tándem es refrendado por los gobiernos de la Transición política y supone un modelo institucional diferenciado del resto de la gestión que el Ministerio de Educación y Ciencia lleva a cabo con las otras etapas del sistema educativo. La administración educativa de esos años mantiene el sesgo segregador en la gestión de la educación especial que las distintas administraciones han mantenido históricamente.

El Real Patronato de Educación Especial (I97678 ) inicia planes generales como son el Plan Nacional de Prevención de la Subnormalidad y el Plan Nacional de Educación Especial. Sobre el primero, su análisis se puede realizar a través

25. Decreto II 5I/I975, de 23 de mayo, por el que se crea el Instituto Nacional de Educación Especial. 26. Real Decreto I023/1976, de 9 de abril, por el que se crea el Real Patronato de Educación Especial. 
de la Memoria del Real Patronato, I976-200I (Real Patronato, 200I:I4) y en cuanto al Plan Nacional de Educación Especial se diseña por el Real Patronato y su ejecución es responsabilidad del INEE conforme a las disposiciones vigentes, $\mathrm{y}$ sobre el cual hacemos algunas consideraciones:

"El Plan Nacional de Educación Especial nace con el firme y decidido propósito de hacer frente, de forma global y coherente, a los graves problemas que la educación de los niños deficientes e inadaptados presentan en nuestro país, problemas que hay que referir no solo a la notoria falta de recursos, sino también a la ausencia de criterios orientadores y definitorios" (Real Patronato de Educación Especial, I978:33).

Hay que tener en cuenta para un análisis adecuado que "El Plan es un plan-marco, plan básico o previo", "no es inmediatamente operativo" (Real Patronato de Educación Especial, I978: I 5-I6).

Bajo estas ideas y términos, el Plan supone uno de los mejores análisis de aquellos años en cuanto a la situación de la educación especial y constituye una valoración crítica hecha tanto por los profesionales del sector como por responsables del mismo sistema educativo representado por el Real Patronato de la Educación Especial y por el INEE. De sus conclusiones se puede inferir que las políticas educativas del régimen de Franco en las enseñanzas de sordos, ciegos y anormales han sido muy limitadas en cuanto a sus resultados y que la Ley General de Educación de 1970 en lo que a la Educación Especial se refiere está implantándose muy lentamente, cuando no insuficientemente.

El mismo INEE considera “dramática y escandalosa” la situación de la Educación Especial ya que hasta el momento "solo menos de un cuarto de la población estimada" la recibe, además define "de escasa calidad a los cursos de formación del profesorado y en general menciona como irritante el estado de abandono del sector" (Real Patronato de Educación Especial, I978:33).
Según las estimaciones del Plan, la población con deficiencias de o a I 8 años alcanza los 330000 individuos y solo están escolarizados el 21,5\%, es decir 72000 (Plan Nacional de Educación Especial, I978: 67-67 y I 59 a I79). Se cifran en casi cuarenta mil quinientos millones de pesetas la inversión a ejecutar en los presupuestos de los 4 próximos años, solo para dar respuesta educativa.

El Plan se basa y fundamenta en una serie de principios aplicados en otros países en el trato a las personas objeto de educación especial, entre otros, los procedentes de la experiencia angloamericana, el informe Warnock y las realizaciones nórdicas, fundamentalmente, también se consideraron, pero a cierta distancia determinados planteamientos de la Ley de Educación de I970, y todas estas ideas y principios se hacen presentes en el Plan con relación a la normalización de los servicios, integración escolar, sectorización e individualización de la enseñanza. El Plan contribuye a fijar estos principios en nuestro ordenamiento jurídico: Constitución de 1978, Ley de Integración Social de los Minusválidos de 1982 (LISMI) o en las regulaciones de la educación especial de I982, I985 y posteriores.

Cabe citar en el orden de las ideas y realizaciones el apoyo prestado por el Real Patronato a la Comisión Especial del Congreso de los Diputados para el estudio de los problemas de los disminuidos físicos y psíquicos, presidida por el diputado Trias Fargas en I 977 ${ }^{27}$, la cual presenta un Proyecto de Ley para la atención de los Disminuidos Físicos, Mentales y Sensoriales, articulado en 4 títulos y un Plan Financiero para la Educación Especial desde I979 a I983, y que en I982 da lugar a la referida LISMI.

La acción del Real Patronato de Educación Especial y el Instituto Nacional de Educación Especial tiene incidencia sobre las enseñanzas

27. La colaboración entre el Real Patronato de Educación Especial y la Comisión Especial de Trias Fargas se concretan en unos borradores de ley tanto de ámbito general como uno específico relativo a la Educación. Archivo del Congreso de los Diputados, Legajo I 358 Único 
específicas de sordos que a finales de la década de los 70 cuenta con un total de unos 4700 alumnos sordos e hipoacúsicos matriculados en centros especiales o unidades de la misma naturaleza (Ministerio de Educación y Ciencia,I981:84), distribuidos en una red pública y privada que alcanza los 40 centros, si bien de éstos, I 3 o I 4 solo sobrepasan los Ioo alumnos.

La intervención combinada de estas dos instituciones se puede concretar en la creación y autorización de al menos 7 centros específicos de sordos, en el periodo I 975 -80 y en cuanto al sistema de formación del profesorado de audición y lenguaje, ambos organismos junto a los nuevos Institutos de Ciencias de la Educación y el Instituto Nacional de Pedagogía de Sordos participan en dos convocatorias.

Como conclusión de este periodo se puede decir que el Real Patronato de Educación Especial es el último patronato contemporáneo no constitucional o previo a los valores constitucionales de 1978 pero que contribuye a su definición especialmente en su última etapa, también es el último patronato en depender del Ministerio de Educación. Entre septiembre y diciembre de 1978 se transforma en el Real Patronato de Educación y Atención a Deficientes, después en el de Prevención y Atención a Personas con Minusvalía y por último en el Real Patronato sobre Discapacidad, que es el único en nuestra historia creado por una ley; aunque sea de medidas fiscales (Ley I $4 / 2000$, de 29 de diciembre) y en consecuencia objeto de debate parlamentario.

\section{Conclusiones generales}

Con la intención de completar las conclusiones presentadas en las etapas históricas se plantean otras más genéricas de evidente interés:

- $\quad$ Primera. Las políticas educativas de los gobiernos del siglo XX en España, hasta la década de los años 80, situaron la gestión y dirección de las enseñanzas de sordomudos o sordos en órganos externos, creados ex profeso con competencias especializadas y comprensivas de la totalidad de las necesidades de estas personas y en cuya estructura se admitía la presencia de profesionales de los sectores implicados y de la sociedad, bajo el control del ministerio correspondiente de Instrucción pública o de Educación y finalmente de ministerios de otras naturalezas.

- $\quad$ Segunda. La incidencia de los patronatos en la educación de las personas sordas se puede fijar en dos dimensiones significativas: A) La administración educativa, tanto en el periodo estudiado de los patronatos como en épocas anteriores (siglo XIX) siempre fue receptiva a su modo y compasiva con los sordomudos y su causa educativa, lo que llevó durante todo el siglo XIX y una buena parte del XX a confundir por la propia administración la acción benéfica o caritativa con la educadora. B) La administración educativa central, tanto en el periodo de los patronatos como en el siglo XIX, en el desarrollo de las políticas educativas siempre fue especialmente interventora en la imposición y definición de métodos y enfoques educativos para la enseñanza del sordomudo, siendo mayormente en el tiempo el de naturaleza oralista, instrumentándose por medio de políticas de formación del profesorado, selección del personal (oposiciones y contrataciones) y una política curricular que establecía los objetivos de oralización e integración del sordomudo en la sociedad.

- $\quad$ No será hasta los primeros años $90 \mathrm{del}$ siglo XX, y representado en el Real Decreto 696/I995, de ordenación de la educación de los alumnos con necesidades educativas especiales. BOE de I 3 de mayo de I 995 , cuando las políticas del gobierno provoquen un cambio en el marco conceptual de las enseñanzas de sordos al contemplarse la posibilidad de incorporar la lengua de signos en los centros educativos, abriéndose 
el camino para una oferta educativa que contase en los currículos con este código y con profesionales sordos e intérpretes de lenguas de signos. Esta vía será paralela al tradicional y mayoritario modelo de oralización del alumnado sordo.
Se aporta mediante un cuadro una información gráfica que facilite la comprensión de la evolución o transformación de los distintos patronatos (I9IO-I978).

\section{Cuadro 1. Evolución o transformación de los distintos patronatos (1910-1978)}

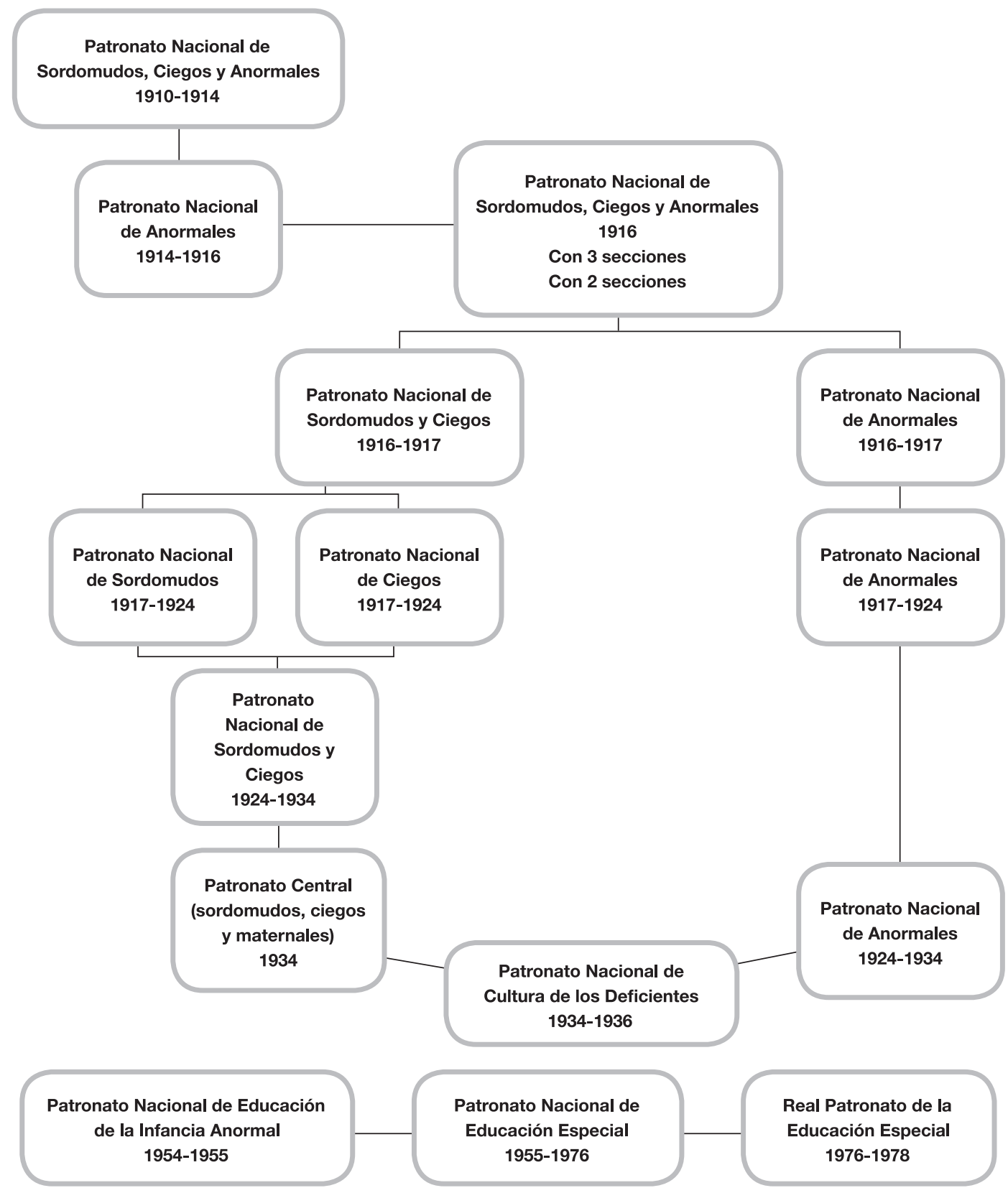


Referencias bibliográficas

Artola, M. (I975): Partidos y Programas politicos I808-I936, Madrid: Aguilar.

Canales, A. F. (20I3): "La modernización del sistema educativo español, I 898-1936". Revista de Pedagogía Bordón, 65 (4), I I I-I I 2.

Carr, R. (2000): España I 808-1975, Barcelona: Ariel Historia.

Committee of Inquiry into education of handicapped children and young. Warnock report (1978): Special Educational Needs. People, London: HMSO. Great Britain. Parliament. House of Commons.

Del Pozo, A. ( I980): "La educación de deficientes mentales en España: Los cincuenta primeros años de su desarrollo (I875-I925)”. Revista Española de Pedagogía, I48.

España. Real Decreto de 22 de enero de I9 Io estableciendo en este Ministerio un Patronato Nacional de sordomudo, ciegos y anormales. Gaceta de 24 de enero de I9ro. Colección Legislativa de España, Tomo XXXVII. Volumen $\mathrm{I}^{\circ}$, Madrid: Imprenta de la Revista de Legislación.

España. Real Orden de 20 de abril de I9ıo por la que se declara constituido provisionalmente el Patronato Nacional de Sordomudos, Ciegos y Anormales. Gaceta de 20 de abril de I9ro.

España. Real Orden de 2 I de julio de I9 Io por la que se establece la constitución definitiva del Patronato Nacional de Sordomudos, Ciegos y Anormales y su división en tres secciones. Gaceta de 22 de julio de I9ro.

España. Real Decreto de 24 de abril de I9I4, reformando el Patronato Nacional de Sordomudos, Ciegos y Anormales, disponiendo que en lo sucesivo se denomine Patronato Nacional de Anormales, y que su objeto, composición, atribuciones y funcionamiento se rijan por las disposiciones que se publican. Colección Legislativa de España, Tomo CLE Volumen I ${ }^{\circ}$ de I9I4, Madrid: Imprenta de la Revista de Legislación.
España. Real Orden de 2 de marzo de I9I 5 por la que se aprueba el Reglamento del Patronato Nacional de Anormales. Gaceta de Madrid, núm. 72, de I3/03/I9I5, pp. 774 a 775 .

España. Real Decreto de ro de marzo de ı9ı6 restableciendo la organización del Patronato de Sordomudos, Ciegos y Anormales, creada por el de 22 de enero de I9Io. Gaceta de I 5 de marzo de r9i6. Colección Legislativa de España, Tomo LVI Volumen I $^{\circ}$ de I9I6, Madrid: Imprenta de la Revista de Legislación.

España. Real Decreto de 8 de agosto de I9I6 disponiendo que el Patronato del Instituto Nacional de Anormales y especial de Sordomudos y de Ciegos, se divida en dos secciones: una de Sordomudos y Ciegos y otra de Anormales. Gaceta de 9 de agosto de I9I6. Colección Legislativa de España, Tomo LVII Volumen $2^{\circ}$ de I9I6, Madrid: Imprenta de la Revista de Legislación.

España. Real Decreto de 22 de diciembre de I9I6 por el que se establece que las dos secciones del Patronato se constituyan en dos patronatos independientes. Gaceta de Madrid, núm. 358 , de 23 de diciembre de I9I6, página 703 .

España. Real Decreto de 24 de agosto de I9I7 reorganizando en tres Patronatos Nacionales, que se denominaran, respectivamente, de Sordomudos, de Ciegos y de Anormales mentales. Gaceta de 26 de agosto de I9I 7. Colección Legislativa de España, Tomo LIX Volumen $2^{\circ}$ de I9 17, Madrid: Imprenta Hijo de Reus.

España. Real Decreto de I 3 de septiembre de I924 declarando disueltos los Patronatos Nacionales de Sordomudos, de Ciegos y de Anormales y creándose los Patronatos Nacionales de Sordomudos y de Ciegos y de Anormales. Gaceta de I4 de septiembre de I924. Colección Legislativa de Instrucción Pública, Madrid: Imprenta "La Enseñanza".

España. Decreto de I 6 de febrero de I934, por el que se crea el Patronato Central, Gaceta de 
I8 de febrero de 1934. Biblioteca Nacional, Hemeroteca. Microfilmado.

España. Decreto de 3 de abril de I934 por el que se crea el Patronato Nacional de Cultura de los Deficientes. Gaceta de 6 de abril de I934. Biblioteca Nacional, Hemeroteca. Microfilmado.

España. Decreto de 6 de marzo de 1953 por el que se crea el Patronato Nacional de Educación de la Infancia Anormal. Boletín Oficial del Estado, 2I de marzo de I953, núm. 80, pp. I486 a I 487 .

España. Decreto de 9 de diciembre de 1955 por el que se reorganiza el Patronato Nacional de la Infancia Anormal, que se denominará "Patronato Nacional de Educación Especial" y se crean sus Secciones provinciales. Boletín Oficial del Estado, 2 de enero de 1956, núm. 2, pp. 28 a 30.

España. Ley I4/ı970, de 4 de agosto, General de Educación y Financiamiento de la Reforma Educativa, Boletín Oficial del Estado, 6 de agosto de I970, núm. I87, pp. I2525 a I2546.

España. Decreto I I 5 I/I975, de 23 de mayo, por el que se crea el Instituto Nacional de Educación Especial. Boletín Oficial del Estado, 3 de junio de I975, núm. I32, pp. II769 a II77I.

España. Real Decreto I023/1976, de 9 de abril, por el que se crea el Real Patronato de Educación Especial y se modifican determinados artículos del Decreto I I 5I/I975 de 23 de mayo. Boletín Oficial del Estado, Io de mayo de I976, núm. II2, pp. 9016 a 9017.

España. Real Decreto 2828/I978, de I de diciembre, por el que se regula el Real Patronato de Educación y Atención a Deficientes. Boletín Oficial del Estado, 7 de diciembre de I978, núm. 292, pp. 27684 a 27685 .

España. Ley I3/I982, de 7 de abril, de integración social de los minusválidos, Boletín Oficial del Estado, 30 de abril de I982, núm. I03, pp. IIIO6 a IIII2.

González, S. (I9I7): “El Sr. Borrell y los niños anormales". Revista España de 25 de enero de I9I7. Seudónimo del Dr. Lafora.
González, S. (I9I7): "Los escándalos de la enseñanza”. Revista España de 26 de abril de I9I7.

Granell, M. (1934): Historia de la Enseñanza del Colegio Nacional de Sordomudos, Madrid: Imprenta del Colegio Nacional de Sordomudos.

Lane, H. (1989): When the Mind Hears. A history of the deaf, New York: Random House

Ministerio de Educación y Ciencia (I969): La Educación en España. Bases para una política educativa, Madrid: MEC.

Ministerio de Educación y Ciencia (I98I): Estadística de la Educación Especial. Análisis cursos I979-80 y I980-8I, Madrid: MEC, Gabinete de Estadística.

Ministerio de Hacienda (I9I3, I9I7,I920 y I922): Presupuestos Generales del Estado para los años económico de I913, I9I7, I920-2Iy I922-23, Madrid: Imprenta de Sucesores de M. Minuesa.

Ministerio de Instrucción Pública y Bellas Artes (1908): Primera Asamblea Nacional para el mejoramiento de la suerte de los sordomudos $y$ de los ciegos. Comunicaciones. Actas. Exposición aneja, Madrid: Imprenta del Colegio Nacional de Sordomudos y de Ciegos.

Ministerio de Instrucción Pública y Bellas Artes (I908): Estadística escolar de España en I 908. Publicada por la Subsecretaria del Ministerio, Madrid: Imprenta de la Dirección General del Instituto Geográfico y Estadístico.

Molina, P. (I900): Instituciones Españolas de sordomudos y de ciegos. Consideraciones sobre lo que son y deberían ser estos centros, Madrid: Imprenta de Hernando.

Molina, P. (I903): Discurso leído el I 8 de octubre de 1903 en la solemnidad de premios a los alumnos de aquel establecimiento por el profesor D. Pedro Molina Martín, Madrid: Imprenta del Colegio Nacional de SordoMudos y de Ciegos.

Molina, S. y Gómez, A. (I992): Mitos e ideologías en la escolarización del niño deficiente mental. Cuándo y cómo surgieron en España las escuelas de educación especial, Zaragoza: Mira Editores. 
Navarro Morgati, M. L. (I9I7): "El Instituto Nacional de Sordomudos. Notas para su reorganización”. Boletín Escolar: $\mathrm{n}^{\mathrm{i}} \mathrm{\textrm {i }}$, pp. 287 y 288 . $\mathrm{N}^{\mathrm{o}}$ I 5 , pp. 3 I 2 y 3 I $3 . \mathrm{N}^{\circ}$ I6, pp. 337 y 338 y No I7, pp. 369 y 370 . Tomo I. Editorial Calleja.

Navarro Morgati, M. L. (I926: "Los métodos para la enseñanza del lenguaje de los sordomudos". Revista de Pedagogía, Año V, I926, 486-496.

Orellana, J. (I9I7): La enseñanza de la palabra a los sordomudos, Madrid: Librería de los sucesores de Hernando.

Pereira, F. (1904): “Necesidad y medios de establecer en España escuelas para anormales". La Escuela Moderna, no I6I, 479-506.

Polaino-Lorente, A. (I983): "Las cuatro últimas décadas de Educación Especial en España”. Revista Española de Pedagogía, n ${ }^{\circ}$ I60.
Puelles, M. (1986): Educación e ideología en España, Barcelona: Labor.

Real Patronato de Educación Especial (I978): Plan Nacional de Educación Especial, Madrid: Edición del Patronato.

Secretaria Ejecutiva del Real Patronato (200I): Memoria del Real Patronato (I976-200I), Madrid: Edición del Real Patronato sobre Discapacidad.

Urquijo, J. M. (2008): Gobiernos y ministros españoles en la edad contemporánea, Madrid: CSIC.

Yuste de Santos, J. (2003): Juan Luis Marroquín, la fuerza de la unidad, Madrid: Fundación CNSE. 


\section{TRIBUNAS}

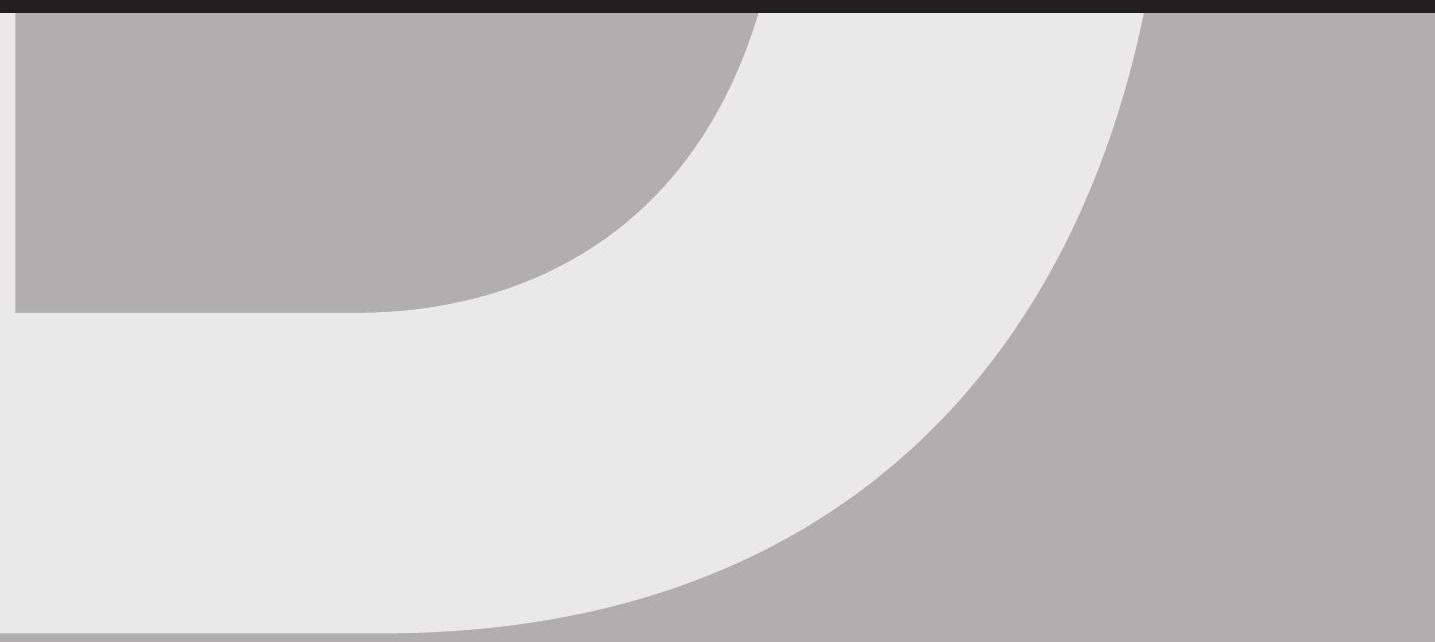





\section{Recomendaciones CODEPEH 2014}

\section{CODEPEH Recommendations}

\section{Palabras clave}

Hipoacusia (congénita, diferida), audición, cribado, infancia, audiología infantil, audioprótesis, interdisciplinariedad, familia.

\section{Key words}

Hearing loss (congenital, late-onset), hearing, screening, childhood, child audiology, hearing aids, interdisciplinarity, family.

\section{INTRODUCCIÓN}

La literatura científica más reciente señala el diagnóstico precoz de la sordera como el elemento fundamental para definir el pronóstico educativo y de inclusión del niño sordo, ya que permite aprovechar el periodo crítico de su desarrollo, que ocupa los tres o cuatro primeros años de vida. En esta edad es cuando la plasticidad cerebral es mayor y tiene lugar la adquisición de determinadas habilidades cognitivas y lingüísticas, difícilmente recuperables si se pierde la oportunidad de actuar en este periodo.

La sordera reúne todos los requisitos mínimos de las patologías que son susceptibles de cribado a través de programas de detección precoz y, además, está demostrado y reconocido que se pueden instaurar de forma precoz tratamientos capaces de evitar las consecuencias de la sordera $\mathrm{o}$, al menos, paliarlas de forma significativa (Yoshinaga-Itano, Sedey, Coulter y Mehl, I998) (YoshinagaItano, Coulter y Thomson, 2000, 200I).

Nota del editor: Este artículo ha sido publicado en Núñez, F. et al. (20I4): "Recomendaciones CODEPEH 20I4", Revista FIAPAS, octubre-diciembre 20I4, nº I 5 I, Separata.

\section{Faustino Núñez Batalla \\ $<$ fnunezb@uniovi.es>}

Presidente de la CODEPEH

\section{Carmen Jáudenes}

Casaubón

<direccion@fiapas.es>

Directora de FIAPAS

Jose Miguel Sequí Canet

Hospital de Gandía-Valencia

\section{Ana Vivanco Allende}

Hospital Universitario Central de Asturias-Oviedo

Jose Zubicaray Ugarteche

Complejo Hospitalario de NavarraPamplona

Para citar:

Núñez, F. et al. (20I 5):

"Recomendaciones CODEPEH 20I4", Revista Española de Discapacidad, 3 (I): I63-I 86 .

Doi: <http://dx.doi.org/IO.5569/23405I04.03.01.09> 


\section{Periodo crítico de desarrollo en el niño}

En el caso de los niños sordos es imprescindible aprovechar el periodo crítico de desarrollo dado que es el momento en que se sientan las bases del desarrollo comunicativo y de la adquisición del lenguaje oral, así como de la maduración de la percepción auditiva y de todas las capacidades y habilidades que de ella se derivan, incidiendo sobre los procesos de maduración neurológica.

Existe una creciente evidencia científica que demuestra que cuando la identificación e intervención se lleva a cabo no más tarde de los seis meses de edad, el niño conseguirá mejores resultados (entre 20 y 40 puntos percentiles) en su capacidad de lenguaje y comunicación: vocabulario, articulación e inteligibilidad del habla, ajuste social y comportamiento (Yoshinaga-Itano, I 995) (Yoshinaga-Itano, 2004) (Yoshinaga-Itano, Sedey, Coulter y Mehl, I998).

Por tanto, se trata de un plazo de tiempo breve e irrecuperable, en el que es necesario disponer de la información auditiva para el desarrollo del cerebro y para adquirir el lenguaje oral de forma global y automática.

Sólo así es posible que los niños y niñas sordos lleguen a interiorizar de forma natural y precoz, en el momento evolutivo que corresponde, los patrones fonológicos, los elementos lingüísticos y la estructura de la lengua oral, compartiendo con sus padres interacciones comunicativas normalizadas y espontáneas, a través de un mismo código, sin restricciones de contenido o forma. Y, en consecuencia, se evitará que la falta de audición llegue a tener un efecto permanente sobre el desarrollo del niño y, más concretamente, sobre el desarrollo del lenguaje oral y de las habilidades de aprendizaje y de comunicación que dependen de él. (Conrad, I979) (Harris y Beech, I995) (Silvestre, I998) (Torres, I998) (Alegría, I999) (Silvestre y Ramspott, 2002) (Torres y Santana, 2004) (Villalba, Ferrer y Asensi, 2005) (Torres, Moreno-Torres y Santana, 2006) (Jáudenes et al., 2007).
En base a lo descrito se justifican las diferencias altamente significativas apreciadas entre las personas sordas estimuladas tempranamente y las que han recibido esta atención específica de forma más tardía y/o inadecuada (Trinidad y Jáudenes, 20II).

Es importante insistir en la trascendencia de llevar a cabo un abordaje global, integral y coordinado, con un protocolo de actuación definido en relación con el niño sordo y con su familia, teniendo en cuenta, más allá de los aspectos clínicos y audioprotésicos ligados a la audición, todas las áreas de su desarrollo (Joint Committee on Infant Hearing, 2013).

La experiencia vivida por miles de familias en nuestro país pone de relieve que el momento del diagnóstico y la actuación inmediata en relación con la adaptación protésica y el inicio de la rehabilitación logopédica son cruciales en la vida de la persona sorda. Hoy podemos afirmar que las implicaciones de la sordera se han modificado sustancialmente gracias a la atención temprana y a la avanzada tecnología protésica, normalizando la situación educativa de los niños y niñas con sordera, su desarrollo emocional, así como las vivencias y conductas familiares (Jáudenes, 2006) (Silvestre y FIAPAS, 2008).

\section{Recomendaciones de la CODEPEH}

El Documento de Recomendaciones de la CODEPEH para 20 Io recordaba que el objetivo final de todo cribado y del tratamiento temprano de la hipoacusia congénita es la optimización de la comunicación y del desarrollo social, académico y profesional de cada niño y niña con pérdida auditiva permanente, así como facilitar el acceso precoz y natural al lenguaje oral a través de la audición, aprovechando la plasticidad cerebral de los primeros años de vida y estimulando el desarrollo comunicativo y del lenguaje del niño.

Asimismo, la CODEPEH, de acuerdo con sus recomendaciones previas, quiere insistir en la necesidad de un seguimiento continuado de la salud auditiva de la población infantil. 
A pesar de que los resultados avalan el cribado neonatal universal de la hipoacusia, dado que permite el inicio precoz del tratamiento, los programas de cribado neonatal tienen su llamado "talón de Aquiles" en la tasa de abandonos en el seguimiento de los niños que presentan resultados alterados en las pruebas realizadas al nacer. De ahí la actual discusión acerca de la necesidad de realizar un cribado a ciertas edades, que permita repescar estos casos puesto que, además, algunos trastornos auditivos en la infancia no son detectables en el cribado neonatal por no estar presentes todavía, como las hipoacusias de aparición tardía o las adquiridas, así como otras hipoacusias que, aunque presentes congénitamente, no son lo suficientemente graves como para que puedan ser detectadas en ese momento (Hyde, 2005) (Georgalas et al., 2008) (Lü et al., 20I I).

Por otra parte, existen deficiencias en la planificación, además de dificultades organizativas y de disposición de recursos en relación con estos programas de cribado, que impiden garantizar la confirmación diagnóstica y el acceso a una intervención temprana de calidad.

Estos hechos no afectan a la justificación intrínseca del cribado universal neonatal de la hipoacusia. Al contrario, lo que implican es que se tienen que llevar a cabo acciones adicionales y diseñar programas más allá del cribado neonatal para asegurar que todos los niños con una hipoacusia significativa sean detectados pronto. Por ello, muchos programas incluyen algún tipo de re-cribado dirigido a ciertos niños que presentan factores de riesgo de hipoacusia de aparición tardía o progresiva. Incluso se deberían plantear programas de cribado preescolar y escolar que ya han demostrado su utilidad (Georgalas et al., 2008), (Lü et al., 20I I).

Ahora bien, la identificación temprana de estos trastornos diferidos requiere de una especial atención y conocimientos en el estamento sanitario, así como de información y sensibilización entre los educadores, que es preciso desarrollar a través de programas de educación y estrategias de información.
Con este propósito, esta Comisión considera oportuno establecer las siguientes recomendaciones dirigidas a todos los profesionales que atienden a los niños durante su infancia.

\section{Detección precoz de la hipoacusia diferida}

\subsection{Epidemiología}

Los trastornos auditivos suponen un problema de salud muy frecuente en la población infantil. Aproximadamente tres de cada r.oo० niños nacen con pérdidas auditivas severas y profundas bilaterales. La incidencia de pérdidas moderadas y leves es mucho mayor (uno de cada Ioo). A esto se añaden las pérdidas adquiridas en el período preverbal, por lo que la prevalencia de trastornos auditivos resulta aún más elevada.

La discapacidad auditiva puede ser una alteración oculta o invisible a ojos de la mayoría, que tampoco es sencillo detectar por métodos clínicos ordinarios. Sin embargo, genera unas consecuencias que pueden llegar a ser muy graves.

Casi la mitad de todos los bebés que presentan una pérdida auditiva no tienen ninguno de los factores de riesgo conocidos para esta alteración. Este dato fundamenta el cribado universal. Cuando se estudian poblaciones seleccionadas según determinados factores clínicos de alto riesgo de daño para la audición, la incidencia de trastornos auditivos se incrementa entre Io y I4 veces (Mauk et al., I99I), siendo importante un seguimiento particular de estos pacientes. Por otra parte, no hay que olvidar que más del $95 \%$ de los padres de niños con deficiencias auditivas son normoyentes (Oysu et al., 2002) (Mitchell y Karmchmer, 2002).

La amplia implantación de los programas de cribado neonatal de la hipoacusia puede llevar a pensar que, descartada en ese momento, esta patología ya no puede afectar al niño a lo largo 
de su desarrollo. Ésta es una falsa y peligrosa creencia que puede perjudicar seriamente el futuro de esos niños puesto que factores postnatales no infrecuentes pueden originar una pérdida auditiva que comprometa alcanzar los hitos de desarrollo adecuados.

Varios estudios (Lü et al., 20I I) (Chen et al., 20I3) demuestran que hasta un $0,75^{-}-0,77$ por mil de niños preescolares presentan pérdida auditiva permanente a pesar de haber superado el despistaje neonatal. Según Watkin (Watkin y Baldwin, 20I I) (Watkin et al., 20I2) la prevalencia podría pasar del 2,52 por mil al nacer (cualquier tipo y grado de hipoacusia) al 3,64 por mil en la etapa de la educación primaria.

En amplias cohortes de niños se ha visto que, aún en los casos con altas sensibilidades en las pruebas neonatales, estas solo identifican el 56-59\% de niños en edad escolar con sordera. Viéndolo de otra forma, hasta uno de cada Io niños con hipoacusia congénita requerirá detección por revisiones postnatales a pesar de tener protocolos de cribado bien establecidos. A estos niños se añaden un $0,25^{-0,56}$ por mil que adquieren o presentan la hipoacusia en periodo postnatal y que también necesitan esas revisiones para su diagnóstico.

Por tanto, se piensa que la prevalencia de hipoacusia infantil en la etapa escolar aproximadamente duplica la esperada en la etapa neonatal, aunque otros estudios elevan esa cifra a 5 veces más (Tokgöz-Y1lmaz et al., 2013), habiendo autores que señalan que la prevalencia global de una hipoacusia de aparición tardía es del Iо \% sobre todas las hipoacusias de la infancia, pero aún podría ser mayor, llegando al $20 \%$ (Benito Orejas, 20I3) (Georgalas et al., 2008).

Todo ello sugiere la necesidad de protocolos diagnósticos que permitan identificar los casos de sordera postneonatal.

\subsection{Etiología}

Gran parte de las sorderas de inicio tardío en la infancia parecen ser debidas a defectos genéticos. Por ello, la tendencia diagnóstica actual debería ir encaminada hacia la realización de estudios genéticos con secuenciación de última generación que permite el estudio simultáneo de muchos genes involucrados en la sordera (en el momento actual hay más de I 50 loci y 64 genes) (Martins et al., 20I3).

Por tanto, se abre la puerta a la terapia génica en los pacientes con alguna mutación relacionada con sordera, lo que puede cambiar totalmente el panorama actual (Chien et al., 20I4).

En el caso de que la genética no justifique la patología auditiva habría que pensar en otras causas como infección congénita por citomegalovirus (CMV) o en trastornos del acueducto del vestíbulo, lo que obliga al estudio de la infección por CMV y a la realización de estudios de imagen complementarios (Alford et al., 20I4).

En cualquier caso hay que recordar que no sólo existen estas causas, sino que el espectro de factores de riesgo es mucho más amplio.

Se debería estar especialmente atento a niños con enfermedades o situaciones de riesgo de pérdida auditiva de posible inicio en la infancia, siguiendo esta clasificación de los tipos y causas de hipoacusia tardía (Smith y Gooi, 20I4):

- Hipoacusia transmisiva (tabla I)

- Hipoacusia neurosensorial (tabla 2)

- Hipoacusia central (tabla 3)

Entre todas estas causas destacan, por su frecuencia e importancia, las siguientes:

- Citomegalovirus: la infección por CMV congénita es la más común con una prevalencia de $0,5 \%$ en recién nacidos, de los cuales más del $94 \%$ son asintomáticos y, de éstos, un $22 \%$ desarrolla hipoacusia de forma neonatal o diferida. Alrededor de un $6 \%$ son sintomáticos y, de éstos, el $33-60 \%$ desarrolla hipoacusia. La pérdida auditiva es progresiva en el I I- $50 \%$ de los casos y de inicio tardío en el 5-1 $8 \%$ (Foulon et ál., 2008). 
Es importante su diagnóstico precoz para valorar el tratamiento farmacológico con ganciclovir o valganciclovir, dado que varios estudios han demostrado su utilidad para mejorar o impedir la progresión de la sordera en estos niños.

- Traumatismo craneoencefálico grave: las fracturas del temporal son un caso de pérdida auditiva frecuente. Las longitudinales ( $80 \%$ de frecuencia) producen pérdida auditiva conductiva por sangre en oído medio o también por perforación timpánica. Las transversas se asocian más a pérdida neurosensorial pero pueden producir lesiones en la cadena osicular. Por otro lado, traumatismos sin fractura, si son de envergadura suficiente, pueden conllevar una pérdida auditiva.

- Estancia en UCIN mayor de 5 días: todos los niños ingresados en Unidades de Cuidados Intensivos Neonatales más de 5 días, se deben considerar con riesgo elevado de hipoacusia, puesto que muchas de las patologías asociadas afectan a este grupo de pacientes (prematuridad, hiperbilirrubinemia, circulación con membrana extracorpórea-ECMO-, hipoxia perinatal, hemorragia intraventricular grados 3 y 4 , infecciones).

- Otitis serosa: la persistencia del fluido en las otitis secretoras es muy frecuente y genera pérdidas auditivas que alteran el desarrollo. Hasta un Io \% de niños presentan otitis secretora a los 3 meses de una otitis aguda. La pérdida media es de alrededor de $25 \mathrm{~dB}$.

Neuropatías auditivas genéticas: que pueden afectar a la audición como única manifestación clínica.

\subsection{RECOMENDACIONES CODEPEH en relación con la detección precoz de la hipoacusia diferida}

- Es necesario llevar a cabo una vigilancia posterior al cribado neonatal en el ámbito de la Atención Primaria.
- En cada visita periódica del Programa del "Niño Sano" se deben evaluar: las habilidades auditivas, el estatus del oído medio y los hitos del desarrollo. Es recomendable que se utilice el algoritmo propuesto por la CODEPEH para aplicarlo a los 6, I 2, I 8, 24 y 48 meses de edad (Figura I).

Si un niño no pasa la evaluación debe ser inmediatamente derivado a un ORL o a una Unidad de Hipoacusia Infantil, con el fin de ser estudiado.

- $\quad$ Es necesario un cuidadoso examen del estado del oído medio a aquellos niños en los que se compruebe una otitis serosa y, si ésta persiste durante al menos 3 meses seguidos, habrán de ser remitidos para una evaluación otológica.

- Los niños con anomalías del desarrollo y del comportamiento deben ser evaluados en la esfera auditiva al menos una vez por el ORL, prestando especial atención en este caso a las otitis serosas recidivantes o persistentes que pueden empeorar su pronóstico.

- Todos los niños con un indicador de riesgo de hipoacusia (Tabla 4 ), independientemente de los hallazgos en su seguimiento, deben ser remitidos para una evaluación audiológica, al menos una vez entre los 24 y 30 meses de edad. Aquellos niños con indicadores de riesgo muy asociados con la hipoacusia de desarrollo diferido, tales como la oxigenación extracorpórea o una infección por citomegalovirus, deben ser sometidos a evaluaciones audiológicas más frecuentes. La confirmación de una hipoacusia en un niño se considera factor de alto riesgo respecto de sus hermanos, que deben ser sometidos en este caso a una evaluación audiológica.

- Todos los niños en cuya familia exista una preocupación significativa acerca de su audición o su comunicación, con independencia de su edad, deben ser 
remitidos sin demora al ORL o a una Unidad de Hipoacusia Infantil para las pertinentes valoraciones audiológicas y del lenguaje. Habrá que proceder de igual manera si la sospecha parte del educador.

\section{PUNTOS CLAVE}

- Sensibilizar, informar y formar a los profesionales que atienden al niño desde el nacimiento y durante la primera infancia, tanto del ámbito sanitario como del educativo

- Incluir las valoraciones del desarrollo auditivo del niño en cada visita a la consulta de atención primaria, independientemente de que presenten o no factores de riesgo

- Realizar unas pruebas de cribado más exhaustivas en las cinco revisiones del "Niño Sano" ya establecidas, a los 6, I 2, I 8, 24 meses y a los 4 años

- Hacer un examen físico cuidadoso del oído y valorar la existencia de anomalías que se asocian a hipoacusia

- Atender a las observaciones hechas por la familia del niño y sus educadores, trasladar la información suficiente y las orientaciones necesarias de forma clara y concreta, involucrándoles en el proceso

\section{Valoración audiológica y adaptación protésica infantil}

El proceso de diagnóstico audiológico, así como el de habilitación auditiva y del lenguaje, tienen la misma prioridad y deben llevarse a cabo en los primeros meses de vida para maximizar el desarrollo óptimo del niño.
Ambos procesos comienzan de forma secuencial, pero se desarrollan simultáneamente.

\subsection{Valoración audiológica}

Conocer de forma fiable la pérdida auditiva del niño es el objetivo de la valoración audiológica para proceder a la adaptación audioprotésica que, no obstante, puede comenzar con estimaciones fiables de un número suficiente de frecuencias y, después, ir ajustándose en la medida en que se va disponiendo de información más precisa.

Los métodos empleados para la valoración varían en función de la edad y de la adquisición por parte del niño de diferentes habilidades y capacidades para la participación en la evaluación. De hecho, los niños requieren sucesivas visitas antes de que se pueda definir la configuración exacta, el grado y la naturaleza de la pérdida auditiva.

Los protocolos de valoración cambian con la edad. A los 6 meses es la edad en que se pasa de las pruebas electrofisiológicas, como procedimiento primario de estimación de umbrales, a métodos conductuales, que aportan resultados fiables si se siguen correctamente los procedimientos durante las sesiones de evaluación.

En el caso de que se trate de niños remitidos desde los programas de cribado neonatal de la hipoacusia, se debe proceder a una evaluación audiológica tras dos cribados fallidos. Existe una excepción a esta norma cuando los niños proceden de cuidados intensivos neonatales, en esta circunstancia, hay que realizar la prueba diagnóstica si superan los cinco días de estancia en UCIN.

A continuación, se describen brevemente las pruebas electrofisiológicas y las conductuales apropiadas para el niño muy pequeño.

- Potenciales evocados auditivos de tronco cerebral (PEATC)

Cuando se lleva a cabo una evaluación audiológica, los PEATC suelen ser la 
primera prueba que se aplica, si bien no se deben hacer de forma aislada respecto de otros test.

Esto se debe a que las respuestas a los clicks correlacionan mejor con los hallazgos audiométricos en el rango de las frecuencias altas, entre I000 y 4000 $\mathrm{Hz}$ (Coats y Martin, I977) (Gorga et al., I985) (Stapells, I989). Y, dado que los clicks contienen energía acústica de amplio rango frecuencial, las respuestas obtenidas no pueden considerarse referidas a ninguna frecuencia específica, por lo que las respuestas obtenidas por estos estímulos no pueden detectar trastornos en determinadas frecuencias. De ahí que el uso aislado de PEATC pueda, incluso, llevar a subestimar o dejar sin detectar una pérdida de audición en una determinada frecuencia o banda frecuencial, dependiendo del grado y configuración de la hipoacusia (Balfour et al., I998) (Stapells y Oates, I997).

No obstante, la predicción del audiograma mediante los potenciales evocados auditivos es posible, siempre que se obtengan dentro de las condiciones y parámetros adecuados.

La correspondencia entre los umbrales conductuales y los obtenidos mediante potenciales es buena, existiendo una diferencia en torno a los Io ó $20 \mathrm{~dB}$ (Balfour et al., I998) (Fjeredal y Lazuli, r989) (Stapells et al., I994).

Cierto es, por tanto, que los PEATC aislados no dan la suficiente información, pero son esenciales para tomar las decisiones adecuadas.

El momento óptimo para realizar esta prueba es mientras el niño duerme. Debe priorizarse la secuencia de la prueba en las distintas frecuencias debido a que el sueño puede interrumpirse inopinadamente o a que la anestesia no puede prolongarse.

Otros elementos necesarios dentro de la evaluación del niño pequeño son: la elaboración de una historia clínica, la timpanometría y las otoemisiones acústicas (OEA).

- Potenciales evocados auditivos de estado estable (PEAEE)

Esta prueba tiene la ventaja de predecir los umbrales específicos para distintas frecuencias en los pacientes cuando no se pueden obtener de forma válida y fiable, como en el caso de niños muy pequeños o en aquellos que presentan retraso en el desarrollo (Cone-Wesson et al., 2002) (Perez-Abalo et al., 200I) (Rance et al., 2005).

La ventaja de esta prueba es que es objetiva, no solo porque no precisa de la colaboración del paciente, sino también porque la presencia o ausencia de la respuesta se basa en un análisis estadístico y no en métodos de valoración visual como los PEATC. Los PEAEE con frecuencia se usan como complemento de los PEATC, y no como único test, para estimar los umbrales dado que aún no se dispone de tanta información y experiencia respecto de los mismos como en el caso de los PEATC.

Otra ventaja de los PEAEE es que permiten examinar los dos oídos simultáneamente, lo que significa un posible ahorro de tiempo respecto a los PEATC.

La generación de las respuestas de los PEAEE, se piensa que ocurre en el troncoencéfalo (Herdman et al., 2002). Se utilizan estímulos tonales modulados en amplitud y frecuencia para evocar respuestas que estiman con cierta exactitud los niveles auditivos de la vía aérea específicos para las distintas frecuencias. Para aplicaciones pediátricas, la modulación de los estímulos ocurre a una frecuencia de 80 a $100 \mathrm{~Hz}$, dado que los PEAEE con modulación de $80 \mathrm{~Hz}$ pueden ser obtenidos en niños pequeños que se encuentran dormidos (Cohen et al., I99I). 
La predicción de los umbrales utilizando los PEAEE se ha comprobado que es bastante fiable para estimar los resultados de la audiometría conductual (Aoyagi et al., I999), (Swanepoel et al., 2004). Los umbrales en adultos con audición normal o con hipoacusia se estiman con esta prueba con un error de entre Io y I $5 \mathrm{~dB}$ (Dimitrijevic et al., 2002). En niños existe menos información pero se conoce que la prueba, aunque sea capaz de detectar una pérdida auditiva en el rango severo o profundo, en general, solamente obtiene una predicción de umbrales fiable en el nivel moderado de la hipoacusia y en la audición normal (Pérez-Abalo et al., 200I).

- Timpanometría

La utilización de sondas de alta frecuencia ( $1000 \mathrm{~Hz}$ ) ofrecen resultados más fiables sobre la función del oído medio del niño menor de 4 meses (Margolis et al., 2003).

El reflejo estapedial puede ayudar mucho en la valoración audiológica del niño ya que, si está presente, es una orientación más hacia una caja timpánica que funciona con normalidad.

\section{- Audiometría conductual}

La audiometría por observación de la conducta da información acerca del tipo de respuestas que el niño produce y de su desarrollo auditivo.

Para los niños mayores de 5 o 6 meses la técnica preferida es la audiometría por refuerzo visual, que es una técnica de condicionamiento operante que permite que la respuesta por giro de la cabeza, que con frecuencia ocurre espontáneamente ante un sonido, se mantenga mediante el uso de reforzamiento visual.

Para maximizar la cantidad de información obtenida durante una visita (no todos los niños completarán la prueba de forma bilateral en una sola sesión), el orden de la presentación de los estímulos debe priorizarse con el fin de obtener información acerca del grado y configuración de la hipoacusia. Para el condicionamiento, un buen punto de partida es utilizar un estímulo verbal puesto que los niños lo encuentran más interesante que uno tonal y responden naturalmente con un giro de la cabeza, que puede ser reforzado.

La presentación de las frecuencias, alternando graves y agudas, permitirá construir un audiograma que contiene parte, si no toda, la información necesaria para predecir el umbral de la pérdida auditiva. En el caso de una hipoacusia severa-profunda, si existe falta de respuestas en las frecuencias altas, el clínico debería pasar a estimular los $500 \mathrm{~Hz}$ o frecuencias más bajas.

Es conveniente hacer pruebas de control para reducir la subjetividad y asegurar unos resultados válidos. Estos controles, en los que no se presenta estímulo auditivo, sirven para observar el giro de la cabeza al azar, cuya cuantificación permite determinar el número y porcentaje de falsos positivos en una sesión, que no debe superar el $30 \%$, pues siendo así indicaría que los datos de dicha sesión no son fiables.

Si somos capaces de condicionar al niño, su nivel madurativo y de desarrollo no influirá sobre los umbrales hallados. De este modo, los umbrales obtenidos usando la audiometría por refuerzo visual no diferirán sustancialmente de lo obtenido en adultos. Este tipo de audiometría no solo permite la valoración de los umbrales, sino que también informa de la integridad de las vías auditivas y de la habilidad de los niños para detectar y discriminar una estimulación auditiva.

Audiometría lúdica es un término utilizado para describir una técnica en la que se emplea el juego para obtener los umbrales. 
Puede usarse a partir de los 24 meses de edad pero está más indicada a los dos años y medio o a los tres. Esta audiometría involucra el condicionamiento del niño para responder a sonidos utilizando una actividad atractiva para él. El condicionamiento se consigue tras mostrar al niño cuatro o cinco respuestas guiadas o demostraciones. A través de esta técnica se puede obtener información sobre los umbrales en las distintas frecuencias de cada oído mediante estimulación aérea y ósea.

En el caso de niños muy pequeños, o que no consigan concentrarse en la tarea, la secuencia de frecuencias debería perseguir la obtención de la información precisa para deducir la configuración y el grado de la pérdida. Puede ser preferible conseguir una información frecuencial parcial de ambos oídos a llegar a obtenerla completa solamente de uno de ellos.

La audiometría convencional puede ser usada cuando el niño alcanza los 5 o 6 años de edad. La respuesta es típicamente la misma que la utilizada para los adultos, enseñando al niño a levantar la mano en cuanto oye el estímulo. Como en todas las técnicas conductuales, la edad cronológica no es determinante en la prueba, sino que lo es el nivel de desarrollo del niño.

En resumen, los hallazgos audiológicos conductuales pueden ofrecer unos resultados fiables, pero se debe tener cuidado en eliminar los falsos positivos utilizando pruebas control para observar el comportamiento del niño cuando no se le presenta estímulo. También se debe prestar atención a las pistas que puedan ofrecer al niño los adultos presentes en la prueba, además de evitar patrones de presentación con pistas o la subjetividad por parte del examinador.

\subsection{Adaptación protésica infantil}

Está demostrado que toda hipoacusia provoca modificaciones en el sistema auditivo central y que una adaptación protésica temprana hará que reviertan dichas lesiones. Este fenómeno es conocido como "aclimatación auditiva" (Arlinger et al., I996).

Durante años ha existido controversia en cuanto al tipo de adaptación, discutiéndose si debería ser monoaural o biaural. Aún mayores discrepancias había en la indicación de la adaptación en las hipoacusias unilaterales. Hoy día está ampliamente documentada la necesidad de la adaptación bilateral, recomendándose también la amplificación auditiva en las hipoacusias monoaurales, independientemente de su nivel, aunque en las severas se deba individualizar dependiendo de cada situación (Gelfand SA. et al.,I987).

Las prótesis auditivas pueden ser de conducción aérea u ósea, implantables (implantes de oído medio, implantes cocleares o de tronco cerebral) o externas (audífonos).

La decisión de proceder a una adaptación protésica debe estar basada en datos audiológicos, del desarrollo del lenguaje y del entorno familiar, escolar y social del niño.

Se hace hincapié en la necesidad de evaluar la audición funcional en los niños pequeños y no depender de los umbrales de la audición. Estos datos también pueden contribuir al proceso de toma de decisiones en la selección de un dispositivo para los niños con pérdida auditiva (Ben-Itzhak et al., 20I4).

Toda adaptación protésica en niños debe ir acompañada de un tratamiento logopédico adecuado y sostenido en el tiempo, así como de su inclusión educativa.

- Intervención interdisciplinar

El especialista en otorrinolaringología es el encargado de coordinar todas las actuaciones del numeroso equipo interdisciplinar que se precisa para el correcto diagnóstico y tratamiento de los niños con hipoacusia, y es el único que 
puede indicar el tratamiento audioprotésico o quirúrgico que precisen (Real Decreto 4I4/I996, de I de marzo, por el que se regula los productos sanitarios). Además es cada vez más necesario, por las características específicas de los niños, que este papel sea realizado por un Otorrinolaringólogo (ORL) que desarrolle su trabajo como ORL Infantil y con amplia formación en audiología.

Los establecimientos de audioprótesis son considerados como establecimientos sanitarios y, como tales, de cumplir con los requisitos (local, profesionales, recursos...) que exige la normativa que los regula y contar con material para hacer el diagnóstico audiométrico específico infantil, como una cabina insonorizada y juguetes calibrados. Entre sus funciones principales están: la interpretación de las prescripciones audioprotésicas, determinar las características anatomofisiológicas del oído, realizar audiometrías y todas las actuaciones necesarias para la adaptación, como la toma de la impresión de los moldes y el control y seguimiento de la adaptación protésica.

Los resultados y respuestas del niño percibidas durante el proceso de adaptación protésica se deben contrastar con la evaluación pedagógica y logopédica llevada a cabo por los logopedas y educadores del niño.

Fundamentalmente el programa de adaptación y seguimiento se desarrolla en tres ámbitos: médico (ORL Infantil), audioprotésico y logopédico.

El médico otorrinolaringólogo controlará la patología del oído medio, que es muy frecuente en los niños, para su rápida solución y evitar así la interferencia con la hipoacusia neurosensorial. Llevará a cabo un control evolutivo de la hipoacusia con sus pruebas pertinentes según la edad del niño y comprobará la calidad, efectividad y eficiencia de la adaptación protésica y su repercusión en la evolución del lenguaje e inclusión en el entorno.
El audioprotesista comprobará el correcto funcionamiento electroacústico de la prótesis, verificará el uso adecuado del audífono, comprobando la humedad, golpes, estado de la pila, etc. También valorará el correcto sellado del sistema audífono, molde, canal y sustituirá los elementos necesarios como codos, tubos y moldes. Por último, comprobará los parámetros establecidos con los objetivos y resultados obtenidos.

El logopeda será el encargado de realizar la (re)habilitación auditiva y del lenguaje. Colaborará, junto con el ORL Infantil y el audioprotesista, en la valoración de la pérdida auditiva y dará información para mejorar la adaptación.

Involucrar a los padres en el proceso del tratamiento de los niños con déficit auditivo resulta esencial, para ello se les debe facilitar información amplia, comprensible y veraz, que ajuste las expectativas sobre el pronóstico.

- Indicaciones para la adaptación audioprotésica en niños

Los niños tienen una serie de peculiaridades que hacen que la adaptación no sea fácil, siendo más complicada cuanto más pequeños sean.

Actualmente, con los programas de detección precoz de la hipoacusia, se llega a un diagnóstico certero de hipoacusia a edades muy tempranas por lo que el audioprotesista se enfrenta a unos conductos auditivos muy pequeños y a niños que no son capaces de indicar si perciben o no sonido, por lo que habrá que orientarse mediante la observación en sus reacciones y pruebas fisiológicas (Kerkhofs, 2013).

En una pérdida auditiva neurosensorial bilateral, con umbrales mayores a $25 \mathrm{~dB}$ HL, en el rango de frecuencias críticas para la discriminación del habla (ı000-4000 
$\mathrm{Hz}$ ), en todo caso se debería considerar proporcionar amplificación debido a las implicaciones que tiene para el desarrollo del lenguaje. De forma indiscutible se admite que está indicada cuando la pérdida supera los $35 \mathrm{~dB}$ HL (Tomblin et al., 20I4). Si el niño tiene pérdida con una caída brusca a partir de $2000 \mathrm{~Hz}$, o en una hipoacusia con audiograma en U, la amplificación debería valorarse individualmente según cada situación. En el caso de las perdidas profundas, se recomienda una adaptación durante al menos tres meses para, en caso de no presentar una respuesta adecuada, proceder a indicar un implante coclear.

La hipoacusia unilateral, aunque sea leve, produce problemas en la integración binaural del mensaje y en la discriminación en ambientes ruidosos, así como en la adecuada localización del sonido (Lieu et al., 2013). Actualmente está indicada la adaptación en estos casos ya que la amplificación en ese oído podría ser beneficiosa.

Se recomienda el uso de audífonos durante un período de prueba con un seguimiento durante los primeros años de vida (Briggs et al., 20I I) (Christensen et al., 20IO).

Se debería realizar una adaptación binaural siempre, salvo que se observase en el niño conductas que hicieran pensar que la adaptación en el peor oído produce un perjuicio en su rendimiento global.

- Cómo llevar a cabo la adaptación audioprotésica

Como ya se ha dicho, antes de proceder a la adaptación audioprotésica se debe hacer una serie de pruebas audiológicas objetivas por métodos fisiológicos y otras subjetivas adaptadas a la edad del paciente.

En niños mayores sería deseable intentar descubrir las zonas muertas de la cóclea por medio de pruebas como Psychophysical Tuning Curve (PTC) y Threshold Equalising Noise (TEN) (Moore et al., 2000).

Los tres pasos que deben ser implementados en la adaptación audioprotésica en la infancia son: selección, verificación y validación.

\section{a. Selección}

La respuesta a la adaptación protésica está condicionada por la patología auditiva, por el tipo de pérdida y por otras alteraciones neurológicas, y no tanto por la intensidad de ésta. La prótesis correctamente seleccionada es la que brinda la mejor amplificación teniendo en cuenta la audición residual del niño.

Hay que saber que la prótesis auditiva no va a suprimir la lesión del oído, solamente modifica el sonido para que pueda ser percibido y mejor aprovechado. El daño coclear implica no solo una pérdida de intensidad, sino fundamentalmente otras alteraciones que repercuten en la distorsión del sonido percibido.

Es importante individualizar cada caso ya que, entre otros motivos, puede haber niños en los que un mal rendimiento audioprotésico se pueda explicar por la presencia de una neuropatía auditiva o que presente lesiones centrales de las áreas de la audición.

Los audífonos deben tener una ganancia suficiente, una curva de respuesta adecuada para cualquier tipo de perdida audiométrica y un límite de salida máxima para evitar lesiones por exceso de volumen.

Hasta los IO-I 2 años de edad el audífono convencional debe ser retroauricular y debemos disponer de distintos tipos de moldes para conseguir una correcta adaptación del molde al conducto auditivo externo, sobre todo en lactantes.

En los problemas de oído medio como agenesias o lesiones supurativas crónicas 
suele ser necesaria la adaptación por vía ósea (Felton et al., 2014) (Fuchsmann et al., 2010).

En los lactantes, que suelen gatear, los micrófonos direccionales no son la mejor elección, ya que no estarán en la posición adecuada para recibir el sonido en muchos momentos del día, prefiriéndose los omnidireccionales.

El diseño de los moldes en los niños es también de gran importancia. Hay que ser muy cuidadoso ya que sus características físico-acústicas variarán según la pérdida auditiva, el volumen del conducto auditivo externo y la presión de salida del audífono. Por todo ello, deben de ser reemplazados cuando cambien estos parámetros. En los niños pequeños hay que valorar cambiarlos aproximadamente cada 4-6 meses y, a partir de los 5 años, una vez al año.

Para evitar extravíos es importante el uso de dispositivos para sujetar las prótesis auditivas dado el tamaño del pabellón y la gran movilidad del niño.

\section{b. Verificación}

El programa de adaptación a las prótesis normalmente se establece por el audioprotesista, no obstante debe estar consensuado con el especialista ORL, dado que el seguimiento concierne a ambos, así como contrastado con el logopeda. Las referencias básicas se encuentran en Northern y Downs (2002), quienes siguen el criterio de "menos tiempo de uso a más tiempo, de menos exposición al sonido a más exposición y de menos complejidad de los sonidos a más complejidad".

En la adaptación de los niños pequeños siempre hay que ser un poco conservador, ya que no tendremos en fases tempranas la información adecuada de los umbrales de disconfort del reclutamiento y otros factores, que se irán descubriendo según va creciendo el niño, lo cual obliga a ir adecuando la adaptación a todo ello de forma progresiva.
Los periodos de seguimiento deben ser:

- los primeros I 8 meses de vida, continuos a demanda de cada situación

- de los I 8 meses a los 3 años, cada 3 meses

- de los 3 a los 6 años, cada 6 meses

- mayores de 6 años con sorderas estables, cada año

\section{c. Validación}

La validación es el proceso continuo que nos indica los beneficios y limitaciones de la adaptación protésica concreta. El objetivo es que el audioprotesista se asegure de que el niño recibe la señal óptima, tanto de su propia emisión, como de las demás personas. Implica tanto la supervisión del audífono, como el comportamiento del niño durante su uso.

El audioprotesista y el logopeda pueden comparar los niveles del audífono en diferentes situaciones de audición. Con el empleo de los exámenes sonda-micrófono se obtiene información cuantitativa y objetiva del nivel percibido del habla por el dispositivo auditivo. También es posible comparar la audibilidad con y sin el audífono.

La valoración funcional ha de tener en cuenta la edad auditiva del niño, tomando como referencia para el cálculo de ésta no sólo los meses transcurridos desde la primera adaptación, sino también las horas de uso efectivo de las prótesis.

\subsection{Recomendaciones CODEPEH en relación con la valoración audiológica y la adaptación protésica}

- Los procesos de diagnóstico audiológico y habilitación auditiva tienen la misma prioridad y necesitan desarrollarse en los primeros meses de vida para maximizar el desarrollo óptimo del niño. Esos dos procesos comienzan de forma secuencial, pero se deben desarrollar simultáneamente. 
- Los periodos de seguimiento deben ser:

- los primeros I 8 meses de vida, continuos a demanda de cada situación

- de los I8 meses a los 3 años, cada 3 meses

- de los 3 a los 6 años, cada 6 meses

- mayores de 6 años con sorderas estables, cada año

- El médico especialista en ORL debe de ser el encargado de coordinar las actuaciones del equipo multidisciplinar implicado en la adaptación audioprotésica, junto con el audioprotesista y el logopeda, siendo el responsable de la indicación del tratamiento audioprotésico.

- Es necesario también la formación de grupos de trabajo, organizados según la estructura de cada comunidad autónoma, para el diagnóstico y el tratamiento integral de los niños con sordera.

- Involucrar a los padres en el proceso de tratamiento de los niños con déficit auditivo resulta esencial, para ello, en todo el proceso, se les debe dar una información amplia, comprensible y veraz, que ajuste las expectativas sobre el pronóstico.

- Complementar los resultados de los potenciales evocados auditivos de tronco cerebral (PEATC) con la realización de potenciales evocados de estado estable (PEAEE).

- Los resultados obtenidos en los potenciales evocados auditivos de tronco cerebral y los de estado estable han de ser completados y confirmados mediante audiometría conductual adecuada a la edad del niño.

- Para llevar a cabo una timpanometría en niños menores de 4 meses de edad, se recomienda la utilización de sondas de alta frecuencia $(\mathrm{I} 000 \mathrm{~Hz})$.

- La decisión de proceder a una adaptación protésica debe estar basada en datos audiológicos, del desarrollo del lenguaje y del entorno familiar, escolar y social del niño.

- Hasta los 10-12 años de edad el audífono convencional debe ser retroauricular. Se debe disponer de distintos tipos de moldes para conseguir una correcta adaptación del molde al conducto auditivo externo, sobre todo en lactantes.

- Las prótesis con micrófonos omnidireccionales, por estar siempre en la posición adecuada para recibir el sonido, son más adecuadas en el caso de los lactantes, que suelen gatear.

- Se debería realizar una adaptación binaural siempre, salvo que se observen en el niño conductas que hagan pensar que la adaptación en el peor oído produce un perjuicio en su rendimiento global.

- Individualizar cada caso ya que, entre otros motivos, puede haber niños en los que un mal rendimiento audioprotésico se pueda explicar por la presencia de una neuropatía auditiva o porque presenta lesiones centrales de las áreas de la audición.

\section{PUNTOS CLAVE}

- Antes de proceder a la adaptación audioprotésica, es necesario completar la información audiológica, no obstante puede comenzar la adaptación con estimaciones fiables en un número suficiente de frecuencias

- Los métodos empleados para la valoración audiológica varían en función de la edad y de la adquisición de diferentes habilidades y capacidades para la participación en la evaluación 
- La predicción de los umbrales utilizando los potenciales evocados auditivos de estado estable (PEAEE) se ha comprobado que es suficientemente fiable para estimar los resultados de la audiometría conductual

- La hipoacusia provoca modificaciones en el sistema auditivo central que pueden revertir si se lleva a cabo una adaptación protésica temprana (“aclimatación auditiva”)

- El diagnóstico y tratamiento de la hipoacusia en niños es multidisciplinar. Es indispensable la comunicación continuada y fluida entre el ORL Infantil, el audioprotesista, los logopedas, los educadores y otras personas involucradas supone la presencia de la sordera en uno de sus miembros

Todo ello es además plenamente coincidente con lo hallado en el Estudio sobre Necesidades, Demandas y Expectativas de las Familias de niños y jóvenes con discapacidad auditiva, menores de I 8 años, realizado entre 2004/05 (Jáudenes, 2006) y contrastado después en el Análisis Prospectivo de las Demandas de las Familias atendidas a través de la Red FIAPAS (Jáudenes y Ruíz, 20I I). En ambos trabajos quedó patente que las familias demandan:

- realización de pruebas diagnósticas al nacer

- existencia de equipos especializados: calidad de la atención prestada y de la formación de los profesionales

- acceso a información asequible y derivación a atención temprana logopedia y servicios de orientación a familias

- coordinación interdisciplinar en el seguimiento

- inversión en avances médicos y técnicos, en educación y en el apoyo a las familias

\subsection{Contexto y principios de actuación}

Los documentos más relevantes de las tres últimas décadas ponen de relieve la evolución desde un concepto de intervención centrado en el niño, a otro más amplio y global que concierne al niño, a su familia y a su entorno. Evolución acorde con el progreso actitudinal y social que se ha dado también entorno a la discapacidad en general (Agencia Europea para el Desarrollo de la Educación Especial, 2005) (CERMI, 2005).

En este escenario debemos introducir la Convención Internacional sobre Derechos de las Personas con Discapacidad (2006), normativa internacional vinculante y ratificada por España, plenamente vigente desde 2008 , que viene a subrayar todo lo que desde otro modelo, menos interactivo y menos social, ya anticipaba la legislación española aún de forma insuficiente.

La Atención Temprana, por tanto, se incardina y se ve afectada en mayor o menor medida por 
un amplio marco legislativo generado en España desde el inicio de la década de los ochenta, tanto en materia sanitaria como educativa y de servicios sociales. Pero la gestión de los derechos de las personas con discapacidad no está exenta de cierta complejidad ya que el diagnóstico, la atención temprana, las ayudas técnicas, etc. deben responder a una coordinación muy eficaz, muy eficiente y muy exquisita que empieza en el espacio sociosanitario, pero finalmente termina en el educativo (Jáudenes, 20I4).

\section{Definición, objetivos y principios de la Atención Temprana}

Tras casi quince años de la publicación del Libro Blanco de la Atención Temprana (GAT, 2000) sigue sin existir una norma básica estatal sobre esta materia, al mismo tiempo que el desarrollo normativo de las distintas comunidades autónomas es desigual, tanto por lo que respecta a previsiones y preceptos, como en la aplicación de recursos y financiación.

El Libro Blanco de la Atención Temprana (GAT, 2000) aportó el marco de referencia necesario y generó el suficiente consenso técnico, evolucionando desde el concepto de la "estimulación precoz" a la "atención temprana”, y concretó que ésta es "El conjunto de intervenciones dirigidas a la población infantil de o-6 años, a la familia y al entorno, que tienen por objetivo dar respuesta lo más pronto posible a las necesidades transitorias o permanentes que presentan los niños con trastornos en su desarrollo o que tienen riesgo de padecerlos". Se apuntaba además que “(...) estas intervenciones deben considerar la globalidad del niño, y han de ser planificadas por un equipo profesional de orientación interdisciplinar".

Por otra parte, "la concepción moderna de la atención temprana hace necesario que dispongamos de modelos diagnósticos integradores que consideren, además de las patologías de la salud, los aspectos evolutivos, de aprendizaje, y aquellos otros factores contextuales emocionales y ambientales que inciden en el crecimiento, la maduración y el desarrollo del niño". A lo que se añade el hecho de que la intervención temprana no solo está indicada cuando la deficiencia ya está presente, sino también en los casos en riesgo de padecerla, lo que implica la vigilancia de los factores de riesgo que puedan provocarla (GAT, 2004-20II).

De acuerdo con el Libro Blanco de la Atención Temprana (GAT, 2000), son objetivos propios de esta atención:

- Reducir los efectos de una deficiencia o déficit sobre el conjunto global del desarrollo del niño

- Optimizar, en la medida de lo posible, el curso del desarrollo del niño

- Introducir los mecanismos necesarios de compensación, de eliminación de barreras y para la adaptación a necesidades específicas

- Evitar o reducir la aparición de efectos o déficits secundarios o asociados producidos por un trastorno o situación de alto riesgo

- Atender y cubrir las necesidades y demandas de la familia y del entorno en el que vive el niño

- Considerar al niño como sujeto activo de la intervención

Y entre los principios básicos se definen:

- el diálogo, la integración y la participación en colaboración con la familia

- la gratuidad, universalidad e igualdad de oportunidades, así como la responsabilidad pública

- la interdisciplinariedad y alta cualificación profesional

- la coordinación y planificación de las actuaciones

- la descentralización y la sectorización

Por su parte, la Agencia Europea para el Desarrollo de la Educación del Alumnado con Necesidades Educativas Especiales (20IO) apunta tres prioridades en relación con la Atención Temprana:

- Llegar a toda la población que necesite atención temprana y apoyo, y hacerlo lo antes posible 
- Garantizar la calidad de la oferta dentro de unos estándares de calidad, bien definidos y evaluables, homogéneos en todo el Estado, sin que las diferencias territoriales signifiquen un handicap añadido

- Respetar los derechos de los niños y las niñas y sus familias configurando servicios responsables, centrados en la familia

Del análisis realizado por la Agencia Europea se desprenden, entre otras, propuestas relativas a la necesidad de disponer no sólo de legislación sobre la materia, sino de que ésta se acompañe de la aplicación y seguimiento de medidas políticas. Así mismo, se señala el rol fundamental de los profesionales en todos los niveles, especialmente en el tratamiento de la primera noticia y, en general, respecto a la transmisión de toda la información a las familias por lo que se subraya, además, la importancia de los programas de formación dirigidos a la capacitación para el trabajo en equipos multiprofesionales, compartiendo criterios comunes, objetivos y trabajo eficaz con las familias. Y se incide también en la importancia de la coordinación intersectorial, particularmente en momentos clave de transición cruciales para las familias y sus hijos.

\subsection{Sordera infantil y Atención Temprana}

Sobre el diagnóstico precoz de la sordera se ha avanzado notablemente bajo este cambio de paradigma antes descrito, donde más allá de los aspectos clínicos, se tienen en cuenta tanto el apoyo a las familias como el proceso habilitador audioprotésico y logopédico, incorporados como parte del todo que es el tratamiento integral a los niños y niñas con sordera.

El Programa de Detección Precoz de la Sordera Infantil, aprobado por el Ministerio de Sanidad y las comunidades autónomas, en 2003, es en este aspecto el más avanzado de los países de nuestro entorno. Y, hoy, podemos decir que resulta plenamente concordante con la concepción contemporánea de la Atención Temprana y el modelo social que propugna la
Convención Internacional sobre los Derechos de las Personas con Discapacidad.

\section{Itinerario de derivación e interdisciplinariedad}

La discapacidad auditiva es un claro ejemplo de cómo lo específico de cada sector administrativo que interviene en estas edades (Sanidad, Servicios Sociales y Educación), junto a los diferentes profesionales (pediatra, médico ORL, audioprotesista, logopeda, maestro...) se han de encontrar y, desde un enfoque interdisciplinar e integral, intervenir en torno al niño y su familia en una acción conjunta planificada, coordinada y convergente de recursos, prestaciones y servicios. De un lado, todo lo relacionado con la salud, como la detección y el diagnóstico precoz, el tratamiento médico, la adaptación de prótesis auditivas (audífonos e implantes), y la (re) habilitación médico-funcional. De otro, y sobre la base de lo anterior, la intervención educativa y social: apoyo a las familias, atención temprana, logopedia y apoyo escolar, valoración de la discapacidad, recursos de apoyo, prestaciones y ayudas sanitarias, educativas y sociales (Jáudenes, 20I4).

Todo ello podrá estar al alcance de los niños y niñas sordos y de sus familias si -y solo si- el Diagnóstico Precoz se sigue de una Atención Temprana Especializada (incluida la adaptación protésica y la intervención logopédica) y del Apoyo a las Familias, siempre a través de redes de servicios y profesionales especializados.

Para lograr este objetivo es fundamental que, tal como contempla el programa aprobado en 2003 entre el Ministerio de Sanidad y las comunidades autónomas, las administraciones, en coordinación interdisciplinar a través de unidades de referencia, aseguren ese itinerario de atención y la continuidad del proceso (CODEPEH, 2OIO).

Según el Informe de la Agencia Europea para el Desarrollo de las Necesidades Educativas Especiales (2003/04), las políticas en relación con la atención y apoyo a las personas con discapacidad, en los países de nuestro entorno 
europeo, se planifican sobre cuatro consensos básicos:

- actuar tan pronto como sea posible

- asegurar la continuidad del proceso

- evitar la descoordinación entre servicios y prestaciones

- prevenir el desconcierto y el peregrinar de las familias

De lo expuesto se desprende la relevancia de disponer de un itinerario fácilmente reconocible por todos los implicados y que, en coordinación intersectorial, por lo que respecta a las administraciones, e interdisciplinar, por lo que respecta a los profesionales, pueda dar una respuesta coherente, adecuada y suficiente a las necesidades y a las demandas de los niños con sordera y de sus familias. En este sentido, tenemos que hacer hincapié en cómo hoy ya nadie discute el rol científico que desempeña la familia, sino que este rol se reconoce de forma unívoca y es estudiado con interés ya que no es posible entender ni atender un caso sin prestar la atención debida a la familia que hay detrás. Así, se asume que la atención, la orientación y el apoyo a la familia forma parte del tratamiento y la atención del niño con discapacidad (Jáudenes, I998, 2003) (Jáudenes y Patiño, 2007).

\subsection{Recomendaciones CODEPEH en relación} con la atención temprana al niño sordo y su familia

- La regulación y la universalización de la atención temprana, estableciendo los 0-6 años de edad como el periodo objeto de atención.

- La necesaria coordinación interadministrativa e intersectorial, que responda a una planificación conjunta de servicios y prestaciones dirigidas al niño y a su familia; además de la coherencia de los apoyos y servicios con respecto a las necesidades del niño/a, su trayectoria y su evolución, así como a la toma de decisiones de las familias.
- La pluralidad de respuestas en la atención a la diversidad: no existe un único patrón de respuesta, hay que adaptarse a la variabilidad individual y a la evolución de los tiempos en todos los terrenos: social, tecnológico, legislativo...

- La actualización competencial y la formación especializada de los profesionales de los distintos ámbitos que convergen en la atención al niño sordo y a su familia.

- La incorporación de las familias en los sistemas que les conciernen en relación con sus hijos sordos y su implicación en cada nivel de intervención, incrementando el conocimiento sobre el apoyo familiar entre todos los agentes implicados.

- El establecimiento de circuitos de derivación e itinerarios de atención al niño/a y a su familia, fácilmente identificables y coordinados entre sí, que aseguren la continuidad del proceso.

- La participación del movimiento asociativo de familias, que no sólo actúa como agente y red social, desarrollando programas de apoyo familiar, incluidos grupos de ayuda mutua, sino que contribuye a evitar desigualdades territoriales, aporta asesoramiento técnico especializado e impulsa cambios necesarios.

- La creación de un registro común básico de los resultados de la aplicación del Programa de Detección Precoz de la Sordera Infantil, alimentado con los datos de las distintas comunidades autónomas. Fundamental para estudios epidemiológicos, adopción de medidas de prevención, planificación de recursos sociosanitarios y educativos subsidiarios a las necesidades de la población afectada, posibilitar estudios comparativos a nivel nacional e internacional...

- El establecimiento de consensos científicos, terminológicos, procedimentales, técnicos, educativos, etc. que permitan 
una descripción y clasificación de las necesidades existentes entre la población infantil afectada por problemas auditivos presentes o en riesgo de padecerlos.

- La información y sensibilización social, y entre los agentes implicados, acerca de la trascendencia de la detección y diagnóstico precoz, del seguimiento y vigilancia de los factores de riesgo, de la necesidad de actuar lo antes posible para instaurar el tratamiento médico y audioprotésico, junto a la intervención logopédica temprana.

- La evaluación continua y rigurosa de servicios, recursos, procedimientos y resultados, con medición cuantitativa y cualitativa respecto de todo ello y a través de indicadores de eficacia y de éxito no sólo sobre el nivel de intervención clínico, sino también sobre el progreso del niño, la satisfacción de las familias y de los profesionales, así como sobre los beneficios del entorno.

\section{PUNTOS CLAVE}

- Regulación y universalización de la Atención Temprana, estableciendo los o-6 años de edad como el periodo objeto de atención

- Coordinación interadministrativa e intersectorial, potenciando el trabajo interdisciplinar

- Actualización competencial y formación especializada de todos los profesionales involucrados

- Incorporación de las familias en los sistemas que les conciernen en relación con sus hijos sordos y su implicación en cada nivel de intervención
- Creación de un registro común básico de los resultados de la aplicación del Programa de Detección Precoz de la Sordera Infantil

- Establecimiento de circuitos de derivación e itinerarios de atención al niño sordo y a su familia

- Gestión de resultados a través de una evaluación continua

\section{Anexo de tablas y figuras}

Tabla 1. Causas de Hipoacusia Transmisiva

\begin{tabular}{|c|c|}
\hline OIDO EXTERNO & OIDO MEDIO \\
\hline congénita & congénita \\
\hline infección & infección \\
\hline traumatismo & perforación timpánica \\
\hline obstrucción & tumores \\
\hline \multirow{2}{*}{} & otoesclerosis \\
\cline { 2 - 2 } & traumatismo \\
\cline { 2 - 2 }
\end{tabular}

Tabla 2. Causas de Hipoacusia Neurosensorial

\section{a. CONGÉNITAS}

\begin{tabular}{|l|l|}
\hline HEREDITARIA & NO HEREDITARIA \\
\hline
\end{tabular}

\section{b. ADQUIRIDAS}

\begin{tabular}{|c|}
\hline Prematuridad \\
\hline Hiperbilirruminemia \\
\hline ECMO \\
\hline Hipoxia/Asfixia neonatal \\
\hline $\begin{array}{c}\text { Hemorragia interventricular grados 3-4, } \\
\text { Leucomalacia periventricular }\end{array}$ \\
\hline
\end{tabular}




\begin{tabular}{|c|}
\hline Infección \\
\hline Drogas Ototóxicas \\
\hline Exposición al ruido \\
\hline Traumatismos \\
\hline Tumores \\
\hline $\begin{array}{c}\text { Síndromes neurodegenerativos } \\
\text { (Charcot Marie, Ataxia de Friedrich) }\end{array}$ \\
\hline Intoxicación con metales pesados \\
\hline
\end{tabular}

\section{Tabla 3. Causas de Hipoacusias Centrales}

\begin{tabular}{|c|c|c|c|}
\hline \multirow[b]{2}{*}{$\begin{array}{l}\text { NEUROPATÍA } \\
\text { IDIOPÁTICA (30\%) }\end{array}$} & \multirow[b]{2}{*}{$\begin{array}{c}\text { NEUROPATÍA ADQUIRIDA } \\
\text { (30\%) }\end{array}$} & \multicolumn{2}{|c|}{ NEUROPATÍA GENÉTICA } \\
\hline & & $\begin{array}{c}\text { ASOCIADAS } \\
\text { A PROCESOS } \\
\text { SENSITIVO-MOTORES }\end{array}$ & $\begin{array}{l}\text { NO ASOCIADAS } \\
\text { A OTROS } \\
\text { PROCESOS }\end{array}$ \\
\hline & $\begin{array}{c}\text { Hiperbilirrubinemia con } \\
\text { exanguinotransfusión, } \\
50 \% \\
\text { (Shapiro et ál., 2001) }\end{array}$ & $\begin{array}{c}\text { Enfermedad de Charcot- } \\
\text { Marie-Tooth } \\
\text { (Kovach et ál., 2002) }\end{array}$ & \multirow[t]{5}{*}{$\begin{array}{l}\text { Mutación Q829X } \\
\text { en el gen OTOF }\end{array}$} \\
\hline & $\begin{array}{c}\text { Causas infecciosas, } 10 \% \\
\text { (Race, 2005) }\end{array}$ & Ataxia de Friedrich & \\
\hline & Prematuridad & S Ehrlers Danlos & \\
\hline & Hipoxia neonatal & $\begin{array}{l}\text { Enfermedad Refsun } \\
\text { (Oysy et ál., 2001) }\end{array}$ & \\
\hline & & $\begin{array}{l}\text { Eritroqueratodermia } \\
\text { (López-Bigas et ál., 2001) }\end{array}$ & \\
\hline
\end{tabular}

\section{Tabla 4. Factores de Riesgo de Hipoacusia Infantil}

\begin{tabular}{|c|c|}
\hline Sospecha familiar de sordera* & Meningitis bacteriana* \\
\hline Historia familiar de sordera & Síndromes con sordera* \\
\hline Hipotiroidismo & Enfermedades neurodegenerativas* \\
\hline Estancia en UCIN mayor de 5 días & Anomalías craneofaciales* \\
\hline Exposición a ototóxicos & Ventilación con membrana extracorpórea* \\
\hline Ventilación asistida & Trauma craneal grave* \\
\hline Otitis persistente & Hiperbilirrubinemia* con exanguinotransfusión \\
\hline $\begin{array}{l}\text { Infecciones perinatales* (CMV, herpes, rubeola, } \\
\text { sífilis y toxoplasmosis) }\end{array}$ & Quimioterapia \\
\hline
\end{tabular}

(") factor de muy alto riesgo de sordera postnatal 
Figura 1. Pautas para detectar problemas de audición en la infancia

\section{REVISIÓN PEDIÁTRICA}

El pediatra verificará que se han realizado y superado las pruebas de cribado, de acuerdo con el Programa de Detección Precoz de la Sordera Infantil, así como la existencia de factores de riesgo

1. ¿Gira la cabeza hacia la voz o un sonido?

2. ¿Responde con sonidos vocálicos cuando se le habla?

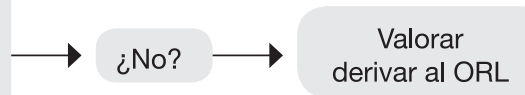

6 meses

3. ¿Reacciona a su nombre?

1. ¿Localiza la fuente del sonido?

2. ¿Señala objetos y personas familiares cuando se le nombran?

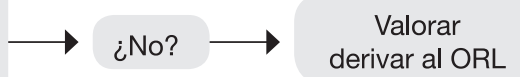

12 meses

3. ¿Dice papá/mamá?

1. ¿Señala partes del cuerpo cuando se le pregunta?

2. ¿Presta atención a las canciones infantiles?

3. ¿Hace frases de dos palabras?

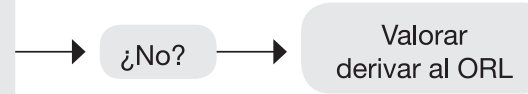

1. ¿Comprende ordenes sencillas sin apoyo de gestos?

24 meses

2. ¿Acude cuando se le llama desde otra

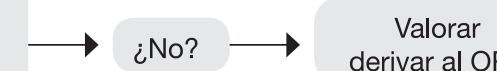
habitación? derivar al ORL

3. ¿Utiliza los pronombres mío/yo/tú?

1. ¿Repite frases sin apoyo visual?

2. ¿Mantiene una conversación?

3. ¿Cuenta una serie de números sencillos (por

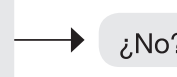

Valorar ej.: del 1 al 10)? 
Referencias bibliográficas

AAP (2007): “Committee on Environmental Health". Pediatrics; IoO: 724-727.

Agencia Europea para el Desarrollo de las Necesidades Educativas Especiales (2005). Atención Temprana. Análisis de la situación en Europa. Aspectos clave y Recomendaciones. Informe Resumen. Bruselas: Agencia Europea para el Desarrollo de las Necesidades Educativas Especiales.

Agencia Europea para el Desarrollo de la Educación del Alumnado con Necesidades Educativas Especiales (2010): Atención Temprana. Progresos y desarrollo. 2005-20I0. Odense, Dinamarca: Agencia Europea para el Desarrollo de la Educación del Alumnado con Necesidades Educativas Especiales. [s.1.]

Alford, R. L. et al. (2OI4): “American College of Medical Genetics and Genomics guideline for the clinical evaluation and etiologic diagnosis of hearing loss". Genet Med; I6(4): 347-55.

American Academy of Pediatrics (r999): “Task force on new born and infant hearing. Newborn and infant hearing loss: detection and intervention". Pediatrics; I03 (527-530).

Aoyagi et al. (I999): "Reliability of $80-\mathrm{Hz}$ amplitude-modulation-following response detected by phase coherence". Audiology o Neuro-otology, 4, 28-37.

Arlinger, S. et al. (1996): "Report of the Eriksholm Workshop on auditory deprivation and acclimatization”. Ear Hear; I7 (3 Suppl): 87S-98S.

Balfour et al. (1998): "Distortion product otoacoustic emission and auditory brainstem response measures of pediatric sensorineural hearing loss with islands of normal sensitivity". Ear and Hearing; I9: 463-472.

Ben-Itzhak, D. et al. (20I4): "Parent Report of the Development of Auditory Skills in Infants and Toddlers Who Use Hearing Aids”. Ear Hear, [Epub ahead of print].
Benito Orejas, J. I. et al. (2013): "Hipoacusia: identificación e intervención precoces”. Pediatría Integral; XVII (5): 330-342.

Briggs L. et al. (20I I): "Outcomes of conventional amplification for pediatric unilateral hearing loss". Ann Otol Rhinol Laryngol 20I I; I 20: 448-54.

Carianne, M. et al. (20I3): "Supplement to the JCIH 2007 Position Statement: principles and guidelines for Early Intervention after a confirmation that a child is deaf or hard-ofhearing. Best Practice Guidelines". Pediatrics; 2OI3-I3I.

CERMI (2005): Plan de Acción del CERMI Estatal en materia de Atención Temprana a Personas con Discapacidad. Madrid: CERMI. Colección CERMI.es, $\mathrm{n}^{\circ} 20$.

Chen, G. et al. (2013): "Screening of delayed-onset hearing loss in preschool children in the midsouth of China". Int J Audiol; 52(8):568-7I.

Chien, W. W. et al. (20I4): "Gene Therapy for Sensorineural Hearing Loss”. Ear Hear. doi: IO.I097 [Epub ahead of print].

Christensen L. et al. (2010): "Update on boneanchored hearing aids in pediatric patients with profound unilateral sensorineural hearing loss". Arch Otolaryngol Head Neck Surg 2010; I36: I75-7.

Coats, A., y Martin, J. (I977): "Human auditory nerve action potentials and brainstem evoked responses: Effects of audiogram shape and lesion". Archives of Otolaryngology $\mathrm{IO}_{3}$, $605-622$.

CODEPEH (Marco et al.) (2004): Control de calidad de los programas de detección precoz de la sordera infantil. Acta Otorrinolaringol Esp 2004, 55 .

CODEPEH (Trinidad et al.) (20I0): Recomendaciones 20Iо CODEPEH. Acta Otorrinolaringol 20I0, En-Febr. 6I(I): 69-77. 
Cohen, L. T. et al. (I99I): “A comparison of steady-state-evoked potentials to modulated tones in awake and sleeping humans". Journal of the Acoustical Society of America; 90: 2467-2479.

Cone-Wesson, B. et al. (2002): "The auditory steady-state response: Comparison with the auditory brainstem response". Journal of the American Academy of Audiology; I3:I73-I 87.

D’Agostino, J. A. et al. (2004): “Auditory neuropathy: A potentially under-recognized neonatal intensive care unit sequela". Advances in Neonatal Care; 344-353.

Dimitrijevic, A. et al. (2002): "Estimating the audiogram using multiple auditory steady-state responses". Journal of the American Academy of Audiology; I3: 205-224.

Federación Estatal de Asociaciones de Profesionales de Atención Temprana - GAT (2005): Recomendaciones técnicas para el desarrollo de la Atención Temprana. Madrid, Real Patronato sobre Discapacidad.

Federación Estatal de Asociaciones de Profesionales de Atención Temprana GAT (20II): Organización Diagnóstica para la Atención Temprana (2004-20II). Madrid, Real Patronato sobre Discapacidad.

Felton, M. et al. (20I4): "The role of stability measurements of the Baha ${ }^{\circledR}$ system in children”. Int J Pediatr Otorhinolaryngol; 78: 5 I3-6.

FIAPAS (Jáudenes, C. y col.) (2003): Guía de Buenas Prácticas para el funcionamiento de los Servicios de Atención y Apoyo a Familias. Madrid, FIAPAS.

FIAPAS (Jáudenes et al.). (2005). Dossier de prevención y atención precoz de los problemas auditivos en edad escolar. Madrid, FIAPAS.

FIAPAS (Jáudenes, C. y Patiño, I.) (2007): Dossier divulgativo para familias con hijos con discapacidad auditiva. Información básica para el acceso temprano a la lengua oral ( $2^{\text {a }}$ edición), Madrid, FIAPAS (2008).

Finckh-Kramer, U. et al. (2000): "Hearing screening of high risk newborn infants". HNS; 48: 2 I 5-20.
Fjermedal, O. y Lazuli, E. (1989): “Pediatric auditory brainstem response and puretone audiometry: Threshold comparison". Audiology; I8:I05-III.

Fligor, B. J. et al. (2005): "Factors associated with sensorineural hearing loss among survivors of extracorporeal membrane oxygenation therapy". Pediatrics; II 5: I 5I9-I 528.

Foulon, I. et al. (2008): “A ro-year prospective study of sensorineural hearing loss in children with congenital cytomegalovirus infection". $J$ Pediatr; I 53(I):84-8.

Fuchsmann C. et al. (2010): "Hearing rehabilitation in congenital aural atresia using the bone-anchored hearing aid: audiological and satisfaction results". Acta Otolaryngol; I30: I343-5I.

Gelfand S. A. et al. (I987): "Long-term effects of monaural, binaural and no amplification in subjects with bilateral hearing loss". Scand Audiol; I6: 20I-7.

Georgalas, C. et al. (2008): “Screening for hearing loss and middle-ear effusion in school-age children, using transient evoked otoacoustic emissions: a feasibility study".J Laryngol Otol; I 22(I 2):I 299-304.

Gorga, M. P. et al. (I985): “Auditory brainstem responses in a case of high-frequency hearing loss". Journal of Speech and Hearing Disorders; 50, 346-350.

Grupo de Atención Temprana (2000): Libro Blanco de la Atención Temprana. Madrid: Real Patronato de Prevención y de Atención a Personas con Minusvalía.

Herdman, A. et al. (2002): "Intracerebral sources of human auditory steady-state responses". Brain Topography; I 5: 69-86.

Hyde, M.L. (2005): "Newborn hearing screening programs: Overview". The Journal of Otolaryngology; 34:S70-S78.

Jáudenes, C. (2006): “Alumnado con discapacidad auditiva: accesibilidad a la comunicación, a la información y al conocimiento" en CNICE (2007), Serie Informes: Accesibilidad, TIC y Educación (on line). Madrid, Centro Nacional 
de Investigación y Comunicación Educativa$\mathrm{M}^{\mathrm{o}}$ de Educación. ‘http//ares.cnice.med informes/I 7 /index.htm>, acceso 8 de septiembre de 2014 .

Jáudenes, C. (2006). “La población con discapacidad auditiva en cifras. Revisión de dos Estudios Sociológicos”. Revista FIAPAS, mayojunio 2006, ${ }^{\circ}$ I IO, Separata. Madrid.

Jáudenes, C. et al. (2007) Estudio sobre la situación educativa del alumnado con discapacidad auditiva. Madrid, FIAPAS.

Jáudenes, C. y Ruíz, E. (20I I) “Análisis prospectivo de demandas atendidas en la Red de Atención y Apoyo a Familias-FIAPAS. Informe Final”. Revista FIAPAS, abril-junio 20I I, n ${ }^{\circ}$ I37. Separata. Madrid.

Jaudenes, C. (20I4): "Las personas sordas y sus familias en la intersección sociosanitaria”. En CERMI.es, febrero 2014 (en línea). http://semanal.cermi.es/noticia/Espaciosociosanitario-discapacidad-opinion-diezarticulos.aspx $<$

Kerkhofs K. y Smith M. (20I3): "Early hearing aid fitting in children: challenges and results". B-ENT; Suppl 2I:I7-25.

Kovach, M. J. et al. (2002): «Anticipation in a unique family with Charcot-Marie-Tooth syndrome and deafness: delineation of the clinical features and review of the literature». Am J Med Gene; 108:295า-303.

Levi, E. C. et al. (I995): "Coherence analysis of envelope following response (Errs) and frequency-following responses (Firs) in infants and adults". Hearing Research; 89: 2I-27.

Lieu J. E. et al. (2013): "Unilateral hearing loss in children: speech-language and school performance”. B-ENT; Suppl 2I: IO7-I 5.

López-Bigas, N. et al. (200I): “Connexin 3 I $\left(\mathrm{GJB}_{3}\right)$ is expressed in the peripheral and auditory nerves and causes neuropathy and hearing impairment". Hum Mol Genet; I0:947-52.

Lü, J. et al. (20I I): "Screening for delayedonset hearing loss in preschool children who previously passed the newborn hearing screening”. Int J. Pediatr Otorhinolaryngol; 75(8): $1045^{-9}$.

Marco, J. y Mateu, S. (coord) (2003): Libro Blanco sobre la Hipoacusia. Detección precoz de la hipoacusia en recién nacidos. CODEPEH y Ministerio de Sanidad y Consumo.

Margolis, R. et al. (2003): "Tympanometry in newborn infants - I kHz norms". Journal of the American Academy of Audiology; I4: 383392.

Martins, F. T. et al. (2013): "Optimization of simultaneous screening of the main mutations involved in non-syndromic deafness using the TaqMan ${ }^{\circledR}$ OpenArray ${ }^{\mathrm{TM}}$ Genotyping platform”. BMC Med Genet; 24; I 4:I I 2.

Mauk, G. W. et al. (I99I): "The effectiveness of screening programs based on high risk characteristics in early identification of hearing impairment”. Ear Hear; I 2: 3 I 2-9.

Mitchell, R. E. y Karmchmer M.A.: "Chasing the mythical ten percent: parental hearing status of deaf and hard of hearing students in the United States", Sign Language Studies. Vol. 4, (2) I38I63. Gallaudet University Press.

Moore, B. C. et al. (2000): “A test for the diagnosis of dead regions in the cochlea". Br J Audiol; 34: 205-24.

Northern, J. y Downs, M. (I99I): "Hearing in children” Baltimore: Lippicott Williams and Wilkins.

Oysu, C. et al. (2002): "Incidence of cochlear involvement in hyper bilirrubinemia deafness". Ann Otorhinolarygol; I I I:IO2 I-5.

Oysy, E. et al. (200I): "The site of the hearing loss in Refsum's disease". Int J Pediatr Otorhinolaryngol; 6I: I29-34.

Paradise, J. et al. (1976): “Tympanometry detection of middle ear effusion in infants and young children". Pediatrics, 58, 198-2 го.

Pérez-Abalo, M. C. et al. (200I): "Steady-state responses to multiple amplitude-modulated tones: An optimized method to test frequencyspecific thresholds in hearing-impaired children and normal hearing subjects". Ear and Hearing; 22: 200-2II. 
Rance, G. (2005): “Auditory Neuropathy/Dyssynchrony and its Perceptual Consequences". Trends Amplification; 9: I-43.

Rance, G. et al. (2005): "Hearing threshold estimation in infants using auditory steady-state responses". Journal of the American Academy of Audiology; г6: 29I-300.

Sand, N. et al. (2005): "Pediatricians reported practices regarding developmental screening: do guidelines work? Do they help?". Pediatrics; II 6:I74-I79.

Shapiro, S. M. et al. (200I): "Bilirubin and the auditory system». J Perinatol; 2I:52-5.

Sheykholeslami, K. et al. (200I): "An isolated and sporadic auditory neuropathy (auditory nerve disease): report of five patients". J Laryngol Otol; I I 5:530-4.

Silvestre, N. y FIAPAS (2008): Estudio Investigación. Interacciones comunicativas entre padres/madres e hijos/as con sordera. Madrid, FIAPAS.

Silvestre, N. y Ramspott, A. (2004). "Valoración del discurso narrativo y de sus precursores en el alumnado con déficit auditivo: Influencia de las modalidades comunicativas". Revista FIAPAS 97. Separata.

Smith, R. J. H. y Gooi, A. (20I4): Hearing impairment in children: Etiology (en línea). http://www.uptodate.com/`, acceso 4 de septiembre de 2014 .

Stapells, D. R. (1989): “Auditory brainstem response assessment of infants and children”. Seminars in Hearing; IO, 229-25I.

Stapells, D. R. et al. (I994): "Electrophysiologic measures of frequency-specific auditory function”. In J. T. Jacobson (Ed.), Principles and application in auditory-evoked potentials (pp. 25I-283). Boston Ed: Allyn and Bacon.
Stapells, D. R., y Oates, P. (I997): "Estimation of the pure-tone audiogram by the auditory brainstem response: A review”. Audiology Neuro-Otology; 2: 225-280.

Swanepoel, D. (2004): “Auditory steady-state response for children with severe-to-profound hearing loss". Archives of Otolaryngology Head and Neck Surgery, I3O, 53 I-535.

Tokgöz-Y1lmaz, S. et al. (2OI3): "Evaluation of hearing and speech-language in preschool children: how important, why we should perform?" Turk J Pediatr; 55(6):606-I I.

Tomblin, J. B. et al. (2OI4): "The influence of hearing aids on the speech and language development of children with hearing loss". JAMA Otolaryngol Head Neck Surg; I40: 403-9.

Torres, S. et al. (1995). Deficiencia auditiva: Aspectos psicoevolutivos y educativos. Málaga: Aljibe.

Torres, S. (1998). "Memoria, fonología y sordera". Revista FIAPAS, 62, 25-28

Trinidad, G. y Jáudenes, C. (coord) (20I I): Sordera Infantil. Del diagnóstico precoz a la inclusión educativa. Guía práctica para el abordaje interdisciplinar. Madrid, FIAPAS

Villalba, A. et al. (2005). La lectura en los sordos prelocutivos. Propuestas para un programa de entrenamiento. Madrid: Entha ediciones.

Watkin, P. et al. (20I2): “The longitudinal follow up of a universal neonatal hearing screen: the implications for confirming deafness in childhood". Int J Audiol; 5 I(7):5 I9-28.

Watkin, P. M. y Baldwin M. (20I I): “Identifying deafness in early childhood: requirements after the newborn hearing screening". Arc Dis Child; 96: 62-66. 


\section{La lectura fácil: una apuesta de valor para las organizaciones ${ }^{1}$}

\section{Easy to read: A commitment of value for organizations}

\section{Palabras clave}

Accesibilidad cognitiva, barreras, comprensión, igualdad, dignidad personal, ciudadanía.

\section{Keywords}

Cognitive accessibility barriers, understanding, equality, personal dignity, citizenship.

\author{
Jorge M. Pérez García \\ <jmperez@cuartosector.coop> \\ Instituto de Lectura Fácil
}

\section{Laura López de la Cruz}

$<$ <lopcru@upo.es>

Este artículo explica lo que es la lectura fácil.

Hay muchas personas en el mundo que no entienden lo que leen.

La lectura fácil es una forma especial de escribir textos y mensajes.

Todas las personas entienden los textos escritos en lectura fácil.

La lectura fácil es una forma de superar las barreras de comprensión que tienen muchas personas. Las organizaciones ayudan a comprender los textos cuando escriben sus mensajes en lectura fácil.
Universidad Pablo de Olavide

\section{Para citar:}

Pérez, J.M y López, L. (20I 5): "La lectura fácil: una apuesta de valor para las organizaciones”, Revista Española de Discapacidad, 3 (I): I87-I92.

Doi: <http://dx.doi.org/IO.5569/23405IO4.03.OI.IO> 
El mandato constitucional de que la dignidad de la persona sea considerada como un pilar básico sobre el que se asienta nuestro ordenamiento jurídico, que se tengan en cuenta los derechos que le son inherentes y el libre desarrollo de la personalidad y que las condiciones de igualdad y libertad sean reales y efectivas (art. Io CE) exige a los poderes públicos la adopción de una serie de medidas dirigidas a remover los obstáculos que en la vida diaria efectivamente impiden a unos ciudadanos las mismas cotas de bienestar y el acceso a determinados servicios públicos y privados en las mismas condiciones que otros.

En efecto, podríamos hacer referencia a determinadas condiciones y circunstancias que afectan a la persona, que no han sido tradicionalmente identificadas ni reconocidas dentro del concepto jurídico de estados civiles, pero que son comunes a distintos colectivos y suponen un condicionamiento a la hora de ejercitar sus derechos de ciudadanía, entendida esta en sentido amplio.

Desde esta perspectiva, en el ámbito propio del Derecho de la persona, algunos autores comienzan a hablar de un nuevo estatuto jurídico al que denominan "condiciones civiles emergentes", y que se refiere a aquellas cualidades y situaciones personales que afectan a los sujetos de derecho, tomadas en cuenta por la norma para garantizar el libre desarrollo de la personalidad, que procuran a la persona un estatuto jurídico diferenciado del ordinario, generalmente de índole mixta" (Gete-Alonso y Calera, 20I3; p. 223). Es decir, se toman en consideración circunstancias y situaciones que afectan a la persona en el desarrollo de su vida diaria, que hasta ahora no se habían estudiado como un conjunto de situaciones generales y de aplicación amplia, que condicionan la vida en sociedad en igualdad de condiciones respecto del resto de ciudadanos y ciudadanas.

Entre estas circunstancias y situaciones personales se alude a la dependencia física derivada de la edad, limitaciones sensoriales, la alteración de las capacidades cognitivas por diversos motivos (edad, accidente o enfermedad, discapacidad), dificultades en el aprendizaje por experiencias vitales de distinta índole (escasa formación, inmigrantes), etc. Es decir, se trata de condiciones personales e individuales que afectan o son comunes a grupos amplios de personas y con un marcado carácter de permanencia que justifican la puesta en marcha de políticas públicas y el desarrollo de proyectos destinados a la plena integración de estas personas en la sociedad.

Cierto es que el legislador, tanto autonómico como estatal, está teniendo en cuenta estas nuevas realidades emergentes, lo que se ha reflejado en la promulgación de normas especiales y en la puesta en marcha de iniciativas cuya finalidad perseguida es garantizar los derechos de los colectivos más vulnerables o desfavorecidos. Así, podemos citar como ejemplos, en materia de dependencia, la Ley 39/2006, de I4 de diciembre, de promoción de la autonomía personal y atención a las personas en situación de dependencia; respecto a las personas con discapacidad, la Ley 4I/2003, de I 8 de noviembre, de protección patrimonial de las personas con discapacidad y de modificación del Código Civil, de la Ley de Enjuiciamiento Civil y de la normativa tributaria con esta finalidad; sobre acogimiento de personas mayores: la Ley 22/2000, de 29 de diciembre, de acogida de personas mayores, de Cataluña o la Ley foral 34/2002, de ro de diciembre, de acogimiento familiar de personas mayores, de Navarra.

En concreto, si atendemos a las situaciones de discapacidad, tradicionalmente las administraciones han priorizado la accesibilidad como medio más efectivo de lograr la igualdad de oportunidades. Sin embargo, llama la atención que las iniciativas de impulso de la accesibilidad tienden de modo sistemático a ignorar la discapacidad cognitiva (véase por ejemplo el Plan de Accesibilidad 2003-2010 del Ministerio de Trabajo y Asuntos Sociales). La explicación de esta laguna es diversa y no es ajena al hecho de que esta discapacidad incluye un enorme y amplísimo número de disfunciones que la hacen difícil de definir y categorizar (Verdugo, 2003) y por ende de visualizar en términos de accesibilidad. La discapacidad 
cognitiva se asocia a trastornos conductuales o de personalidad, o a alteraciones de diverso tipo (cromosómicas, neurológicas, trastornos cerebrales...) que derivan en una disminución de las funciones mentales superiores (inteligencia, lenguaje, pensamiento...) y que condicionan las posibilidades del sujeto de asimilar y comprender la información compleja que recibe desde distintos medios, especialmente cuando esta se presenta en formato escrito.

Pero estas dificultades de comprensión no sólo afectan a personas con un grado mayor o menor de discapacidad, también a personas que por sus circunstancias vitales, y dentro de estas condiciones civiles emergentes a la que hemos hecho referencia, no tienen un fácil acceso a la información escrita. Entre ellas, cabe citar a colectivos de inmigrantes que deben familiarizarse por primera vez con la lengua española o aquellas personas que por su escaso nivel formativo no comprende o asimila fácilmente los mensajes escritos que reciben (analfabetos funcionales).

El acceso a la lectura representa un combinado de funciones mentales muy diversas, que van desde la capacidad para prestar atención, a la abstracción que representan los signos de la escritura. La lectura moviliza por igual al lenguaje natural y al pensamiento abstracto. Por lo tanto, cualquier disfunción que afecta a la lectura distorsiona la capacidad para desenvolverse en un mundo constituido por signos, desde los meros iconos hasta la escritura propiamente dicha. De hecho, se podría afirmar que ser analfabeto en la sociedad actual tal vez represente un handicap mucho más grave que una determinada limitación física o un trastorno neurológico, ya que la realidad cotidiana en que nos desenvolvemos es de una alta densidad semiótica (iconos, textos, anuncios, emoticones, etc.).

Como consecuencia, la dificultad para acceder plenamente a la información escrita puede convertirse en una fuente de desigualdad e incluso de desprotección de estos colectivos. La limitación al acceso a recursos públicos, a la cultura, a información relevante en la vida cotidiana, en definitiva puede suponer una enorme barrera que impida la participación efectiva en la sociedad. Por todo ello, se requieren iniciativas y proyectos que proporcionen a todas estas personas a las que se ha hecho referencia las herramientas necesarias para eliminar las barreras de la comprensión en un mundo condicionado y regido por el lenguaje escrito.

Y es en este contexto donde surge la iniciativa de la Lectura Fácil (IFLA, 20I0), que se presenta como un medio de proporcionar accesibilidad en un mundo crecientemente literario, basado en textos. Reconociendo este hecho, la iniciativa que promueve la Lectura Fácil trasciende al propio concepto de discapacidad para extenderse a aquel sector de la población no plenamente alfabetizado o a aquellos ámbitos tan especializados a los que la mayoría de los ciudadanos difícilmente pueden acceder por lo preciso y complejo del lenguaje en el que se formulan (leyes y normativas, contratos, documentos en el ámbito de la salud, instrucciones de uso...). Como señala la International Federation of Library Associations and Institutions (20I0) en su informe sobre Lectura Fácil "Proporcionar materiales de lectura fácil es una cuestión tanto de accesibilidad como de democracia. Los textos de lectura fácil, por tanto, están dirigidos tanto a personas con alguna discapacidad que tienen una necesidad permanente de este tipo de textos como a lectores con competencia lingüística limitada, que pueden necesitar recurrir a los mismos de modo temporal o en relación a temáticas concretas y particulares.

Partiendo de este reconocimiento, la iniciativa de Lectura Fácil tiene por objeto, generar textos, o traducir aquellos ya existentes, en un formato que permita la compresión de los mismos para la gran mayoría de la población. Para lograr esto se usarán recursos que varían desde una simplificación del lenguaje, al uso de ilustraciones o el empleo de estrategias concretas de maquetación de los textos.

Hay estudios internacionales que muestran que más del $25 \%$ de la población adulta en la mayoría de los países, y por diversas causas, no alcanza el grado de alfabetización o destreza 
lectora esperada después de la educación oficial. Para las empresas y organismos públicos debe ser por tanto una prioridad el hecho de que sus mensajes sean accesibles para todas las personas. Siendo, como se ha dicho, un derecho de todo ciudadano y ciudadana el comprender la información que se transmite, constituye una obligación de quién transmite el mensaje el hacerlo de manera comprensible. Por otro lado, es una fórmula rentable el hecho de que la información de nuestra empresa o institución llegue a un número mucho mayor de personas.

Por todo lo dicho, no cabe duda de que constituye una apuesta atrevida y un guiño hacia la innovación social el hecho de que un conjunto de entidades de la economía social se hayan embarcado en este mundo por explorar como es la accesibilidad cognitiva en general y la lectura fácil en particular. En esa tarea se encuentra el Instituto Lectura Fácil (www. institutolecturafacil.org), una institución de ámbito nacional cuyos fines principales son dos: reivindicar ante las administraciones la necesidad de hacer comprensibles los mensajes y, proporcionar al conjunto de organizaciones todo el proceso completo de adaptación, validación, edición y maquetación de textos en lectura fácil.

En esta ambiciosa meta que es la lectura fácil y la eliminación de las barreras de la comprensión, quedan muchos ámbitos por explorar, mucho conocimiento que generar. No obstante, estamos embarcados en un emocionante reto y animamos a aquellas organizaciones comprometidas con la igualdad de oportunidades a poner en marcha iniciativas que contribuyan a fomentar la accesibilidad cognitiva.

En esta lucha, desde el Instituto Lectura Fácil trabajamos bajo las premisas de: responsabilidad, independencia, permanencia y trascendencia, sostenibilidad, igualdad de derechos y respeto a la diversidad para ir de la mano en favor de las personas con especiales dificultades en la comprensión. Lo que se pretende, en definitiva, es poner en valor a las empresas y organismos públicos o privados que apuestan por la lectura fácil y ayudarles en esta tarea que contribuye a hacer una sociedad más democrática y comprometida con los valores constitucionales. 


\section{Referencias bibliográficas y normativas}

Asociación Internacional de Editores (I992). Carta para el Lector. (Texto aprobado en el XXIV Congreso de la Asociación Internacional de Editores). Comisión Internacional del Libro. UNESCO.

Centro de Referencia Estatal de Autonomía Personal y Ayudas Técnicas, CEAPAT. (2013) Cuestionarios de Vivienda (en línea). http:// www.ceapat.es/ceapat_oI/centro_documental/ accesibilidad/vivienda/IM_07288 .

España. Ley I3/I982, de 7 de abril, de integración social de los minusválidos. Boletín Oficial del Estado, núm. Io3, de 30 de abril de I982, pp. IIIO6 a IIII2.

España. Ley 26/20I I de I de agosto, de adaptación normativa a la Convención Internacional sobre los Derechos de las Personas con Discapacidad. Boletín Oficial del Estado, núm. I 84, de 2 de agosto de 20 I I, pp. 87478 a 87494 .

España. Ley 39/2006, de I4 de diciembre, de promoción de la autonomía personal y atención a las personas en situación de dependencia. Boletín Oficial del Estado, núm. 299, de 15 de diciembre de 2006, pp. 44I42 a 44I 56.

España. Ley 49/2007, de 26 de diciembre, por la que ese establece el régimen de infracciones y sanciones en materia de igualdad de oportunidades no discriminación y accesibilidad universal de personas con discapacidad. Boletín Oficial del Estado, núm. 3 IO, de 27 de diciembre de 2007, pp. 53278 a 53284 .

España. Ley 5I/2003, de 2 de diciembre, de igualdad de oportunidades, no discriminación y accesibilidad universal de las personas con discapacidad. Boletín Oficial del Estado, núm. 289 , de 3 de diciembre de 2003, pp. 43 I 87 a 43195 .

España. Real Decreto Legislativo I/20I3, de 29 de noviembre, sobre el Texto Refundido de la Ley General de derechos de personas con discapacidad y de su inclusión social. Boletín
Oficial del Estado, núm. 289, de 3 de diciembre de 2013 , pp. 95635 a 95673.

Fundación ONCE (2013). Pautas de diseño de pictogramas para todas las personas (en línea). http://accesibilidadcognitivaurbana. fundaciononce.es/docs/Manual_pictogramas. pdf.

García Moreno, D. (20I2). "Diseño de sistemas de orientación espacial: Wayfinding”. En VV.AA.: Accesibilidad universal y diseño para todos. Arquitectura y urbanismo. Madrid: Fundación Once.

Gete-Alonso, M.C. (20I3). "El estado civil y las condiciones de la persona”, En Gete-Alonso, M.C. (dir.) y Solé, J. (coord.): Tratado de Derecho de la Persona física. Navarra: Civitas Thonson Reuters, pp. 22I y ss.

International Federation of Library Associations and Institutions (2010). Guidelines for easyto-read materials. (IFLA Profesional Report I20). Non Published Manuscript. The Hague, Netherlands.

Naciones Unidas (2006). Convención Internacional sobre los Derechos de las Personas con Discapacidad (en línea). http://www.un.org/ spanish/disabilities/default.asp? $i d=497$. .

TECHNOSITE. (2009). Accesibilidad y Capacidades Cognitivas. Movilidad en el entorno urbano. Vol. I, Conocimiento y Experiencias. Madrid: Fundación Once.

UNAPEI, fédération d'associations française de représentation et de défense des intérêts des personnes handicapées mentales et de leurs familles (2010). Guide Pratique de l’Accessibilité (en línea). ‘http://www.unapei. org/IMG/pdf/GuideAccess.pdf.

UNESCO / IFLA (I994). Manifiesto de la Biblioteca Pública (en línea). http://www. unesco.org/webworld/libraries/manifestos/ libraman_es.html.

UNESCO / IFLA (I999) Manifiesto de la Biblioteca Escolar (en línea). http://www.unesco. 
org/webworld/libraries/manifestos/school_ manifesto_es.html.

Verdugo, M.A. (2003). “Análisis de la definición de discapacidad intelectual de la Asociación
Americana sobre retraso mental de 2002". Revista Española sobre discapacidad Intelectual. Vol. 34 (I). 205, 5-I9. 


\section{Nuevas medidas de protección legal de personas con discapacidad: la asistencia}

\section{New measures of legal protection for persons with disability: assistance}

\section{Palabras clave}

Asistencia, protección legal, apoyos, vida independiente, derechos, autodeterminación.

\section{Keywords}

Assistance, legal protection, supports, independent living, rights, selfdetermination.

\section{Introducción: sobre la capacidad legal y la protección de las personas con discapacidad}

Tradicionalmente, las figuras de protección para personas con discapacidad aplicadas en la mayoría de las legislaciones de nuestro entorno se han inspirado en el derecho romano. Este presuponía para todas aquellas personas a las que no se les reconocía capacidad suficiente, la necesidad de ser representadas, normalmente por el "pater familias" o cabeza de familia, que era quien tomaba las decisiones en nombre de la persona en cuestión.

Esta forma de representación es la que se ha venido usando en nuestro derecho civil y en los de nuestro entorno.

Nuestro sistema presupone la capacidad de toda persona. Bajo esta presunción, nuestro ordenamiento jurídico sitúa las declaraciones de incapacidad (ahora modificaciones de capacidad) en el ámbito judicial. Es decir, será un juez quien determine si una persona necesita protección en la toma de decisiones y el grado de esta protección.

El sistema de protección de personas con discapacidad que no tienen

\author{
Josep Ruf i Aixàs \\ <pruf@fcsd.org> \\ Fundación Catalana Síndrome de \\ Down
}

\section{Josep Tresserras Basela} $<$ tresserras@somfundacio.org>

Som - Fundació Catalana Tutelar Aspanias

Para citar:

Ruf, J. y Tresserras, J. (20I 5):

"Nuevas medidas de protección legal de personas con discapacidad: la asistencia”, Revista Española de Discapacidad, 3 (I): 193-209.

Doi: <http://dx.doi.org/I0.5569/23405IO4.03.OI.II> 
capacidad suficiente en la toma de decisiones, presupone confirmar que la discapacidad sea incapacitante y es en esa situación en la que la persona debe tener a alguien, persona física o jurídica, que tome decisiones por ella. Esto lo que se denomina toma de decisiones por sustitución.

Pero nuestro ordenamiento civil presenta algunos matices:

- $\quad$ Por un lado, la modificación de la capacidad establece que a las personas que no tengan capacidad suficiente se les nombre un tutor, que deberá tomar decisiones en su nombre. En este caso será por sustitución.

- Por otro lado, en el caso de aquellas personas a las que el juez estime capacidad de comprensión con ayuda, la modificación de la capacidad será relativa y estará sometida a su curatela. En estos casos la persona conservará parcialmente su capacidad, en las áreas que el juez estime oportunas. Para que las decisiones que tome la persona, en las áreas en las que necesita apoyo, tengan validez, deberán ser consensuadas entre la persona y su curador.

Nuestro derecho civil obliga a los jueces a adecuar las sentencias de modificación de capacidad a las necesidades reales de cada persona, o lo que se ha denominando "hacer un traje a medida”. Esta práctica permite ofrecer los apoyos adaptados a las necesidades individuales reales. Se entiende que de algún modo, un buen uso de esta adecuación de la protección acerca estas prácticas a los requerimientos de la Convención Internacional sobre los Derechos de las Personas con Discapacidad de Naciones Unidas (ONU).

El artículo I 2 de esta Convención reafirma que las personas con discapacidad tienen derecho al reconocimiento de su personalidad jurídica, en igualdad de condiciones con las demás personas y en todos los aspectos de la vida. Por ello, se deben adoptar las medidas necesarias para proporcionar los apoyos que puedan requerir en el ejercicio de su capacidad jurídica, con las salvaguardas adecuadas y efectivas que impidan abusos y velen por sus derechos, voluntades y preferencias.

En este sentido, muchos países han empezado a revisar sus marcos legales para adaptarlos a los principios de la Convención y se están haciendo algunos avances, pero aún dista mucho de conseguir una regulación homogénea. La principal dificultad al respecto ha sido que desde la aprobación de la Convención en el año 2006 los distintos países que la han ido ratificando han interpretado el artículo I 2 de distinta manera, hecho que dificulta su aplicación. Por este motivo, el I I de Abril de 20I4 el Comité sobre los derechos de las personas con Discapacidad aprobó la Observación general $n^{\circ}$ I 20I4 sobre el Artículo I2: Igual reconocimiento como persona ante la ley. ${ }^{\mathrm{I}}$

En el documento se interpreta el artículo I 2, para despejar las dudas que puedan surgir en su aplicación por los Estados parte, dejando claro que el nuevo paradigma, según dicho artículo, se basa en los apoyos que deben recibir las personas para la toma de decisiones. Este documento va a obligar a los distintos países que han ratificado la Convención a adoptar las medidas necesarias para adaptar les legislaciones o al menos a posicionarse al respecto. También debemos de tener en cuenta la recomendación $\mathrm{n}^{\circ} 99$ (4) del Comité de Ministros del Consejo de Europa, del 23 de febrero de I999, relativa a los principios de protección jurídica de personas adultas incapaces, basada en principios como: la mínima intervención, la subsidiaridad, la flexibilidad, la individualización, la proporcionalidad de las medidas, el respecto y la promoción de la autonomía.

I. Comité sobre los derechos de las Personas con Discapacidad. I I ${ }^{\circ}$ período de sesiones. 3 I de marzo a i I de abril de 20I4. Observación General No I (20I4). Artículo I 2: Igual reconocimiento como persona ante la ley. 


\section{Aparición de la asistencia como figura de protección legal en Catalunya}

La ley $25 / 2010$, del 29 de Julio, del libro $2^{\circ}$ del Código Civil de Catalunya, mantiene las instituciones de protección tradicionales existentes (tutela, curatela, defensa judicial, etc.) y regula otras nuevas, como la figura de la asistencia, con el objetivo de dar respuesta a la diversidad de situaciones en las que pueden encontrarse las personas con discapacidad.

La ley pretende reforzar la autonomía personal de las personas, flexibilizando la respuesta jurídica y evitando, en la medida de lo posible, procedimientos de modificación de capacidad innecesarios y/o desproporcionados para las necesidades reales de algunas personas. No debemos olvidar que estos procesos someten a las personas y a sus familias a unos procedimientos, a menudo, largos y dolorosos debido a su naturaleza y su complejidad.

Esta ley se enmarca en los principios de la Convención Internacional sobre los Derechos de las Personas con Discapacidad de Naciones Unidas (2006), que defiende y propugna un modelo de protección legal que respete al máximo la autonomía de la persona y que determine los apoyos que esta necesitará, en función de sus necesidades. De todos modos, debemos de tener en cuenta que seguirán existiendo situaciones en las que no será posible conocer la voluntad de la persona o en las cuales habrá que decidir por ella para protegerla adecuadamente.

La figura de la asistencia tiene distintos antecedentes en derecho comparado, como el modelo normativo alemán de asistencia. Hasta el año I99I, en Alemania operaba la incapacitación de la persona (Entmündigung) seguida del nombramiento de tutor, con unas facultades similares a las propias de la tutela de menores de edad. En el año I 990 se instaura un modelo que pone el acento en la necesidad de proteger a la persona sin cambiar su estado civil. Esta ley derogó las causas de incapacitación, abolió el procedimiento de incapacitación y la distinción entre grados de incapacidad. La tutela y curatela de mayores de edad se sustituyeron por un único régimen, denominado asistencia (Betreuung) que prevé que una persona puede necesitar protección para gestionar sus propios asuntos, siempre a instancia propia.

Otro modelo de referencia proviene del derecho francés, que contempla un régimen de protección para personas que no puedan gestionar sus propios intereses, pero en unas condiciones basadas estrictamente en la alteración de las facultades mentales o corporales, probadas médicamente, que impidan le expresión de la voluntad de la persona. La autoridad judicial es la encargada de determinar la mejor protección para la persona, incluyendo la tutela y la curatela.

Por lo tanto, tenemos referencias de países en los que las medidas de protección legal siguen basándose en la incapacitación legal, con el ejercicio de la tutela o la curatela, otros donde la asistencia coexiste con dichas medidas y otros países donde las ha sustituido.

\section{Presentación del proyecto de colaboración}

La aparición de la asistencia hace necesario empezar a planificar estrategias de difusión y aplicación de esta nueva medida de protección legal de las personas con discapacidad en Catalunya. Es preciso que las personas con discapacidad, sus familias y los profesionales o servicios que los orientan en sus decisiones vitales, conozcan esta alternativa que preserva la capacidad jurídica de la persona. Pero necesitamos disponer de experiencias reales de aplicación de la asistencia que confirmen su adecuación y viabilidad como medida de protección.

Por este motivo, SOM-Fundación Catalana Tutelar Aspanias y la Fundación Catalana 
Síndrome de Down (FCSD) diseñaron un proyecto conjunto que sirviera para experimentarla con personas con discapacidad intelectual. Colaboraciones anteriores entre las dos entidades favorecieron este proyecto con objetivos como:

- Difundir la máxima información sobre la asistencia.

- Analizar las condiciones más favorables de aplicación de esta medida.

- Diseñar un protocolo para su tramitación y aplicación.

- Desarrollar una metodología de trabajo.

- Experimentar la idoneidad de los casos susceptibles de beneficiarse de la figura de la asistencia.

- Analizar resultados de su aplicación real.

Cabe decir, que desde el año 2002 empieza a consolidarse en Catalunya la opción de vida independiente para muchas personas con discapacidad intelectual, como alternativa a la convivencia familiar y a su institucionalización en servicios residenciales. Esto se debe a la creación de servicios de apoyo personal en sus domicilios y en la comunidad, regulados a través de una nueva prestación social denominada "Programa de apoyo a la autonomía en el propio hogar" del Departamento de Bienestar Social y Familia de la Generalitat de Catalunya, del cual se benefician I 200 personas actualmente.

Previamente, la FCSD pone en marcha, en el año 2000, con carácter pionero en el Estado Español, el primero de estos servicios que ha evidenciado la viabilidad de una opción de vida autónoma o la capacidad de autogobierno de estas personas, con los apoyos adecuados, indistintamente de su situación personal, social y legal.

La experiencia en el seguimiento y apoyo a los proyectos vitales de estas personas, confirma que sumando los apoyos formales de los servicios con los apoyos naturales de los que disponga la persona (familia, vecinos, amigos, etc.) se atienden y resuelven la mayoría de necesidades personales que implica una vida autónoma. Pero el verdadero fomento de la autonomía personal también presenta, a menudo, dilemas técnicos y éticos. Especialmente, en el caso de personas sin referentes naturales significativos, que concentran sus demandas de orientación en decisiones personales y patrimoniales al servicio de apoyo. A menudo estas situaciones pueden favorecer un excesivo intervencionismo por parte de los profesionales, creando relaciones de dependencia injustificadas y sobrepasando los límites de neutralidad de los apoyos ofrecidos.

Algunos ejemplos prácticos se han dado ante demandas tales como pedir orientación en la elaboración de actos testamentarios, donaciones, consejo en operaciones financieras, de compraventa o en la gestión del propio patrimonio, solicitud de delegación de decisiones médicas actuales o futuras, etc.

En muchos de estos casos, estas demandas cursaban con funcionamientos personales lo suficientemente autónomos, con capacidad de pedir ayuda y sin señales de vulnerabilidad que pudieran justificar objetivamente la necesidad de instar un una medida de protección legal convencional.

La aparición de la asistencia supuso una alternativa que ofrece nuevos apoyos, perfectamente compatibles con los existentes y totalmente legítimos, dada su naturaleza y reconocimiento legal. Es en este contexto que surge la idea de iniciar este proyecto de colaboración.

\section{Entidades colaboradoras}

Sóm-Fundación Catalana Tutelar Aspanias (SÓM-FCTA) es una entidad tutelar creada el año I987, referente y pionera entre las entidades tutelares a nivel estatal y autonómico, inscrita en el Registro de Fundaciones de la Generalitat de Catalunya con el número 327 y que en la actualidad cuenta con 504 tutelas en ejercicio. 
La misión de esta entidad es velar para que las personas con discapacidad psíquica y del desarrollo dispongan de las ayudas y apoyos necesarios para poder desarrollar su proyecto personal a lo largo de su vida. Sus valores son:

- Compromiso y responsabilidad social: con las personas que tutela y con la sociedad en general a fin de identificar y hacer visible el desarrollo de los derechos sociales y exigir una responsabilidad pública y social. Los criterios en los que se basa para conseguirlo son: personalización, acompañamiento, integridad, justicia y humanismo.

- Transparencia: en la administración de las cuentas y patrimonio, en general, tanto de la entidad como de las personas tuteladas, con el rigor y los principios generales contables supervisados por los órganos pertinentes (Protectorado, Administración, Fiscalía, etc.). Los criterios en los que se basa la gestión son: eficacia, eficiencia, profesionalidad, austeridad e innovación.

- Independencia: A fin de garantizar el control de la calidad de vida y el bienestar de las personas tuteladas, la entidad no presta servicios asistenciales: residenciales, laborales, educativos, etc., para no perder objetividad en la defensa de sus derechos e intereses. Los criterios en los que se basa son: objetividad, subsidiariedad y no discriminación.

- Confianza: entendemos la confianza de las familias, de los tutores de las personas con discapacidad intelectual, así como de las entidades sociales y las administraciones públicas, junto con la proximidad, la empatía, la personalización y el reconocimiento como valores básicos de nuestra actividad y objetivos.

La Fundación Catalana Síndrome De Down (FCSD) es una entidad privada, sin ánimo de lucro, constituida en I984, declarada de utilidad pública e inscrita en el Registro de Fundaciones de la Generalitat de Catalunya con el número 6I.
Nacida como la iniciativa de un grupo de familias y profesionales con el objetivo de profundizar sobre el síndrome de Down (SD) y otras discapacidades intelectuales, a través de la investigación y la experiencia práctica en los campos de la pedagogía, la psicología, la medicina y el área social y contando con la participación de científicos internacionales. Su carácter pionero constituye un punto de referencia para entidades públicas y privadas, nacionales e internacionales.

\section{A lo largo de estos años la FCSD ha} desarrollado programas y servicios que atienden las necesidades de las personas y de sus familias a lo largo de todas las etapas vitales, desde la primera infancia hasta la vejez, siempre con el objetivo de hacer posible la plena inclusión social en todos entornos sociales ordinarios. $\mathrm{Su}$ actividad se basa en principios y valores como:

- Derechos humanos: reconocidos en la Declaración Universal de los Derechos Humanos (I948) y la Convención de Derechos de la Persona con Discapacidad de la ONU.

- Concepto de discapacidad de la OMS: que entiende la discapacidad como la consecuencia de la interacción entre las condiciones de salud, los factores personales y las condiciones ambientales.

- Normalización: para promover el cambio social y acciones inclusivas.

- Autogestión: las personas son sujetos activos y capaces de gestionar su propia vida con el apoyo individualizado necesario.

- Apoyo a las familias: como referente principal en la trayectoria vital de estas personas.

- Atención Integral: basada en un modelo bio-psicosocial.

- $\quad$ Salud: la definición de la OMS la entiende como el estado de bienestar físico, psicológico y social.

- Inclusión: una sociedad justa cree en la igualdad de oportunidades, la no discriminación y la diversidad como fuente de riqueza.

- Educación: los alumnos con discapacidad tienen derecho a ser escolarizados en 
centros educativos ordinarios y a recibir una educación personalizada.

- Vida independiente: derecho a decidir dónde y con quién quieren vivir, a disponer de los apoyos necesarios (formales y naturales) y de unas políticas de vivienda accesible y asequible.

- Capacidad legal: el goce y ejercicio de derechos y deberes.

- Empleo y formación profesional: derecho al mercado laboral ordinario, con los apoyos necesarios y una formación profesional continua que les promocione.

- Ocio y tiempo libre: inclusivo, normalizado y que fomente la autodeterminación.

- Investigación: liderar la innovación y la divulgación de los avances biomédicos y psicosociales sobre el síndrome de Down y la discapacidad intelectual.

- Gestión eficiente: de los recursos públicos o privados y su reparto equitativo. La transparencia en las actividades, las cuentas de resultados y los balances.

- Seguimiento y evaluación de nuestros servicios: garantizar una respuesta adecuada a las necesidades cambiantes de las personas y de la sociedad, y conseguir la mejora continua en la calidad de nuestro sistema de gestión.

- Equipo humano: un equipo humano multidisciplinario, comprometido con la misión de la Fundación, sus principios y sus valores.

La FCSD defiende un mundo en el cual las personas con discapacidad participen de forma plena en la sociedad, en igualdad de condiciones que el resto de la población. Y trabaja para mejorar la calidad de vida de estas personas, facilitando su total inclusión social y la consecución del máximo grado de bienestar, autodeterminación, desarrollo personal, respeto y dignidad.

La participación de la FCSD en el proyecto piloto de aplicación de la asistencia se gestiona desde el servicio de apoyo a la vida independiente "Me voy a casa" que atiende a personas con discapacidad intelectual que han accedido a una vida autónoma, emancipándose de sus familias o de un servicio residencial. Cada persona decide y crea su propia unidad de convivencia (solos, en pareja o con algún amigo) $\mathrm{y}$ accede a una vivienda propia, en régimen de alquiler o propiedad.

Para llevar a cabo esta experiencia piloto, se creó un equipo de colaboración entre ambas entidades compuesto por:

- SOM-FCTA: trabajadora social y abogado asesor financiero que coordinarían la acogida de los solicitantes, la tramitación de la demanda y la provisión de la asistencia.

- FCSD: educador social, personas de apoyo y pedagogo, como referentes de la derivación de los solicitantes y la posterior coordinación entre las tareas de apoyo con las de la asistencia.

\section{Definición de la asistencia}

La propia regulación de la asistencia, establece que la persona mayor de edad que lo necesite, para tener cura de ella misma o de sus bienes, debido a una discapacidad no incapacitante de sus facultades físicas o psíquicas, podrá solicitar a la autoridad judicial el nombramiento de un asistente (Capítulo VI , Libro $2{ }^{\circ}$ CCC , artículo 226-I del Código Civil).

La asistencia es concebida como un medida de protección a disposición de las personas para las cuales, por sus condiciones psicofísicas, la incapacitación y la tutela no son posibles, ni siquiera aconsejables. La ley pone énfasis en la capacidad natural de las personas y en el respecto a su autonomía en el ámbito personal y familiar.

La asistencia se da en un procedimiento de Jurisdicción voluntaria en el que es necesaria una resolución judicial, en la que el juez determine el ámbito: personal y/o patrimonial. La autoridad judicial tiene que respetar la voluntad de la persona a la que se debe asistir 
en cuanto al nombramiento o la exclusión de alguna persona para ejercer la función de asistencia (Capítulo VI Artículo 226-2).

\section{Finalidad de la asistencia}

La asistencia tiene la finalidad de proporcionar la ayuda, ofrecer apoyos (acompañamiento, consejos, orientación, asesoramiento...) y velar para que la persona acceda a la información de los asuntos que le incumben de manera adecuada, con el fin de lograr el cuidado de sí misma o de sus bienes y así prevenir riesgos por parte de terceras personas.

Como sistema de apoyos, desde el principio es controlado por la propia persona, actúa a petición de la misma y en ningún caso sustituye sus propias voluntades.

7. Perfil de los candidatos del proyecto piloto

Dada la inexistencia de experiencias previas y con el objetivo de facilitar al máximo la aplicación experimental de esta nueva figura de protección, se definieron unas características personales de inclusión en el proyecto piloto para los posibles candidatos/as.

Estas características obedecen a dos circunstancias determinantes de la puesta en parcha del proyecto piloto:

- Las características personales de los usuarios del servicio de apoyo a la vida independiente que determinaba unas situaciones de origen con necesidades y demandas previas detectadas.

- La necesidad de garantizar la comprensión y aceptación de la asistencia por parte de la propia persona.
De esta manera se establecieron unos criterios de inclusión de posibles candidatos al proyecto:

- Presentar una discapacidad intelectual ligera o inteligencia límite que facilitara la comprensión del proyecto.

- Baja incidencia de trastorno mental en las capacidades volitivas de la persona.

- Conciencia de las propias limitaciones y de la necesidad de apoyo para garantizar la demanda explícita de ayuda.

- Actitud manifiesta de colaboración con aquellos agentes referentes de la persona y con el equipo del proyecto.

- Residencia en Catalunya para poder beneficiarse de los recursos legales y sociales propios del territorio, ya que fuera de Catalunya la medida no es aplicable por ser derecho civil autonómico.

- Mayoría de edad como requisito para la plena capacidad jurídica de decisión.

Estas variables no respondían a un único perfil de solicitante sino que debían ser valoradas en las circunstancias individuales de cada caso. Pero, en cualquier caso, debían garantizar las competencias necesarias para participar y argumentar el proceso legal que supone tramitar una demanda de asistencia.

Uno de los objetivos del análisis de resultados de este proyecto piloto sería revisar posteriormente estos perfiles para estudiar su confirmación, ampliación e introducir las modificaciones necesarias.

\section{8. Ámbitos y funciones de la asistencia}

En las resoluciones de nombramiento de asistencia, la autoridad judicial determina los apoyos y los intereses de los que debe tener cura el asistente en los ámbitos personal y/o patrimonial, de acuerdo con lo expresado en la demanda inicial y lo establecido en la ley: 
7.I. Esfera personal: el asistente debe velar por el bienestar de la persona asistida, respetando plenamente la voluntad y las opciones personales. Corresponde al asistente recibir la información y dar el consentimiento, si la persona asistida no puede decidir por ella misma sobre la realización de actos, tratamientos médicos y no ha otorgado un documento de voluntades anticipadas.

Por encima de lo que dice la ley, entendemos que en la esfera personal el asistente, si así lo quiere la persona, puede ofrecer un seguimiento más global para detectar, orientar y apoyar, no sólo en cuanto al bienestar físico, sino también en otras áreas como las del bienestar emocional, desarrollo personal, relaciones interpersonales, inclusión social, derechos y autodeterminación y puede intervenir en las incidencias que se puedan producir dentro de estas áreas y que pongan en riesgo el bienestar personal del asistido, realizando así una acción preventiva. Este seguimiento deberá respectar siempre las voluntades de la propia persona.

Principalmente, los apoyos en la esfera personal harán referencia a: la toma de decisiones para el logro del bienestar personal, toma de decisiones y otorgamiento de consentimiento informado para cualquier intervención o tratamiento médico, con especial atención a los tratamientos psiquiátricos, psicológicos y/o farmacológicos; toma de decisiones relativas a la actividad laboral, al ámbito doméstico con especial incidencia en el mantenimiento del domicilio, la alimentación y la higiene personal y que pueda conservar el derecho de sufragio electoral.

8.2. Esfera patrimonial: El asistente debe intervenir, junto con la persona asistida, en los actos jurídicos relacionados con las funciones de la asistencia. A petición de la persona asistida, la autoridad judicial también puede conferir al asistente funciones de administración del patrimonio de la persona asistida (Artículo 226-2). Los actos jurídicos que la persona asistida haga sin la intervención del asistente, si esta fuera necesaria, serán anulables.
Una vez definido lo que dice la ley, entendimos que el asistente, si así lo requiere la persona asistida, puede ofrecer información, apoyo, intervenir junto con ella en todos los actos que pida.

Algunos ejemplos: actuaciones referidas a la administración de su sueldo y patrimonio, adquirir bienes, alquilar una vivienda, disponer de bienes inmuebles y muebles, contratar préstamos o compromisos de pago diferidos, establecer hipotecas, cargas sobre inmuebles o sobre patrimonio, contratar operaciones bancarias o financieras que supongan compromisos patrimoniales, sea cual sea su alcance temporal o cuantitativo, realizar disposiciones para decidir sobre su patrimonio, sin perjuicio de que pueda disponer de dinero para sus gastos personales por valor del importe que fije su asistente, que informe de la decisión a la entidad bancaria donde perciba sus ingresos.

Entendemos que tanto si se trata de intervenir en la esfera personal como en la patrimonial es imprescindible establecer un vínculo y una relación con la persona basada en la confianza y el respeto mutuo.

\section{Tramitación de la asistencia}

Para acceder a esta medida de protección legal, es necesario formular y presentar una demanda de nombramiento de asistente en el Juzgado correspondiente al domicilio de la persona que lo solicita.

Cabe decir que en los casos derivados y/o atendidos dentro del proyecto piloto, la demanda es formulada por la propia persona acompañada por los servicios legales de la entidad tutelar.

Una vez presentada la demanda, el juez cita al presunto futuro asistido, donde también intervendrá el ministerio fiscal y el médico forense que deberán confirmar que la persona presenta una disminución no incapacitante. 


\section{Protocolo de aplicación del proyecto piloto}

\subsection{Fase de acogida:}

Los solicitantes pueden acceder al proyecto a través de tres vías:

- Por propia demanda de la persona y/o familia: la entidad tutelar recibe una primera demanda directa de información y planifica todas las entrevistas necesarias de cada fase.

- Por derivación desde un servicio o profesional derivantes: el derivando (en este caso, Servicio de apoyo a la vida independiente "Me voy a casa" de la FCSD) formula una hipótesis de demanda a la entidad tutelar, envía la documentación requerida y planifican una primera reunión conjunta de valoración de la derivación. La entidad tutelar abre el expediente individual de asistencia (EIA)

- Petición a la entidad tutelar por parte del órgano judicial.

\subsection{Fase de valoración:}

- Traspaso de la documentación requerida del servicio derivante a la entidad tutelar (Fotocopia DNI, reconocimiento discapacidad, valoración dependencia, informes médicos, psicológicos, etc.).

- Primera reunión de derivación entre la entidad tutelar y el servicio derivante para valorar, confirmar la derivación del caso.

- Primera entrevista de presentación de la persona interesada acompañada por el agente derivante para recibir información de la entidad tutelar y de la asistencia. En esta entrevista se empieza a recoger información de la persona interesada y a sondear su demanda hipotética inicial.

- Visita en el domicilio de la persona interesada con el objetivo de conocer y valorar el estado del entorno de la persona y clarificar algunas informaciones proporcionadas de la asistencia, ello permite confirmar su comprensión y atender dudas.

- Entrevistas entre la persona interesada y la entidad tutelar para que pueda formular, con toda la información de la que dispone y sin ninguna influencia externa, sus propias consultas y así confirmar su demanda de asistencia. Esta fase concluye con la redacción de una propuesta de asistencia que concretará las voluntades de la persona y permitirá derivar el caso a los servicios legales de la entidad tutelar.

- Entrevista de devolución y derivación a los servicios legales para confirmar la demanda formulada en la propuesta de asistencia realizada por parte de la entidad tutelar y derivar el caso al área jurídica de la entidad tutelar que iniciará toda la tramitación.

\subsection{Fase de tramitación}

Los servicios jurídicos de la entidad tutelar redactan junto con la persona solicitante la demanda de asistencia que presentarán ante el órgano judicial y que se acompaña de la documentación necesaria para su tramitación, que acredite la discapacidad de la persona y un certificado médico o psicológico que acredite sus capacidades cognitivas y volitivas, así como que se trata de una discapacidad no incapacitante.

La tramitación de la demanda incluye todas las acciones que los servicios jurídicos de la entidad tutelar tendrán que gestionar con la persona interesada hasta llegar a la aprobación y nombramiento del asistente por parte del juez. La FCSD realiza un seguimiento del proceso con el usuario y se coordina con la entidad tutelar para garantizar que la persona solicitante dispone y comprende toda la información del proceso.

\subsection{Nombramiento}

La resolución judicial confirma los ámbitos de asistencia y el nombramiento del asistente de acuerdo con lo establecido en la demanda presentada y según define la ley. El 
nombramiento debe ser inscrito en el Registro Civil para que sea efectivo.

\subsection{Fase de aplicación de la asistencia}

Una vez finalizada la tramitación y nombramiento del asistente, se inicia propiamente la aplicación de la asistencia como medida de apoyo y protección legal.

I. Entrevista de inicio de la asistencia con la persona interesada, ahora ya asistida, para informarle del nombramiento, elaborar el pacto de asistencia de acuerdo con la resolución judicial y así planificar el inicio de la asistencia.

2. Entrevistas de seguimiento que se consideren necesarias para coordinar todas aquellas demandas, incidencias y necesidades surgidas.

3. Actualización anual del Plan de Asistencia con todos los agentes principales decididos por la persona asistida.

\section{Metodología de la asistencia}

Partimos de una absoluta voluntariedad y conciencia de dificultades específicas, detalladas en la demanda, por parte del propio asistido, como base de una relación de confianza que permitirá al asistente asesorar, informar y orientar sin ningún interés individual sobre las decisiones y conveniencias del asistido.

El asistente se reúne con el presunto asistido las veces que haga falta, siguiendo las orientaciones del protocolo, para llegar a acuerdos y hacer la compilación de la información necesaria.

La premisa es detectar demandas, necesidades y dificultades a nivel personal y/o patrimonial que motiven la demanda de la persona. Con la información de las entrevistas y de la documentación aportada (informes sociales, médicos, etc.) se valora la idoneidad y adecuación de la figura de la asistencia al solicitante.

La empatía con cada situación personal y la escucha activa permiten conocer cuáles son las expectativas del presunto asistido para encuadrar aquellos aspectos relevantes de su vida y adaptar la ayuda de la asistencia. A partir de la aceptación inicial se definen conjuntamente los objetivos específicos de cada ámbito (personal y patrimonial).

La asistencia requiere de una relación cercana y continuada a través de visitas periódicas o llamadas telefónicas que permitirán hacer el seguimiento de la evolución de los objetivos planteados. Es importante que la persona asistida entienda que se trata de una figura que asesora y acompaña puntualmente en las situaciones previstas o ante una demanda concreta.

Ante situaciones de angustia, estrés emocional o de desconcierto, el asistente procurará el apoyo emocional que disminuya la percepción negativa o de conflicto, destacando las competencias personales y las ventajas de la relación de ayuda que permite encontrar las soluciones necesarias.

El plan de trabajo debe atenerse a lo dispuesto por la sentencia judicial, si bien, a medida que avance la asistencia se irán adaptando las estrategias a las necesidades que vayan surgiendo.

Es imprescindible mantener un clima de absoluta confianza que aporte a la relación el marco referencial de la asistencia y facilite el intercambio de opiniones, deseos y pensamientos.

La finalidad de la asistencia será potenciar las habilidades, actitudes, recursos personales y comportamientos de la misma persona asistida para dotarla de nuevas herramientas que mejoren su autonomía y su adaptación al entorno, que lo permitan funcionar en las condiciones previstas a su plan de trabajo.

Es imprescindible la sinceridad y transparencia para aportar el máximo de información fiable 
que permita dar y buscar las propuestas que mejoren la calidad de vida de la persona.

Otras tareas que desarrolla el asistente incluyen acompañamientos en gestiones, trámites, visitas, reuniones, etc., si se precisa. Y también la observación y la detección de dificultades que obstaculicen su bienestar y su desarrollo.

Así se trabajará para:

- Procurar una relación de confianza y transparencia.

- Potenciar la autonomía personal.

- Mejorar el funcionamiento individual y la adaptación al entorno.

- Complementar las competencias personales, no sustituirlas. "No se trata de entregarle el pescado, sino, más bien, de enseñar a pescar dentro de lo posible.".

- Preservar la autodeterminación de la persona.

- Mantener una escucha activa

- Proporcionar acompañamiento social

- Fomentar la mejora de la calidad de vida

- Prevenir incidencias que pongan en peligro el bienestar y la seguridad personal.

\section{Principios y valores del proyecto piloto de asistencia}

Entendemos por principios aquellas leyes universales, inmutables y válidas para todo el mundo que inspiran la buena conducta personal y social. Destacamos cuatro principios importantes en la asistencia, además de los propios de una relación asistencial que procura el beneficio de la persona, destacamos:

- Principio de inclusión social, como proceso que se orienta para ofrecer a la persona asistida todas las oportunidades y recursos personales para poder desarrollarse y participar plenamente en todos los ámbitos de la vida en la comunidad.
- Principio de autogestión, en su proyecto, en la elaboración de su plan de trabajo o plan de asistencia para influir en su proceso de toma de decisiones y diseño de sus objetivos.

- Principio de corresponsabilidad, como compromiso para cooperar en la construcción de su plan de asistencia, detección de necesidades y voluntad de mejora.

- Principio de respeto a la dignidad, como condición esencial de la asistencia que se ofrece de una manera desinteresada y benefactora.

Atendemos a valores como el bien descubierto y escogido de forma libre, que es buscado y realizado por las personas y que deber ser reconocido por los demás. Al mismo tiempo, la asistencia deberá responder, entre otros, a los valores siguientes:

- El valor del desarrollo humano, para ejercer un rol que favorezca la consecución de objetivos personales, la mejora del crecimiento personal, de las condiciones de vida, con equilibrio entre los derechos y las responsabilidades de la persona.

- El valor de la equidad, que implica un trato justo a todas las personas a partir del reconocimiento, la justicia y la eliminación de cualquier actitud y/o acción discriminatoria.

- El valor de la igualdad, en relación con la eliminación de barreras y perjuicios.

- El valor de la tolerancia, que implica respetar, escuchar y aceptar ideas, opiniones, creencias y prácticas del otro.

13. Derechos y obligaciones de las partes

La regulación de la asistencia establece claramente unos derechos y unas obligaciones para las partes que van a participar de la aplicación de esta medida de protección y de una relación ayuda. 


\subsection{Derechos y deberes de la persona} asistida:

- Derecho a recibir voluntariamente la asistencia.

- Derecho a recibir la información en relación a los aspectos que le incumben.

- Derecho a presentar sugerencias y/o reclamaciones sobre la asistencia para ser valorados.

- Derecho a la intimidad y a la no divulgación de los datos personales que figuren en sus expedientes, a mantener privacidad mediante el secreto profesional de todos los datos personales.

- Derecho a disfrutar de una atención personalizada y continuada.

- Derecho a ser tratado sin discriminación, con el respeto y la consideración debidos a su dignidad, de acuerdo con sus particulares convicciones culturales, religiosas o filosóficas, y a ser tenida en cuenta su situación personal y familiar.

- Obligación de facilitar la percepción de la asistencia y a cumplir los acuerdos establecidos.

- Obligación de asistir a las citas.

- Obligación de comunicar cambios importantes.

- Obligación a mantener actitud colaboradora

- Obligación a informar de datos importantes, destacables y decisivos.

- Obligación de mostrar respeto y sinceridad.

\subsection{Derecho y deberes del asistente:}

- Derecho a comunicar a los órganos pertinentes cualquier situación de riesgo.

- Derecho a expresar una valoración objetiva argumentada ante las situaciones planteadas por el asistido.

- Derecho a orientar las decisiones del asistido para prevenir riesgos o peligros.

- Derecho a anular actos susceptibles de ser anulados, tal y como establece la ley.

- Obligación de trabajar para mejorar la calidad de las decisiones tomadas por la persona asistida.
- Obligación de velar por el buen funcionamiento y orden de los asuntos que se hayan declarado a la demanda.

- Obligación de respetar sus decisiones.

- Obligación de asesorar, informar y dotar de recursos adecuados para cada situación personal consultada.

14. Anulabilidad de los actos de la persona asistida

La ley establece en el artículo 226-3 que los actos jurídicos que la persona asistida haga sin la intervención del asistente, si esta intervención fuera necesaria, son anulables a instancia del asistente o de la persona asistida. También lo son a instancia del tutor, si se constituye tutela, y de los herederos de la persona asistida, en el plazo de cuatro años a partir desde la puesta en tutela o desde su muerte, respectivamente.

15. Modificación de la asistencia (Artículo 226-4)

A instancia de la parte interesada, incluida la persona asistida, la autoridad judicial debe acordar la reducción o la ampliación del ámbito de funciones del asistente si fuera necesario dadas las circunstancias.

Si el asistente tiene conocimiento de circunstancias que permitan la extinción de la asistencia o la modificación de su ámbito de funciones, debe comunicarlo a la autoridad judicial. 


\section{Extinción de la asistencia (Artículo 226-5)}

La asistencia se puede extinguir por las causas siguientes:

a. Por la muerte, la declaración de muerte o de ausencia de la persona asistida.

b. Por la desaparición de las circunstancias que la determinaron.

c. Por la modificación de la capacidad de la persona asistida.

En el supuesto del apartado b), la autoridad judicial, a instancia de parte interesada, debe declarar el hecho que pudiera dar lugar a la extinción de la asistencia que dejaría sin efectos el nombramiento del asistente.

\section{Régimen jurídico (Artículo 226-6)}

Mientras sean compatibles con la función de la asistencia, se aplicaran al asistente las normas de este código en materia de aptitud, excusa y remoción de los tutores, y también las relativas a la rendición de cuentas si el asistente tuviera atribuidas funciones de administración ordinaria del patrimonio de la persona asistida.

18. Publicidad registral (Artículo 226-7)

La asistencia, mientras no se inscriba en el Registro Civil, no es oponible a terceros.

La toma de posesión del cargo de asistente se debe inscribir en el Registro Civil del domicilio de la persona asistida mediante la comunicación de la resolución judicial.

\section{Valoración de solicitantes para el proyecto piloto}

Se seleccionaron tres propuestas de posibles solicitantes, en base a los criterios de acceso al proyecto piloto, junto con la valoración de distintos motivos que argumentaran las propuestas:

Caso A: se trata de una persona de 50 años de edad, con un diagnóstico de inteligencia límite y epilepsia y un grado de disminución reconocido de un $36 \%$, que vive sola desde hace años aunque se derivó al servicio de vida independiente años más tarde, trabaja en un centro especial de empleo como oficial de jardinería para el Ayuntamiento de su ciudad. Debido a algunos antecedentes de conflictiva socio-familiar, no mantiene ninguna relación significativa con sus familiares, con lo que la necesidad de apoyo se concentraba en los servicios de referencia (laboral y vida independiente). El plan de atención personal (PAP) elaborado por el servicio de apoyo a la vida independiente incluía, entre otros, apoyos relacionados con la gestión de la propia salud (seguimientos médicos, atención psicológica, etc.), la gestión de sus bienes materiales (salario y cuentas de ahorro), y la toma de decisiones personales vitales. Con el objetivo de aumentar los apoyos disponibles y de garantizar la máxima neutralidad de estos, se consideró que la asistencia podía suponer una nueva ayuda independiente de los servicios asistenciales y legitimada legalmente.

En el proceso de derivación la solicitante confirmó demandas referidas a:

- Orientación y ayuda para hacer testamento y documento de voluntades anticipadas.

- Ayuda para hacer la declaración anual del IRPF y el seguimiento de los depósitos bancarios.

- Prestar consentimiento informado y manifestaciones de última voluntad, en el caso de hacerlo ella misma, de acuerdo con sus instrucciones verbales, si antes no había 
otorgado un documento de voluntades anticipadas.

- Orientación en momentos personales de angustia en sus relaciones con otras personas.

Caso B: se trata de una persona de 53 años de edad, con un diagnóstico de trastorno de la afectividad y adaptativo, con un grado de disminución reconocido del $40 \%$, que trabaja como reponedora en unos grandes almacenes y comparte piso con un amigo desde hace nueve años, cuando murieron sus padres, sin ningún tener contacto alguno con ningún otro familiar.

Su plan de atención personal (PAP) incluye apoyos relacionados con la búsqueda de trabajo y su seguimiento, la gestión de ayudas sociales, la gestión de su vivienda, y un seguimiento cercano a nivel personal y psicológico.

En este caso, la situación de desamparo, la precariedad material y una alta fragilidad emocional provocaban una relación de dependencia con el servicio de referencia. Por estos motivos se valoró que la asistencia podía suponer una nueva ayuda complementaria que aumentara los apoyos disponibles.

En el proceso de derivación de la persona solicitante formuló demandas referidas a:

- Ayuda en las relaciones con las Administraciones públicas.

- Acompañamiento en la firma de contratos de trabajo y en su ejecución, velando por sus derechos y siendo el asistente el interlocutor en las relaciones con la empresa o entidad para la que preste sus servicios profesionales.

- Ayuda en la búsqueda de prestaciones sociales a las que pueda tener derecho.

Caso C: El último caso seleccionado se trataba de una persona de 29 años de edad, con un diagnóstico de discapacidad intelectual, hidrocefalia y problemas de salud física, con un grado de disminución reconocido del $65 \%$ que vive sola hace años, desde que su madre se trasladó a otra comunidad autónoma, con la que mantiene contactos ocasionales.
Derivada por los servicios sociales, su plan de atención personal (PAP) elaborado e iniciado hace cinco años por el servicio de de vida independiente incluía apoyos relacionados con la gestión económica, de prestaciones sociales, de varias deudas acumuladas, la búsqueda de vivienda, de formación profesional y de trabajo y un seguimiento intenso debido a distintos problemas de salud física y mental.

En este caso, la solicitud de asistencia se concretó en referencia a:

- Ayuda en la tramitación de la aceptación de una supuesta herencia familiar.

- Ayuda en el pago y amortización de deudas pendientes.

- Ayuda en la tramitación de prestaciones sociales a las que tuviera derecho.

20. Tramitación de las demandas de los solicitantes

Una vez confirmadas y formuladas las demandas de asistencia de los tres casos seleccionados por parte de los servicios jurídicos, los solicitantes fueron citados en el Juzgado pertinente. A diferencia de los procesos de incapacitación legal, en este caso el Juez y el médico forense solamente atendieron a la única declaración de la propia persona interesada y la información extraída de la documentación presentada.

Esencialmente, en las declaraciones se hizo mucha insistencia en preguntar los motivos por los cuales la persona solicitaba la asistencia, confirmar que no hubiera indicios de influencia externa en la demanda personal, confirmar también la identidad de los futuros asistentes propuestos y la conciencia de las consecuencias del acto jurídico en curso.

Por otro lado, el órgano judicial confirmó con la entidad tutelar del proyecto su conformidad con la futura aceptación de la asistencia del solicitante. 
La duración media de la tramitación de las demandas osciló entre los 6 y 9 meses. Durante este periodo, el equipo del proyecto piloto mantuvo un seguimiento continuo con los solicitantes que permitió mantenerlos informados de todo el proceso, empezar a desarrollar la concreción de los futuros apoyos de la asistencia e ir construyendo una relación de confianza per permitiera iniciar la provisión asistencia de una manera adecuada, llegado el momento.

\section{Resultados de las resoluciones y nombramientos}

De las demandas presentadas, dos casos tuvieron una sentencia judicial favorable al nombramiento de los asistentes y una denegatoria.

En los casos favorables, la sentencia determinaba las funciones de la asistencia en la esfera patrimonial, referida a la administración de bienes, por los motivos expuestos en las correspondientes demandas (realización de la declaración del IRPF, actuaciones ante las administraciones públicas, solicitud de prestaciones y ayudas sociales, a excepción de la demanda de orientación para preparar el otorgamiento de testamento, atendido el carácter personalísimo de este acto de última voluntad para el que no se requiere un pronunciamiento judicial. De las funciones relativas al patrimonio, el asistente debe rendir cuentas anuales al juzgado.

Y en la esfera personal las sentencias determinaban funciones referidas a velar por el bienestar personal a partir de las demandas que la persona asistida pudiera formular a su asistente, junto con otras más explícitas como prestar consentimiento informado en caso de no disponer de un documento de voluntades anticipadas.

En ambos casos, se confirmó el pacte individual de asistencia que ha permitido planificar y proveer los apoyos previstos en las funciones de la asistencia. Asimismo la aplicación de la asistencia se coordinó con los servicios asistenciales de referencia para garantizar la complementariedad y adecuación de los apoyos previstos gracias al trabajo en red realizado.

En un caso, la demanda fue rechazada apelando a la falta de confirmación de las voluntades del solicitante como factor determinante de todo el proceso de solicitud, valoración, aceptación o extinción de la asistencia. Las limitaciones de las capacidades cognitivas y volitivas que se evidenciaron en algunas declaraciones y contradicciones de la solicitante durante la vista, hicieron que el juez negara la conveniencia de la asistencia como medida de protección.

\section{Algunas conclusiones}

Los resultados de este proyecto piloto evidencian la viabilidad de esta nueva medida de protección legal como alternativa a los procesos de incapacitación legal.

Asimismo, es del todo necesario experimentar esta figura con el máximo de casos posibles para poder disponer de datos que permitan validar las posibilidades y los límites que ofrece.

A finales de 20I4, en Catalunya se registraron I 8 casos de personas acogidas a la asistencia por parte de entidades tutelares pero se desconoce la cifra de los casos en los que se haya demandado y nombrado a personas físicas como asistentes.

Al tratarse de una figura que coexiste con la tutela y la curatela con supuestos y regulaciones distintas, debemos explorar aquellas características y/o circunstancias que permitan orientar cada una de estas medidas de protección. Ampliar los recursos de protección de las personas exige desarrollar criterios para poder orientar y apoyar decisiones en este sentido.

Es necesario hacer la máxima difusión de la asistencia con una información que permita a 
las personas interesadas y sus referentes valorar la conveniencia de acogerse a esta $u$ otras medidas de protección legal. Mientras no sea así, seguirán prevaleciendo medidas como la tutela o la curatela que implican la modificación de la capacidad de la persona. Ello quizás sea necesario en algunos casos pero debemos procurar la individualización y adecuación de las medidas a las necesidades y las voluntades reales de cada persona.

La misma difusión debe hacerse con los órganos judiciales y colegios de abogados para dar a conocer la incidencia de su aplicación en nuestro territorio, de manera que se consolide como una verdadera opción a la incapacitación legal.

La creciente aplicación de la asistencia permitirá iniciar el análisis de la regulación de las fórmulas de protección legal de las personas con discapacidad en nuestro país. No menos importante es la revisión de cómo aplican estas medidas de protección los asistentes, sean personas físicas o jurídicas, mediante procedimientos y protocolos que orienten su ejercicio hacia las buenas prácticas, el fomento de la autonomía personal y la defensa de sus derechos. 


\section{Referencias bibliográficas}

Naciones Unidas (2006). Convención Internacional sobre los Derechos de las Personas con Discapacidad (en línea). ‘http://www.un.org/ spanish/disabilities/default.asp id=497>.

Catalunya. Llei 25/2010, del 29 de juliol, del llibre segon del codi Civil de Catalunya, relatiu a la persona i la família. Diari Oficial de la Generalitat de Catalunya, 5 d'agost de 20I0, núm. 5686.

Follia, R. (20I2): "La defensa de la dignidad de la persona en el libro II del Código civil de Cataluña. Medios para su protección”. La Notaria, (2): 36-43.

Inclusion International (20I4). Independiente pero no solo. Informe mundial sobre el derecho a decidir. Canadá: Is five Communications.

Martín, J.A. (20I I): “La asistencia como alternativa a los instrumentos tradicionales de protección de las personas con discapacidad.
Notas sobre el nuevo derecho de personas en Cataluña”, en R. Barrada Orellana, et al. (coord.): El nuevo Derecho de la persona y de la familia: Libro Segundo del Código Civil de Cataluña. Barcelona: Bosch.

Padial, A. et al. (2010): "La protección de las personas discapacitadas en el Libro II del Codi Civil de Catalunya, relativo a la persona y la familia”, en S. de Salas Murillo (coord.): Hacia una visión global de los mecanismos jurídico-privados de protección en materia de discapacidad. Zaragoza: El Justicia de Aragón.

Pereña, M. (20Iо) “Autonomía y voluntad en la dependencia y la incapacidad “. En: Jornadas DINCAT, (Barcelona 22 de Octubre de 2010), [S.l.]: [s.n.].

Ribot Igualada, J. (20I2) "L'assistència: abast i limitacions de la nova institució". En: XVIIenes Jornades de Dret Català a Tossa, (Tossa de Mar, septiembre de 20I2). [S.1.]: [s.n.]. 



\section{Responsabilidad social empresarial e integración laboral de personas con discapacidad intelectual. Estudio de caso}

\author{
Corporate social responsibility and \\ integration of people with intellectual \\ disabilities. Case study
}

Palabras clave

Responsabilidad social empresarial, discapacidad intelectual, empleo con apoyo, preparador laboral.

\section{Keywords}

Corporate social responsibility, intellectual disabilities, supported employment, job coach.

\section{Introducción}

Este ensayo es fruto del análisis de diez años de trabajo en la integración laboral de personas con discapacidad intelectual. Desde 2005 el Grupo Alimerka gestiona un programa de empleo con apoyo que ha sido reconocido en 20I 3 por la Fundación ONCE con el Premio Solidarios ${ }^{\mathrm{T}}$. Los datos de las evaluaciones anuales de este programa nos permiten presentar algunas reflexiones sobre el empleo en entornos normalizados.
I. Además del Premio Solidarios otorgado en 2013 por la Fundación ONCE al Grupo Alimerka por la labor de integración social y laboral de personas con discapacidad, el programa de empleo con apoyo coordinado por la Fundación Alimerka ha recibido los siguientes reconocimientos: Reconocimiento especial por la colaboración en beneficio de las personas con discapacidad, otorgado por la Asociación Emburria de Cangas de Onís (20I2); Premio de la Confederación Española de Personas con Discapacidad Física y Orgánica (COCEMFE Asturias) por la integración laboral de personas con discapacidad (20I0); Premio de la Federación de Asociaciones de Familiares y Personas con Enfermedad Mental de Castilla y León, a la responsabilidad social corporativa (2008); y Premio Martillo Solidario - Rompiendo Barredas de la Asociación Down de León (2006).

\section{Antonio Blanco Prieto}

<antonioblanco@fundacionalimerka.es>

Fundación Alimerka. Universidad de Oviedo

\section{Para citar:}

Blanco, A. (20I 5): "Responsabilidad social empresarial e integración laboral de personas con discapacidad intelectual. Estudio de caso", Revista Española de Discapacidad, 3 (I): 2II-2I7.

Doi: <http://dx.doi.org/I0.5569/23405IO4.03.OI.I2> 


\section{Responsabilidad social empresarial}

La responsabilidad social empresarial (en adelante RSE) expresa la voluntad de la empresa de aportar a la sociedad contribuciones positivas -adicionales a las exigidas por la ley- y a las que constituyen su responsabilidad básica de creación de riqueza (Blanco, 20I0). De este modo las empresas, conscientes del origen de sus activos económicos, podrán reinvertir parte de sus beneficios en el desarrollo de otros aspectos humanos, sociales y medioambientales que no le son ajenos, satisfaciendo con ello las expectativas de sus principales grupos de interés o stakeholders (Carroll, I993; Freeman, I984; Lozano, 2002; Verbeke y Tung, 2013).

El Libro Verde para Fomentar un marco europeo para la responsabilidad social de las empresas (Comisión de las Comunidades Europeas, 200I: 5 ) recuerda que la RSE puede contribuir de forma positiva al objetivo del Consejo Europeo de Lisboa de desarrollar una economía competitiva, dinámica y socialmente cohesionada. Una economía que potencie “prácticas idóneas en relación con la formación continua, la organización del trabajo, la igualdad de oportunidades, la integración social y el desarrollo sostenible”. Para ello, el documento de la Comisión destaca que las prácticas responsables de una empresa en materia social afectan tanto a una dimensión externa como interna y, dentro de ésta, en especial a la inversión en sus recursos humanos, la gestión del cambio y el desarrollo social en entornos dinámicos y competitivos.

En el ámbito específico de la gestión de personas, el Marco Promocional de la RSE elaborado por la Comisión de RSE de la Confederación Española de Organizaciones Empresariales (CEOE, 2006) identifica ocho actuaciones o buenas prácticas destinadas a los empleados como grupo de interés, entre las que podemos subrayar cuatro por su evidente relación con la integración laboral de colectivos vulnerables: a) respeto a su dignidad; b) respeto al principio de no discriminación; c) mejora de colectivos específicos con dificultad para la integración en el mercado de trabajo; y d) contribución a la empleabilidad de los trabajadores. Estos dos últimos apartados, de carácter voluntario al superar las exigencias legislativas vigentes, están directamente relacionados con la formación en prácticas y el empleo de personas con discapacidad intelectual.

\section{Empleo con apoyo de personas con discapacidad intelectual}

Aunque puedan presentarse incentivos económicos a la contratación de determinados grados de discapacidad, las ofertas de empleo para personas con discapacidad intelectual (que deban vincularse a programas de empleo con apoyo), revisten un carácter voluntario más allá del Real Decreto Legislativo I/20I3, que aprueba el texto refundido de la Ley General de Derechos de las Personas con Discapacidad y de su Inclusión Social. Por este motivo, el empleo con apoyo (en adelante EA) podría considerarse una práctica de RSE -y más específicamente cuando hacemos referencia a personas con mayores dificultades de integración sociolaboral, como puedan ser solicitantes de empleo con Síndrome de Down o personas con inteligencia límite-.

El EA hace referencia a la integración laboral de personas con discapacidad en empresas normalizadas gracias al "apoyo" de un preparador que acompaña al nuevo trabajador en el puesto de trabajo hasta lograr su autonomía e integración, supervisando posteriormente su evolución en la empresa (Kamp y Lynch, 2003). Por ello podríamos destacar que se trata de un sistema de refuerzo para personas que necesiten un seguimiento laboral individualizado en empresas ordinarias; seguimiento y apoyo que habría de ir retirándose progresivamente o bien espaciándose, hasta alcanzar un grado de autonomía satisfactorio por parte del trabajador (Verdugo et al, 1998). 


\section{El programa de integración de la Fundación Alimerka}

Alimerka es un grupo empresarial asturiano que cuenta con una red de I77 supermercados en Asturias, Castilla y León y Galicia. Con interés de centralizar la obra social de la empresa e iniciar nuevos proyectos de carácter socio comunitario, se constituyó la Fundación homónima en el año 2003 (BOPA I77, 3 I de julio de 2003).

Entre los años 2005 y 2014 la Fundación Alimerka coordinó el programa para facilitar la incorporación de personas con discapacidad intelectual en las empresas del Grupo, diseñando un protocolo con seis fases de trabajo para orientar los pasos a seguir por los diferentes implicados ${ }^{2}$ :

- Fase I. Identificación de los puestos de trabajo y los contextos adecuados. A partir de los análisis de puestos se identifican las funciones que podrán ser desempeñadas por personas con discapacidad intelectual. También se valoran los contextos adecuados: aspectos como número de empleados en cada supermercado o departamento, número de clientes diarios, proximidad a la asociación que prestará el apoyo, o acceso a medios de transporte, serán considerados para elegir los puestos y contextos más adecuados para la inserción.

- Fase 2. Contacto con las organizaciones sociales. Cuando surge una oportunidad laboral, se contacta con la organización de personas con discapacidad más próxima, solicitando su participación en el programa de EA y estableciendo un convenio de colaboración.

- Fase 3. Selección y formación de candidatos. La asociación correspondiente selecciona los

2. El vídeo titulado "Integración Laboral", disponible en el canal YouTube de Fundación Alimerka, resume el programa de empleo con apoyo desarrollado en la cadena de supermercados Alimerka. candidatos acordes con el perfil del puesto e imparte la formación para el empleo adecuada, combinando el desarrollo de habilidades sociales (saludo y despedida a clientes, petición de información a compañeros, etc.), con el conocimiento del producto o servicio, y el desarrollo de aptitudes específicas para el puesto (por ejemplo preparación de bandejas para horneado o colocación del producto en el punto de venta). En esta fase se considera esencial la colaboración de las familias, que deben conocer las características del EA y las condiciones laborales de la empresa, solicitando su consentimiento para continuar con el programa.

- Fase 4. Formación y sensibilización de los compañeros de trabajo. Se organizan reuniones entre representantes de las asociaciones y supervisores o mandos de la empresa para describir el programa, resolver dudas y eliminar posibles prejuicios y estereotipos que los futuros compañeros de trabajo pudiesen tener sobre el nuevo empleado.

- Fase 5. Acogida y empleo con apoyo. Cada joven contratado estará acompañado por un preparador laboral hasta que alcance autonomía en el puesto de trabajo. Este profesional será un referente estable tanto para el nuevo trabajador como para su familia y compañeros. En la elaboración de las adaptaciones necesarias al puesto de trabajo, el preparador prestará especial atención a la captación de "apoyos naturales”, identificado a quienes muestren más empatía y creen un clima laboral positivo e integrador para el trabajador.

- Fase 6. Seguimiento y evaluación. La implantación de un programa de estas características exige un seguimiento y una evaluación sistemática. La evaluación se establece ante tres hechos: el desempeño laboral del trabajador, la percepción que la empresa posee del resultado de la incorporación al puesto de trabajo y la actitud que mantiene el trabajador. 


\section{Resultados del programa}

El programa desarrollado ha facilitado el acceso al mundo laboral de I 7 jóvenes (diez personas con Síndrome de Down y siete con inteligencia límite), de los cuales nueve disfrutan de contratación indefinida. Por otro lado, en el programa de prácticas se oferta una media de diez plazas anuales en diferentes puestos.

La edad de estos jóvenes está comprendida entre los I9 y los 32 años, reconocidos con diferentes grados de discapacidad entre el $33 \%$ y el $68 \%$. El $48 \%$ son mujeres y el $52 \%$ hombres, residiendo el $63 \%$ en Asturias y el $37 \%$ en Castilla y León (León y Valladolid).

Para el seguimiento del programa se considera una inserción satisfactoria aquella que, pasados como mínimo dos años desde la finalización del EA, la persona sigue manteniendo su puesto de trabajo, desempeña adecuadamente las funciones del mismo y muestra indicadores de autonomía personal y social superiores a los manifestados antes de su incorporación al mundo laboral normalizado.

Respecto a la evaluación, se han empleado dos técnicas complementarias: un cuestionario a compañeros y supervisores de los trabajadores con discapacidad intelectual, y encuentros anuales con miembros de las asociaciones implicadas. La experiencia y los resultados hasta la fecha son satisfactorios, tanto desde el punto de vista laboral como social, valoración que también podemos extender hacia los clientes y, especialmente, las familias de los trabajadores, que manifiestan haber detectado un incremento de la autonomía, integración social y satisfacción personal de sus hijos o hermanos.

Para los encuentros anuales, la Fundación Alimerka ha coordinado ocho jornadas con responsables y técnicos de empleo de las Asociaciones Down de Asturias, León y Valladolid, la Fundación Edes y la Asociación Emburria. En estas jornadas, celebradas entre
2006 y $2014^{3}$, se ha podido reflexionar sobre el trabajo realizado en el marco del EA, así como fomentar el conocimiento personal de los preparadores de diferentes provincias y valorar el desarrollo del programa, identificando posibles cambios o actualizaciones en el diseño de puestos.

En las dos primeras jornadas el mayor peso lo tuvieron los miembros de las juntas de gobierno de las asociaciones implicadas, que debatieron sobre la forma idónea de articular las relaciones entre la empresa y las asociaciones de personas con discapacidad intelectual. A partir de 2008, el enfoque de las jornadas fue orientándose hacia una óptica más técnica, enfatizando el protagonismo de los preparadores laborales y mandos de la empresa. A partir de 20I2, también se invitó a participar a los jóvenes contratados y en prácticas, ofreciéndoles la oportunidad de evaluar el programa de empleo desde su mirada como personas con discapacidad ${ }^{4}$.

El análisis de contenido de las actas de las jornadas técnicas, donde se recogen las intervenciones de los diferentes participantes -gestores, preparadores laborales, trabajadores con discapacidad y supervisores-, permite identificar conclusiones que podríamos agrupar en tres áreas de trabajo: el de gestión de asociaciones, el de orientación y preparación laboral, y el de gestión de recursos humanos en la empresa contratante. Estas conclusiones se numeran a continuación:

\section{Aspectos a valorar desde la gestión de las Asociaciones de personas con discapacidad}

I. Es necesario implicar a las familias en los procesos de integración laboral. Para

\footnotetext{
3. I ${ }^{\mathrm{a}}$ Jornada técnica, celebrada el I 2/06/2006 en Down León; $2^{a}$ Jornada técnica: 23/10/2007, en Down León; $3^{a}$ Jornada: I 5/04/2008, en Down León; 4 J Jornada: 31/05/2009, en Centro Logístico Alimerka; 6 a Jornada: 29/I I/I 2, en Centro Logístico Alimerka; $7^{\mathrm{a}}$ Jornada: 28/05/2013, en Asociación Emburria, Cangas de Onís; 8 a Jornada: ०8/07/20I4, en Down León.

4. Un resumen de una de estas jornadas puede encontrarse en el canal YouTube de Fundación Alimerka, bajo el título "Jornada de Empleo con Apoyo - Cangas de Onís 2013”.
} 
motivar a las familias es adecuado que las asociaciones "rompan" esquemas y prejuicios de los padres, organizando pequeños talleres y potenciando la difusión de la integración laboral tanto a nivel asociativo como a través de los medios de comunicación.

2. El equipo directivo debe sensibilizar a las familias sobre la importancia del contenido del trabajo en vez de la imagen social del mismo. En este caso, los trabajos de “cuello azul” pueden llegar a ser, según las funciones y tipo de empresa, más complejos que otros trabajos de "cuello blanco", tanto desde un punto de vista cognitivo como manipulativo. En vez de prejuzgar una oferta laboral por su status asociado, debe valorarse la descripción del puesto, funciones o relaciones sociales que se establecen.

3. Debe coordinarse el trabajo entre tres unidades: empresa-asociación-familia. La empresa debe implicarse tanto con la asociación como con la familia, del mismo modo que la familia debe aceptar su vínculo tanto con la empresa como con la asociación.

4. El organigrama de cada asociación repercute directamente en los programas de empleo. En aquellas organizaciones en las que los preparadores laborales y técnicos poseen más autonomía y flexibilidad de trabajo resulta más eficiente la incorporación del trabajador y la integración del triángulo familia-empresaasociación.

\section{Aspectos a valorar desde los equipos de empleo}

I. El preparador laboral deberá conocer el puesto de trabajo que será ocupado, desempeñando previamente unas horas o unos días las principales actividades del puesto para luego poder trasmitirlas.
2. El preparador debe acompañar al trabajador a visitar su futuro centro de empleo unos días antes de su incorporación. Como el preparador ya conocerá la empresa ejercerá de “anfitrión” junto con la persona encargada del centro de trabajo.

3. Para vincular e incentivar a los futuros compañeros de trabajo, conviene hacer una presentación que responda a tres interrogantes: ¿qué es la discapacidad intelectual?, ¿qué características tiene un trabajador con síndrome de Down / inteligencia límite / etc.? y ¿qué función cumple el EA?

4. Además de la propia incorporación laboral, los preparadores pueden organizar grupos de autogestión del ocio. De este modo, los asociados que ya estén trabajando pueden reunirse semanalmente con sus preparadores laborales para decidir y planificar su tiempo libre.

5. Sería adecuado disponer de un protocolo de EA que indicase pautas a seguir, competencias que deben trabajarse o estrategias para trabajar en el entorno de trabajo. Esto no debe hacernos olvidar la variabilidad de cada incorporación laboral ni la flexibilidad necesaria para adaptarse a cada situación.

6. El preparador debe preguntarse qué pasará cuando se vaya y, si tiene dudas, pensar en posibles acciones de apoyo y seguimiento.

7. El foro y el chat de Down España es una importante fuente de información y resolución de dudas para los preparadores laborales. También los encuentros periódicos entre preparadores laborales son muy útiles para contrastar puntos de vista $\mathrm{y}$ formas de trabajo diferentes.

\section{Aspectos a valorar por la empresa}

I. La empresa ha de definir su objetivo con la integración de trabajadores con 
discapacidad intelectual. Debe identificar si persigue una acción de RSE, una ganancia de reputación social, la cobertura de un puesto de trabajo o una fusión de todos estos objetivos.

2. En caso de necesitar la cobertura de un puesto de trabajo, es necesario insistir en la diversidad, pues cada trabajador y cada centro de trabajo tienen características específicas. Por tanto, algunos trabajadores con discapacidad intelectual serán un apoyo importante pero no podrán desempeñar con máxima eficacia todas las funciones de un puesto.

3. Es necesario reflexionar sobre los motivadores que la empresa ofrece a los compañeros del trabajador con discapacidad intelectual, pues éstos también sentirán "desgaste" por la interacción continua. Refuerzos como reconocer su papel de apoyo, y escuchar sus valoraciones pueden ser muy valorados.

4. Los trabajadores con discapacidad intelectual necesitan tener un "apoyo natural” o compañero de trabajo que sea su referente en la empresa. No debemos confundir jerarquía con apoyo natural, pues la empresa no debe imponer este rol a ningún encargado o trabajador y será la propia dinámica de las relaciones interpersonales la que hará que surjan vínculos afectivos.

5. Es muy importante la actitud de los compañeros y supervisores en el lugar de trabajo, por lo cual hay que seleccionar adecuadamente el destino para la incorporación, procurando evitar centros con alta rotación de empleados para poder conseguir apoyo natural.

\section{Conclusión}

La Fundación Alimerka ha gestionado entre 2005 y 2014 un programa de integración laboral en la empresa ordinaria, impulsando la contratación de I 7 jóvenes con Síndrome de Down o con inteligencia límite en puestos de ayudante de panadería y de reponedor en supermercados, así como gestionando prácticas de una media de ro personas al año con discapacidad intelectual.

Con ánimo de efectuar un seguimiento sistemático de este programa, durante ocho años se realizaron tanto cuestionarios como encuentros con todas las partes implicadas (gestores de las asociaciones y preparadores laborales, trabajadores con discapacidad y representantes de la empresa). Estos encuentros han sido determinantes para conocer las características del programa de incorporación laboral de personas con discapacidad intelectual, comprendiendo que su buena gestión implica un mayor compromiso que la mera contratación laboral.

La implicación conlleva la coordinación del trabajo con asociaciones o entidades de personas con discapacidad, así como un seguimiento del empleo con apoyo y la evaluación de sus resultados tanto laborales como sociales. Por ello podríamos defender que la integración laboral de personas con discapacidad intelectual supone un acto laboral acorde con la legislación vigente, pero también un reto y una práctica de RSE. Y es que los fines de toda acción de responsabilidad social en una empresa habrán de ser coherentes con los retos de la sociedad de la que forma parte, como el desempleo, la integración de personas con discapacidad o la igualdad de las personas. 


\section{Referencias bibliográficas}

Blanco, A. (2010): "Las aportaciones de la Sociología española a la Responsabilidad Social Empresarial". Revista Internacional de Sociología (RIS), 68: 577-602.

Carroll, A. (1993): Business \& Society - Ethics and Stakeholder Management, Ohio: South-Western Cengage Learning $\left(2^{\mathrm{a}} \mathrm{Ed}\right)$

Comisión de las Comunidades Europeas (200I): Libro Verde. Fomentar un marco europeo para la responsabilidad social de las empresas. $\mathrm{COM} / 200 \mathrm{I} / 366$ final, de I 8 de julio de $200 \mathrm{I}$ (en línea). <http://eur-lex.europa.eu/legalcontent/ES/TXT/?uri=CELEX:5200IDC0366,, acceso 8 de enero de 2015 .

Confederación Española de Organizaciones Empresariales (CEOE) (2006): Borrador del Marco Promocional de la Responsabilidad Social, de 4 de noviembre de 2006, Documento interno.
Freeman, R.E. (1984): Strategic Management: A Stakeholder Approach, Boston: Pitman.

Kamp, M. y Lynch, C. (2003): Handbook Supported Employment, Middelharnis, Netherlands: Stichting Zuidwester.

Lozano, J.M. (2002): “ ¿Hacia la empresa ciudadana?”, en Albarello, M. (coord.): La Responsabilidad Social Corporativa y los Códigos de Conducta: ¿̇eneficios para todo el mundo? Barcelona: Fundació Pau i Solidaritat de Comissions Obreres de Catalunya.

Verbeke, A. y Tung, V. (20I3): "The Future of Stakeholder Management Theory: A Temporal Perspective”. Journal of Business Ethics, vol. I I2 (3): 529-543.

Verdugo, M.A. et al. (I998): "Situación actual del empleo con apoyo en España”. Siglo Cero, I75, vol. 29: 23-3I. 



\section{RESEÑAS}





\section{Renguear el estigma. Cuerpo, deporte y discapacidad motriz (Buenos Aires, 1950-2010) \\ Carolina Ferrante (2014) Argentina: Biblos}

\author{
Daniela Testa \\ <danitestu@yahoo.com.ar> \\ Hospital José T. Borda. Buenos Aires, Argentina
}

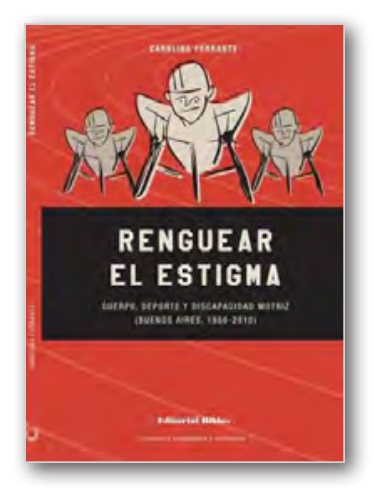

RENGUEAR EL ESTIGMA retarma
Este libro contribuye a los debates en torno a los estudios sociales de la discapacidad, no sólo porque aborda un tema poco estudiado desde la comunidad sociológica local, sino porque articular una lectura desde el cuerpo, la discapacidad y el deporte representa un original enfoque que ilumina nuevas aristas del problema. El título, como primer acercamiento entre el libro y el lector, parece haber sido pensado para despabilar la curiosidad y el ingenio de aquellos interesados en pensar el cuerpo, el deporte y la discapacidad motriz en perspectiva social. A través de la metáfora y de la ironía, la autora nos adelanta que el tema será abordado en complejidad, y además, con frescura y gran agudeza crítica. Desde los primeros párrafos queda enunciado que asumir tales reflexiones en las sociedades occidentales actuales requiere, como condición necesaria, tensionar fronteras, forzar dicotomías y desnaturalizar conceptos. Las luchas simbólicas por el cuerpo legítimo, las tiranías de la perfección, la mirada médica hegemónica sobre la discapacidad, la naturalización del déficit, la discapacidad como problema individual que enluta la existencia y/o como problema social, son algunas de las conceptualizaciones que irán constituyendo un entramado dialéctico a medida que se avanza en el libro.
La autora sedimenta el punto de partida de su estudio a partir de la problematización entre la mirada armonicista sobre los efectos del deporte en la discapacidad, (concebido como un espacio de pura sociabilidad e intrínsecamente positivo) y la visión teórica opuesta (que sostiene que el deporte adaptado es una de las formas de integración excluyente). Ferrante toma distancia de estas posturas para señalar que ambas, ya sea por aceptación o rechazo del deporte adaptado, parten de una concepción biologicista del cuerpo, sin historizar el déficit ni rescatar la dimensión social del cuerpo como producto de las condiciones de existencia y pivote de la experiencia. Buscando la capacidad de agencia de los sujetos y sin temor a enfrentar las aristas ambiguas de lo social, la autora se sumerge en el tema a partir de preguntarse cómo influye la práctica deportiva en los modos de ser, pensar y sentirse discapacitado. Sí parece claro que es imposible pensar las prácticas deportivas adaptadas sin considerar los procesos sociales, históricos y políticos, también lo es, la necesaria desnaturalización conceptual de las nociones de déficit, cuerpo, deporte y discapacidad. Asimismo, la autora revisa empíricamente conceptualizaciones teóricas originadas en otras latitudes a través del análisis inductivo del material empírico. De ese modo, constituye un conocimiento concreto que posibilita otras lecturas, tendientes a oradar falsos reduccionismos y a reconocer la experiencia del deporte adaptado como práctica intersticial de resistencia y de gran potencia transformadora en la resignificación de la experiencia de la discapacidad para sus protagonistas.

El libro presenta cinco capítulos. Los dos primeros, de carácter histórico, analizan el origen y la constitución del campo del deporte para personas con discapacidad motriz en la ciudad de Buenos Aires, entre I950 y 1976. Con el fin de identificar la filosofía del deporte adaptado, construida a partir de las prácticas deportivas, se analizan las instituciones que lo constituyeron. Entre ellas, el Club Marcelo Fitte, fundado en 1948 por y para personas con discapacidad y la creación de la Comisión Nacional del Lisiado, en I956, surgida como una de las respuestas del gobierno de facto ante un grave azote de la poliomielitis. La primera vez que un grupo de deportistas argentinos participó en los VI Juegos Olimpicos para Parapléjicos

Revista Española de Discapacidad, $3(\mathrm{I}): 22 \mathrm{I}-222$. 
de Stocke Mandeville (Inglaterra), en I957, acuñó uno de los hitos históricos del campo e inició una profusa cosecha de posteriores éxitos deportivos. A su vez, la experiencia dio lugar a importantes aprendizajes que luego se vieron reflejados en el proceso de politización de los agentes. En estos capítulos iníciales es presentada la categoría nativa "rengo" como una noción que expresa un modo duradero de "ser" discapacitado, creado y promovido en el momento fundacional del campo. Será una metáfora re-significada como una categoría esencial que acompañará al lector durante todo el recorrido (cuya utilización en el campo continúa vigente).

En el capítulo tres se analizan las concepciones del cuerpo discapacitado legítimo en relación con la mirada médica rehabilitadora y los desafíos y disputas surgidos a partir de otras miradas disonantes que cuestionaron aquellas implícitas en el campo, concebido como escuela de moralidad. La presencia de los denominados "nuevos rengos" refleja un cambio sanitario epidemiológico que señala el aumento de las discapacitaciones por causas prevenibles, (como heridas de bala o arma blanca, accidentes de tránsito o de trabajo). Ello generó cambios y constituyó un desafío a la moral tradicional, (basada en la superación y el esfuerzo personal), al poner sobre el tapete las prácticas de mendicidad como una de las estrategias para la sobrevivencia. Distintas formas de ser rengo: "el espíritu libre", "el que trata de vivir sin ser Maradona” y "el que ejerce la mendicidad", son parte de un abanico en los diversos modos de renguear el estigma. Si bien se jerarquiza un estilo de vida tributario de la definición de cuerpo sano y bello en el nivel de la sociedad global, queda señalado que este no es el único modo de ser que se teje en el espacio deportivo sino que convive con otras de formas de ser y vivir con una discapacidad motriz. Dichas experiencias diferenciales están asociadas a la posición de clase y a la posibilidad de incorporar exitosamente los mandatos de autocuidado corporal valorados en el campo.

En el capítulo cuatro, la autora profundiza en las experiencias encarnadas de la discapacidad, es decir en las formas de sentir la discapacidad, más allá del género, la clase social y el tipo de discapacidad adquirida. Es importante destacar que todos los entrevistados refieren un antes y un después en la experiencia corporal de la discapacidad a partir de su llegada al deporte. La adquisición de saberes prácticos y el intercambio con pares habilita intersticios que conducen a quebrar estereotipos a través de las prácticas deportivas.

Sin embargo, como señala Ferrante, comprender y asumir una posición ética y comprometida ante las formas de organización social de la discapacidad, es una tarea compartida. Dicho a través de sus palabras:

$$
\begin{aligned}
& \text { “...luchar en el plano político académico } \\
& \text { para desmantelar la dominación que erigen } \\
& \text { las tiranías de la perfección, no sólo sobre } \\
& \text { las personas con discapacidad sino sobre } \\
& \text { todos aquellos cuerpos que escapamos a } \\
& \text { la normatividad hegemónica, constituyen } \\
& \text { elementos que nos comprometen a todos”. } \\
& \text { (Ferrante, 20I4, p.I29) }
\end{aligned}
$$

La relevancia social del tema, las conceptualizaciones críticas y la fuerza de la evidencia empírica relevada a partir de la experiencia de los protagonistas, hacen que la lectura de este libro sea estimulante, tanto para revisitar aquellos autores que acompañaron la construcción del objeto teórico y los argumentos elaborados (como Erving Goffmam, Merleau Ponty, Pierre Bourdieu, Michel Foucault, Axel Honneth), como para propiciar la deconstrucción de aquellas situaciones de índole más concreta que reproducen los procesos de estigmatización y opresión en la vida cotidiana.

Es así como este libro se constituye en lectura recomendada para investigadores de esta área de estudios y para todos aquellos que organicen su quehacer y preocupaciones profesionales en torno a la temática. Es bueno saber que leer Renguear el estigma invita, además, a interrogarnos sobre los propios modos de ser, pensar-nos y sentir-nos, quizá un poco rengos de humanidad, quizá un poco rengos de la cabeza, todos enlazados en las inequidades e injusticias de un mundo social compartido. 


\title{
Adultez, trabajo y discapacidad. El trabajo de crecer \\ Patricia Brogna (2014) \\ México: Trillas
}

\author{
Carolina Ferrante \\ <caferrante@gmail.com>
}

Fondo Nacional de Desarrollo Científico y Tecnológico (FONDECYT), Escuela de Psicología, Universidad Católica del Norte (UCN), Antofagasta, Chile.

El libro Adultez, trabajo y discapacidad. El trabajo de crecer es el fruto de 20 años de experiencia en el campo de la discapacidad de Patricia Brogna. La misma incluye no sólo la teorización respecto a la comprensión de la discapacidad como asunto social que generó numerosas publicaciones y su tesis doctoral en Sociología (Brogna, 20 I 2), sino también, su militancia en el plano del reconocimiento de los derechos de las personas con discapacidad y su labor en conjunto a las personas con discapacidad en los ámbitos educativo y del trabajo como terapeuta ocupacional. Da cuenta también de su transición por estas áreas en la provincia de Neuquén, Argentina (su país de origen) y en el DF,

México (su lugar de actual residencia). Estas múltiples inscripciones profesionales y geográficas, que en realidad podrían entenderse como una trayectoria de trabajo consistente y comprometida por alcanzar el respeto y la inclusión de las personas con discapacidad, se sintetizan en este nuevo libro de la autora, editado por Trillas en México.

La problematización que aborda el texto, desde su inicio, desnaturaliza algo que la estigmatización de las personas con discapacidad en general, y muy en particular de aquellas con discapacidad intelectual, niega: la posibilidad de las mismas de desarrollarse como miembros plenos de la sociedad y encarnar las expectativas normativas generales. Específicamente el libro se concentra en dos de ellas íntimamente relacionadas: el devenir adulto y el ejercer el derecho al trabajo. Partiendo de una perspectiva enmarcada en el modelo social de la discapacidad, la argumentación apunta a enfatizar que este inconveniente poco tiene que ver con las deficiencias orgánicas. La raíz del problema se encuentra en los procesos sociales que intervienen en la configuración de la persona con discapacidad en una "posición de otro en el campo de lo social", alejado de un "nosotros adulto". Al respecto, en el Capítulo I, "Definición de los conceptos”, Brogna señala: El objeto borroso 'otros-nosotros adulto' está formado por un extremo de 'plena membresía a otro', una zona intermedia, gradual, de 'plena no membresía' a partir de la cual inicia (como la imagen reflejada en un espejo) la zona de 'plena membresía a nosotros' (Brogna, 20I4: I I).

Como podemos advertir, el recorte del objeto de estudio que se privilegia en este texto, es decir, el cruce discapacidad intelectual-adulteztrabajo constituye una elección teórica y metodológica muy inteligente, ya que permite poner en foco varios de los nodos conceptuales que estructuran la unidad problemática discapacidad-estigma-sociedad.

Ahora bien, ¿qué elementos llevan a que el agente quede ubicado en estas posiciones virtuales de extrañeza o familiaridad? O mejor aún ¿qué es lo que hace que un adulto sea considerado tal? $\mathrm{Al}$ respecto, la autora señala, que, a partir de la investigación que dio fruto a su tesis doctoral, pudo identificar que el ser adulto en nuestras sociedades no tiene que ver con un rasgo etario o demográfico, sino con el desempeño de cuatro dominios de valoración: el cuidado de sí, la distancia física, el trabajo y la sexualidad/procreación. Los mismos, a la vez, comprenden diversos grados de inclusión y membresía en el continuum otrosnosotros adultos. Los dominios de valoración del ser adulto son concebidos como una secuencia ordenada y jerárquica de escalones, en donde, si no se dan los primeros, es imposible para el agente proyectarse o ejercer activamente los últimos. En este aspecto, uno de los principales hallazgos de la investigación citada,

Revista Española de Discapacidad, 3 (I): 223-226. 
señala Brogna, lo constituyó el visibilizar una ausencia de claridad al respecto en las instituciones educativas y laborales y en las familias. Desde esta perspectiva, si el ser adulto se asocia a un camino a recorrer en el que se adquieren diversas habilidades, el protagonista del mismo lo constituye el niño o joven con discapacidad. La comunidad, como agente multidimensional, será otro actor importante en promover esta transición ya sea exitosamente o estableciendo obstáculos y poniéndole trabas en ese recorrido, haciéndolo permanecer en una posición de eterno infante.

En el Capítulo 2, "Un recetario sin recetas", la socióloga plantea ¿cómo hacer que un hijo o niño transite a la adultez exitosamente y con el menor conflicto posible? Al respecto, señala que tanto en niños con o sin discapacidad no existirá una única respuesta al respecto, sino múltiples posibilidades. Asumiendo esta complejidad, señala que este interrogante podría abordarse desde diversos niveles de análisis de lo social, tales como el macro (que refiera a la gran escala), el meso (lo institucional o comunitario) o el micro social (lo familiar e individual). Debido a la ausencia de trabajos en América Latina que puntualicen en los dos primeros niveles, decide privilegiar el nivel meso social. Este recorte del objeto podemos decir, además, que posee la virtud de detectar las posibilidades y barreras existentes en uno de los mayores espacios de sociabilización de las personas con discapacidad, por lo cual resulta una elección metodológica muy rica, que habilita una contribución social muy importante en la investigación en discapacidad, más si pensamos cómo la intervención en cada una de las dimensiones de lo social descriptas posee consecuencias en las otras. En este sentido, analizar qué puede hacerse desde el nivel comunitario para propiciar el trabajo de crecer (con las implicancias en afianzamiento de una perspectiva de ciudadanía y de derechos de las personas con discapacidad), qué elementos obstaculizan esta tarea, constituye un recorte desde lo político empoderador.

Asumiendo que no existen recetas mágicas que favorezcan la transición exitosa de las personas con discapacidad a la adultez, Brogna señala que sí existen algunas “claves” que lo promoverán. Entre las mismas señala: comenzar la planificación tempranamente; tener una visión de mediano y largo plano; buscar apoyos para la sede de trabajo en sede; explorar alternativas en la comunidad; evaluar opciones y alternativas; poner en marcha un plan de acción: evaluar los progresos periódicamente; identificar contactos y recursos necesarios. Todas estas claves son desarrolladas y explicadas claramente.

A continuación, adoptando el recorte mesosocial señalado, la autora se centra en el rol de la institución escolar y laboral en la transición a la adultez de las personas con discapacidad intelectual y en las redes comunitarias que propiciarán la misma. Para ello despliega algunas estrategias que promueven transiciones eficaces y el desarrollo de habilidades adaptativas. Estas últimas comprenden competencias conceptuales, sociales y prácticas que permiten a un agente ser un miembro socialmente diestro en la vida cotidiana. Para propiciar las mismas, expone actividades para adquirir habilidades de comunicación y habilidades sociales (a las cuales refiere como "ser y estar en sociedad") en los jóvenes con discapacidad intelectual. Las mismas no apuntan a un adiestramiento del cuerpo, al estilo del modelo médico reparador, sino que constituyen actividades que permiten adquirir un saber social necesario para luego poder desempeñar efectivamente un rol adulto en la vida social. A la vez, las mismas no hacen énfasis únicamente en el individuo, sino en su entorno. Brogna indica que el desarrollo de estas habilidades sociales, son "objeto y objetivo de intervención docente" (20I4: 38), sin embargo, en América Latina estos aspectos se encuentran subvalorados en la currícula en pos del desarrollo habilidades académicas. El problema de esta situación reside en que, como vimos anteriormente, sin el desarrollo de estas habilidades y el desempeño del cuidado de sí y la distancia física se convierte en ficticia la posibilidad de posterior desempeño adulto de los jóvenes con discapacidad. 
En el Capítulo 3, "Derecho al trabajo de la persona con discapacidad", partiendo del doble carácter del mismo en tanto derecho y obligación, la autora realiza un mapeo de la legislación relacionada a trabajo y discapacidad. El mismo abarca un pormenorizado rastreo de los antecedentes históricos internacionales al respecto y de las herramientas actuales a nivel global, regional y de México. Estos elementos también son desarrollados en uno de los Anexos que consta el libro.

Por último, en el Capítulo 4, “Trabajo y empleo" la autora clarifica algunos conceptos nodales para "analizar, planificar y organizar acciones tendientes a la capacitación e inclusión laboral" (Brogna, 20I4: 57). Entre los mismos explica la definición y la importancia de nociones tales como: competencia profesional, habilidades específicas, capacidades, conocimientos, actitudes, apoyos e intensidades de los mismos, intereses, análisis ocupacional o del puesto de trabajo, profesiograma, comunicación, lenguaje, discriminación por causa de discapacidad, ajustes razonables, diseño universal, personas con discapacidad y discapacidad. Algunas de estas herramientas también son ejemplificadas en los anexos.

Asimismo, en este último capítulo, recuperando los aportes de la sociología de Robert Castel señala por qué el derecho al trabajo constituye uno de los ejes de reivindicación del modelo social de la discapacidad. Al respecto, recuperando al autor francés, indica cómo en nuestras sociedades contemporáneas el trabajo no sólo se asocia a las posibilidades de supervivencia material, sino con las opciones de inscripción en la estructura social y de construcción de relaciones sociales, influyendo en la zona social que el agente ocupará. Desde esta perspectiva, estar privado de trabajar, en este contexto, implica mucho más, simbólicamente, que estar desempleado, significa una lesión en la identidad del individuo y en sus soportes de inscripción. Esto, a la vez poseerá fuertes consecuencias en su ubicación en zonas de escasa cohesión social. En este sentido, el no trabajo, el asistencialismo y el trabajo precario al cual se ven afectadas la amplia mayoría de las personas con discapacidad a nivel global aún hoy, constituye un factor que promueve la vulnerabilidad y desafiliación o exclusión social de las mismas. Y por ello, el derecho al trabajo constituye la principal vía para transformar esta situación.

En este aspecto, Brogna, recuperando la Convención Internacional sobre los Derechos de las Personas con Discapacidad enfatiza la necesidad de abandonar figuras como la del taller protegido para empezar a pensar en los talleres integrados. Señala que los primeros, a lo sumo, podrían funcionar sólo como trampolín para la inclusión laboral, pero que no constituye la solución al problema. Tampoco considera válido asumir posturas resignadas que, ante la dificultad de derribar los obstáculos que impiden la inclusión laboral de las personas con discapacidad, se contenten con reproducir lo que en este contexto excluyente "es posible". Al respecto, indica que es necesario pensar "en lo debe ser". Este último aspecto resulta una reivindicación fundamental y una bocanada de aire importante de tener presente en espacios sociales como los actualmente generados por el neoliberalismo, donde se impone la frustración y la imposibilidad de pensar el cambio social. Tener bien claro que debemos luchar por lo que debe ser constituye, a mi entender, una bandera que todos los que queremos ver un mundo más justo debiéramos tener bien clara. Y en este aspecto, Adultez, trabajo y discapacidad constituye un ejemplo de la importancia y el valor que posee desde la investigación social desarrollar abordajes que desnaturalicen la estigmatización, la expliquen para permitir comprender el por qué, pero que también propongan soluciones. En este aspecto quizá el diálogo multidisciplinario juegue un papel importante para poder pensar estas posibilidades. Pero, insisto, lo que creo que es nodal, y este libro logra privilegiadamente, es el desafío de brindar herramientas teóricas para comprender a la discapacidad como forma de opresión, y, a la vez, proponer estrategias que permitan promover la toma de conciencia, visibilizando espacios y actores de transformación social. 


\section{Referencias bibliográficas}

Brogna, Patricia (2012). Condición de adulto con discapacidad intelectual. Posición social y simbólica de "otro". Tesis de Doctorado en Ciencias Políticas y Sociales, Universidad Nacional Autónoma de México. Disponible en: http://I32.248.9.I95/ptd2013/ abril/50545II $58 / 50545$ I I 58 .pdf). 


\section{La construcción imaginaria de la discapacidad (Segunda Edición Ampliada) Marcelo Silberkasten (2014) Buenos Aires: Topía Editorial}

\section{Carolina Ferrante}

<caferrante@gmail.com>

Fondo Nacional de Desarrollo Científico y Tecnológico (FONDECYT), Escuela de Psicología, Universidad Católica del Norte (UCN), Antofagasta, Chile.

La Construcción Imaginaria de la Discapacidad, de Marcelo Silbekasten, es un libro perteneciente a la Colección Psicoanálisis, Sociedad y Cultura de Topía Editorial. Tuvo su primera edición en el año 2006, y, tras estar agotado, fue reeditado en el 2014 en la Ciudad de Buenos Aires. Tal como señala Pablo Snieg, en el prólogo a esta nueva impresión, este libro, en el campo de la discapacidad de Argentina, se había convertido en una recomendación que circulaba de "boca en boca". El difícil acceso tras su agotamiento, hizo que se generara una esperada ansiedad ante esta nueva edición. Hoy se accede no sólo a este libro tan recomendado por personas que sostienen miradas críticas de la discapacidad, sino también, a una versión ampliada que consta de un nuevo prólogo y de una nueva introducción.

Cuando se decide reseñar un texto que se considera muy bueno, una de las tensiones que emerge es similar a aquella que nace cuando se quiere recomendar una película en el cine: por un lado, se intenta dar argumentos para interesar al potencial lector/espectador, y, por otro, se busca no darle tanta información como para desinteresar su acercamiento a la obra. Espero a lo largo de esta breve reseña saber mantener esta tensión, y de contagiar las ganas de leer el texto a los potenciales lectores.
El interrogante que estructura $L a$ Construcción Imaginaria de la Discapacidad es “¿qué define en la subjetividad que alguien sea representado como discapacitado?" (Silberkasten, 20I4:58).

Inscribiéndose críticamente en el modelo social de la discapacidad, a través de esta problematización el psicoanalista argentino des-naturaliza lo que el sentido común da por obvio: que esta representación se asocia a la portación de una deficiencia corporal. $\mathrm{Al}$ respecto, el autor sostiene, como hipótesis de trabajo, que lo que define a una persona como discapacitada es "su exclusión del sistema de producción de bienes y servicios de una comunidad" históricamente determinada (Silberkasten, 2014: 59). Desde esta perspectiva, sostiene que la "noxa no define" que una persona sea considerada discapacitada, "cosa que sí hace, su lugar en el sistema social" (Silberkasten, 20I4: 59). En este punto, afirma, la credencial médica que certifica la portación de una discapacidad, lo que legitima es esta exclusión laboral, a partir de una visión ideológica del individuo funcional al sistema productivo.

Esta exclusión estigmatizante en lo económico posee consecuencias representacionales y simbólicas: la persona con discapacidad al ser exiliada del mundo de la producción,

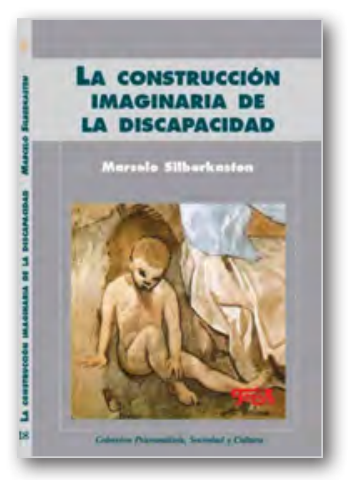

"no circula por un sistema de intercambio", quedando fijado a una identidad devaluada que le niega su pleno carácter humano. Esta última construcción se impregna en el lenguaje mismo con el cual se piensa a la discapacidad y posee consecuencias concretas en la vida cotidiana de las personas con discapacidad y en el espacio social.

En este aspecto, Silberkasten señala que si bien en los últimos años en las políticas se han avanzado en leyes que apuntan a la inclusión de las personas con discapacidad, en los hechos, al no cuestionarse las bases estructurales de la exclusión se reproducen los mecanismos que la generan y reproducen. Ironizando al respecto, señala que como continuidad a lo largo de la historia occidental el único derecho por el cual no han tenido que luchar las personas con discapacidad es el derecho a mendigar. En tales sociedades, que transformar al trabajo no sólo en el espacio de inscripción en la estructura social, sino en un imperativo ético asociado al auto valimiento y la exaltación individualista, las personas con discapacidad tienen derecho

Revista Española de Discapacidad, 3 (I): 227-229. 
a pedir dinero sin contraprestación, es decir, a pedir limosna, legalidad que para aquellos agentes no percibidos como discapacitados posee fuerte sanción social. Esta lógica parece atravesar la discapacidad, y, para referirse a este mecanismo, Silberkasten utiliza el concepto de ideología de la caridad. Esta noción señala un tipo de relación en donde el vínculo establecido con la persona con discapacidad, mediado por su connotación desgraciada y culpógena, fija su infravaloración y exclusión productiva, convirtiéndolo en un objeto tributario de diversas especies de contraprestación, anulando la posibilidad de reconocimiento intersubjetivo. Por ejemplo, cuando se establece una pensión por "invalidez" laboral, o, en pos de una medida de discriminación positiva, se exime a las personas con discapacidad de pagar el transporte público se puede visualizar la lógica de la limosna en acción.

A lo largo de los doce capítulos que componen el texto, Silberkasten, analiza estos mecanismos en los vínculos sociales cotidianos, en la familia, en el espacio de la escuela, de la rehabilitación, en las políticas y en la identificación de la persona con discapacidad.

Discute la tesis que sostiene que en la discapacidad existe una herida narcisista a resolver en el individuo y en la familia, sosteniendo que el problema reside en la no posibilidad de identificación a partir de la exclusión del sistema productivo y de representaciones. Asimismo, cuestiona las intervenciones psicológicas, médicas y políticas que únicamente hacen eje en el cuerpo individual, sin modificar al cuerpo social, ese que produce la exclusión de las personas con discapacidad.

Si como se indicaba más arriba estas críticas inscriben esta obra al modelo social de discapacidad, en esta nueva edición que reseñamos encontramos también una vuelta de rosca al respecto. En este punto, el psicoanalista argentino señala que si en los ocho años que separan esta versión a la original se han registrado importantes avances en la visibilización de las personas con discapacidad, no obstante, también afirma que es posible observar cierta banalización en algunas posturas cuestionadoras de los abordajes tradicionales. $\mathrm{Al}$ respecto, el autor señala un uso demasiado "amplio" y "liviano", por ejemplo, del concepto de discriminación (Silberkasten, 20I4: I3). Esto hace que el mismo termine perdiendo su potencia "política y social", al deslegitimarse frente a la sociedad general. En este punto, y en línea con la argumentación central del libro, Silberkasten sostiene que: "detrás de lo que se piensa como discriminación la mayoría de las veces hay una simple falta de representación producto en parte de la misma invisibilización de la discapacidad" (2014: I3).

En este sentido, sostiene que si el avance del modelo social en el plano del reconocimiento de los derechos de las personas con discapacidad y en los abordajes teóricos han generado mecanismos e instrumentos de anclaje en una perspectiva de ciudadanía, que va dejando atrás miradas estrictamente médicas, también parece existir una simplificación en los planteos. De acuerdo a su postura, en la deconstrucción del concepto de modelo rehabilitador y de la normalidad, la deficiencia algunas veces aparece reducida a un discurso producido por un maquiavélico poder médico. El riesgo de esta operación, a su entender, es que "por querer ubicar la dificultad en el tejido social se termine renegando de la problemática individual y renegando déficits corporales, falta de funciones. $Y$ termine, como modelo, en un descrédito a ojos de los mismos portadores de la problemática" (Silberkasten, 20I4: I8). Para Silberkasten el problema de la discapacidad no se reduce a esquemas dicotómicos ni a hechos discursivos, el tema anida en la falta de inserción material en el sistema productivo.

Un aspecto destacable de la postura crítica del libro parece provenir no sólo de la agudeza intelectual de la mirada teórica propuesta por el autor, sino del saber concreto generado por su labor clínica con niños con mielomeningocele en el Hospital Ricardo Gutiérrez de Buenos Aires. $Y$ en relación a esto se desprenden dos rasgos más positivos del texto. El primero de ellos reside en que, tratándose de un libro académico, 
el tono de la escritura, las constantes referencias a la clínica, aportan un tipo de lectura atractiva y accesible tanto para profesionales como para el público general. Resulta muy difícil no identificarse en muchas de las escenas o situaciones que el autor escribe. El segundo de ellos se asocia a que el análisis crítico, tal como indica Snieg en el prólogo, no va de la mano de una postura con dedo acusador, moralista, sino a un intento por comprender, transformar y habilitar el reconocimiento efectivo de las personas con discapacidad. En este aspecto, al reconocerse en esas situaciones descritas ya no aparece la culpa, sino la capacidad de poder comprender y deshacer eso que la construcción imaginaria de la discapacidad en nuestra sociedad niega: encontrar en ese otro con discapacidad un sujeto. 



\section{BREVES RESEÑAS BIOGRÁFICAS}



Francisco Alcantud Marín es catedrático de Psicología Evolutiva y de la Educación y director del Centro Universitario de Diagnostico y Atención Temprana de la Universitat de Valencia.

Ma Ángeles Alcedo Rodríguez es profesora Titular del Departamento de Psicología de la Universidad de Oviedo. Su actividad docente se centra en las materias de "Evaluación y diagnóstico psicológico”, "Psicología de la discapacidad" y "Violencia contra las mujeres". Es especialista en Piscología Clínica (MECD-Ministerio de Sanidad), supervisora de programas de formación en el ámbito de la discapacidad y miembro del Instituto Universitario de Integración en la Comunidad de la Universidad de Salamanca y de la Sociedad Asturiana de Psicología de la Rehabilitación. En los últimos 6 años ha realizado investigaciones y publicaciones en el ámbito de la Psicología de la rehabilitación, Psicología de la discapacidad, Evaluación en rehabilitación, Actitudes hacia las personas con discapacidad, Discapacidad y envejecimiento, Discapacidad y dependencia, Discapacidad y universidad y Violencia de género en el ámbito de la discapacidad y de la exclusión social. En relación a estas temáticas ha participado en Congresos Nacionales e Internacionales a través de comunicaciones y pósters.
Alfredo Alcina Madueño es Doctor en Historia de la Educación, Inspector de Educación en la Consejería de Educación, Juventud y Deportes de la Comunidad de Madrid y es experto en políticas educativas de las personas con discapacidad auditiva.

Yurena Alonso Esteban es Doctora en Psicología y técnico superior de apoyo a la investigación de la Unidad de Investigación Acceso del Departamento de Psicología Evolutiva y de la Educación de la Universidad de Valencia.

Sagrario Anaut Bravo es titular de Universidad Pública de Navarra y miembro del Equipo de investigación ALTER, especializado en el ámbito de la exclusión social. Ha sido subdirectora del Departamento de Trabajo Social de la UPNa y directora del Máster Universitario en Intervención social con individuos, familias y grupos. Colabora como revisora en tres revistas en lengua castellana y es autora o co-autora de una treintena de artículos y una docena de libros. Las líneas de investigación se centran en los servicios sociales y la asistencia social, colectivos vulnerables de personas mayores y personas con discapacidad, y la atención sociosanitaria en enfermedades crónicas degenerativas (esclerosis múltiple y Parkinson). 
Javier Arza Porras es Doctor en Trabajo Social y profesor en el departamento de Trabajo Social de la Universidad Pública de Navarra donde desarrolla su labor docente en diferentes áreas: trabajo social aplicado, educación familiar y gestión de organizaciones y proyectos. En el ámbito investigador, es miembro del Equipo ALTER de la Universidad Pública de Navarra, especializado en el ámbito de la exclusión social y es miembro del Instituto Interuniversitario de Desarrollo Social y Paz. En colaboración con este instituto ha participado en la creación del "Centre on Social Inclusión and Health", centro colaborador para Europa de la Organización Mundial de la Salud.

En el ámbito de la discapacidad, desarrolla desde el año 20I2, una línea de investigación sobre calidad de vida y esclerosis múltiple. Asimismo, ha participado en el proyecto "Formación curricular en diseño para todas las personas”, de Fundación ONCE y CRUE.

Antonio Blanco Prieto es director de la Fundación Alimerka y profesor de Innovación y Responsabilidad Social Corporativa en la Universidad de Oviedo.

Patricia Cisneros Fernández es licenciada en Psicología por la Universidad de Salamanca, técnico superior en interpretación de lengua de signos española y guía-intérprete de personas sordociegas. Ha desarrollado su labor profesional en el campo de la discapacidad especializándose en discapacidad intelectual desde diversos ámbitos: centro de día, viviendas, colegio de educación especial. En el presente es psicóloga de los Centros Residenciales y responsable del área de Investigación e Innovación de la Fundación Obra San Martín.
Sonia Fernández EzQuerra es licenciada en Psicología por la Universidad del País Vasco, Máster en Psicopatología y Salud por la UNED y Máster en Integración de Personas con Discapacidad, Calidad de Vida por la Universidad de Salamanca. Actualmente es responsable de Programas de los Centros de Atención Diurna de la Fundación Obra San Martín, Santander y coautora de la Escala San Martín: evaluación de la calidad de vida de personas con discapacidades significativas (Verdugo, et al 20I4). Cuenta con una dilatada experiencia en el ámbito del apoyo psicológico a personas con discapacidad intelectual y su trabajo se centra en el desarrollo de estrategias de cambio organizacional que faciliten modelos de apoyos alineados con el Modelo de Calidad de Vida.

Carolina Ferrante es licenciada en Sociología y doctora en Ciencias Sociales por la Universidad de Buenos Aires. Actualmente disfruta de una beca posdoctoral del Consejo Nacional de Investigaciones Científicas y Técnicas (CONICET), con sede de trabajo en el Instituto de Ciencias de la Rehabilitación y el Movimiento de la Universidad Nacional de San Martín (ICRyM), ejerciendo de docente en estos dos últimos centros.

Laura E. Gómez Sánchez es doctora europea por la Universidad de Salamanca, Premio Extraordinario de Doctorado y Premio Infanta Cristina 2010 en su modalidad de investigación. Actualmente es profesora ayudante doctora en el Departamento de Psicología de la Universidad de Oviedo y coautora de siete instrumentos de evaluación de la calidad de vida para personas con discapacidad (e.g., GENCAT, INICOFEAPS, San Martín, KidsLife) y numerosos artículos en revistas internacionales. Su línea preferente de investigación se centra en la calidad de vida de personas con discapacidad intelectual y otros colectivos en riesgo de exclusión social. 
Borja GonZález Luna Doctorando en Sociología de la Universidad Complutense de Madrid, licenciado en Sociología por la Universidad Pablo de Olavide y Máster en Metodologías de Investigación en Ciencias Sociales: Innovaciones y Aplicaciones por la Universidad Complutense de Madrid. Participó como voluntario de la Federación en favor de las personas con discapacidad intelectual en Andalucía (FEAPSAndalucía), dentro de un proyecto piloto para la creación de un servicio de ocio que utilizó metodologías de investigación-acciónparticipación (IAP) en una entidad de la ciudad de Sevilla entre enero del 2008 y junio del 20 IO.

Joydi Hernández Díaz es diplomada en Ciencias Empresariales y Grado en Finanzas y Contabilidad por la Universidad de Huelva. Posee experiencia profesional en el sector bancario (Caja General de Ahorros de Granada, 2008-I2) y en el sector metalúrgico (Atlantic Cooper), habiendo prestado apoyo en los departamentos contable (20I2) y logístico (20I4). Su Trabajo de Fin de Grado (supervisado por el profesor José María Millán) ha versado sobre la situación laboral de las personas con discapacidad en España, y su evolución durante la reciente crisis económica.
Irene Hierro Zorrilla es licenciada en Psicología por la Universidad de Oviedo (2003), Máster en Terapia de Conducta (2005) por la UNED y Máster en Integración de Personas con Discapacidad, Calidad de Vida por la Universidad de Salamanca (20I3). Actualmente es Responsable de Programas de los Centros Residenciales de la Fundación Obra San Martín, Santander. Es coautora de la Escala San Martín: evaluación de la calidad de vida de personas con discapacidades significativas (Verdugo, et al 20I4). Su línea principal de trabajo se centra en el desarrollo de sistemas de apoyos basados en prácticas contrastadas que mejoren la calidad de vida de personas con discapacidad intelectual, especialmente, de personas con discapacidades significativas.

ANTONIo IáñEz DomínguEz es profesor Titular de la Facultad de Trabajo Social de la Universidad Pablo de Olavide.

Carmen Jáudenes Casaubón es directora de FIAPAS y vocal de la Comisión para la Detección Precoz de la Sordera (CODEPEH) Es pedagoga y logopeda.

Luis Lanne-Lenne Ortega es ingeniero industrial. En la actualidad es proyect management de lectura fácil en la cooperativa social Cuarto Sector y dirige numerosos proyectos del Instituto Lectura Fácil. 
Laura López De La Cruz es Doctora en Derecho y profesora de Derecho Civil en la Universidad Pablo de Olavide, de Sevilla. Ha investigado en la Universidad de Ferrara y Urbino (Italia), la Universidad de SaintÉtienne y Nancy (Francia) y la Universidad de Oxford (Reino Unido), centrando su investigación en Derecho de contratos y Derecho de familia. Ha sido adjunta a la Secretaría General y vicepresidenta ejecutiva de las Fundaciones de la Universidad Pablo de Olavide.

José María Millán Tapia es Máster en Economía Cuantitativa por la Universidad de Alicante (Programa QED, 200I-03), Doctor en Economía por la Universidad de Huelva y Premio Extraordinario de Doctorado (Área de Ciencias Sociales y Jurídicas; Curso Académico 2007-08). Ha sido docente en las Universidades de Alicante, Pablo de Olavide, Oviedo y La Laguna, y en la actualidad es profesor contratado Doctor en la Universidad de Huelva. Asimismo, ha realizado estancias de investigación en el Max Planck Institute of Economics (Jena, Alemania, 2005), en la Universidad Carlos III de Madrid (2006) y en la Erasmus University Rotterdam (Holanda, 2OIO-II).

LuCía Morán SuÁrez es personal técnico de apoyo en el Departamento de Psicología de la Universidad de Oviedo. Su ámbito de trabajo se centra en la calidad de vida de personas con discapacidad intelectual.

Luisa Navarro Juárez es licenciada en Ciencias Políticas y Sociología por la Universidad Complutense de Madrid. Es la coordinadora del proyecto Spread the Sing en España Servicios integrales de Lengua de Signos e Intérprete de Lengua de Signos de CNSE.
FAustino Núñez Batalla es presidente de la Comisión para la Detección Precoz de la Sordera (CODEPEH) en representación de la Sociedad Española de Otorrinolaringología. Médico del Servicio de Otorrinolaringología del Hospital Universitario Central de Asturias y profesor de la Universidad de Oviedo.

Jorge M. Pérez García es licenciado en Psicología y Máster en Dirección de Empresas Sociales. Lleva más de 20 años dirigiendo organizaciones sociales. Actualmente preside la cooperativa social Cuarto Sector y el Instituto Lectura Fácil, entidad sin ánimo de lucro que acompaña a otras organizaciones a mejorar en el fomento de la accesibilidad cognitiva.

Jaime Ponte Mittelbrunn es especialista en rehabilitación y máster en atención temprana y vicepresidente de la Asociación Gallega de Atención Temperá (AGAT). Desde AGAT coordina dos unidades experimentales en convenio con la Xunta de Galicia en las comarcas del Deza y del Salnés. Es redactor y coautor del Libro Blanco de Atención Temprana y ha dirigido distintos proyectos de investigación para el IMSERSO, el Real Patronato de Discapacidad y de la Xunta de Galicia. En 2003 fue seleccionado por el Ministerio de Educación para representar a España como experto en el proyecto "Atención Temprana” de la Comisión Europea.

Darío Rico Bañón es Doctor en Psicología y Coordinador de Centro Universitario de Diagnostico y Atención Temprana. 
JosEe RuF I AIxÀs es coordinador del Servicio de vida independiente "Me voy a casa" de la Fundación Catalana Síndrome de Down, coordinador de la Red Nacional de Vida Independiente de Down España y profesor de educación social de la Universitat de Barcelona (UB) y de la Universitat Oberta de Catalunya (UOC).

José Miguel Sequí Canet es jefe de Pediatría del Hospital de Gandía-Valencia y vocal de la Comisión para la Detección Precoz de la Sordera (CODEPEH).

Daniela Testa es licenciada en Terapia Ocupacional, especialista en Política, Evaluación y Gerencia social, Magister en Diseño y Gestión de Programas Sociales. Actualmente es profesora adjunta de Dirección de Organizaciones Sociales, de la Escuela de Política y Gobierno de la Universidad Nacional de San Martín y auxiliar docente en la carrera de Terapia Ocupacional de la Universidad de Buenos Aires.

Josep Tresserras Basela es Director-Gerente de Som - Fundació Catalana Tutelar Aspanias desde I99I, presidente de l'ERESS (Espacio de Reflexión Ética en Servicios Sociales) Dincat, miembro de la Junta Directiva de la Asociación Española de Fundaciones Tutelares y de la Comisión de Asesoramiento y Supervisión de les personas jurídicas sin ánimo de lucro que tengan atribuida la tutela de menores e incapacitados de la Generalitat de Catalunya.
Miguel Ángel Verdugo Alonso es catedrático de Personalidad, Evaluación y Tratamientos Psicológicos y director del Instituto Universitario de Integración en la Comunidad (INICO) de la Universidad de Salamanca. Director del Servicio de Información sobre Discapacidad (SID) del Ministerio de Sanidad, Servicios Sociales e Igualdad y dirige el Máster en Integración de Personas con Discapacidad y Calidad de vida desde 1990 y el Máster en Integración (Programa Iberoamericano) desde I993.

Director de Siglo Cero. Revista Española sobre Discapacidad Intelectual, editada por FEAPS y ha publicado más de 75 libros y 400 artículos.

Ana Vivanco Allende trabaja en el Servicio de Pediatría del Hospital Universitario Central de Asturias-Oviedo y es vocal de la Comisión para la Detección Precoz de la Sordera (CODEPEH).

José Zubicaray Ugarteche es médico especialista en Otorrinolaringología Infantil en el Complejo Hospitalario de Navarra-Pamplona y es vocal de la Comisión para la Detección Precoz de la Sordera (CODEPEH). 



\section{Extracto de las normas de presentación de originales}

La Revista Española de Discapacidad (REDIS) es un espacio abierto a la publicación de artículos por parte de profesionales, investigadores, representantes institucionales y de todas aquellas personas interesadas que trabajan e investigan en el campo de la discapacidad, desde una perspectiva multidisciplinar.

Los artículos deben ser inéditos y estar relacionados con los objetivos de la revista (proporcionar un marco para la reflexión y el análisis en materia de discapacidad desde distintas áreas y disciplinas científicas y producir conocimiento teórico y aplicado en materia de discapacidad).

Una vez recibidos, los artículos serán sometidos a un proceso de revisión anónima por pares, por parte de especialistas externos a la revista, que son invitados a participar en el proceso de revisión contando con el aval del Consejo de Redacción. Desde el punto de vista formal los manuscritos deberán cumplir las siguientes pautas:

- El texto del manuscrito propuesto debe contar con una extensión máxima de $\mathbf{1 0 . 0 0 0}$ palabras, excluyendo título, resúmenes, palabras clave y bibliografía (con interlineado 1,15 en letra Arial 11, sin justificar el texto y sin sangrías al comienzo).

- Los trabajos irán precedidos del título en español y en inglés; nombre de autor/a o autores; su adscripción institucional y su dirección email de contacto; un breve resumen de entre 100 y 150 palabras, que tendrá una versión en español y otra en inglés (abstract), de idéntico contenido; y palabras clave (entre 4 y 8) en español con su correspondiente traducción en inglés (keywords); también deberán ir acompañados por una breve reseña biográfica de cada autor/a (no más de 150 palabras por cada persona).

- Las notas irán a pie de página. Las referencias bibliográficas de los artículos seguirán las normas ISO 690/2010. Para más detalle, véanse las directrices para autores.

Los interesados e interesadas podrán mandar los manuscritos originales a través de la aplicación informática destinada a tal efecto o por correo electrónico <redis@cedd.net>.

Una vez aceptados los artículos para su publicación, la dirección de la revista se reserva el derecho a modificar el título y epígrafes de los textos, así como de realizar las correcciones de estilo que se estimen convenientes, de acuerdo con las normas de estilo de la revista.

Para ver nuestros últimos números, haz click aquí.

Para más información:

Teléfono: +34 9174524 46/47

http://www.cedd.net/redis 

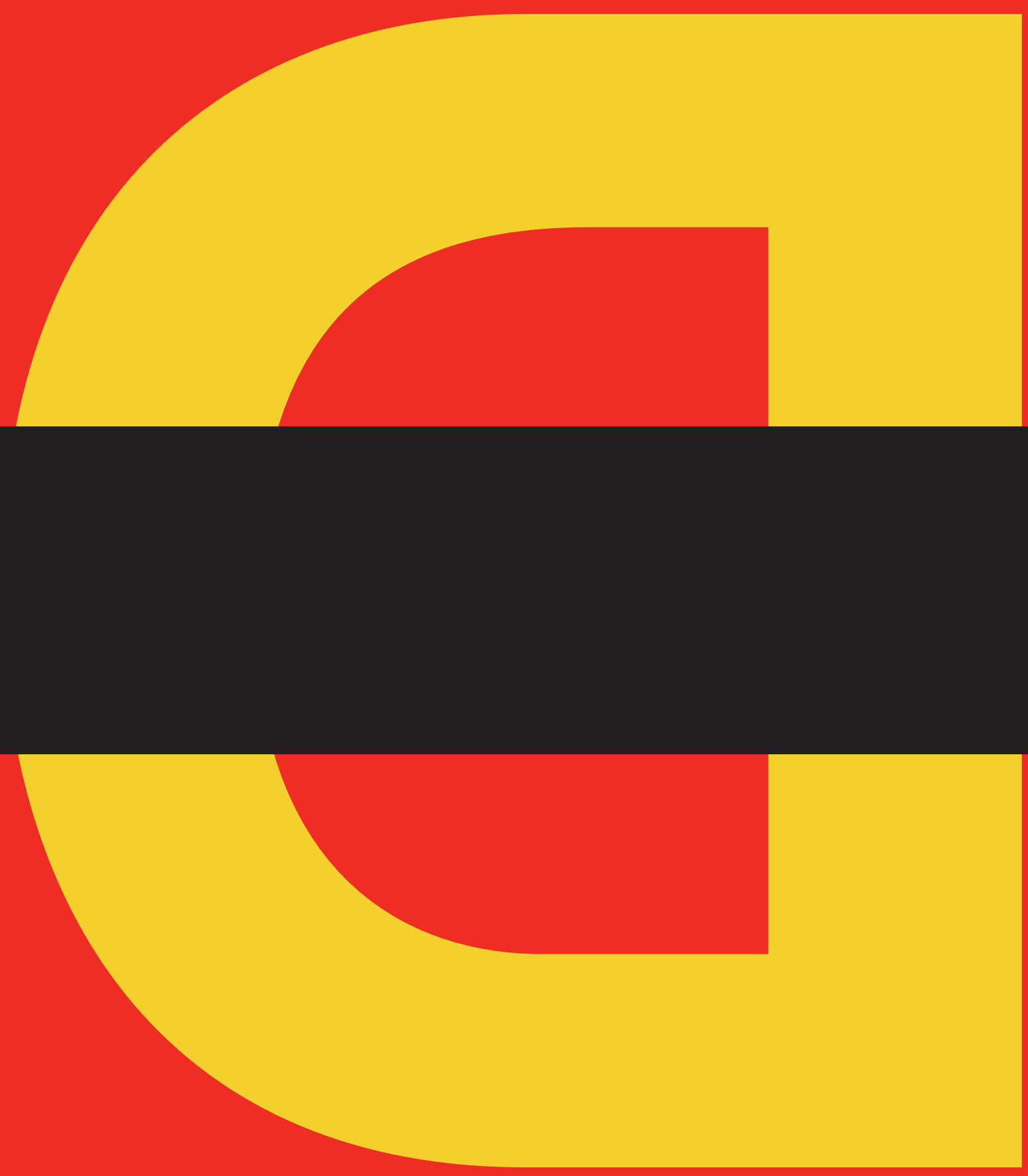

10 